NISTIR 5263

\title{
Summaries of BFRL Fire Research In-house Projects and Grants, 1993
}

Nora H. Jason

Building and Fire Research Laboratory

Gaithersburg, Maryland 20899

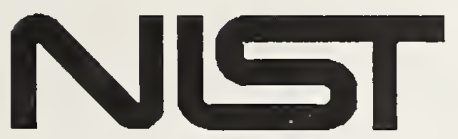

United States Department of Commerce Technology Administration

$-Q C$ National Institute of Standards and Technology 



\section{Summaries of BFRL Fire Research In-house Projects and Grants, 1993}

Nora H. Jason

September 1993

Building and Fire Research Laboratory

National Institute of Standards and Technology

Gaithersburg, MD 20899

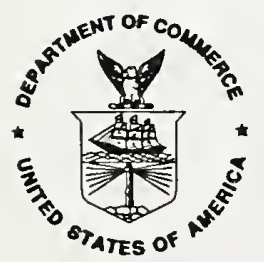

U.S. Department of Commerce

Ronald H. Brown, Secretary

Technology Administration

Mary L. Good, Under Secretary for Technology National Institute of Standards and Technology

Arati Prabhakar, Director 

This report describes the fire research projects performed in the Building and Fire Research Laboratory (BFRL) and under its extramural grants program during Fiscal Year 1993. BFRL is one of the eight major technical units of the National Institute of Standards and Technology (NIST).

The BFRL Fire Research Program is nationally recognized as the focal point for fire research in the United States of America. BFRL has a multi-disciplinary technical staff that is supported by extensive laboratory and computing facilities and a definitive fire research library.

The BFRL pursues NIST's commitment to meeting the critical needs of the fire community as they relate to all three of the Institute's goals: assistance to industry, fundamental research, and public health and safety. The BFRL fire program combines careful attention to the fire safety community's needs for advances in fire safety technology with its mandated role as the focal point for fire research in the United States. BFRL staff then performs basic research to improve the understanding of the elemental phenomena of fire and applied research to develop and to adapt technological tools and procedures to address critical issues of fire safety.

In addition to its in-house programs, the BFRL maintains a fire research grants program that supplements its in-house programs and through which supports most of the academic fire research in the United States. This was initiated under the Federal Fire Prevention and Control Act of 1974, which authorized the Secretary of Commerce to conduct a fire research program directly or through contracts and grants.

Third, BFRL responds to the needs of other Federal agencies and private sector organizations. This publication summarizes work performed both with funds appropriated to the BFRL Fire Research Program and under contract to outside organizations.

The BFRL Fire Research Program has directed its efforts under three program thrusts. The in-house priority projects, grants, and externally-funded efforts thus form an integrated, focussed ensemble. This publication is organized along those lines:

FIRE RISK AND HAZARD PREDICTION

Carbon Monoxide Prediction

Turbulent Combustion

Soot

Engineering Analysis

Fire Hazard Assessment

Large Fires

FIRE SAFETY OF PRODUCTS AND MATERIALS

Materials Combustion

Furniture Flammability

Wall and Ceiling Fires

ADVANCED TECHNOLOGIES FOR FIRE SENSING AND CONTROL

Fire Detection

Fire Suppression

For the convenience of the reader, an alphabetical listing of all grants is contained in Part 2.0. 



\section{CONTENTS}

BFRL/NIST Fire Program projects (in-house projects, associated grants funded by NIST, and projects funded by other agencies and private sector organizations)

\section{A. FIRE RISK AND HAZARD PREDICTION}

A1. Carbon Monoxide Prediction 3

Carbon Monoxide Production and Prediction (in-house) . $\quad 5$

Compartment Fire Combustion Dynamics (grant) $\quad$ $\quad$. $\quad$ • 9

Fundamental Mechanisms for $\mathrm{CO}$ and Soot Formation in

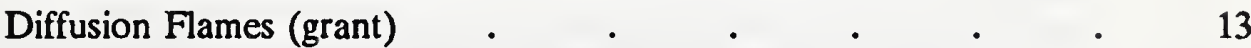

A2. Turbulent Combustion 17

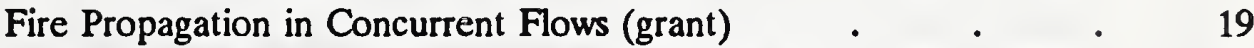

Simulation of Turbulent Combustion and Transport in

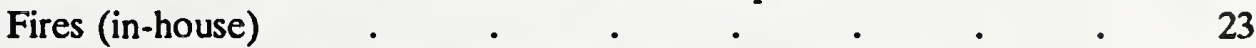

A3. Soot 27

Experimental and Modeling Studies of Soot and Carbon Monoxide in an Ethylene/Air Diffusion Flame (grant)

Fundamental Mechanisms for $\mathrm{CO}$ and Soot Formation in Diffusion

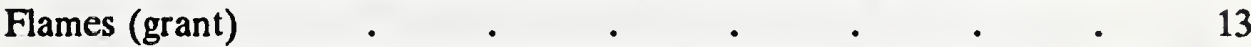

Ground-Based Smoke Sampling Techniques Training Course and

Collaborative Local Smoke Sampling in Saudi Arabia (KSA) 33

Light Scattering Studies of Fractal Soot Aggregates (grant) - 35

Soot, Carbon Monoxide and Radiant Emissions of Luminous Turbulent

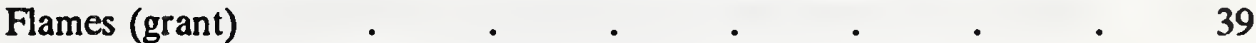

Soot Formation and Evolution (in-house) $\quad$. $\quad . \quad \ldots \quad$. $\quad . \quad 43$

A4. Engineering Analysis 47

Comprehensive Fire Risk Assessment Method (in-house) . $\quad$ • 49

Experimental Study of Heat Transfer and the Environment in a

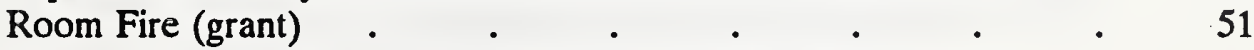

Fire and Thermal Characteristics of Navy Fire Fighter

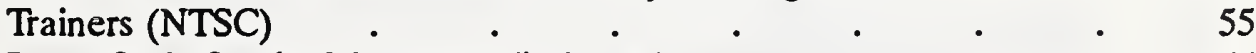

Large Scale Smoke Movement (in-house) . $\quad$ • $\quad$ • $\quad$ • 56

Movement of Smoke and Hot Gases in Open Shafts (grant) . 59

Risk Analysis for the Fire Safety of Airline Passengers (FAA) . 63

Study of Smoke Agglomerates (NASA) $\quad$ - $\quad . \quad$. 65

Support of the Navy Fire Modeling Program (NRL) . . $\quad$. 67 
A5. Fire Hazard Assessment 69

Computational Heat Transfer for Zone Fire Modeling (grant) • 71

Development of the FDMS Database System for Fire-Related

Data (in-house) . . . . . . . 75

Evaluation of Fire Safety Requirements for Potential Application to

U. S. Passenger-Guided Ground Transportation Sysíems (DOT) . 77

EXIT89 (grant) . $\quad . \quad . \quad . \quad . \quad . \quad .79$

HAZARD Development (in-house) • $\quad$. $\quad$. $\quad$. $\quad$. 81

Mathematical Modeling of Human Egress from Fires in Residential

Buildings (grant).$\quad \cdot \quad \cdot \quad \cdot \quad \cdot \quad \cdot \quad \cdot 85$

Merger of FPEtool and HAZARD (in-house) $\quad . \quad$. $\quad \% \quad 89$

A6. Large Fires 91

Computer Simulation of the Environmental Impact of Large Fires: Plume

Rise and Dispersion (grant) . $\quad . \quad$. $\quad . \quad$. 93

In-Situ Burning of Oil Spills (MMS, USCG, API) . $\quad . \quad . \quad \quad \quad 97$

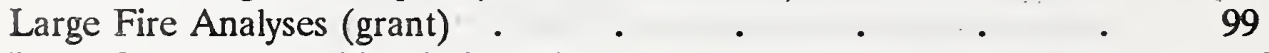

Large Scale Test Facility (in-house) - $\quad$. $\quad . \quad$. $\quad . \quad$. 103

Office Building Fire Research Program (GSA) : . . . . 107

Smoke Plume Trajectory from In Situ Burning of Crude Oil in

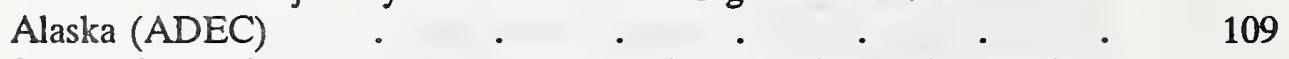

Study of Entrainment and Flow Patterns in Pool Fires Using Particle

Imaging Velocimetry (grant) . $\quad . \quad \ldots \quad$. $\quad . \quad$. 111

Study of Simulated Oil Well Blowout Fires and Flares (grant) • 115

Wind Blown Large Fires (in-house) . . . . . . . 119

\section{B. FIRE SAFETY OF PRODUCTS AND MATERIALS}

B1. Materials Combustion 121

Burning Rate of Materials (in-house) . . . . . 123

Char Structure and Flammability (Director's Reserve) . . : 127

$\begin{array}{lllll}\text { Cigarette Ignition Metrology (CPSC) } & \text { • } & \text {. } & \text { • } & 129\end{array}$

Fire Growth Models for Materials (grant) . $\quad$. $\quad$. $\quad 131$

Fire Resistant Aircraft Materials (FAA) . $\quad$. $\quad$. $\quad . \quad 135$

$\begin{array}{lllllllllll} & \text { Flame Retardant Study (GE) } & \text {. } & \text {. } & \text {. } & \text {. } & & 137\end{array}$

Material Flammability Predictive Techniques/Methods (USN) 139

Radiative Ignition and Subsequent Flame Spreading in Microgravity

Environment (NASA) $\quad . \quad$. $\quad . \quad . \quad . \quad . \quad 141$

Polymer Flammability Modeling (in-house) . - . . . . 143

B2. Furniture Flammability 147

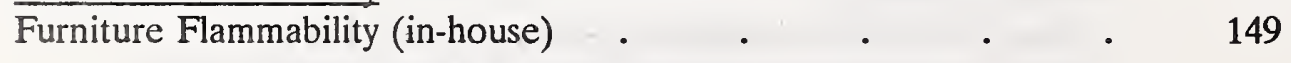

B3. Wall and Ceiling Fires 151

Ceiling Fires (in-house) . $\quad$. . . $\quad . \quad$. $\quad . \quad$. 153

Fire Spread Along the Vertical Corner Wall, Part I (grant) . $\quad$. 155

Prediction of Fire Dynamics (grant) . $\quad$. $\quad . \quad$. $\quad . \quad 159$ 
B3. Wall and Ceiling Fires (cont)

Study of Heat and Smoke Movement and Their Influence on Detector and Sprinkler Response in Enclosed Spaces with Complex Ceiling

Geometries (NFPRF)

Upward Flame Spread on a Vertical Wall Under External

Radiation (grant).$\quad \cdot \quad \cdot \quad \cdot \quad \cdot \quad \cdot$.

C. ADVANCED FIRE SENSING AND SUPPRESSION

C1. Fire Detection

Advanced Fire Detection Systems (in-house) . . . 173

Balanced Design (in-house) . $\quad$. $\quad . \quad$. 177

Detection and Monitoring of Fires with Open-Path FTIR (Director's

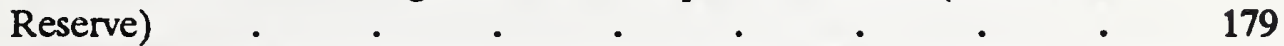

Development of an Economical Video Based Fire Detection and Location

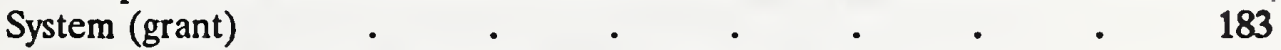

Smart Fire Detection Using Neural Networks (grant) . $\quad$ • 187

C2. Fire Suppression 191

Agent Screening for Halon 1301 Aviation Replacement (USAF) 193

Agent/System Compatibility for Halon 1301 Aviation

Replacement (USAF) . $\quad$. $\quad$. . . . . 195

Basic Research on Fire Suppression (grant) . $\quad$. $\quad$. 197

Dynamics of Fire Suppression (in-house) . $\quad$. $\quad$. $\quad$. 201

Evaluation of Metal vs Plastic Piping for Use in Fire Sprinkler

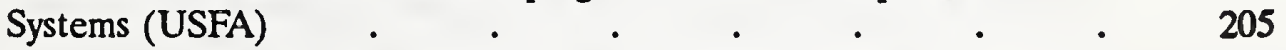

Experimental Studies on the Extinction of Diffusion Flames Using

Halon Substitutes (grant) . $\quad . \quad$. $\quad . \quad$. 207

Need for a Sprinkler Standard for Board and Care Facilities (USFA) 211

Predicting the Response of Sprinklers and Detectors in Large

(GSA, NASA) . $\quad . \quad$. $\quad . \quad$. $\quad 213$

Transient Cooling of a Hot Surface by Droplets Evaporation (grant) 215

Part 2.0 Alphabetical Listing of BFRL Fire Research Grantees and Their Grants 

Part 1.0 BFRL/NIST Fire Program Projects (in-house projects, associated grants funded by NIST, and projects funded by other agencies and private sector organizations) 



\section{A. Fire Risk and Hazard Prediction}

A1. Carbon Monoxide Prediction 



\section{BUILDING AND FIRE RESEARCH LABORATORY \\ FIRE RESEARCH PROGRAM \\ PRIORITY PROJECT - FY93}

\section{CARBON MONOXIDE PRODUCTION AND PREDICTION}

\section{Professional Personnel}

William M. Pitts, Project Leader

Nelson P. Bryner, Chemical Engineer

William D. Davis, Physicist

Erik L. Johnsson, Mechanical Engineer

George W. Mulholland, Research Chemist

\section{$\underline{\text { Project Objective }}$}

To develop for the fire safety engineering community a fundamental understanding of the mechanisms of carbon monoxide formation in fires sufficient to produce an estimation model by July, 1994 and a detailed predictive model by July, 1998.

\section{Scope}

This program is designed to assess the importance of $\mathrm{CO}$ in fire toxicology (i.e., the levels of $\mathrm{CO}$ generated) and to provide the scientific background required to allow the prediction of $\mathrm{CO}$ in real fires. Efforts range from purely empirical studies such as assessments of $\mathrm{CO}$ production in full-scale fire tests to fundamental studies designed to improve the understanding of the chemically reacting turbulent flows which ultimately produce $\mathrm{CO}$. New information which is generated is incorporated into existing BFRL models of fire behavior.

\section{Technical Accomplishments}

During FY93 work has focused on five (discussed below) components of the overall priority project plan [see W. M. Pitts, "Long-Range Plan for a Research Project on Carbon Monoxide Production and Prediction," NISTIR 89-4185, October 1989]. All of these components are designed to allow an assessment of whether or not the global equivalence ratio (GER) concept offers a viable approach for the prediction of $\mathrm{CO}$ formation in real fire situations. The GER concept refers to the experimental observation that concentrations of major gas species, including $\mathrm{CO}$, in the well defined layers of combustion gases above simple fires can be correlated in terms of the GER. The GER is defined as the ratio of fuel to air available normalized by the ratio of fuel and air required for complete combustion to water and carbon dioxide.

\section{Investigation of CO Formation in a Reduced-Scale Enclosure (Johnsson, Bryner)}

Despite the importance of the problem, very few detailed investigations of $\mathrm{CO}$ production during fullscale fire tests are available. The principal reason for this lack of data is the high cost associated with full-scale testing. An approach which is often used is to perform experiments on a reduced scale where costs are lower and the tests are more easily manageable. A major drawback to this approach is that all the important fire parameters cannot be scaled simultaneously. Despite this, reduced-scale testing has contributed immensely to the understanding of fire behavior for conditions where the 
effects of scaling are properly understood. A reduced-scale enclosure (RSE) fabricated here at NIST has been used to characterize $\mathrm{CO}$ formation for a variety of test conditions.

Natural gas was used as fuel for over 140 test fires during FY 91-92. These test showed that CO concentrations as well as the other products of incomplete combustion observed in the upper layer at the rear of the enclosure were in good agreements with concentrations predicted by the GER concept. However, in the front of the enclosure (i.e., nearest the doorway) upper-layer $\mathrm{CO}$ concentrations were roughly 50\% higher. Analysis showed that the higher CO concentrations were due to the direct entrainment of air into the upper layer where it reacted with the rich gases to generate $\mathrm{CO}$ in preference to $\mathrm{CO}_{2}$. As required by this explanation, the upper layer local equivalence ratios were lower in the front than in the rear of the enclosure.

One of the major drawbacks of the experimental system has been the uncertainty of the air inflow rate into the enclosure. The air flow rate into the enclosure is required in order to calculate the GER. An approach for measuring the mass flow rate originally developed by Quintiere, Steckler and Baum (see 20th Sym. (Int.) Comb. (1984) 1591-1600) yielded results with were inconsistent with observed concentrations of combustion products or with local $\phi$-meter (see ahead) measurements. Very recently, a new approach for this measurement has been published by Janssens and Tran (J. Fire Sciences 10 (1992) 528). Even though this approach was developed for relatively small and quiescent fires than typical for the RSE studies, it was found to provide consistent estimates of air flow into the RSE. All of the RSE data were reanalyzed in terms of this approach which resulted in much improved agreement between measured GERs and results from the $\phi$-meter. The appearance of products of incomplete combustion was now found to coincide with a $\phi_{\mathrm{g}}$ of 1 . Our findings show that the Janssens and Tran approach can be used to estimate doorway flows for room fires which are flashed over and highly underventilated.

Previous burns in the RSE have employed natural gas as fuel. During the current fiscal year studies have been extended to liquid (hexane) and solid (wood crib) burns. The designs for the systems have been developed, liquid burners constructed, and preliminary burns completed.

Some previous full-scale fire tests at NIST had recorded CO concentrations much higher than predicted by the GER concept. Many of these fires used wood as the fuel. It was hypothesized that pyrolysis of wood in high temperature, oxygen-depleted upper layers would generated CO directly. In order to test this hypothesis, a series of RSE natural gas enclosure fires have been burned in which the upper walls and ceiling within the upper layer were lined with plywood. Figure 1 shows a plot of $\mathrm{CO}$ concentration versus time for such a fire where the methane flow rate corresponds to a heat release rate of $100 \mathrm{~kW}$. It can be seen that concentrations of $\mathrm{CO}$ reached $14 \%$ in the rear and $8 \%$ in the front of the upper layer. The GER concept predicts CO concentrations on the order of $2 \%$ The measured levels in the front and rear are much higher showing that the pyrolysis of wood in a high temperature, highly vitiated upper layer can generate $\mathrm{CO}$. The concentrations of $\mathrm{CO}$ remain high until the wood falls from the walls and ceiling at $500 \mathrm{~s}$ when it promptly drops back to the low levels expected for a natural gas fire of this heat release rate. The high concentrations of $\mathrm{CO}$ observed during these experiments provides an explanation for the full-scale fire test results and supports the hypothesis that pyrolysis of wood is responsible.

\section{Field Modeling of the Reduced-Scale Enclosure Fires (Davis)}

During FY92 a commercial field modeling code, FLOW3D, was used to simulate experiments within the RSE. Predicted velocity flow fields and distributions of combustion products (assuming simple 


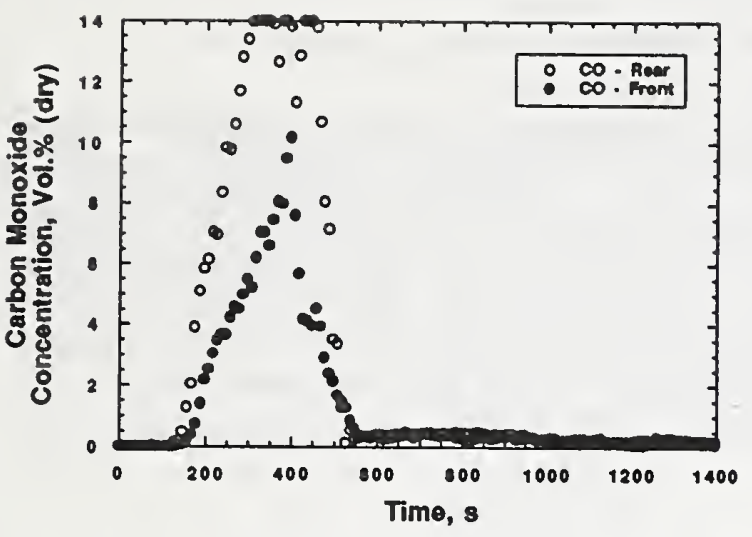

Figure 1. $\mathrm{CO}$ versus time for a $100 \mathrm{~kW}$ natural gas fire with the ceiling and upper walls lines with plywood. which will allow prediction of $\mathrm{CO}$ concentrations. Comparisons of calculated and experimental behaviors are to be used to assess the validity of the model.

\section{Chemical Stability of Upper Layers in Fires (Pitts)}

Previous work had employed detailed chemical kinetic modeling to predict the reaction behavior of combustion gases observed in the hood experiments. These calculations showed that if air were entrained directly into a rich, high temperature upper layer, reaction would occur which would generate primarily $\mathrm{CO}$ in preference to $\mathrm{CO}_{2}$. The results for the natural gas burns in the RSE have been explained in this way.

During the current year equilibrium calculations for the combustion gas mixtures observed in upper layers above fires burning in an open laboratory have been carried out. These indicate that very high levels of $\mathrm{CO}$ will be formed if the high temperature gases come into full chemical equilibrium. It has been found, however, that the gases do not start to approach equilibrium in reasonable times until temperatures exceed $1300 \mathrm{~K}$. Since enclosure fires generally have upper-layer temperatures below $1300 \mathrm{~K}$, the findings indicate that full equilibrium is unlikely in most enclosure fires. The combustion gases are therefore "frozen" in a nonequilibrium state determined by quenching of the fire plume and reactions within the upper layer. A manuscript describing these findings has been prepared for publication.

4. Development of an Instrument for Measuring the Global Equivalence Ratios in Fire Gases (Mulholland and Babrauskas)

This device uses complete oxidation and a single oxygen measurement to yield the local equivalence ratio for a sample of combustion gases. A manuscript has been prepared and submitted which describes the development and use of the $\phi$-meter. 


\section{Laboratory Studies of Underventilated Laminar Flames}

George Mulholland has performed a study of laminar, underventilated flames in conjunction with Professor Santoro and coworkers at The Pennsylvania State University. A coflow burner was employed in which fuel (either methane or ethene) entered a coflow of air enclosed by a circular duct. By varying the ratio of fuel to air flow rates it was possible to vary the global equivalence ratio. Measurements of combustion gas concentrations downstream of the flame showed that $\mathrm{CO}$ concentrations increased significantly as the burner became fuel rich. This behavior is reminiscent of enclosure fires. These experiments offer the promise of an improved understanding of the quenching mechanisms responsible for the "frozen" mixtures of combustion gases which are observed in enclosure fires.

\section{Reports and Publications}

"Reactivity of Product Gases Generated in Idealized Enclosure Fire Environments," W. M. Pitts, Twenty-Fourth Symposium (International) on Combustion (1992) The Combustion Institute, pp. 17371746.

"The Phi-Meter: A Simple, Fuel-Independent Instrument for Monitoring Combustion Equivalence Ratio," V. Babrauskas, W. J. Parker, G. Mulholland, and W. H. Twilley, submitted to Reviews of Scientific Instruments

"Generation of CO and Smoke During Underventilated Combustion," S. Léonard, G. W. Mulholland, R. Puri, and R. J. Santoro, submitted to Combustion and Flame.

"Application of Thermodynamic and Detailed Chemical Kinetic Modeling to Understanding Combustion Product Generation in Enclosure Fires," W. M. Pitts, to be submitted for publication.

"Carbon Monoxide Production in Compartment Fires--Reduced-Scale Enclosure Test Facility," N. P. Bryner, E. L. Johnsson, and W. M. Pitts, to appear as NISTIR.

"The Global Equivalence Ratio Concept and the Prediction of Carbon Monoxide Formation in Enclosure Fires," W. M. Pitts, to appear as NIST Monograph.

\section{Related Grants}

"Fundamental Mechanisms for $\mathrm{CO}$ and Soot Formation in Diffusion Flames," R. J. Santoro, Pennsylvania State University.

"Radiation From Turbulent Luminous Fires," G. M. Faeth, University of Michigan.

"Compartment Fire Combustion Dynamics," U. Vandsburger, Virginia Polytechnic Institute and State University and R. J. Roby, Hughes Associates.

"Simplification of Diffusion Flame Chemistry: A Theoretical and Experimental Study of the Structure of Laminar Diffusion Flames," J. H. Miller, George Washington University. 


\section{BUILDING AND FIRE RESEARCH LABORATORY \\ FIRE RESEARCH PROGRAM \\ NATIONAL INSTITUTE OF STANDARDS AND TECHNOLOGY \\ GRANTEE PROJECT - FY93}

Institution: Virginia Polytechnic Institute \& State University

Grant No: $\quad$ 60NANB 1D 1176

Grant Title: $\quad$ Compartment Fire Combustion Dynamics

Principal Investigators: $\quad$ Uri Vandsburger

Department of Mechanical Engineering

Virginia Polytechnic lnstitute \& State University

Blacksburg, Virginia 24061-0238

Richard J. Roby

Hughes Associates

Suite 125

6770 Oak Hall Lane

Columbia, Maryland 21045

Other Professional Personnel: $\quad$ David S. Ewens (M.S. Candidate)

Wade Cole (Undergraduate Assistant)

C. Harrison Smith (Undergraduate Assistant)

NIST Scientific Officer: $\quad$ Dr. William M. Pitts

Technical Abstract:

\section{Introduction and Facilities}

Compartment fires under fuel rich conditions (typical of compartment fires) have been shown to produce hazardous levels of carbon monoxide and smoke. Previous research has investigated the effect of external burning on exhaust gases as they spill into the open atmosphere and mix with ambient air [1]. That work has shown significant oxidation of carbon monoxide and smoke during sustained external burning of the exhausting gases [1]. However, the leading cause of deaths in compartment fires is carbon monoxide inhalation in neighboring rooms, remote from the fire. The present study focuses on the transport, and oxidation, of fuel rich exhaust gases in enclosed spaces located adjacent to and remotely from a compartment fire.

The goals for the current three year research effort are to (1) further quantify the efficiency of external flames in destroying toxic gases produced in the compartment, and (2) evaluate the robustness of existing $\mathrm{CO}$ yield correlation's for forced ventilation compartment fires designed to include poorly defined two-layer environments.

The main structure used consists of two levels, a $1.2 \times 1.5 \times 1.2 \mathrm{~m}$ fire compartment located above a $1.2 \times 1.4 \times 0.3 \mathrm{~m}$ high air distribution plenum. The inside of the fire compartment is covered with $2.54 \mathrm{~cm}$ thick Fire Master, UL rated, fire insulation board. A $1.8 \mathrm{~m}$ long, $30.5 \mathrm{~cm}$ diameter air inlet duct allows air to be drawn naturally into the air distribution plenum. The air plenum supplies air uniformly to the fire compartment through two thermally shielded vents, one on each side of the fire compartment floor. A window style exhaust vent, centered in the width direction, is located on the front of the fire compartment and opens into a $3.66 \mathrm{~m}$ long, $1.14 \mathrm{~m}$ wide, and $1.47 \mathrm{~m}$ tall hallway. The exhaust vent size is adjustable in order to vary the overall equivalence ratio. The hallway ceiling consists of the same fire board as in the compartment and the walls consist of dry wall covered with Fiberfax fireproof insulating sheets.

A $1.5 \times 1.5 \mathrm{~m}$ hood collects all exhaust gases exiling the end of the hallway, and into a $45.7 \mathrm{~cm}$ diameter duct. A gas sampling probe and laser system in the exhaust duct allow for continuous 
measurement of exhaust species concentrations and soot volume fraction. An orifice plate allows measurement of the volumetric flow rate through the duct. A second gas sampling probe is located inside the hallway together with a thermocouple rake to investigate the effects of the hallway on the exhaust gas composition. The position of both probes is adjustable in three dimensions. The rake holds 9 thermocouples spaced $5.1 \mathrm{~cm}$ apart in a vertical array. The gas sampling system measures $\mathrm{CO}, \mathrm{CO}_{2}, \mathrm{O}_{2}$, and unburned hydrocarbons (UHC). The fire compartment is also equipped with a stationary vertical rake holding 8 thermocouples in the front corner of the compartment. An overall equivalence ratio is obtained by measuring the air flow rate in the inlet duct and the fuel volatilization rate using a load cell.

\section{CO, UHC, Soot, and $\mathrm{O}_{2}$ Levels}

Comparison of results from the hallway experiments with those from external jet burning, both measured in the exhaust duct, indicated a significant effect of the hallway on intermediate exhaust species destruction. A comparison of $\mathrm{CO}$ yields ( $\mathrm{Kg} \mathrm{CO}$ produced / $\mathrm{Kg}$ fuel burned) is given in Figure 1 as a function of the "quasi" steady state equivalence ratio. Note that for equivalence ratios above 1.7, previous research [1] indicates that the $\mathrm{CO}$ yield inside the compartment reaches a steady value of about 0.22 . Also, from previous research on external jet burning [1], sustained external burning occurred for fires with equivalence ratios above 1.7, resulting in a decrease in $\mathrm{CO}$ yield to $10-25 \%$ of in-compartment levels. Results of hal lway experiments with sustained external burning indicated less efficient oxidation of $\mathrm{CO}$, to $39-45 \%$ of in-compartment levels. The lower conversion efficiency is attributed to mixing limited combustion of the exhaust gases in the hallway. Similarly to the external jet burning, for all overventilated experiments the $\mathrm{CO}$ yield was insignificant.

Unburned hydrocarbon yields are given in Figure 2. In-compartment yields reach a steady value of about 0.33 for equivalence ratios above 1.7. The hallway experiments with sustained external burning indicate fairly efficient oxidation of unburned hydrocarbons to $7-17 \%$ of in-compartment levels. This is significantly more efficient than for $\mathrm{CO}$.

Smoke yields are given in Figure 3 having a fair amount of scatter. Results for external jet burning [1] indicated a $50-100 \%$ decrease in smoke yield during sustained external burning compared to the levels before external burning occurred. The hallway results show as good as or better smoke oxidation, even without sustained external burning. This result may be in part due to soot collection on the hallway ceiling and walls, as was observed. It has been observed that soot does not accumulate on the hallway surfaces, implying that soot burnoff is occurring.

The exhaust duct measurements of exhaust gas species show efficient oxidation of unburned hydrocarbons and soot during sustained external burning but inefficient oxidation of carbon monoxide. Hallway sampled experiments aided in investigating this phenomena. The results indicated that $\mathrm{CO}$ is oxidized only $5 \%$ in the first half of the hallway and another $67 \%$ in the second half. Unburned hydrocarbons on the other hand were oxidized $92 \%$ in the first half of the hallway, and another $6 \%$ in the second half. Oxygen concentrations in the hallway were low, as expected, from $0.5 \%$ by volume at the compartment end of the hallway to $7.0 \%$ at the exhausting end. These results and other research $[2,3,4]$ suggest that the oxidation of carbon monoxide is much slower than the oxidation of unburned hydrocarbons and other species in an oxygen limitod environment. Also, temperature measurements in the hallway indicated temperature levels at which $\mathrm{CO}$ oxidation becomes very temperature sensitive, around $875 \mathrm{~K}$ [1]. This also acts to hinder $\mathrm{CO}$ oxidation. The reduced oxidation rate of $\mathrm{CO}$ observed here posses a serious threat in compartment fires, as low levels of $\mathrm{CO}$ can be lethal.

\section{Characteristic Equivalence Ratios}

Characteristic equivalence ratios where external flashes and sustained external burning begin were also reported in the previous research for external jet burning [1]. These results indicated that the characteristic equivalence ratios remained constant with respect to exhaust vent area and fuel pan size [1]. 
Figure 4 shows these equivalence ratios for the hallway experiments versus exhaust vent area for one fuel pan size $(22.9 \mathrm{~cm}$ diameter). The data appears to suggest exponential behavior, as would be expected for vent areas approaching zero or infinity. The exhaust vent area (and fuel pan size) acts to limit the ignition source (i.e. flame jets from the compartment) from igniting the exhausting gases. Exponential curves fit to the data are shown in the figure with the regions of external burning indicated.

\section{Summary}

The transport of compartment fire exhaust gases through an adjacent hallway has a dramatic effect on the evolution of combustion intermediates. Most notable the oxidation of $\mathrm{CO}$ is much reduced compared with external jet burning, resulting in a higher $\mathrm{CO}$ yield. Unburned hydrocarbons in contrast are oxidized efficiently. Soot is oxidized as efficient or more efficient than in the external jet experiments. The inefficient $\mathrm{CO}$ oxidation is attributed to a relatively low kinetic oxidation rate as a result of limitations on oxygen availability and temperature levels. Characteristic equivalence ratios display exponential behavior with respect to exhaust vent area, where this behavior was not as evident in the external jet experiments. Future work includes completing more detailed hallway experiments. Experiments on a forced ventilation compartment will also be completed in the future.

\section{References:}

1. Gottuk, D. T., "The Generation of Carbon Monoxide in Compartment Fires," Ph.D. Dissertation, Virginia Polytechnic Institute \& State University, Department of Mechanical Engineering, 1992.

2. Glassman, I., "Combustion", second edition, Academic Press, Inc., Orlando, Fla., 1987.

3. Pitts, W. M., "Reactivity of Product Gases Generated in Idealized Enclosure Fire Environments," Twenty-fourth Symposium (International) on Combustion, The Combustion Institute, 1992, p. 1737.

4. Dagaut, P., Boettner, J. C., and Cathonnet, M., International Journal of Chemical Kinetics, Vol. 22. 1990 , p. 641.

\section{Acknowledgments:}

We would like to thank Dan Gottuk for his thoughts and suggestions, enabling us a smoother start. The personnel of the mechanical engineering machine shop have also been very helpful in fabricating the new equipment.

\section{Reports and Papers:}

Peatross, M. J., "Experimental Study of Forced Ventilation Glove Box Fires," M.S. Thesis, Virginia Polytechnic Institute \& State University, Department of Mechanical Engineering, August 1992.

Gottuk, D. T., "The Generation of Carbon Monoxide in Compartment Fires," Ph.D. Dissertation, NISTGCR-92-619, Virginia Polytechnic Institute \& State University, Department of Mechanical Engineering, September 1992.

Gottuk, D. T., Roby, R. J., and Beyler, C. L., " A Study of Carbon Monoxide and Smoke Yields from Compartment Fires with External Burning," presented at the Twenty-Fourth Symposium on Combustion, Combustion Institute, December 1992, pp. 17-29.

Gottuk, D. T., Roby, R. J., Peatross, M. J., and Beyler, C. L., "Carbon Monoxide Production in Compartment Fires," Journal of Fire Protection Engineering, Vol. 4, No. 4, 1992, p. 133.

Ewens, D. S., Vandsburger, U., and Roby, R. J., "Oxidation of Exhaust Gases in a Remote Location from a Burning Compartment," presented at the Eastern States Section Meeting of the Combustion Institute, Princeton, NJ, October 25-27, 1993. 


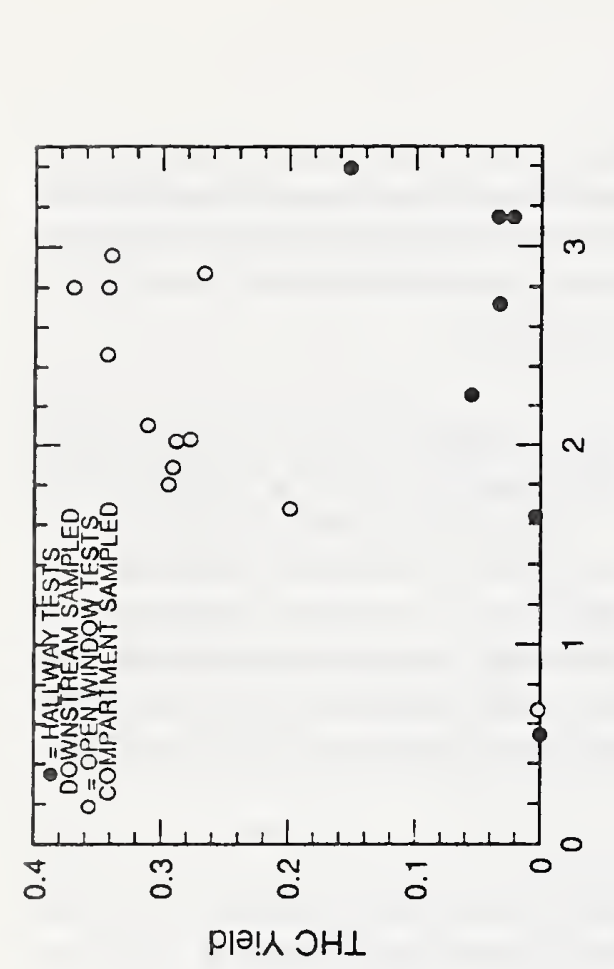

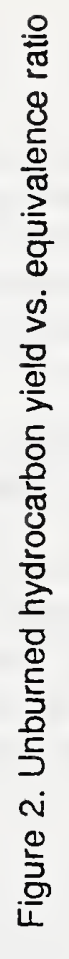
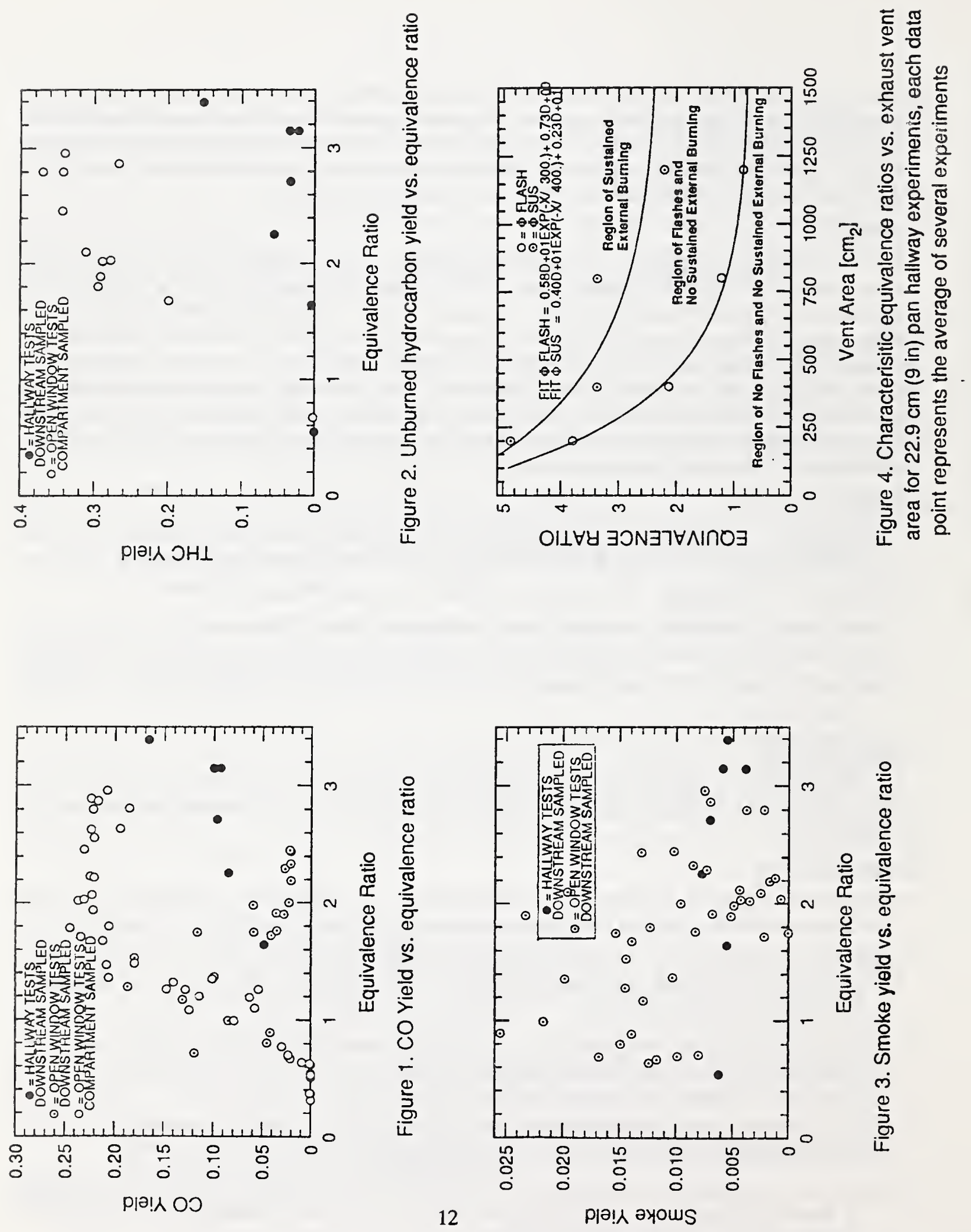


\section{BUILDING AND FIRE RESEARCH LABORATORY FIRE RESEARCH PROGRAM \\ NATIONAL INSTITUTE OF STANDARDS AND TECHNOLOGY \\ GRANTEE PROJECT - FY93}

Institution:

Grant No.:

Grant Title:

Principal Investigator:

Other Professional Personnel:

NIST Scientific Officer:
The Pennsylvania State University

60NANB0D 1035

Fundamental Mechanisms of $\mathrm{CO}$ and Soot Formation in Diffusion Flames

Professor Robert J. Santoro

Department of Mechanical Engineering

240 Research Building E

University Park, PA 16802

R. Puri, Doctoral Student

S. Léonard, Graduate Student

Dr. Kermit C. Smyth

Technical Abstract:

Introduction: Since $\mathrm{CO}$ inhalation is one of the major causes of fire fatalities, significant effort has been directed towards obtaining an understanding of the increased $\mathrm{CO}$ production in fires. Numerous workers have observed a correlation between the amounts of $\mathrm{CO}$ and soot produced in diffusion flames [1] as well as compartment fires [2]. There have also been several studies of the species produced by underventilated turbulent flames $[3,4]$. In these studies, there is an abrupt increase in the $\mathrm{CO}$ concentration at a global equivalence ratio of 1.0. This large increase in $\mathrm{CO}$ is of concern in regards to safety implications for fires in structures and is a motivation for the present study of simpler underventilated laminar diffusion flames.

The focus of the present study is to provide a quantitative data base on the production of $\mathrm{CO}$ and smoke particulates from laminar underventilated diffusion flames a la Burke and Schumann [5]. Advantages of the underventilated laminar diffusion flame system include a wide range of $\Phi$ up to at least 4 , the ease in measuring $\Phi$ and the yields of $C O$ and smoke, and the potential for theoretical analysis of the generation rates of the combustion products. In the present study, emphasis is given to the general trends observed for both $\mathrm{CO}$ and soot production in terms of the global equivalence ratio. The trends in the $\mathrm{CO}$ and soot yields in these underventilated laminar flame studies differ distinctively from results observed in overventilated diffusion flames. Additionally, the very nature of the soot formed in these flames is different from that observed in the more widely studied overventilated conditions.

Experimental Approach: Underventilated diffusion flames refer to conditions where the amount of oxidizer flow is insufficient to result in the oxidation of all of the fuel to carbon dioxide and water. In the present study, the fuel-to-oxidizer ratio is characterized by the overall equivalence ratio, $\Phi$, based on the ratio of the inlet fuel and air flow rates, where $\Phi$ greater than one correspond to fuel-rich conditions. 
The burner consists of two concentric tubes which could be varied in size to investigate the sensitivity of the results to burner geometry effects. Results for a single burner will be presented which are representative of the general behavior observed for the $\mathrm{CO}$ and soot yields. This burner had a fuel tube of $0.73 \mathrm{~cm}$ i.d. and outer air annulus with a $2.9 \mathrm{~cm}$ i.d. Both methane $\left(\mathrm{CH}_{4}\right)$ and ethene $\left(\mathrm{C}_{2} \mathrm{H}_{4}\right)$ fuels were studied. For the methane flames, fuel flow rates of $10 \mathrm{~cm}^{3} / \mathrm{s}$ and $20 \mathrm{~cm}^{3} / \mathrm{s}$ were examined, while for ethene, flow rates of 3.2 and $6.4 \mathrm{~cm}^{3} / \mathrm{s}$ were considered. The air flow rates were selected in each case to allow the overall equivalence ratio $\Phi$, to be varied between 0.5 and 4.0. Measurements of $\mathrm{CO}$ and $\mathrm{CO}_{2}$ concentrations were obtained using individual NDIR instruments, while soot particles were collected separately using filters and analyzed for mass deposited by a weighing procedure. Yields for $\mathrm{CO}$ and soot on a mass basis were determined from the measured concentrations and known flow rates of the gases supplied to the burner. Detailed species concentration profiles were obtained using intrusive probe techniques followed by gas chromatographic analysis. Complementary temperature measurements were made using thermocouples. These measurements were used to investigate the evolution of flame structure of these underventilated laminar diffusion flames as a function of radial and axial position.

Results and Analysis: It is convenient to express the results in terms of a yield based on the mass of CO or soot produced per mass of fuel entering the burner. The $\mathrm{CO}$ yield increases abruptly with $\Phi$ to a peak value of 0.37 for methane and 0.47 for ethene. As shown in Fig. 1, the peak in the methane curve occurs at a slightly smaller $\Phi$ than for ethene, 1.3 relative to 1.7. Additional measurements were performed at other fuel flow rates and with a second burner configuration to determine the generality of this shift, and the results were inconclusive in regard to the difference being attributed to fuel chemistry. Decreasing the fuel flow rate for ethene by a factor of two to $3.2 \mathrm{~cm}^{3} / \mathrm{s}$ was observed to shift the peak to the left by an amount similar to the difference between ethene at $6.4 \mathrm{~cm}^{3} / \mathrm{s}$ and methane at $10 \mathrm{~cm} / \mathrm{s}$.

The smoke yield curve peaks at smaller $\Phi$, near 1.0 , compared to the result for $\mathrm{CO}$ yield as shown in Fig. 2, which displays the results for an ethene flame. Also for large $\Phi$, the percentage decrease for smoke is much greater than for CO. The smoke yield decreases sharply for $\Phi>1.5$ as shown in Fig. 3 as the fuel flow rate decreases. This is the same trend as for the CO yield (see Fig. 1). The large reduction in the smoke yield at $\Phi=0.5$ for the $3.2 \mathrm{~cm}^{3} / \mathrm{s}$ fuel flow rate case is expected since the fuel flow rate is then below the smoke point for the overventilated flame.

The filter samples for smoke generated at large $\Phi$ appeared lighter in color and the deposit on the combustion burner tube had a liquid character. In fact, for methane at $\Phi=4$, the filter had a yellowish appearance. Thermo-optical analysis of the smoke collected on the quartz filters indicated that as $\Phi$ increased, the organic fraction of the smoke increased relative to the elemental carbon fraction. For $\Phi \geq 2$, the organic-to-elemental carbon ratio exceeded 0.5 for both the methane and ethene flames. Such large amounts of organic carbon in the soot particles is viewed to be quite interesting and differs from observations in overventilated flames where a ratio closer to 0.1 is usually observed. Additional evidence of the difference in character of the high $\Phi$ smoke compared to the low $\Phi$ smoke was obtained from electron micrographs of the ethene smoke collected at $\Phi=4$ and $\Phi=1$. In both cases the smoke was observed to have an agglomerated structure, however, at $\Phi=4$ the agglomerate appeared to be agglutinated, indicating the presence of a liquid-like component.

The peak CO yields for methane and ethene differ only by $20 \%$, while the peak smoke yields differ by about a factor of five. This result that the $\mathrm{CO}$ and smoke yields seem uncorrelated for underventilated burning differs markedly from the strong correlation between $\mathrm{CO}$ and smoke yields for overventilated burning observed for gaseous hydrocarbons [1] and for plastics and lumber [6].

Summary: An investigation of the generation of $\mathrm{CO}$ and smoke for underventilated laminar diffusion flames has revealed both strong similarities and differences with studies considering overventilated 
conditions. In particular, the proportionality between smoke yield and $\mathrm{CO}$ yield observed for the postflame (overfire) region of overventilated flames for a wide range of fuels is not found to be valid for the underventilated case. In fact, the soot observed in the underventilated flames is observed to vary considerably in terms of the chemical structure from that typically observed in overventilated flames. The highly organic nature of the soot implies that the structure of the soot may be more similar to early agglutinated soot particles recently observed in diffusion flames than to the more aged aggregates typical of the post-flame region for overventilated flames. Based on additional results, comparisons in terms of the ratio of $\mathrm{CO}$ and $\mathrm{CO}_{2}$ as a function of global equivalence ratio in the post-flame region of the underventilated flames show a similar behavior to that previously observed for in-flame measurements for both overventilated and underventilated diffusion flames which examined the dependence of this ratio on local equivalence ratio conditions. This suggests that for the in-flame fuel-rich region, the chemical environment excluding soot is correlated with equivalence ratio in a similar way for both an overventilated flame and an underventilated flame. The low production of $\mathrm{CO}$ in the post-flame region of overventilated flames is simply a result of the oxidation of $\mathrm{CO}$ to $\mathrm{CO}_{2}$ in the upper region of these flames. Finally, the present studies illustrate the utility of the study of underventilated flame environments where product yields and trends can be quite different from overventilated conditions. These studies should have significance for combustion phenomena in which underventilated conditions are typical, such as in fires.

Acknowledgement: The work done at The Pennsylvania State University was supported under grant 60NANB0D1035 from the National Institute of Standards and Technology. Contributions to this work by Drs. Kermit C. Smyth and George W. Mulholland of the Building and Fire Research Laboratory are gratefully acknowledged.

\section{References:}

1. Köylü, Ü.Ö., Sivathanu, Y.R., and Faeth, G.M., Fire Safety Science - Proceedings of the Third International Symposium (G. Cox and B. Langford, Eds.), Elsevier, p. 625 (1991).

2. Fischer, S.J., and Grosshandler, W.L., Twenty-Second Symposium (International) on Combustion, p. 1241 (1988).

3. Zukoski, E.E., Morehart, J.H., Kubota, T. and Toner, S.J., Combustion and Flame, 83:325-332 (1991).

4. Beyler, C.L., Fire Safety Journal 10:47-56 (1986).

5. Burke, S.P. and Schumann, T.E.W., Industrial and Engineering Chemistry, 20:998-1004 (1928).

6. Mulholland, G., Yusa, S., Yanssens, M., Twilley, W., and Babrauskas, V., Fire Safety Science Proceedings of the Third International Symposium (G. Cox and B. Langford, Eds.), Elsevier, pp. 585-594 (1991).

\section{Reports and Papers:}

1. Puri, R., Moser, M., Santoro, R.J. and Smyth, K.C., "Laser-Induced Fluorescence Measurements of OH Concentrations in the Oxidation Region of Laminar, Hydrocarbon Diffusion Flames," The Twenty-Fourth Symposium (International) on Combustion, The Combustion Institute, pp. 1015-1022 (1992).

2. Puri, R., Richardson, T.F., Santoro, R.J. and Dobbins, R.A., "Aerosol Dynamic Processes of Soot Aggregates in a Laminar Ethene Diffusion Flame," Combustion and Flame, 92:320-333 (1993).

3. Léonard, S., Mulholland, G.W., Puri, R. and Santoro, R.J., "Generation of CO and Smoke During Underventilated Combustion," submitted to Combustion and Flame.

4. Puri, R., Santoro, R.J. and Smyth, K.C., "The Oxidation of Soot and Carbon Monoxide in Hydrocarbon Diffusion Flames," submitted to Combustion and Flame. 


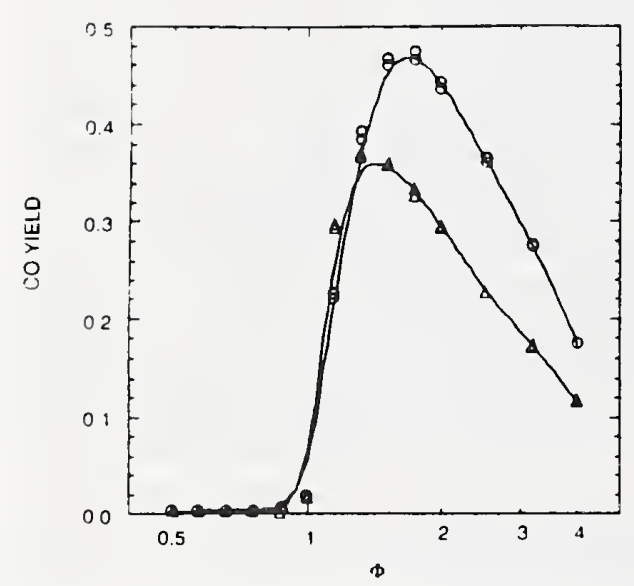

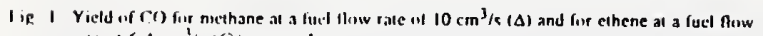
rate it $64+m^{2} / 5101$ versus th.

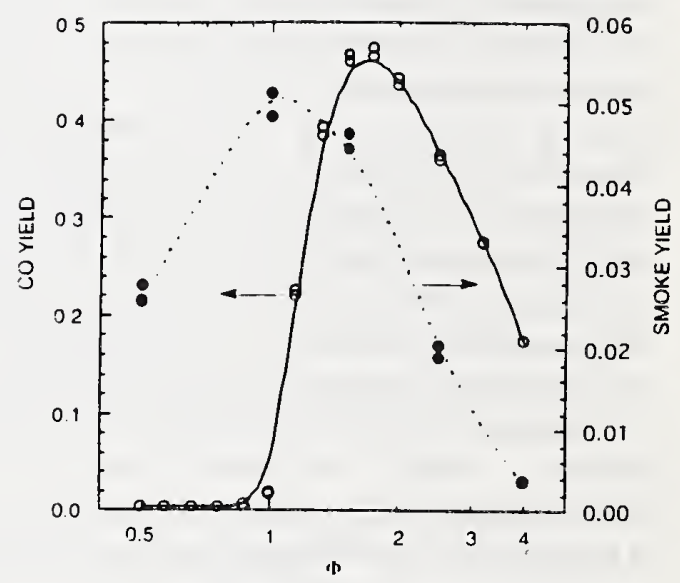

Hig. 2 Yiclds of $\mathrm{CO}(\mathrm{O})$ and snove 10 ) as a function of $\Phi$ for ethene at a fuet fow rate of 6.4 $\mathrm{cm}^{3 / 5}$

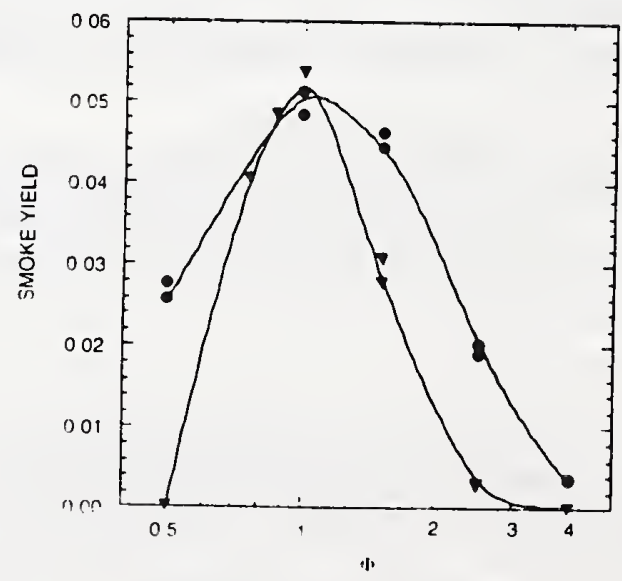

Fig 3 Yield un smoke fir ethene a s lind lluw rate of $64 \mathrm{~cm}^{3} / \mathrm{s}(0)$ and at a fuel fow rate of $17 \cos ^{3} /\left.\right|_{1} \mid$ 
A2. Turbulent Combustion 



\section{BUILDING AND FIRE RESEARCH LABORATORY \\ FIRE RESEARCH PROGRAM \\ NATIONAL INSTITUTE OF STANDARDS AND TECHNOLOGY \\ GRANTEE PROJECT-FY93}

Institution:

Grant No.:

Grant Title:

Principal Investigator:
University of Califomia, Berkeley

60NANBIDI174

Fire Propagation in Concurrent Flows

Professor A. Carlos Fernandez-Pello

Department of Mechanical Engineering

University of Califomia

Berkeley, CA 94720

Telephone: (510) 642-6554

Fax: (510) 642-6163

Other Professional Personnel: Y.H. Chao, Doctoral Student

NIST Scientific Officer: $\quad$ Mr. Kenneth Steckler

\section{Technical Abstract:}

An experimental study is being conducted of the effect of gas flow velocity, turbulence intensity, and oxygen concentration on the concurrent spread of flames over the surface of a solid combustible. These experiments address both the transport and chemical kinetics mechanisms that control flame spread, and thus should provide information about what which ones are dominant, and under what conditions they are. This information could be used to provide simplified formulas of flame spread rate for use in fire models. The experiments include measurements of the flame spread rate, mass buming rate, flame length, surface heat flux, combustion products $\left(\mathrm{CO}, \mathrm{CO}_{2}, \mathrm{HC}\right)$, and soot, as a function of the flow conditions. The tests are conducted in a combustion wind tunnel with the fuel mounted in the ceiling or the floor of the tunnel test section to observe, by comparison, the effect of buoyancy and geometry. All the tests are conducted with PMMA sheets $76 \mathrm{~mm}$ long, $37 \mathrm{~mm}$ wide and $12.7 \mathrm{~mm}$ thick. The tests are conducted with air flow velocities ranging from 0.25 to $4.5 \mathrm{~m} / \mathrm{s}$, grid induced turbulence intensities from $1 \%$ to $15 \%$, and oxygen mass fractions from 0.19 to 0.4 .

The measurements show that there is a complex interaction between the flow transport mechanisms, and the chemical kinetics mechanisms that control the flame spread process. This interaction determines the surface heat flux, the flame length, the rate of heat release, and through them the flame spread rate. Currently we are working on completing a test matrix that will allow us to map the different regimes of flame spread. The objective is to detemine the regimes at which the flame spread process is controlled by transport mechanisms, or by chemical kinetics mechanisms. Such differentiation will help in the development of simplified fomulas of flame spread to be used in models of fire development.

\section{Turbulent, Concurrent. Ceiling Flame Spread}

The flame spread rate measurements show that, in general, the flame spread rate increases as the flow velocity and oxygen concentration is incrcased although the rate of increase depends on the level 
of the llow turbulence intensity. Also, the dependence of the flame spread rate on the flow turbulence intensity varies with the flow velocity and oxygen concentration. Figure 1 shows an example of the flame spreat rate dependence on the flow turbulence intensity, for different oxygen concentrations, and for a flow velocity of $1 \mathrm{~m} / \mathrm{s}$. The spread rate is an average of the value through the sample and from two to three diflerent tests. No data for oxygen mass fraction lower than 0.19 was obtained because the spread of the llame could not be initiated or flame extinction occurred after the flame had propagated for a short chistance. From Fig. 1 it is seen that as the turbulence intensity is increased the flame spread rate first increases, reaches a maximum, at approximately $15 \%$ turbulence intensity, and then decreases. This trend is more marked at higher oxygen concentrations, and the location of the maximum depends on the flow velocity. Current data indicates that for relativcly large flow velocitics (larger than $1 \mathrm{~m} / \mathrm{sec}$ ), the maximum is displaced toward lower values of the turbutence intensity, and that the opposite occurs at low flow velocitics (less than $0.75 \mathrm{~m} / \mathrm{s}$ ).

The mechanisms by which the flow parameters affect the flame spread rate can be inferred from the theoretical analysis of the spread process. A simplificd heat transfer model of the flame spread provides the following expression for the rate of spread:

$$
V_{p}=\frac{4 q_{f}^{2} l_{f}}{\pi k \rho c\left(T_{p}-T_{f}\right)}
$$

where $q_{f}$ is the surface heat flux, $l_{f}$ the flame length, kpc are the thermal incrtia of the solid, and $T_{p}$ and $\mathrm{T}_{\mathrm{i}}$ are the solid pyrolysis and initial temperatures, respectively. The flow velocity, turbulence intensity and oxygen concentration can alfect both $\mathrm{q}_{\mathrm{f}}$ and $l_{\mathrm{f}}$ and through them the flame spread rate. Thus, it is important to determine how the flow characteristics affect these parameters.

The measured variation with the turbulence intensity of the ratio of the flame length to the pyrolysis length is presented in Fig. 2 and of the surface heat flux in Fig. 3. It is scen that the flame length is approximately proportional the pyrolysis length to a power, that although close to unity, depends on the flow conditions. From Fig. 3 it is seen that the surface heat flux squared is proportional to the pyrolysis length, with the constant of proportionality and the power depending on the flow conditions. For a given pyrolysis length, as the turbulence intensity is increased, both the flame length and the surface heat flux first increase, reach a maximum, and then decrease. This trend is more noticeable at low pyrolysis lengths and high oxygen concentrations, and depends on the flow velocity. It should be noted that these dependencies are similar to those observed for the flame spread rate (Fig. 1). These data have been nomalized using Eq. (1), and the results, which are presented in Fig. 4, provide validation for a mockel of flame spread based on a encrgy analysis of the process. The chemical kinetics mechanisms appear in Eq. (1) through the flame length and surface heat flux.

To further investigate the importance of chemical kinetics as flame spread controlling mechanisms, major species concentrations and soot were measured in the exhaust gas. The variation of the $\mathrm{CO}$ concentration with the turbulence intensity for several oxygen concentrations is presented in Fig. 5, for a llow velocity of $1 \mathrm{~m} / \mathrm{s}$. It is seen that as the turbulence intensity is increased, the CO concentration decreases (combustion is more complete), probably duc to the improved mixing of the fuel and oxidizer. The increase in combustion completeness is further verified by the measured average gas temperature data which shows that the temperature increases with the turbulence intensity. A more complete combustion should result in an increase in the heal release rate, and consecquently of the surface heat flux. A larger 
surface heat flux would, in tum, result in an enhanced solid heating, a larger pyrolysis rate and consequently a larger flame length. However, the enhanced mixing should also result in a shorening of the flame as the combustion efficiency is improved. The competition between these two effects, would determine the final flame length and its dependence on the turbulence intensity. The $\mathrm{CO}$ measurements also show that the worst conditions for incompleteness of combustion are low oxygen concentration, velocity and turbulence intensity. This observation is important since these are conditions that often prevail in fires.

\section{Publications and Presentations}

1. Zhou, L. and Femandez-Pello A.C., "Turbulent, Concurrent, Ceiling Flame Spread: The Effect of Buoyancy," Combustion and Flame, 92, 45, 1993.

2. Zhou, L. and Femandez-Pello A.C., "Solid Fuel Combustion in a Forced, Turbulent, Flat Plate Flow: The Effect of Buoyancy" Twenty-Fourth International Symposium on Combustion. The Combustion Institute, Pittsburgh, PA, 1721, 1992.

3. Zhou, L., "Solid Fuel Flame Spread and Mass Buming in Turbulent Flow" Ph.D. Thesis, University of Califomia, Berkeley, CA, 1991.

4. Chao, Y.H. and Femandez-Pello, A.C., "Flame Spread in a Vitiated Concurrent Flow," Heat Transfer in Fire and Combustion, 1992 ASME/AIChE National Heat Transfer Conference, San Diego, CA, August 1992.

5. Chao, Y.H. and Femandez-Pello, A.C., "Turbulent Concurrent Flame Spread: Effect of Oxygen Concentration," 1993 Spring Meeting, Westem States Section/The Combustion Institute, Salt Lake City, UT.

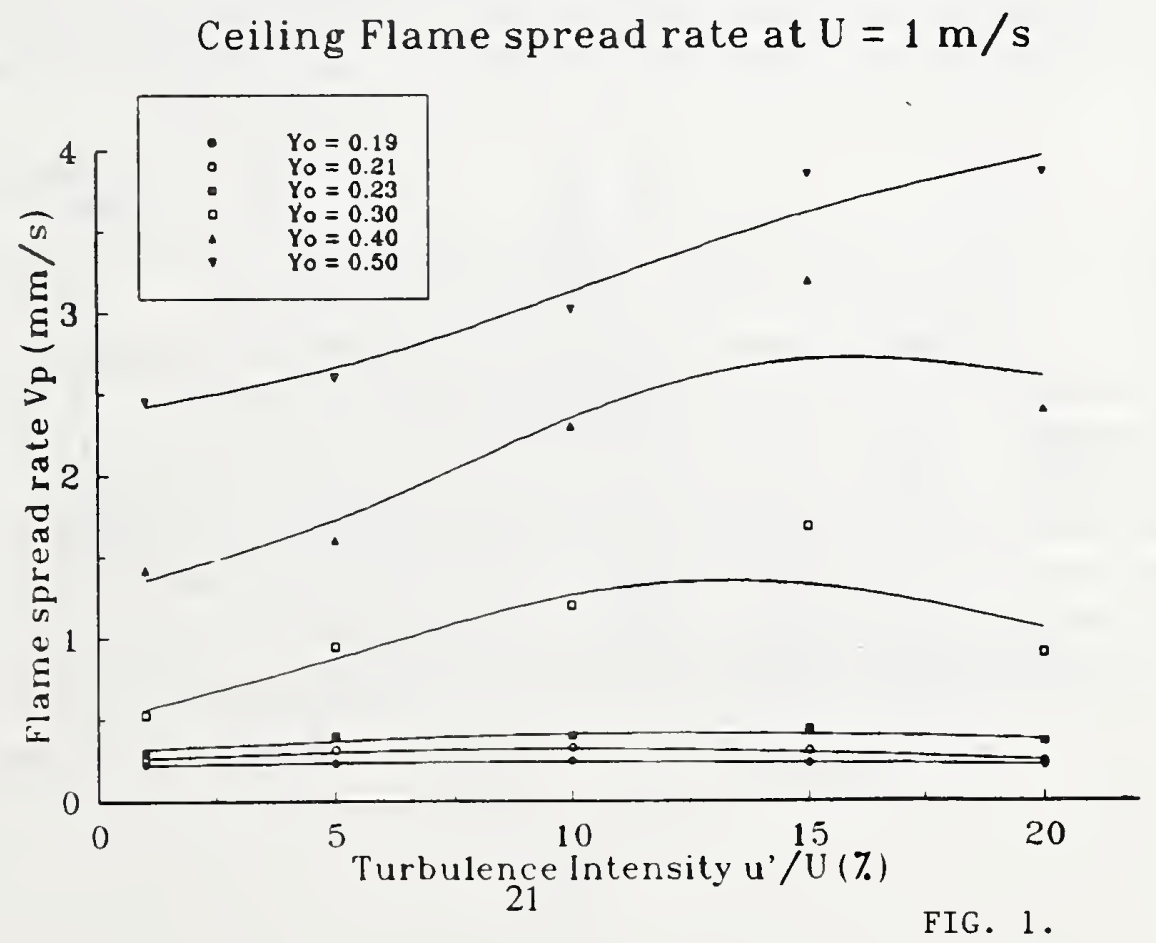



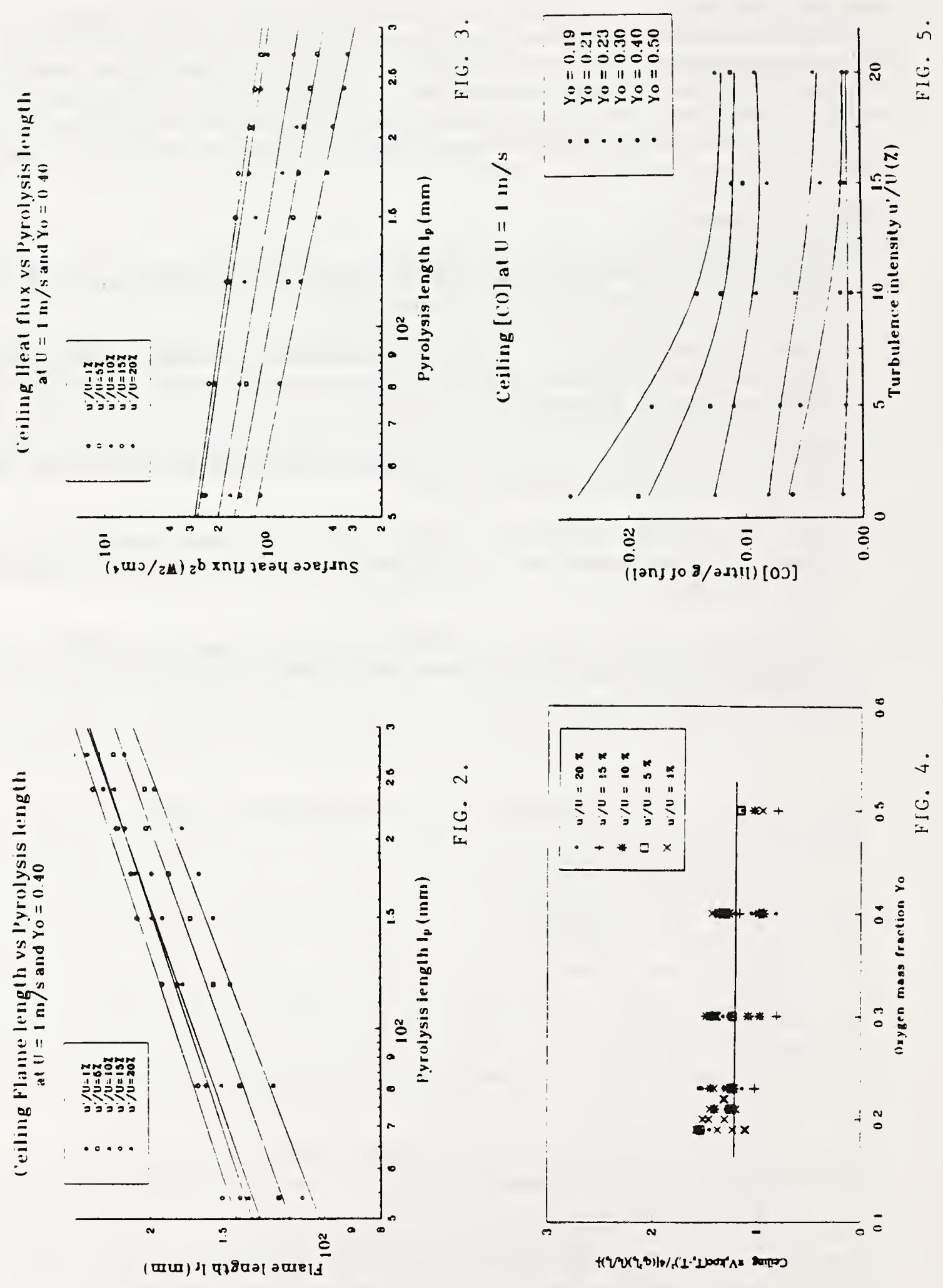


\section{BUILDING AND FIRE RESEARCH LABORATORY \\ FIRE RESEARCH PROGRAM \\ PRIORITY PROJECT -FY93}

\section{SIMULATION OF TURBULENT COMBUSTION AND TRANSPORT IN FIRES}

\section{$\underline{\text { Professional Personnel }}$}

Howard R. Baum, Project Leader

Ronald G. Rehm, CAML

Kevin B. McGratten

Ofodike A. Ezekoye (now at U. Texas Austin)

\section{Project Objective}

To develop a fundamental understanding of the mechanisms which control the gas phase combustion and transport processes in fires and develop a predictive capability which will allow the computer simulation of these processes to be based on the mathematical expression of underlying physical principles.

\section{$\underline{\text { Scope }}$}

A theoretical and computational approach to the study of the transport, mixing, diffusion, reaction, and radiation processes occuring in both enclosure and exterior fires. Emphasis is placed on gaining an understanding both of the individual phenomena, which occur on widely differing length and time scales, and on the interaction between them. Analyses and computer simulations of separate phenomena are combined and applied to problems of general interest.

\section{Technical Accomplishments}

The enclosure fire model contains a employing calculation based on two-dimensional time dependent solutions of the Navier-Stokes equations in the Boussinesq limit. The calculations are performed using a conformal transformation of the spatial variables allowing the equations to be solved in an arbitrary polygonal domain. The conformal map transforms the physical geometry into a rectangular domain in which the transformed equations are solved using finite difference techniques. The flows are driven by a combustion model in which the heat is released on Lagrangian fuel elements which are convected by the large scale fluid motion. This is the high Reynolds number limit of diffusion controlled combustion on discrete fuel elements. The model permits computations of smoke and hot gas transport at Reynolds numbers of order $10^{5}$ in enclosures of complex shape without employing empirical turbulence models. 
The model has been compared with salt water experiments performed at U.C. Berkeley under the direction of Prof. Pagni to understand the hydrodynamics of the window breaking and backdraft phenomenon. It has also been compared with analogous experiments at Cal Tech under the direction of Prof. Zukoski used to study smoke movement down long corridors. The agreement with both sets of experiments is quite good, demonstrating that the large scale transport of smoke and hot gases can be reasonably described without employment of empirical turbulence models.

The "thermal element" model contains a local scale diffusion controlled combustion model which consists of a small sphere of gasified fuel being consumed by a transient flame. A prescribed fraction of the fuel is converted to soot which can emit radiation to its surroundings or absorb radiation from other thermal elements. At large scales which characterize the overall geometry of the scenario under investigation the model consists of a large number of point sources of energy and volume. The large and small scale pictures are coupled together both hydrodynamically and thermally. The location in space and time of each thermal element is determined by a particle tracking computation of its thermal elements. The local asymptotic expansion velocity, together with the chemical and net radiative heat sources are fed back into the computational mesh used to calculate the large scale flow.Thus, the overall fire induced flow is decomposed into an irrotational expansion flow and a solenoidal buoyancy generated flow. The Navier-Stokes equation simulations described above determine the solenoidal flow while the thermal elements determine the expansion field and generate the thermal sources for the large scale buoyancy field.

To date, the model has been developed with the solenoidal flow field replaced by a prescribed toroidal "Hills" vortex, which is an exact solution of the Navier Stokes equations at infinite Reynolds numbers. This flow pattern, which is an idealization of the large quasi-periodic eddies generated in a fire plume, has been successfully coupled to the combustion problem using 2000-5000 thermal elements, permitting three-dimensional time dependent burning to be simulated. The calculations performed include radiation to a prescribed target of finite area, permitting radiative feedback to fuel beds to be determined.

The smoke transport and deposition model is designed to predict the ground level footprint of particulate matter generated downwind of a large pool fire. The work is part of a larger project (described elsewhere) sponsored by the Minerals Management Service of DOI investigating the feasibility of cleaning up oilspills by burning the spill material. The plume is described in terms of the steady state physical location of the hot gas and particulate matter introduced by the continuously burning fire into the atmosphere. It is assumed that the overall heat release rate and the particulate mass generation rate are known, and that the initial plume structure within a few flame lengths of the fire is not of interest. The atmosphere has a prescribed stratification (which can be fairly general) with a uniform wind. The subgrid (less than 10 meters) mixing due to the natural turbulence in the atmosphere is represented by a constant eddy viscosity. All scales above this are calculated directly from the governing equations, which take the form of two dimensional Navier-Stokes equations in a cross-flow plane moving with the wind. The particulate matter is represented by a large number of Lagrangian elements which are convected by the combined effects of the atmospheric and plume induced 
motion. The model predicts the rise and stabilization of the thermal plume, the separation of the particulate plume, and its descent to ground level. When the particulate is within one computational cell of the ground, it is removed from the atmosphere and its position in the ground plane recorded. The totality of final ground level positions is the particulate deposition pattern.

The trajectory predicted by the model has been compared with field observation performed at the U.S. Coast Guard site in Mobile, AL, for the rising and stabilization portions of the plume. The results to date are quite encouraging. The observed large scale eddy structure in particular is captured quite well by the model.

\section{Publications}

Baum, H.R., "Simulation of Convection and Combustion Processes in Fires", in Computers and Computing in Heat Transfer Science and Engineering, (Nakayama, W. and Yang, K.T., Eds), CRC Press, Boca Raton, p.207, (1992).

Rehm, R.G., Baum, H.R., Tang, H.C., and Lozier, D.C., "Finite-Rate Diffusion-Controlled Reaction in a Vortex", Combust. Sci. and Tech., Vol. 91, p.143, (1993).

Ghoniem, A.F., Zhang, X., Knio, O., Baum, H.R., and Rehm, R.G., "Dispersion and deposition of smoke plumes generated in massive fires", J. Hazardous Materials, 33, p.275, (1993).

Baum, H.R., Ezekoye, O.A., McGrattan, K.B., and Rehm, R.G., , "Mathematical Modeling and Computer Simulation of Fire Phenomena", Proceedings of the Ninth Symposium on Turbulent Shear Flows, Kyoto, Japan, (1993).

Walton, W.D., Evans, D.E., McGrattan, K.B., Baum, H.R., Twilley, W.H., Madrzykowski, D., Putorti, A.D., and Rehm, R.G., "In Situ Burning of Oil Spills: Mesoscale Experiments", Proceedings of the Sixteenth Arctic and Marine Oil Spill Program Technical Seminar, Environment Canada, Ottowa, p.679, (1993).

\section{$\underline{\text { Related Grants }}$}

"Radiation from Turbulent Luminous Flames", Prof. G.M. Faeth, University of Michigan.

"Fire Modeling", Prof. P.J. Pagni, University of California, Berkeley.

"Numerical Modeling of Plume Dispersion and Smoke Deposition from Large Scale Fires", Prof. A.F. Ghoniem, Massachusetts Institute of Technology.

"Modeling of Combustion, Fluid Mechanics, and Radiation in Buoyant Turbulent Fires", Prof. O.A. Ezekoye, University of Texas at Austin 

A3. Soot 



\section{BUILDING AND FIRE RESEARCH LABORATORY \\ FIRE RESEARCH PROGRAM \\ NATIONAL INSTITUTE OF STANDARDS AND TECHNOLOGY \\ GRANTEE PROJECT - FY93}

Institution:

Grant Number:

Grant Title:

Principal Investigator:

Other Personnel:

NIST Scientific Officer:
The George Washington University

60NANB1DI292

Experimental and Modeling Studies of Soot and Carbon Monoxide in an Ethylene/Air Diffusion Flame

Professor J. Houston Miller

Department of Chemistry

The George Washington University

Washington, DC 20052

(202) 994-7474

Mr. R. Reed Skaggs, Graduate Student

Mr. Michael Marro, Graduate Student

Mr. Michael Tolocka, Graduate Student

Ms. Khanh Le, Undergraduate Student

Dr. Kermit C. Smyth

\section{Technical Abstract:}

During the past year our work focussed on three areas:

- the continuing development of a model for PAH growth in hydrocarbon diffusion flames with an emphasis on those burning ethylene.

- the application of tunable diode laser absorption spectroscopy to the study of ethylene/air diffusion flames near their smoke point, and

- the development of an efficient simulation program for infrared spectral signatures such as those which are observed at high resolution using narrow bandwidth lasers as well as those which would be available using more conventional Fourier Transform Infrared Spectrometry (FTIR).

Significant progress was made in all three of these areas as will be described below.

PAH growth model in ethylenelair flames

We have made some preliminary progress in modelling PAH and soot growth in ethylene/air flames. In last year's report, we described the development of this model for axially symmetric methane/air flames. Our model begins with a simple parabolic calculation of flame structure which solves conservation equations for mass, momentum, and mixture fraction. The energy equation is not solved; instead the experimentally determined dependence of temperature on mixture fraction is used. 
Superimposed on this structure we track the nucleation. growth, and oxidation of high mass organics, with no differentiation made hetween large $\mathrm{PAH}$ and particulates.

In the past year we have modified our code to calculate ethylene/air flame structures. The flames we chose to model are those studied by Santoro et al. [1] who studied a series of flames at different fuel flow rates: $3.85 \mathrm{~cm}^{3} / \mathrm{s}$ (non-sooting, NS, flame), $4.6 \mathrm{~cm}^{3} / \mathrm{s}$ (incipient sooting, IS, flame), and $4.9 \mathrm{~cm}^{3} / \mathrm{s}$ (a sooting flame). The model predicted the expected result that the soot volume fractions in any of the ethylene flames was higher $\left(\approx 10^{-5}\right)$ than those calculated for methane/air flames (in the low $10^{7} \mathrm{~s}$ ). However, the model failed to predict soot breakthrough at the flame tip in the higher fuel flow rate flames. This failure can he traced to the fact that our model does not include some important processes that are known to occur at the flame tip. First, radiative cooling of the flame was not included in our model formulation: the same temperature versus mixture fraction correlation is used at the top of the flame (where there is significant quantity of particulate) as that used low in the flame. The higher tip temperatures predicted hy the model will exaggerate the oxidation rate. Secondly, hydroxyl radicals are known to be depleted by the presence of soot particles [2]. This effect is also not included in our current model. Because $\mathrm{OH}^{-}$is a primary oxillizer of soot at the tip. we will again exaggerate the oxidation rate.

Our current efforts in this project are aimed toward remedying these model deficiencies.

\section{TDLAS diagnostics in Axially Symmetric Ethylene/air Diffusion Flames}

We have begun a series of in situ measurements of carbon monoxide concentration and local flame temperature in the same series of ethylene/air axially symmetric laminar diffusion flames discussed above. These measurements will allow for further insight into the dynamics of thermal loss from soot radiation, soot oxidation, and carbon monoxide emission processes that occur in "sooting" flames. Santoro et. al. $|1|$ studied soot formation in these environments using a thermocouple to measure the local flame temperature and laser light scattering and extinction to measure local soot properties. Their results have shown gualitatively how temperature at the flame tip decreases with fuel flow rate due to increased radiative heat transfer at higher soot loadings. Our measurements compliment these earlier ones by adding carbon monoxide concentrations to the data available at the flame tip and providing a check of the thermocoruple temperature measurements.

The use of tunable diode laser ahsorption spectroscopy (TDLAS) for in situ diagnostics is developing into a useful tool for combustion diagnostics. High sensitivieties are available using wavelength modulation technicues which is critical in short beam length regions such as that at the tip of these diffusion flames. During the past year, our research has involved the study of two axisymmetric laminar hydrocarbon diffusion flames, methane/air and ethylene/air, using TDLAS. Both flames have been previously studied hy Santoro et. al, using probe, thermocouple, and optical techniques [1]. Probe and thermocouple are intrusive and difficult to employ in highly sooting environments (because of probe clogging and soot deposition), but infrared absorption is applicable in studies of particle-laden flows because of the relative insensitivity to scattering and extinction at long wavelengths.

Our studies of a methane/air flame allowed for the development of a reliable experimental technique that was extended to ethylene/ai flames with flow rates near the sooting limit. In our experiments with the three ethylene/air flames described above, second harmonic spectra of the (CO) lines, $\mathrm{R}(15)$ \& $\mathrm{R}(7)$, were collected every $0.5 \mathrm{~mm}$ at a height of approximately $55 \mathrm{~mm} \mathrm{HAB}$ (Height Ahove Burner). For measurements at a height of $10.0063 \mathrm{~mm} \mathrm{HAB}$, the (CO) lines, $\mathrm{R}(11)$ \& $\mathrm{R}(19)$, 
were collected using a direct ahsorption technique. Because TDLAS is a line-of-sight technique, it is necessary to employ tomographic reconstruction to ohtain radial data from the collected projection data, which is the convolution of the incremental absorptions from each spatial location in the flame traversing the length of the laser beam. We use a three point Abel inversion algorithm |3| for tomographic reconstruction of spectra for each radial location. The reconstructed spectra is then individually fit to the functional form of the second harmonic signal of a Lorentzian line shape [4]. This technique, as suggested by Varghese et al. [5]. should lead to the most accurate measurements of temperature and concentration using TDLAS.

Soot particles have a graphitic morphology. Because aromatic oxidation procluces copius yields of $\mathrm{CO}$, we antcipate an increase in carbon monoxide concentrations at the flame tip as the quantity of soot is increased. Puri et al. have found that increased amounts of soot result in larger concentrations of CO in higher regions of flames as well as depleted hydroxyl radical species [2,7] in a series of methane flames which are either undiluted, diluted with butane, or hutene. Our preliminary analysis of our data shows that centerline $\mathrm{CO}$ concentration levels are much higher at $55 \mathrm{~mm} \mathrm{HAB}$ in the IS flame compared to those in the NS flame. The CO levels found in the sooting flame are slightly higher than those observed in the IS flame. We also observe a slight decrease in the centerline temperature for the series NS, IS, S.

\section{Spectral Simulation using the HITRAN data hase}

Over the past few years we have demonstrated the application of tunable diode laser absorption spectroscopy (TDLAS) for the measurement of concentration and temperature in hydrocarbon diffusion flames. These studies have focussed on absorptions of carhon monoxide neal $2150 \mathrm{~cm}^{-1}$. The great promise of the mid infrared region is that almost every molecule of interest absorbs light here.

The fractional absorption of infrared laser light is given by

$$
\ln \left(\frac{I^{o}}{I}\right)=S(T) \cdot g\left(v-v^{o}\right) \cdot p_{j} \cdot l
$$

where $\mathrm{I}^{\circ}$ is the incident beam intensity, $\mathrm{I}$ is the transmitted beam intensity. $\mathrm{g}$ is the line shape factor (in our work assumed to be Lorentzian), $\Gamma_{\mathrm{j}}$ is the partial pressure of the absorhing species, and 1 is the path length through the absorbing medium.

The line strength at flame temperatures is given by:

$$
S(T)=S(296) \cdot \frac{Q_{296}}{Q_{T}} \cdot R \cdot \exp \left[\frac{h c}{k} \cdot E^{\prime \prime} \cdot \frac{(T-296)}{(T \cdot 296)}\right]
$$

with

$$
R=\frac{1-\exp \left[-\frac{h c}{k} \cdot \frac{\left(E^{\prime}-E^{\prime \prime}\right)}{T}\right]}{1-\exp \left[-\frac{h c}{k} \cdot \frac{\left(E^{\prime}-E^{\prime \prime}\right)}{296}\right]}
$$


Here the Q's refer to partition functions, and $E^{\prime}$ and $E^{\prime \prime}$ refer to the upper and lower state energies, respectively. To simulate a spectrum in the infrared it is necessary to convolute the contribution of all of the absorbing lines in the spectral region of interest. This requires access to considerahle spectral data: partition functions, collision halfwidths, state energies, etc. The HITRAN data hase is a collection of infrared spectral data which includes data for molecules of atmospheric (and combustion) interest. Within the last year, the data hase became significantly more accessible with distribution on CD-ROM. We have written a DOS hased spectral simulation program that may he used to accurately predict the appearance of infrared absorption spectra. The program input includes concentrations of species of interest, temperature, and pathlength. A new option allows for the simulation of the more sensitive wavelength modulation spectra. Our simulation program is also incorporated into all of our spectral fitting programs.

We are currently preparing a Windows version of the simulation package which will dramatically streamline the user interface. A new option for the prediction of lower resolution spectral data (i.e., FTIR spectra) is also heing added.

\section{References}

1. R.J. Santoro, T.T. Yeh. J.J. Horvath, and H.G. Semeriian: "The Transport and Growth of Soot Particles in Laminar Diffusion Flames," Combust. Sci. and Tech., 53. 89-115 (1987).

2. R. Puri, R.J. Santoro, and K.C. Smyth, Combuss. and Flame, submitted for publication.

3. C.J. Dasch: Appl. Optics, 31, 1146 (1992).

4. R. Arndt: J. Appl. Phys., 17, 2477 (1965).

5. X. Quyang. P.L. Varghese: Appl. Optici. 29, 4884-4890 (1990).

6. R.J. Santoru. H.G. Semerian, and R.A. Dobbins: Combust. and Flame, 51, 203-218 (1983).

7. R. Puri, R.J. Santoro: Fire Safefy Science, Proceedings of Third International Symposium, 595504.

Publications during this reporting period:

1) "Comparison of Experimental and Computed Species Concentration and Temperature Profiles in Laminar. Two-dimensional Methane/Air Diffusion Flames," T.S. Norton, K.C. Smyth, J.H. Miller, and M.D. Smooke. Combust. Sci. Technol. 90, 1 (1993).

2) "Radical Concentration Measurements in Hydrocarbon Diffusion Flames." K.C. Smyth, T.S. Norton. J. H. Miller. M.D. Smooke, R. Puri, M. Moser, and R.J. Santoro,

International Workshop on Mechanisms and Models of Soot Formation (Springer-Verlag, in press).

3) "Tunable Diode Laser Measurement of Carbon Monoxide Concentration in a Laminar Methane/Air Diffusion Flame." J.H. Miller, S Elreedy, B. Ahvazi, F. Woldu, and P. Hassanzadeh. Appl. Optics, in press.

4) "Axially Symmetric Hydrocarbon Diffusion Flames: Calculations and Optical Diagnostics. "Reed Skaggs. Khanh Le. J.H. Miller, Damon Honnery, and John Kent. Combustion Fundamentals and Applications (1993) p. 167. 


\section{BUILDING AND FIRE RESEARCH LABORATORY \\ FIRE RESEARCH PROGRAM \\ OTHER AGENCY PROJECT - FY93}

\section{GROUND-BASED SMOKE SAMPLING TECHNIQUES TRAINING COURSE AND COLLABORATIVE LOCAL SMOKE SAMPLING IN SAUDI ARABIA}

Funding Agency: $\quad$ Ministry of Defence and Aviation, Kingdom of Saudi Arabia

Professional Staff: $\quad$ Nelson Bryner, Project Leader Bruce A. Benner, Jr., Research Chemist (CSTL)

Robert A. Fletcher, Research Chemist (CSTL)

James E. Brown, Research Chemist

George W. Mulholland, Research Chemist

\section{Project Objective:}

Train three Saudi operators in smoke sampling techniques, collect samples in Saudi Arabia, and jointly analyze smoke samples. Visit facilities in Riyadh, Saudi Arabia.

Technical Accomplishments:

Operator Training - NIST has trained three Saudis to operate portable gas and particulate sampling instrumentation. This training which occurred at NIST on August 17-28, 1992 involved lectures and demonstrations of gravimetric measurements, light scattering cells, portable size classifiers, battery-powered gas analyzers and filter sampling trains. NIST's organic analytical group demonstrated sample preparation and illustrated the use of gas and liquid chromatography instrumentation.

Local Sampling in Saudi Arabia - In order to demonstrate the operation of portable gas and particulate sampling instrumentation, a team of NIST researchers travelled to Riyadh in December 1992 to collect smoke and gas samples in Saudi Arabia for analysis. Analysis of smoke and gas samples will include determination of $\mathrm{PAH}, \mathrm{CO}, \mathrm{CO}_{2}$ and total particulate concentrations. Split-sample analysis is being conducted with some samples being locally analyzed and other samples returned to NIST for more specialized analysis, such as laser microprobe analysis and scanning electron microscopy. 



\section{BUILDING AND FIRE RESEARCH LABORATORY \\ FIRE RESEARCH PROGRAM}

NATIONAL INSTITUTE OF STANDARDS AND TECHNOLOGY

GRANTEE PROJECT-FY93

Institution:

Grant Number:

Grant Title:

Principal Investigator:

Other Professional Personnel:

NIST Scientific Officer:
Kansas State University

NSF CTS 9024668

Light Scattering Studies of Fractal Soot Aggregates

Professor C.M. Sorensen

Department of Physics

Kansas State University

Manhattan, KS 66506-2601

(913) 532-6786

Mr. J. Cai, Graduate Student

Mr. N. Lu, Graduate Student

Mr. G. Roberts, Undergraduate Student

Dr. R. Gann

\section{Technical Abstract:}

\section{WORK COMPLETED DURING THE PAST YEAR}

1. A Comparison of Cluster Size and Morphology Determined by Static Light Scattering and Electron Microscope Analysis

With the development of the fractal concept for describing clusters of particles and the realization that random aggregation processes lead to fractal clusters, our ability to describe and quantify the morphology of clusters so generated was significantly improved. This engendered the problem of how to experimentally determine cluster morphological parameters such as the radius of gyration, $R_{\mathbf{g}}$, the fractal dimension, $\mathrm{D}_{\mathrm{f}}$, the number of monomers per aggregate, $\mathrm{N}$, and the monomer radius (assumed spherical), a. This is a problem for both visual inspection via transmission electron microscopy and more so for light scattering measurements.

In previous work supported by this grant we demonstrated how the combined use of both optical structure factor measurements (scattered intensity as a function of scattering angle) and scattering/extinction measurements could yield in-situ determination of $\mathrm{R}_{\mathrm{g}}, \mathrm{D}_{\mathrm{f}}, \mathrm{N}$ and a for soot in a flame. It would be useful and important, however, to be able to make direct comparisons of these optical measurements with soot particles physically sampled from the flame. This would test the theory for the optics of fractal clusters, substantiate our ability to make in-situ optical measurements, and check the consistency of light scattering and mechanical sampling.

Our flame was supported on a cooled porous frit burner obtained from McKenna Products. The premixed gases, $\mathrm{CH}_{4}$ and $\mathrm{O}_{2}$, passed through a $6 \mathrm{~cm}$ diameter porous frit. This frit was surrounded by an annular sheath region $0.5 \mathrm{~cm}$ wide through which nitrogen was passed. A $15 \mathrm{~cm}$ diameter steel stagnation plate was placed $30 \mathrm{~mm}$ above theburner surlaceto stabilize the flame. The cold gas velocity, 
uniform across the frit, of the mixture was $6 \mathrm{~cm} / \mathrm{s}$. This arrangement yielded a quasi-one-dimensional flame with the only major variable being the height above the burner, $h$.

The light scattering used on incident $\mathrm{Ar}^{+}$laser at $\lambda=488 \mathrm{~nm}$. A photomultiplier tube at $\theta=0^{\circ}$ detected the beam after it passed through the flame to determine flame turbidity. A second photomultiplier was used to detect the scattered light at angles of $10^{\circ} \leq \theta \leq 110^{\circ}$. The scattered light measurement was made absolute by calibration to scattering from gases of known cross section.

A thermophoretic soot sampling device was built that could insert Formvar coated copper TEM grids into the flame with residence times of $15 \mathrm{msec}, 50 \mathrm{msec}$ and $100 \mathrm{msec}$. Then the grids were examined with a transmission electron microscope (TEM) and negatives of soot pictures were obtained at a magnification of 19200 . TEM micrographs of the soot were digitized by an optical scanner and these digitized images were stored in a computer. The images were computer processed into two different formats, a 16-shade format which preserved three dimensional information for the clusters despite their projection onto a two dimensional plane by the electron microscope, and a 2-shade format in which the cluster was uniformly dark and the background uniformly bright. The two formats have allowed us to accurately assess the effects of the three to two dimensional projection process, inherent in electron microscopy, on the measured size and morphological parameters. The TEM measurement of $R_{g}, D_{f}, N$ and a were then compared to the light scattering measurements.

Comparisons between light scattering and TEM measurements were very good, especially for $\mathbf{R}_{\mathbf{g}}$ and $D_{f}$, as shown below

\begin{tabular}{||ll|l|l||}
\hline & & \multicolumn{1}{|c|}{ Light Scattering } & \multicolumn{1}{c|}{ TEM } \\
\hline$R_{\mathrm{g}}(\mathrm{nm})$ & $\begin{array}{l}(\mathrm{h}=12 \mathrm{~mm}) \\
(\mathrm{h}=18 \mathrm{~mm})\end{array}$ & 67 & 69 \\
& & 115 & 112 \\
\hline $\mathrm{D}_{\mathrm{f}}$ & $1.79 \pm 0.1$ & $1.70 \pm 0.1$ \\
\hline $\mathrm{N}$ & $(\mathrm{h}=12 \mathrm{~mm})$ & 6 & 8 \\
& $(\mathrm{~h}=18 \mathrm{~mm})$ & 10 & 17 \\
\hline $\mathrm{a}(\mathrm{nm})$ & $(\mathrm{h}=12 \mathrm{~mm})$ & 13 & 12 \\
& $(\mathrm{~h}=18 \mathrm{~mm})$ & 14 & 15 \\
\hline
\end{tabular}

We conclude that first order theories of fractal optics (scattering and absorbtion) are adequate for in-situ optical particle sizing, and that mechanical probing and light scattering yield consistent results. Error analysis showed us that improvement can be made if uncertainties in soot particle refractive index can be made and if the proportionality constant $k_{o}$ in $N=k_{o}\left(R_{g} / a\right) D_{f}$ was better known.

\section{CURRENT WORK}

\section{Diffusivity of Fractal Aggregates}

Our static light scattering method allows for a direct and accurate measurement of the cluster radius of gyration, $\mathrm{R}_{\mathrm{g}}$. Dynamic light scattering allows us to determine the cluster diffusion coefficient. We have performed both measurements for soot clusters in premixed $\mathrm{CH}_{4} / \mathrm{O}_{2}, \mathrm{C}_{3} \mathrm{H}_{8} / \mathrm{O}_{2}$ and $\mathrm{C}_{2} \mathrm{H}_{4} / \mathrm{O}_{2}$ flames. Typically $20 \mathrm{~nm} \leq \mathrm{R}_{\mathrm{g}} \leq 150 \mathrm{~nm}$ and the gas molecule mean free path is ca. $350 \mathrm{~nm}$. So far we are finding that the diffusion coefficient is well described by the Epstein equation and the mobility radius 
$R_{m}$ is proportional to $R_{g}$ with ratio $R_{m} / R_{g}=0.6$. Further work is in progress to carefully check this proportionality compared to a dependence on cluster projectional area which is plausible and would yield nearly the same result.

\section{Depolarized Light Scattering from Aggregates}

Static measurements of the depolarization ratio $\rho=\mathrm{I}_{\mathrm{VH}} / \mathrm{I}_{\mathrm{VV}}$, i.e., the ratio of scattered intensities horizontally and vertically polarized for incident vertical polarization, have been made from $\mathrm{CH}_{4} / \mathrm{O}_{2}$, $\mathrm{C}_{3} \mathrm{H}_{8} / \mathrm{O}_{2}$ and $\mathrm{C}_{2} \mathrm{H}_{4} / \mathrm{O}_{2}$ flames. We find $0.3 \leq \rho \leq 1.5 \%$ and $\rho$ decreases with height above the burner. Furthermore $\rho \sim \lambda^{-4}$ and is not dependent on the scattering volume. These facts indicate $\mathrm{I}_{\mathrm{VH}}$ is due to intracluster multiple scattering and not intercluster multiple scattering or cluster anisotropy. We hope this study will yield further understanding of cluster optics and methods of particle characterization for monomers per cluster and cluster index of refraction.

\section{Cluster Morphology}

An overlooked but important parameter is $k_{o}$ in

$$
N=k_{0}\left(R_{g} / a\right)^{D_{f}}
$$

for fractal aggregates. We have recently measured $\mathrm{k}_{\mathrm{o}}$ for soot aggregates collected from premixed $\mathrm{CH}_{4} / \mathrm{O}_{2}$ flames to find $\mathrm{k}_{\mathrm{o}}=1.2 \pm 0.15$. We are currently using computer simulations to create diffusion limited cluster aggregates and analysis shows these clusters to have $k_{0}=1.1 \pm 0.1$. Work is underway to study other types of clusters and to obtain more real-world data.

\section{PAPERS}

1. "Light Scattering Measurements of Monomer Size, Monomers per Aggregate and Fractal Dimension for Soot Aggregates in Flames," Appl. Optics 31, 6547 (1992), C.M. Sorensen, J. Cai and N. Lu.

2. $\quad$ "Test of Static Structure Factors for Describing Light Scattering from Fractal Soot Aggregates," Langmuir $\underline{8}, 2064$ (1992), C.M. Sorensen, J. Cai and N. Lu.

3. "Comment on 'Structure of Silica Gels'," accepted in Phys. Rev. Lett., C.M. Sorensen, J. Cai and N. Lu.

4. "Comparison of Size and Morphology of Soot Aggregates as Determined by Light Scattering and Electron Microscopic Analysis," accepted in Langmuir, J. Cai, N. Lu and C.M. Sorensen. 

BUILDING AND FIRE RESEARCII LABORATORY

FIRE RESEARCH PROGRAM

NATIONAL INSTITUTE OF STANDARDS AND TECHNOLOGY

GRANTEE PROJECT -FY93

Institution:

Grant No.:

Grant Title:

Principal Investigator:

Qther Personnel:
The University of Michigan

NANB1D1175

Soot, Carbon Monoxide and Radiant Emissions of Luminous Turbulent Flames

Professor G. M. Faeth

Department of Aerospace Engineering

The University of Michigan

Ann Arbor, MI 48109-2140

Z. Dai, Doctoral Candidate

Ü. Ö. Köylü, Postdoctoral Fellow

L.-K. Tseng, Postdoctoral Fellow

NIST Scientific Officer: $\quad$ Dr. Howard R. Baum

Technical Abstract:

Introduction. This investigation is examining two aspects of unwanted fires: (1) the structure of buoyant turbulent plumes and (2) the physical and optical properties of soot in diffusion flame environments. The findings of the research have applications to modeling fires in structures, developing materials test codes, and developing fire detectors.

Structure of Turbulent Plumes. Recent work has shown that turbulence/radiation interactions cause mean radiation levels to be biased upward (by factors of 2-4) in fire environments, in comparison to estimates based on mean scalar properties (Kounalakis et al., J. Heat Trans. 113, 437, 1991). Unfortunately, treating this effect requires information about mixture fraction fluctuations, that is not known very well for buoyant turbulent flows. Thus, the objective of this phase of the investigation was to complete measurements of the structure of round turbulent plumes - a classical buoyant turbulent flow relevant to fire environments. The study emphasizes the self-preserving region of the flow, where appropriately scaled properties become independent of the source.

The test plumes consisted of dense gas sources (carbon dioxide and sulfur hexafluoride) to provide negatively-buoyant plumes in still and unstratified air. Mixture fraction measurements were made using laser-induced iodine fluorescence (LIF); velocity measurements were made using laser velocimetry. Measurements emphasized large distances from the virtual origin of the flows in order to assure self-preserving conditions, i.e., up to 151 source diameters and 43 Morton length scales.

An important finding of present measurements was that earlier studies did not consider sufficient distances from the source to reach self-preserving conditions. Figure 1 is an illustration of the development of mean mixture fraction distributions with distance 
from the virtual origin. The results are plotted in terms of similarity variables for turbulent plumes, to yield a universal plot within the self-preserving portion of the flow. For these coordinates, the profiles of mean mixture fractions become progressively narrower, and scaled values near the axis become progressively larger, with increasing distance from the source. Self-preserving conditions are reached (within experimental uncertainties) for distances $\geq 87$ source diameters. This is appreciably farther from the source than earlier work where self-preserving behavior was reported for $\left(x-x_{0}\right) / d$ in the range 8-62, see Dai et al. (J. Heat Trans., in press). Results from the earlier work are similar to present results for the same range of streamwise distances, yielding wider profiles with smaller scaled values near the axis. Results for mean velocity distributions were similar. Additionally, mixture fraction and streamwise velocity fluctuations near the axis were higher and lower, respectively, for self-preserving plumes than earlier results for transitional plumes. Buoyancy/turbulence interactions were manifested by differences between fluctuating properties in plumes and nonbuoyant jets, as well as the presence of an interesting inertialdiffusive region in the temporal spectra of fluctuations in plumes that is not observed in nonbuoyant turbulent flows.

Use of earlier transitional plume data has contributed to problems of developing and evaluating models of buoyant turbulent flows. The recent work of Pivovarov et al. (Combust. Flame 92, 308, 1992) illustrates the difficulty. In particular, they recommend substantial changes of empirical constants in turbulence models, from widely accepted values established for nonbuoyant flows, based on comparison of their predictions assuming self-preserving flow with the existing transitional plume data in the literature. In contrast, their results using standard turbulence model constants are in reasonably good agreement with present measurements that are properly within the self-preserving region.

Current work is emphasizing measurements of velocity fluctuation properties of self-preserving plumes. Subsequent work will consider the combined mixture fraction/velocity statistics needed to determine Favre-averaged quantities that are widely used in models of turbulent flames; these results will be found using combined LIF and laser velocimetry.

Soot Properties. There are three phases to this part of the study, as follows: (1) evaluation of approximate soot optical theories based on measurements within laminar diffusion flames, (2) evaluation of approximate soot optical theories based on numerical computations using more exact theory, and (3) evaluation of soot refractive indices based on measurements within the overfire region of buoyant turbulent diffusion flames. The findings have applications to nonintrusive measurements of soot concentrations and structure, as well as prediction of continuum radiation from soot, in fire environments.

Earlier work had established reasonably good performance for an approximate soot scattering theory (denoted RDG-PFA theory) based on measurements for the large soot aggregates found in the fuel-lean (overfire) region of buoyant turbulent diffusion flames (Köylü and Faeth, J. Heat Trans., in press). A limitation of this evaluation, however, was that the large aggregates limited considerations to the large angle (power-law) scattering regime, raising questions about the performance of the theory for small soot aggregates where the small-angle (Guinier) scattering regime is more important. This limitation was addressed by considering small soot aggregates for conditions where both soot structure and scattering properties were known.

The new measurements of soot structure and optical properties involved the relatively small soot aggregates in the fuel-rich (underfire) region of laminar jet diffusion flames. Soot structure was measured using thermophoretic sampling and analysis by 
transmission electron microscopy (TEM). Soot scattering and extinction were measured using an argon-ion laser operating at $514.5 \mathrm{~nm}$, in conjunction with a variable angle detection system. The measurements involved round laminar jet diffusion flames of ethylene and acetylene burning in coflowing air. The structure measurements yielded fractal dimensions in the range 1.73-1.77, which is very similar to other recent measurements for a variety of flame conditions, see Köylü and Faeth, (J. Heat Trans., $115,409,1993)$. Ranges of other soot structure properties for these test conditions were as follows: primary particle diameters of 21-54 nm, mean number of primary particles per aggregate of 31-83 and volume mean aggregate diameter of $87-189 \mathrm{~nm}$. The scattering measurements indicated that properties of the Guinier regime, and the transition regime between Guinier and power-law scattering, were dominant; therefore, experimental objectives were satisfied. The comparison between RDG-PFA predictions, based on measured soot structure, and measured scattering properties was very good, well within discrepancies anticipated due to the experimental uncertainties of the soot structure and scattering measurements. Typical measured and predicted angular scattering patterns are illustrated in Fig. 2; the agreement between predictions and measurements is seen to be excellent. Complete results for this phase of the study are reported in Köylü and Faeth ( $\mathrm{J}$. Heat Trans., submitted).

The second phase of the study involved comparing RDG-PFA predictions with results computed using the ICP approach (Iskander et al., Appl. Optics 28, 3083, 1989) which is a more exact treatment of scattering from aggregates of primary particles. In this case, aggregates were constructed using a numerical simulation, analogous to the approach of Mountain and Mulholland (Langmuir 4, 1321, 1988) to yield populations of aggregates of various sizes (up to 512 primary particles per aggregate). The findings indicate good performance of RDG-PFA theory, well within uncertainties of the ICP computations. Complete results of this phase of the study are reported in Farias et al. (6th AIAA/ASME Thermophysics and Heat Transfer Conference, submitted).

At the present time, the greatest impediment to the use of RDG-PFA scattering theory for nonintrusive measurements of soot properties, and estimates of the radiative properties of soot, involves long-standing uncertainties about soot refractive indices (Köylü and Faeth, I. Heat Trans., 115, 409,1993). Thus, current work is concentrating on measuring soot refractive indices for a variety of fire environments. Subsequent work will focus on the radiative properties of soot aggregates .

\section{Reports and Papers}

1. Z. Dai, L.-K. Tseng and G.M. Faeth, "Structure of Round, Fully-Developed, Buoyant Turbulent Plumes," J. Heat Trans., in press; also_29th National Heat Transfer Conference, Atlanta, 1993.

2. Z. Dai, L.-K. Tseng and G.M. Faeth, "Buoyant Turbulent Plumes Revisited." Proceedings of ISHMT/ASME Heat and Mass Transfer Conference, Bombay, in press.

3. U.Ö. Köylü and G.M. Faeth, "Radiative Properties of Flame-Generated Soot," L. Heat Trans., Vol. 115, No. 2, pp. 409-417, 1993.

4. Ü.Ö. Köylü and G.M. Faeth, "Optical Properties of Overfire Soot in Buoyant Turbulent Diffusion Flames at Long Residence Times," J. Heat Trans., in press.

5. Ü.Ö. Köylü and G.M. Faeth, "Optical Properties of Soot in Buoyant Turbulent Diffusion Flames," J. Heat Trans., submitted; also, 29th National Heat Transfer Conference, Atlanta, 1993.

6. G.M. Faeth, and Ü.Ö. Köylü, "Soot Morphology and Optical Properties in Nonpremixed Flames," Proceedings of Second International Conference on 
Combustion Technologies for a Clean Environment, Lisbon, Portugal, July 1993, in press.

7. U..O. Köylü and G.M. Faeth, "Soot Scattering Properties at Fuel-Rich Conditions in Buoyant Laminar Diffusion Flames," Proceedings of the Eastern and Central States Sections Technical Meeting, The Combustion Institute, Pittsburgh, pp. 547-551, 1993.

8. T. Farias, M.G. Carvalho, Ü.Ö. Köylü, and G.M. Faeth, "Computational Evaluation of Approximate Rayleigh-Debye-Gans/Fractal-Aggregate Theory for the Scattering and Extinction Properties of Soot," 6th AIAA/ASME Thermophysics and Heat Transfer Conference, Colorado Springs, 1994, submitted.

9. Ü.Ö. Köylü, Z. Dai, L.-K. Tseng, and G.M. Faeth, "Radiation and Mixing Properties of Buoyant Turbulent Diffusion Flames," Report No. GDL/GMF-92-03, University of Michigan, Ann Arbor, 1992.

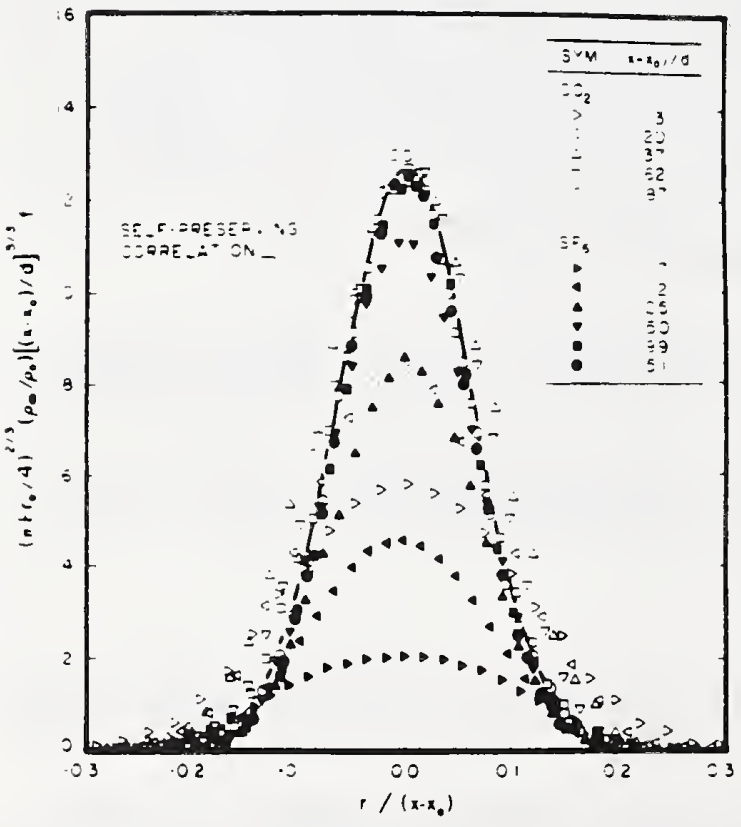

Fig. 1 Mean mixture fraction distributions within buoyant turbulent plumes.

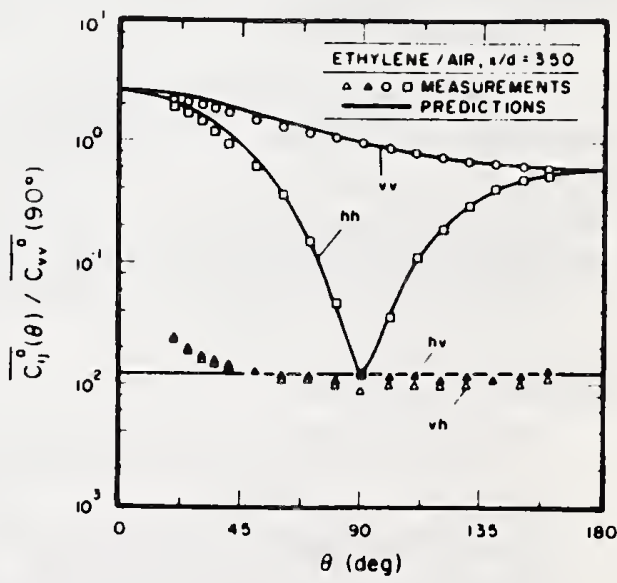

Fig. 2 Angular scattering pattern for underfire ethylene soot. 


\section{BUILDING AND FIRE RESEARCH LABORATORY \\ FIRE RESEARCH PROGRAM \\ PRIORITY PROJECT - FY93}

SOOT FORMATION AND EVOLUTION

\section{Professional Personnel}

Kermit C. Smyth, Project Leader

George W. Mulholland, Project Leader

Joel E. Harrington, NRC-NIST Postdoctoral Research Associate

Christopher R. Shaddix, NRC-NIST Postdoctoral Research Associate

Nelson P. Bryner, Chemical Engineer

\section{Project Objectives}

Develop scientifically sound principles, metrology, and data which contribute to a predictive model for the formation and evolution of smoke components in flames based upon the best available information for use in understanding fire phenomena. This work embraces broad areas underpinning the BFRL Fire Research Programs, with focussed study of hot gas chemistry and physics. The most successful descriptions of the key steps of soot formation and evolution will be identified for a comprehensive model by September, 1993. This will be used by the modelers of combustion product yields from fires.

\section{Technical Accomplishments}

During hydrocarbon combustion the exothermic chemical reactions which lead to the formation of water and carbon dioxide consume most of the fuel. However, in many cases a significant fraction of the fuel is converted into species which participate in chemical growth reactions. These processes lead to dramatic consequences in numerous combustion environments. For example, the formation of intermediate hydrocarbons, such as polycyclic aromatic hydrocarbons (PAH), occurs under fuel-rich conditions and poses a potential long term health hazard since many PAH are carcinogenic. In addition, such compounds are also involved in further growth reactions to form soot particles. Radiation from soot dominates energy transfer from large fires, and thus soot formation plays a key role for flame spread. In turn, particle formation and radiative energy transfer control the amount of smoke produced, which is important in fire detection and pollutant emission. In contrast to the oxidation of simple hydrocarbons, which is reasonably well understood, the detailed mechanisms for producing large hydrocarbons during combustion have not been established. The elucidation of chemical growth mechanisms continues to be one of the most challenging research problems in combustion science today.

While the chemical growth reactions play a key role in regard to the total amount of smoke produced, the actual structure of the smoke leaving the flame region is determined by a physical agglomeration process of particles sticking and forming a cluster. The agglomerate structure consists of a number of 
primary particles with diameters of about $30 \mathrm{~nm}$ connected in a rather open structure. The light extinction coefficient and light scattering coefficient, both of which affect the visibility through smoke, are not well characterized for agglomerate structures. The aerodynamic properties, which control smoke deposition in the respiratory tract, are also poorly specified. Understanding the relationship between the geometric structure of an agglomerate and its properties is a key research topic in both aerosol research and condensed matter physics.

\section{Soot Formation}

This project is part of a long-term study of the fundamental chemistry of soot formation. We have investigated the detailed chemical composition of laminar, hydrocarbon diffusion flames using a variety of laser-based optical techniques as well as mass spectrometric sampling. The first optical measurements of formaldehyde in a flame have been made, including profile results. In addition, this year we have completed a detailed investigation of soot oxidation processes and have begun a new experimental study of time-varying diffusion flames:

(1) In collaboration with Rahul Puri and Bob Santoro at Penn State quantitative $\mathrm{OH} \cdot$ concentrations and primary soot particle sizes have been determined in the soot oxidation regions of axisymmetric diffusion flames burning methane, methane/butane, and methane/1-butene in air at atmospheric pressure. The total carbon flow rate was held constant in these flames while the amount of soot was varied considerably. Laser-induced fluorescence measurements of $\mathrm{OH} \cdot$ were placed on an absolute basis by calibration against earlier absorption results obtained at NIST in our Wolfhard-Parker burner. The primary size measurements of the soot particles were made using thermophoretic sampling and transmission electron microscopy. $\mathrm{OH} \cdot$ concentrations are greatly reduced in the presence of soot particles. Whereas large super-equilibrium ratios are observed in the high-temperature reaction zones in the absence of soot, the $\mathrm{OH}$ - concentrations approach equilibrium values when the soot loading is high. The diminished $\mathrm{OH}$. concentrations are found to arise from reactions with the soot particles and only to a minor degree from lower temperatures due to soot radiation losses. Analysis of the soot oxidation rates computed from the primary particle size profiles as a function of time along the flame centerlines show that $\mathrm{OH} \cdot$ is the dominant oxidizer of soot, with $\mathrm{O}_{2}$ making only a small contribution. Higher collision efficiencies of $\mathrm{OH} \cdot$ reactions with soot particles are found for the flames containing larger soot concentrations at lower temperatures. A comparison of the soot and $\mathrm{CO}$ oxidation rates shows that although $\mathrm{CO}$ is inherently more reactive than soot, the soot successfully competes with $\mathrm{CO}$ for $\mathrm{OH} \cdot$ and hence suppresses $\mathrm{CO}$ oxidation for large soot concentrations.

These experimental results should both test and guide the development of soot production models which include oxidation processes, since current soot models must utilize either assumed or estimated $\mathrm{OH}$. concentrations. It is especially noteworthy in this regard that equilibrium and partial equilibrium approaches may not even be a reasonable starting points for estimating $\mathrm{OH}$ - concentrations in the region where soot oxidation rates are expected to be largest.

(2) Planar images of laser-induced fluorescence from $\mathrm{OH} \cdot$ radicals and elastic scattering from soot particles have been obtained in time-varying, laminar $\mathrm{CH}_{4}$ /air diffusion flames burning in a co-flowing, axisymmetric configuration at atmospheric pressure. Acoustic forcing is used to phase lock the periodic flame flicker to the pulsed laser system operating at $10.13 \mathrm{~Hz}$. For conditions where the tip of the flame is clipped, the intensity of the light scattered by the soot particles increases dramatically (by more than a factor of 7 for the maximum signals at a point) compared to a steady-state, laminar flame with the same mean fuel flow velocity. Comparison of the scattering signals integrated along the flame radius has been 
carried out in the steady-state and time-varying tlames as a function of height above the burner. Quantitative measurements of the increase in soot volume fraction in the time-varying flames have been made using extinction and tomographic reconstruction methods. These are the first spatially resolved measurements of the soot volume fraction in a time-varying flame.

Time-varying flames exhihit a larger range of combustion conditions than observed in corresponding steady-state flames, including different residence times, temperature histories, local stoichiometries, and strain and scalar dissipation rates. Thus, their investigation promises to yield new insights into a wide variety of chemistry-flowfield interactions which are prominent in turbulent combustion.

\section{Smoke Agglomerates}

This portion of the project focusses on the properties of the smoke agglomerates above the flame zone. During the past year, we have compared the fractal smoke optics model with light extinction measurements. We are also in the process of comparing soot volume fraction measurements made by an optical technique with results obtained gravimetrically.

The mass specific extinction was measured at wavelengths of 450,630 , and $1000 \mathrm{~nm}$ in a smoke filled chamber with an optical pathlength of $1.0 \mathrm{~m}$. The facility was equipped to continuously monitor particle mass concentration with a tapered element microbalance and number concentration with a condensation nucleus counter over a 90-120 min interval. The smoke was generated by the burning of crude oil in a pool fire. The mass specific extinction at all three wavelengths was found to be constant even though the agglomerate number concentration decreased by about a factor of 25 owing to cluster-cluster agglomeration. During this time period the average number of primary spheres per agglomerate increased from about 200 to a final value of about 4500 . The constancy of the specific extinction was observed for the chamber at ambient temperature and at $100^{\circ} \mathrm{C}$. Thie measured mass extinction coefficients agree with fractal optics prediction if the real part of the refractive index is near 1.55 and the imaginary part varies systematically with the wavelength of light from the violet to IR spectral regions. However, the real and imaginary portions of the refractive index are uniquely defined only when both specific extinction and specific absorption are prescribed. A major conclusion of our study is that the treatment of the agglomerates as an effective sphere together with using Mie theory is inconsistent with our measurements.

Recent studies indicate a large uncertainty in the measurement of the soot volume fraction by optical techniques because of the uncertainty in the particle refractive index. To quantify the uncertainty in the optical measurements, we are performing simultaneous soot volume fraction measurements by two independent methods for soot generated by a premixed acetylene burner. One method is hased on light extinction measurements and the second is a gravimetric technique which involves isokinetic sampling of the soot, measurement of the mass of soot collected, and the determination of the soot density by helium pyncnometry. The soot is diluted with nitrogen above the flame so that the gas temperature is about $500 \mathrm{~K}$ where the sampling and optical measurements are performed. Preliminary results indicate that the optical measurements at a wavelength of $632.8 \mathrm{~nm}$ hased on the Dalzell-Sarofim dispersion relation overestimate the soot volume fraction by 30 to $50 \%$ for the acetylene burner operating at equivalence ratios of 2.3 and 2.5 .

In addition to the studies outlined above, Kermit Smyth and George Mulholland have completed an internal document which identities the hest available modeling capabilities for the key steps of soot formation, destruction, and evolution. Remaining issues are also specified. 


\section{Publications}

R. Puri, M. Moser, R.J. Santoro, and K.C. Smyth, Twenty-Fourth Symposium (International) on Combustion, 1015 (1992). Laser-Induced Fluorescence Measurements of $\mathrm{OH}$ - Concentrations in the Oxidation Region of Laminar, Hydrocarbon Diffusion Flames.

J.E. Harrington and K.C. Smyth, Chemical Physics Letters 202, 196 (1993). Laser-Induced Fluorescence Measurements of Formaldehyde in a Methane/Air Diffusion Flame.

R. Puri, R.J. Santoro, and K.C. Smyth, submitted to Combustion and Flame (1992). The Oxidation of Soot and Carbon Monoxide in Hydrocarbon Diffusion Flames.

K.C. Smyth, J.E. Harrington, E.L. Johnsson, and W.M. Pitts, Combustion and Flame, in press. Greatly Enhanced Soot Scattering in Flickering $\mathrm{CH}_{4}$ /Air Diffusion Flames.

G.W. Mulholland and N.P. Bryner, Atmospheric Environment, in press. Radiometric Model of the Transmission Cell-Reciprocal Nephelometer".

R.A. Dobbins, G.W. Mulholland, and N.P. Bryner, Atmospheric Environment, in press. Comparison of Fractal Smoke Optics Model with Light Extinction Measurements.

\section{Related Grants}

I. Soot Morphology in Buoyancy Dominated Flames, Richard A. Dobbins, Brown University.

2. Fundamental Studies of Diffusion Flame Chemistry

J. Houston Miller, George Washington University.

3. Fundamental Mechanisms for $\mathrm{CO}$ and Soot Formation in Diffusion Flames Robert J. Santoro, Pennsylvania State University. 
A4. Engineering Analysis 



\section{BUILDING AND FIRE RESEARCH LABORATORY \\ FIRE RESEARCH PROGRAM \\ PRIORITY PROJECT - FY93}

\section{COMPREHENSIVE FIRE RISK ASSESSMENT METHOD}

Professional Personnel

Richard W. Bukowski, Project Leader

Scot Deal

\section{Project Objective}

To develop an internationally accepted fire risk calculation method that is suitable as the foundation for a performance fire code by 1996.

\section{Scope}

The first step is to establish an international, cooperative effort under one or more of the organizations mentioned above. We will volunteer to chair the activity, but acceptance of this is up to a vote of the group. A working group will be established where participants are funded by their own organizations. This group will need to review the existing body of work and identify the elements which should form the final methodology, including optional components. The three methods reviewed in a recent paper (Japan, Australia, and US) are ostensibly complete, although some portions of each contain only place holders due to limitations in the technology. These need to be identified and the research needed to fill these gaps needs to be done.

\section{Technical Accomplishments}

A working group has been established with participation from about 12 countries. The FORUM has endorsed the activity and committed to provide financing for staff to participate. A formal charter from CIB W14 is being sought in order to facilitate the financial arrangements from the individual participating countries. Papers related to the project have been solicited from all participants and have been collected and circulated.

Several initial project collaborations have been identified and the working relationships are being worked out. A joint effort on structural performance prediction has been established between US and Canada with interest expressed by Australia and Japan. A project on uncertainty assessment of models and data has been outlined. This would provide a mechanism for qualifying calculational techniques on the basis of computational uncertainty related to design safety factors. Interest in working this issue has been expressed by Sweden, Norway, UK, and Australia; and would be led by US. Other collaborations on verifying zone models and adding phenomena to CFAST have been discussed.

Some effort has been put into establishing a grants program in risk at FM. This will proceed, and will provide insight into Bayesian techniques which can be used to supplement sparse data on incidents. 



\section{BUILDING AND FIRE RESEARCH LABORATORY \\ FIRE RESEARCH PROGRAM \\ NATIONAL INSTITUTE OF STANDARDS AND TECHNOLOGY \\ GRANTEE PROJECT - FY93}

Institution:

Grant No.

Grant Title:

Principal Investigator:

Other Professional Personnel:

NIST Scientific Officer:

\author{
California Institute of Technology
}

60NANB9D0958

Experimental Study of Heat Transfer and the Environment in a Room Fire

E. E. Zukoski

Jet Propulsion Center, 301-46

California Institute of Technology

Pasadena, CA 91125

T. Kubota, Professor Emeritus

R. Chan, Doctoral Student

S. Palm, Master's Student

D. Revolinski, Doctoral Student

Dr. Leonard Y. Cooper

\section{TECHNICAL ABSTRACT}

During the past year we have been investigating four problem areas. These are the influence of viscosity on the propagation of hot smoke layers in horizontal passages with a large length to width ratio, the evolution of chemical species in a transient ceiling layer formed in a large hood by a suddenly lighted fire with a constant heat release rate, the entrainment of ambient air by fire-plumes, and the flow of hot gas up a closed shaft with a large height to width ratio. Progress made in each of these areas is reported in the following paragraphs with emphasis on a proposed model for entrainment of ambient gas into a fire-plume. Reports concerning the first three areas are now available.

Gravity Currents: Experiments concerning the motion of shallow gravity currents in long halls have been completed and are described in Chan (1993). The influence of the viscosity of the current and the ambient fluid have been clarified in these experiments.

Transient Development of a Ceiling Layer: We have investigated the transient development of the ceiling layer in a hood that is $2.44 \mathrm{~m}$ square by $1.22 \mathrm{~m}$ deep and that is open on the bottom. A $67 \mathrm{~kW}$ natural gas fire stabilized on a $19 \mathrm{~cm}$ diameter burner is started at the beginning of the experiments and the burner surface is located about $10 \mathrm{~cm}$ below the lower edge of the hood. This arrangement gives a steady state equivalence ratio for the gas entering the hood in the fire plume of 2.17 . The data obtained in this work include measurements of 
concentrations of $\mathrm{CO}, \mathrm{CO}_{2}, \mathrm{CH}_{4}, \mathrm{O}_{2}$ and $\mathrm{H}_{2} \mathrm{O}$, and the gas temperature at 6 levels with in the hood. Measurements are made over a period of about $2200 \mathrm{sec}$ with the fire ignited, and for 1000 sec after the fire is extinguished.

The results of this work are available as a report by Palm and Zukoski (1993). The experiments show that $\mathrm{CO}$ is produced at a much faster rate early in the fire than was predicted from the steady state data for the same fire, and suggeset that the natural convection currents on the walls of the hood played a large role in reintroducing oxygen into the hood gas after the fire is extinguished.

Buoyant Flows in Shafts: Buoyant flows in vertical shafts are being investigated in an experimental program that will elucidate the influence of heat transfer from the buoyant fluid to the walls on the penetration rate of hot gas up the shaft from a source at the bottom of the shaft. The experimental shaft is a $30 \mathrm{~cm}$ square aluminum duct that is about $3 \mathrm{~m}$ high. Walls of the duct are instrumented with temperature and heat transfer gauges and fast response sensors are used to measure the gas temperature within the duct. The walls of the shaft are thick enough to allow the walls to be initially treated as constant temperature heat sinks.

At the beginning of the current experiments, the bottom of the shaft is suddenly opened to a large volume of gas that is kept at $400 \mathrm{~K}$ and the propagation of the hot gas up the shaft due to a turbulent mixing process is studied. See the accompanying sketch. Propagation of the hot gas front takes place by the development of a transient plume, sketch(a), and after the plume reaches the side walls, sketch(b), by a turbulent mixing process that is driven by the gravitational instahility resulting from the placement of cold, heavy gas above the hot, lighter gas at the bottom of the shaft.

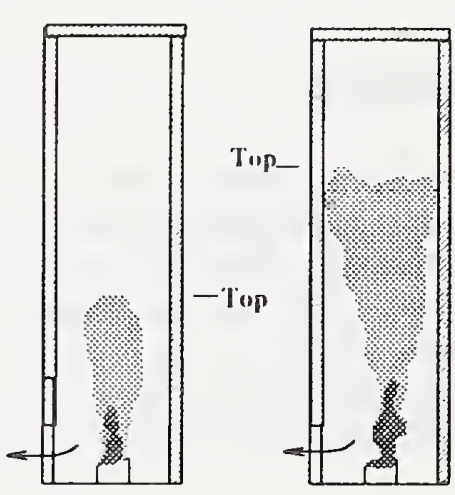

(a) (b)

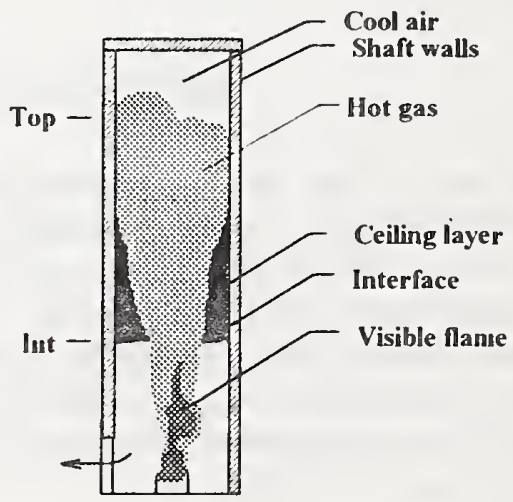

(c)

Figure 1. Sketch of Flow in Shaft

These experiments are based on a series of experiments in which the water/water-salt modeling technique was used to study this problem. In this water modeling work, heat transfer effects were totally absent. Experiments have been started with the shaft at room temperature and the hot gas at $100^{\circ} \mathrm{C}$. 
Model for Entrainment in Fire-Plumes: Models for the entrainment into buoyant plumes have typieally been based on the work of Morton, Taylor, and Turner (1950) and their predictions have been found to be satisfaetory for buoyant plumes rising above a point source. The primary problem in applying these results to firc plumes is the requirement that the souree of the equivalent point source plume must be loeated with respect to the level of the fire. Experimental mass flux data obtained by Cetegen et al (1984) in a hood apparatus and data based on temperature profiles along the centerline of the plume by Kung and Stavrianidis (1984) and Hasemi (1989) have been analyzed by Heskestad (1981), Cetegen et al (1984) and Hasemi (1989) with the result that several models are now available to prediet the elevation of the souree for the equivalent point source

plume relative to the elevation of the fire source. The resulting eorrelation for the mass flux, $\dot{m}_{f}$, in an adiabatie and far ficld plume at a point, $Z+\Delta Z_{f}$, above its souree and for a fire with heat release $\dot{Q}$ is diseussed in Cetegen et al, (1984) and ean be written as:

$$
\dot{\mu}_{f} \equiv \frac{\dot{m}_{f}}{\rho_{\infty} \sqrt{g D} D^{2}}=0.21\left(Q_{D}^{*}\right)^{1 / 3}\left(\frac{Z}{D}+\frac{\Delta Z_{f}}{D}\right)^{5 / 3}
$$

Here, $Q_{D}^{*} \equiv \dot{Q} /\left(\rho_{\infty} C_{p \infty} T_{\infty} \sqrt{g D}(D)^{2}\right), Z$ is the elevation above the surface of the burner, and $\Delta Z_{f}$ is the distanee that the origin of the plume lies below the surfaee of the burner.

Deseriptions of the entrainment into the flaming region of the fire, ealled the fire plume, have not been as satisfaetory. A reeent review has been made of measurements made at Calteeh, see Cetegen et al (1984) Lim (1988), Toner (1988) and Morehart (1990), of the mass flux rates of fireplumes for natural gas and several other fuels in flames stabilized on 10,19 and $50 \mathrm{~cm}$ diameter burners. These data, show that the entrainment rate for flames in the regime for which $0.1 \leq Q_{D}^{*} \leq 17$ have at best a very weak dependenee on heat addition rate and eertainty does not seale linearly or with the square root of the heat release rate. Entrainment rates obtained by Thomas et al (1963) and Beyler (1982) also showed no dependenee on the heat release rate.

The near field, also ealled the the fire-plume, data eolleeted at Calteeh ean be most simply eorrelated by the cxpression, $\dot{m}_{n} \equiv C_{\text {ef }} Z D \quad$ or $\quad C_{e f}=\dot{m}_{n} / Z D$, for $0.1<Q_{D}^{*}<17$. The parameter $C_{e f}$ depends on $Q_{D}^{*}$ and the data indieate that, $C_{e f}$ is about 0.62 when $0.1 \leq Q_{D}^{*} \leq 4$ and inereases strongly with $Q_{D}^{*}$ when $Q_{D}^{*} \geq 4$.0. Unfortunately, this simple mass flux eorrelation is not dimensionally eorreet and some other eorrelation must be sought. When allowanee is made for an offset, with the origin for the $Z$ axis loeated at $\Delta Z_{n}$ below the fire surfaee, a eorrelation similar to that suggested Thomas,

$$
\dot{\mu}_{n} \equiv \frac{\dot{m}_{n}}{\rho_{\infty} \sqrt{g I)} D^{2}}=0.18\left(\frac{Z}{D}+\frac{\Delta Z_{n}}{D}\right)^{3 / 2}
$$


was found to agree well with the data for the range, $0.1 \leq Q_{I}^{*} \leq 4$. The value of the constant is very close to that suggested ciarlicr by Thomas et al (1963). For given values of $(Z / D)$ and $Q_{l}^{*}$. the mass flow rates given by Equations 1 and 2 scale in an identical manner with the dianeter and heat release rate when the offsets scale with the dianeter and, at most, a function of $Q_{D}^{*}$. Under these circumstances, the value for $Z / D$ at the intersection of the two curves will not change with burner diancter $D$ or heat release rate when the value of $Q_{D}^{*}$ is fixed.

The application of the model depends on obtaining accurate representations for both offsets and data for the fire plume offset is available for only two burner diameters. The offsets obtained from the limited data presently available to us suggests that the offset is proportional to the burner diameter but is not yet sufficient to define accurately dependenee of the offset on the parameters of the s! stem

Although experimental entrainment data for large fires are required to clarify these modeling results, the proposed correlations do give an accurate description of the experimental data for fires up to one hundred kilowatts. The scaling proposed here depends on $Q_{D}^{*}$ and the assumption that the offsets scale with burner diancter $D$ and a function of $Q_{D}^{*}$. If these assumptions are correct, and if values for the offset for the firc plume data can be obtained, this scaling procedure will give a good represcintation of the plume miss flus in both the firc-plume and the far field plume.

\section{REFERENCES}

Beyler, C. L., Ph.D. Thesis, Harvard University, 1983.

Cetegen, B. M., Zukuski, E. E., and Kubota, T. Comb. Sci. and Tech., 39: 305, 1984.

Hasemi, Y. , Fire Sit. and Tech., 7. \#2, pp. 27-34, 1989.

Heskestad, G., Twenty-First Symp. (Int.) on Comb., The Comb. Institute, pp. 111--120, 1986.

Kung. H. and Stavrianidis, P., Ninete'enth Symp. (Int.) on Comb., pp. 905--912, 1982.

Lim. C., Engineer's Degree Thesis, Calif. Institute of Tech., June 1984.

Morehart, J. H., Ph.D. Thesis, Calif. Institute of Tech., Pasadena, Calif. 1991.

Morton. B. R., Taylor, G. I., and Turner, J. S., Proc. Royal Soc., A 234:1, 1956.

Palm, S. and Zukuski, E. E. , Jet Prop. Center Rep. 8-93 \#1, Calif. Institute of Tech., 1993.

Toner, S. J., Ph.D. Thesis, California Institute of Technology, Pasadena, Calif. 1987

\section{REPORTS 9/1992 to 9/1993}

Chan, W. R., "Experimental and Numerical Studies on Two-Dimensional Gravity Currents in a Horizontal Channel," Ph.D. Thesis, Calit. Institute of Tech., June 1993, Pasadena, CA.

Palm. S. and Zukoski. E. E. "Evolution of chemical species present in ceiling layer with steady state plume equivalence ratio of 2.3." Jet Propulsion Center Report.

Calif. Institute of Tech. September 1993, Pasadena, CA.

Zukuski, E. E., "Entrainment in Fire Plumes," presented at the UJNR Meeting. Tsukuba, Japan, Octoher 1992. 


\section{BUILDING AND FIRE RESEARCH LABORATORY \\ FIRE RESEARCH PROGRAM \\ OTHER AGENCY PROJECT - FY93}

\section{FIRE AND THERMAL CHARACTERISTICS OF NAVY FIRE FIGHTER TRAINERS}

Funding Agency: Naval Training Systems Center, Orlando, Florida

Professional Staff: Robert S. Levine, Project Leader

Project Objective:

Support the development and implementation of prototype fire fighter trainers.

In fighting naval fires at sea, it is essential that each seaman be trained so that they do the right thing the first time. The ship is a complex of highly flammable equipment, fuels and munitions. There is no place to retreat to if the suppression is not successful. Fire fighting may have to proceed while the ship is in action against an enemy.

The Navy's program provides facilities to allow at least one hot fire fighting training experience to each person per year. To provide safety and also minimize environmental problems, the trainers use propane as fuel.

The fire is controlled by valves, and can be shut off if the trainees are in danger. This also makes it possible to provide a good learning experience - the trainees can make a mistake, not be harmed by the fire, and can do better next time.

This is the fifth year of NIST's participation in the Navy's program. Thermal and toxic products measurements have been made in each of the five types of trainers in this program, and support has been provided for solving a number of developmental problems.

Technical Accomplishments:

Most of the effort this FY has been directed at measurements of minor air pollutants in prototype trainers, especially the Submarine Fire Fighter Trainer at Norfolk Naval Base. Information was obtained to satisfy environmental authorities at other trainer locations, especially in Washington and California. Measurements have been made utilizing the technique and equipment of the "Indoor Air Pollution" project at NIST. Estimation of pollutant concentrations are made using the EPA "SCREEN" code.

We have also measured artificial smoke density in the trainers from improved smoke generators, and have analyzed for decomposition of the smoke agent.

Two of the Navy contractors are building trainers for civilian fire fighters. Separately funded, we have made related measurements for them.

Publications:

Results have been reported in memos to the sponsors. They have handled additional distribution. 


\title{
BUILDING AND FIRE RESEARCH LABORATORY \\ FIRE RESEARCH PROGRAM \\ PRIORITY PROJECT - FY93
}

\section{LARGE SCALE SMOKE MOVEMENT}

\author{
Professional Staff: $\quad$ John H. Klote, Project Leader \\ Leonard Y. Cooper \\ Glenn P. Forney
}

Project Objective:

Over the next five years, develop and verify algorithms for modeling large scale smoke movement in buildings. The building configurations of interest are corridors, atria, open shafts, and stair shafts.

\section{Scope:}

Visualization of smoke flow in corridors, atria, open shafts, and stair shafts using physical and computational modeling provides the basis of conceptual models for each of these building elements.

\section{Technical Accomplishments:}

Work continued on a joint NIST/FRI plan for studying atrium smoke movement. Cooper traveled to FRI in Japan where he participated in experiments in the scale model atrium. These experiments were of an exploratory nature, and it is anticipated that FRI will generate significant data next year. Cooper has developed a theoretical analysis for atrium venting incorporating the effects of different densities below and above the vent. In some cases, the flow through the vent is about $30 \%$ of what would be calculated by a simple orifice equation model. This flow difference has significant implications for atrium smoke control technology, and work has started on a gencralized model for this atrium vent llow.

Klote and Forney conducted a study of smoke movement simulation in a multi-story building using a modilied zone fire model. The zone fire model was modified to allow shafts to be simulated as one zone and to allow different initial conditions than the common zero flow conditions. The nature of tall shafts is such that two zone modeling is inappropriatc. The initial conditions allowed verification of the treatment of stack effect in the zone fire model, but the initial conditions did not have a significant effect on gross smoke movement in the building. However, these initial conditions may have important consequenees regarding tenability. Upper layer initiation temperature was also examined, because warm outside air could form a phantom upper layer before smoke reached a room. This phantom layer could result in overprediction of upper layer thickness and underprediction of upper layer temperature. However, the conditions of the example runs were such that the phantom layer was not significant. The study showed that the type of shaft model has significant impact on smoke flow to floors remote from the fire.

Computational fluid dynamic modeling using the Harwell FLOW3D program has been used to gain an understanding of smoke transport in corridors and large spaces. Because of the importance of radiative and conductive heat transfer in building smoke flow, Forney developed a wall heat transfer model to be used with FLOW3D or other field models. The radiation portion of this model was based on the ten wall model in CFAST, and the conduction model is based on the wall conduction model 
in CFAST. The cell size for conduction is the same as that defined for the field model, but the cells for radiation are the ten walls and upper layer of the room. The average temperatures of the ten walls and the upper layer are calculated from the previous step calculations of the field model. The conduction routine uses input of the average radiation plus the convection based on the adjacent fluid cell to calculate wall temperatures. This approach is considerably more efficient and numerically stable than the corresponding routines in FLOW3D.

Reports and Publications:

"Smoke Movement in a Corridor: Hybrid Model, Simple Model and Comparison With Experiments," Matsushita, T., Klote, J.H., National Institute of Standards and Technology, NISTIR 4982, 1992.

"Design of Smoke Management Systems," Klote, J.H., Milke, J.A., American Society of Heating, Refrigerating and Air Conditioning Engineers, Atlanta, GA 1992.

"Workshop on Elevator Use During Fires," Klote, J.H., Deal, S.P., Levin, B.M., Groner, N.E., Donoghue, E.A., National Institute of Standards and Technology, NISTIR 4993, 1993.

"Design of Smoke Control Systems for Areas of Refuge," Klote, J.H., National Institute of Standards and Technology, NISTIR 5132, 1993.

\section{Related Grants:}

Flow Through Horizontal Vents as Related to Compartment Fire Environments, Rutgers - State University of New Jersey.

Experimental Study of Environmental and Heat Transfer in a Room Fire, CALTECH. 



\section{BUILDING AND FIRE RESEARCH LABORATORY \\ FIRE RESEARCH PROGRAM \\ NATIONAL INSTITUTE OF STANDARDS AND TECHNOLOGY \\ GRANTEE PROJECT - FY93}

Institution:

Grant No.:

Grant Title:

Principal Investigator:

Other Professional Personnel:
Rutgers, The State University of New Jersey

New Brunswick, New Jersey

60NANB1H1171

Movement of Smoke and Hot Gases in Open Shafts

Prof essor Yogesh Jaluria

Department of Mechanical and Aerospace Engineering

Rutgers, The State University of New Jersey

New Brunswick, NJ 08903

Telephone: (908)932-3652

S.H.-K. Lee (Ph.D. Student)

G.P. Mercier (M.S. Student)

W.K.-S. Chiu (Research Assistant)

Dr. Leonard Y. Cooper

Technical Abstract:

Introduction. This work has been been involved with two experimental studies related to the modeling of enclosure fires. Though most of the effort has been directed at the study initiated in October 1993 on the movement of smoke and hot gases in open vertical shafts, work has also been carried out to complete the earlier project on flow through horizontal vents. The experimental findings of the research have applications to the modeling of fires in enclosed spaces with vents, such as ships and multi-room compartments, and in multi-leveled buildings with vertical shafts.

Movement of Smoke and Hot Gases in Vertical Shafts. The experimental arrangement is shown in Fig. 1. Smoke or hot gases are injected into the shaft at the lower opening and the downstream flow is monitored by means of thermocouples, visualization and optical sensors. The inlet temperature of the hot gases can be varied up to around $80^{\circ} \mathrm{C}$. Both natural and forced ventilation can be investigated in the shaft. The opening height can be varied up to around $0.2 \mathrm{~m}$. The shaft is about $2.0 \mathrm{~m}$ in height and has an aspect ratio of about 3.0. However, the aspect ratio can be varied to consider its effect on the transport processes. The conditions at the outlet are also monitored to determine the effects of entrainment and heat transfer to the walls. Wide ranges of all the physical variables in the problem are obtainable, allowing the simulation of typical flows in multi-leveled buildings with vertical open shafts.

A few characteristic results for flow without ventilation are shown in Figs. 2 and 3. The time taken for the hot gases injected at the lower opening to reach the top opening as a function of the inlet temperature difference, over the ambient temperature, and of the mass flow rate indicate expected trends. With increasing temperature at the inlet, the buoyancy effect is larger resulting in higher velocities and shorter time to reach the top. This time is an important quantity since it indicates the speed with which the smoke and other combustion products reach into the higher levels of the building. The effect of the mass flow rate is smaller, with a larger flow rate resulting in smaller time. The temperature at the outlet depends on heat transfer to the walls as well as on the flow velocity. 
Since these two effects oppose each other, the resulting ratio of the outlet temperature difference to the inlet temperature difference does not show a monotonic increase or decrease with an increase in inlet temperature. Again, the outlet temperature is an important consideration in this problem. Further work is being carricd out to quantify these effects and to study the influence of forced ventilation on the flow.

Flow Through Horizontal Vents. The experimental set-up consists of four sub-systems. These are the glass tank, the temperature mcasurement and regulation system, the pressure measurement and regulation system and the data acquisition system. The interior of the glass tank measures $0.41 \mathrm{~m} \mathrm{x}$ $0.41 \mathrm{~m} \times 0.46 \mathrm{~m}$, and all the interior edges and corners were sealed to ensure an air-tight enclosure, see Fig. 4. To measure the temperature within this tank, thermocouples were mounted vertically along one wall. On the top of this wall, a pressure tap was also placed. Due to the low pressures of interest, mean flows within the enclosure rendered accurate pressure readings difficult. Therefore, a diffuser for the inlet as well as a buffer for the pressure tap were added. A precise pressure transducer with an accuracy of less than $0.1 \mathrm{mPa}$ was employed for the pressure measurements. To control the temperature within the double-panel glass enclosure, a temperature controller was used to operate finned strip heaters. In order to control the pressure, a stagnation chamber was used to pressurize the glass enclosure. Its pressure was raised by a compressor, and controlled by a pressure regulator. A flow meter was connected upstream of this chamber to measure the mean flow rate, $\dot{m}$.

Once steady state was achieved, the internal temperatures were measured before and after the experiments to ensure uniform temperature. Typically the measurements showed a temperature difference between the top and bottom of the glass tank to be less than $5 \%$ of the average value. Most importantly, the top region near the exit duct attained temperature uniformity of better than $1 \%$. Also the ambient temperature and pressures were recorded before and after each experiment. During the experiment, the outputs from the thermocouples and pressure transducer were recorded through a data acquisition system.

The flows through the vent were found to be oscillatory in nature for pressures ranging from zero up to flooding. Attempts were made to correlate the frequency of the oscillation with the pressure difference across the vent. The flooding pressure, $\Delta \mathrm{p}_{\mathrm{c}}$, was correlated (correlation coefficient $>0.98$ ) against the temperature difference $\Delta \mathrm{T}$ using a second order polynomial. This can be seen in figure 5 . Attempts are also presently underway to track the oscillation in temperatures. Although the oscillatory nature of the flow made the determination of the mean pressure very difficult, the correlation of the net flow rate against pressure differences across the vent was more successful. The data were fitted with a polynomial where the correlation coefficient was greater than 0.97 . Typical results are shown in Fig. 6. Results were obtained for vents with four L/D ratios $(0.0144,1,2,4)$ and two temperature differences $(\Delta T=20 \mathrm{~K}$ and $40 \mathrm{~K})$. As seen in these figures, the basic trends resemble that of the Bernoulli relation, where the deviation is due to existing viscous and buoyancy forces. Also, the correlation showed that at low pressures, the mass flow rate was essentially independent of temperature difference or the length of the vent. However, at higher pressure, the flow rate increases with decreasing vent length and temperature differences. This is intuitively consistent since a shorter vent would present less frictional force while a smaller temperature would present less opposing buoyancy force. Efforts are presently underway to investigate the effect of different vent diameters.

Acknowledgments: The several discussions with Dr. Leonard Y. Cooper on these problems are acknowledged.

Reports and Papers:

1. K. Kapoor and Y. Jaluria, "Penetrative Convection of a Plane Turbulent Wall Jet in a Two-Layer Thermally Stable Environment: A Problem in Enclosure Fires," Int. J. Heat Mass Transfer, 36, 155$167,1993$. 
2. Y. Jaluria and K. Kapoor, "Wall and Corner Flows Driven by a Ceiling Jet in an Enclosure Fire," Combust. Sci. Tech., 86, 311-326, 1992.

3. Q. Tan and Y. Jaluria, "Flow Through a Horizontal Vent in an Enclosure Fire," in Heat Transfer in Fire and Combustion Systems, ASME Heat Transfer Div., 199, 115-122, 1992.

4. Y. Jaluria, S.H.-K. Lee, G.P. Mercier and Q. Tan, "Visualization of Transport Across a Horizontal Vent due to Density and Pressure Differences," Nat. Heat Transfer Conf., Atlanta, GA, 1993.

5. S.H.-K. Lee, W.K.-S. Chiu and Y. Jaluria, "Experimental Study of Enclosure Fires with Horizontal Vents," Fall Tech. Meet. Eastern Scct. Combust. Inst., Princeton, NJ, 1993.

6. Q. Tan and Y. Jaluria, "Flow Through Horizontal Vents as Related to Compartment Fire Environments," Tech. Rep. NIST-GCR-92-607, Nat. Inst. Stds. Tech., Gaithersburg, MD, 1992.

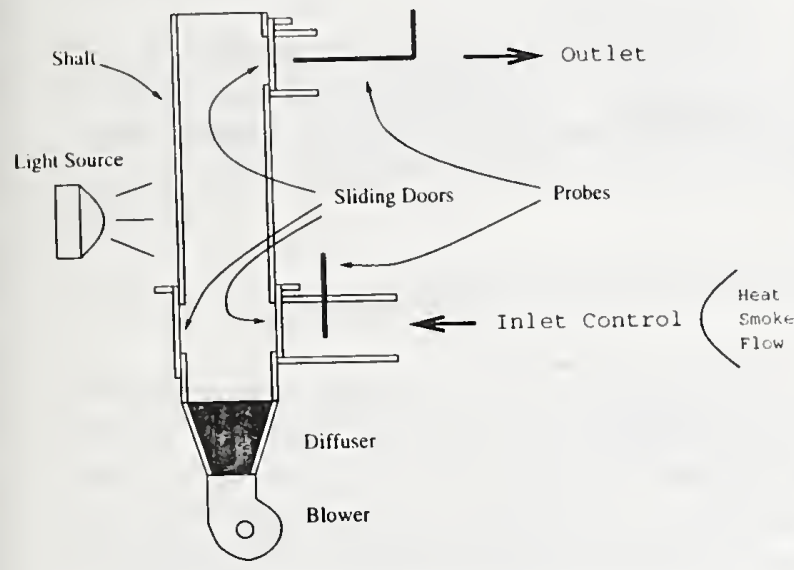

Fig. 1. Experimental arrangement for the vertical shaft study.

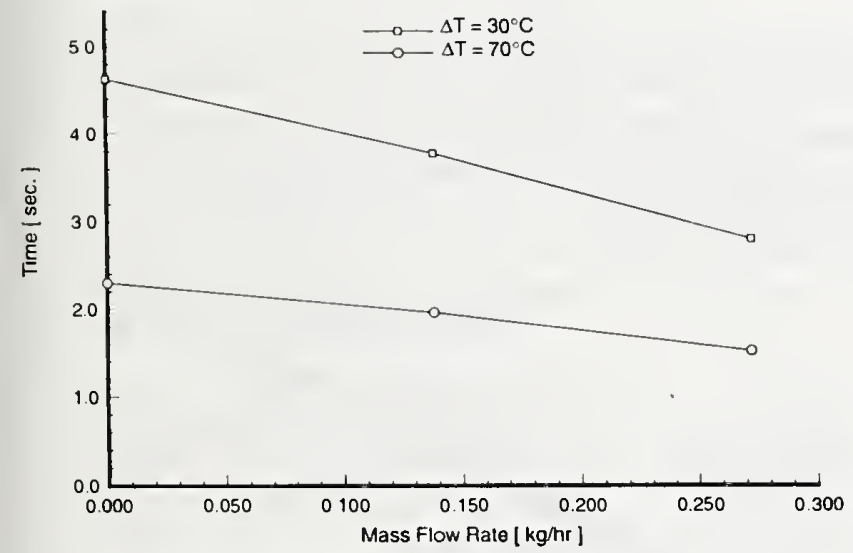

Fig. 3. Effect of injected mass flow rate on time taken by injected gases to reach the top opening.

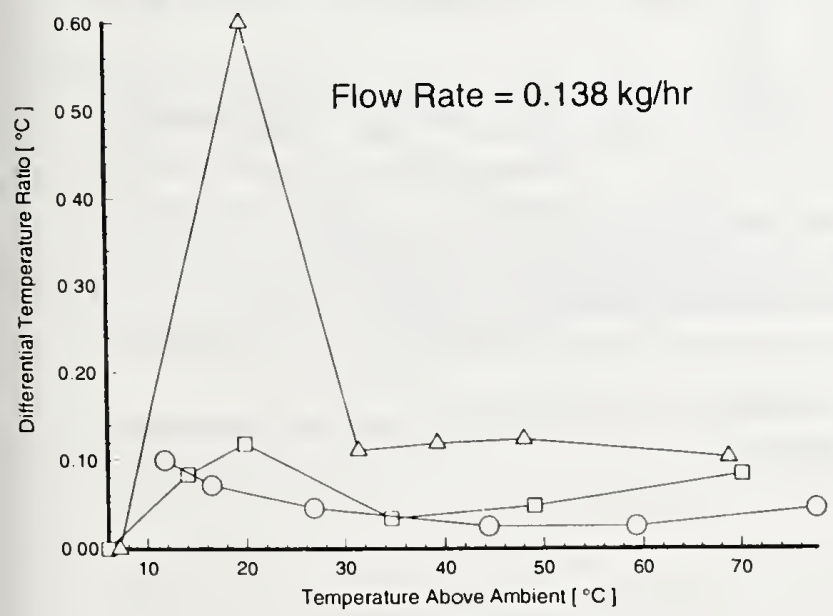

For Flow Rate $=0.138 \mathrm{~kg} / \mathrm{hr}$.

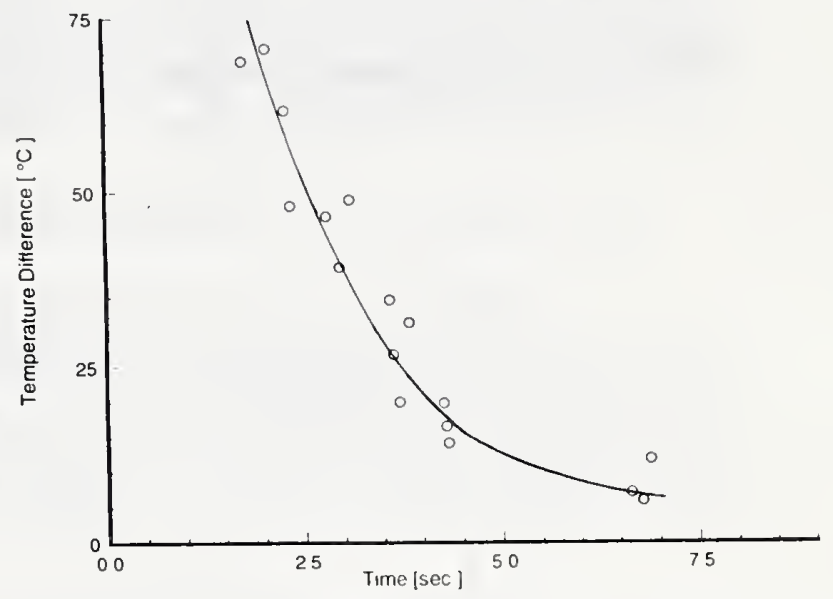

For Flow Rate $=0.272 \mathrm{~kg} / \mathrm{hr}$

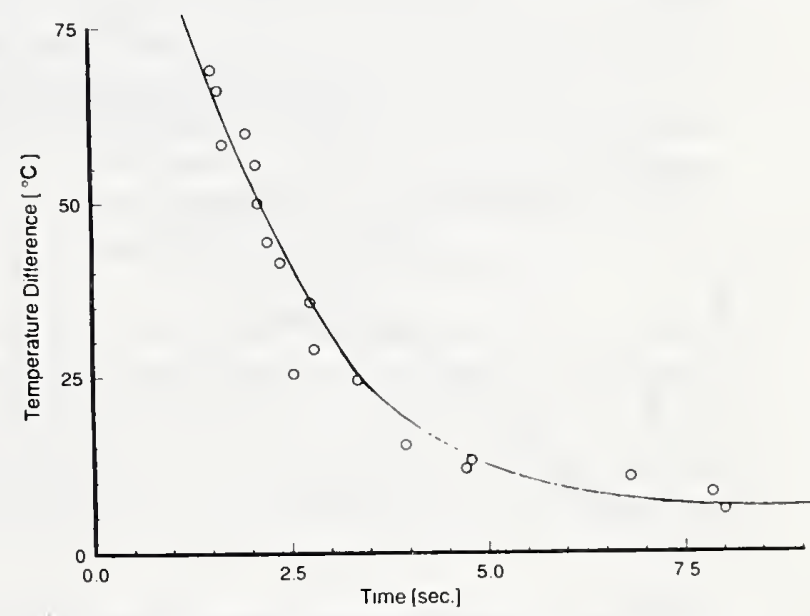

Fig. 2. Effect of inlet temperature difference, over the ambient temperature, on the time taken by hot gases injected at the lower opening to reach the top opening.

Fig. 4. Effect of inlet temperature difference, over the ambient temperature, on the ratio of the outlet temperature difference to the inlet temperature difference. 


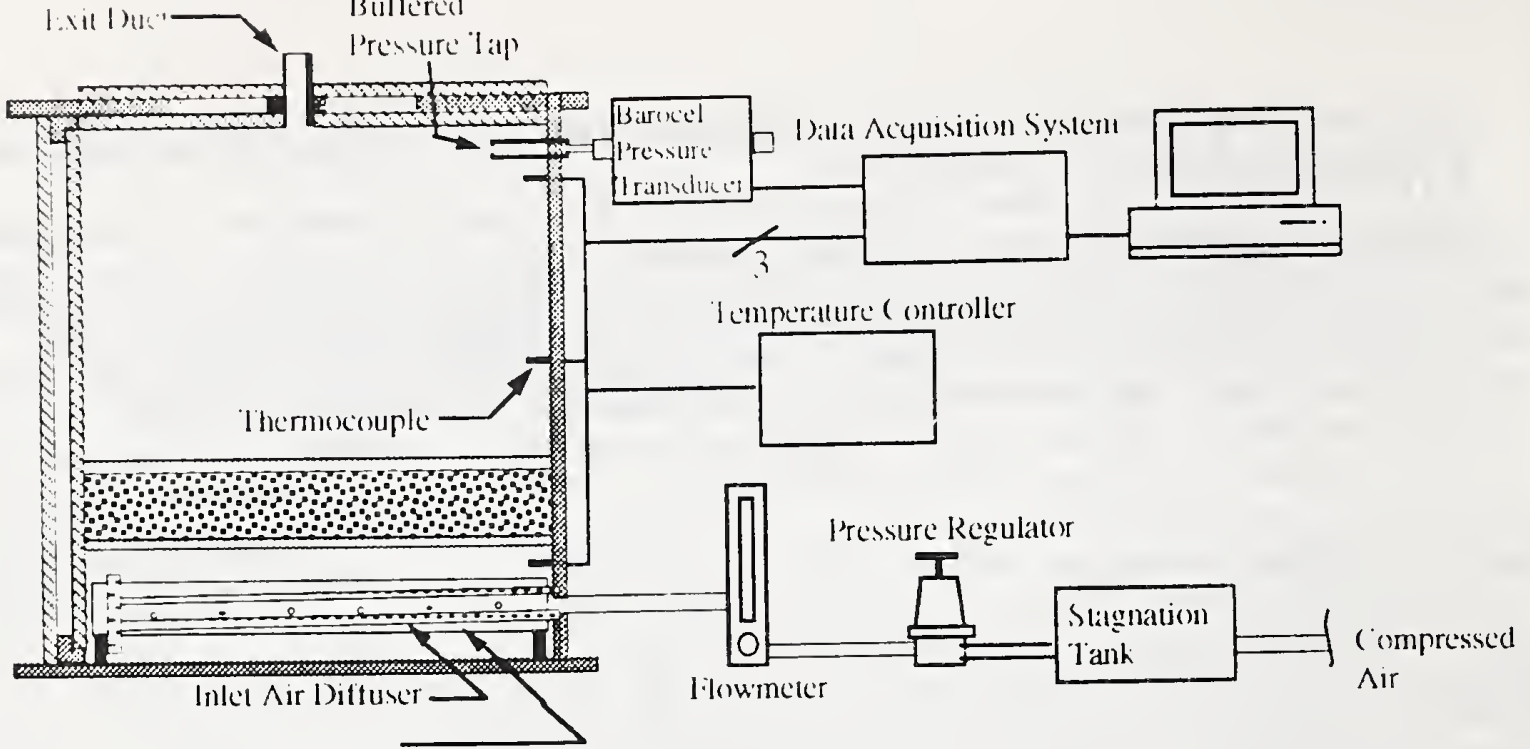

Fig. 5. Schematic of the experimental system for horizontal vent study.

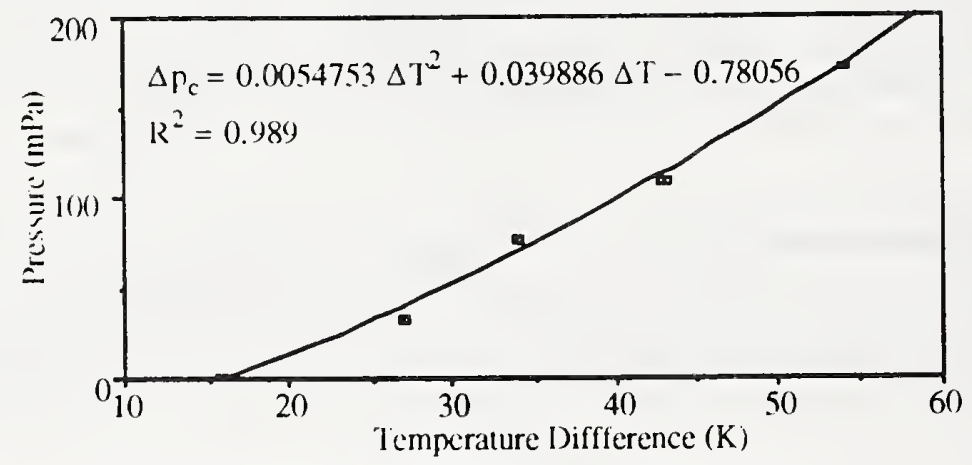

Fig. 6. Plot of the purging pressure as a function of temperature difference for a vent with $L / D=0.0144$.

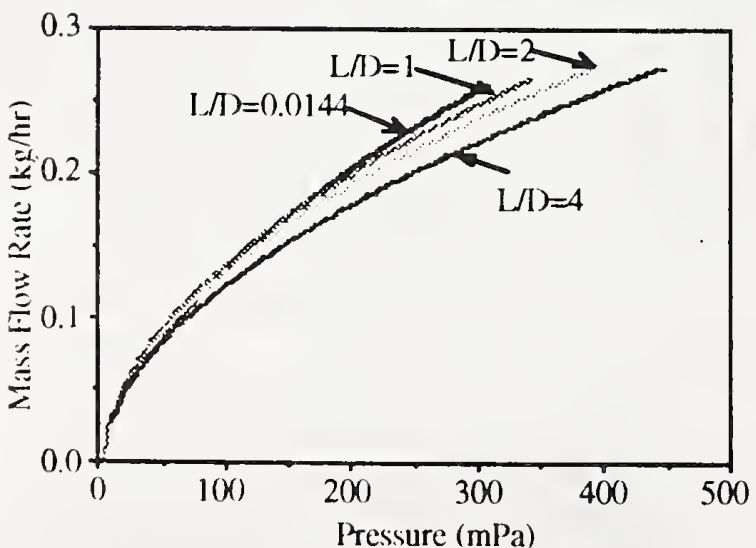

1./1 $=0.0144: m=(0.0003078 \Delta p+() .0(0) 4068)^{0.5}-0.053$ $1 / 1=1: m=\left(0.0(002224 \Delta p-0.00008244)^{0.5}-0.000375\right.$ $1 / 1 k=2: m=(0 .(x) 19699 \Delta-0 .(x) \mid 551)^{05}-0.002423$ IJ上4: $m=(0.0(k)] \times(1) .3 \Delta p-0 .(k)(4) 2214)^{6.5}-0.0102(0484$

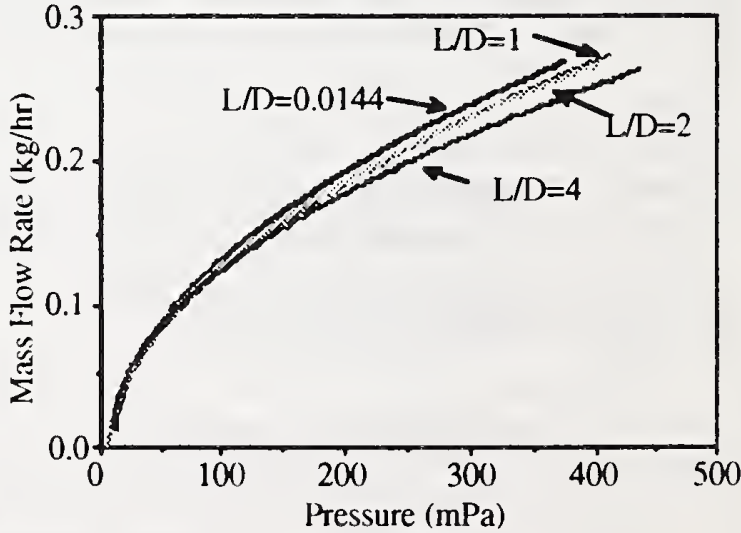

$I / D=0.0144: m=(0.0001973 \Delta p+0.002417)^{0.5}+0.0002564$ $1 / \mathrm{I}=\mathrm{I}: \mathrm{m}=(0.0002032 \Delta \mathrm{p}-0.0(0) 07603)^{0.5}-0.01531 .3$ $1 / \mathrm{D}=2: \mathrm{m}=\left(0.0001781 \Delta \mathrm{p}-(0 .(\mathrm{x}) 1715)^{0.5}+(0.0) 1835\right.$ $\mathrm{i} / \mathrm{l}=4: \mathrm{m}=(0.0001535 \Delta \mathrm{p}-0.00147538)^{0.5}+(0.00662617$

Fig. 7. Effect of the L/D ratio on the variation of the mass flow rate through a horizontal vent with pressurc at temperature differences of 20 and $40 \mathrm{~K}$, respectively. 


\section{BUILDING AND FIRE RESEARCH LABORATORY \\ FIRE RESEARCH PROGRAM \\ OTHER AGENCY PROJECT -- FY93}

\section{RISK ANALYSIS FOR THE FIRE SAFETY OF AIRLINE PASSENGERS}

Funding Agency: Federal Aviation Administration

Professional Staff: $\quad$ Dr. Richard L. Smith

Project Objective: The objective of this project is to develop the generic methodology and an intelligent computer program that will compute the fire risk for passengers of airlines. The program will determine the risk assuming the implementation of various fire safety regulations. The emphasis is on assisting the decision-maker gain greater understanding of the decision to be made rather than furnishing a "correct" conclusion.

\section{Technical Accomplishments:}

One approach to evaluating the merit of a fire safety system is to do a cost benefit analysis based on an analysis of past accidents using classical statistical techniques. We note that injuries or deaths due to airplane fires are rare events. Also, each crash is studied so that changes can be made in procedures or equipment to reduce the likelihood of a similar accident occurring. Therefore, the evidence available is inappropriate for the applications of classical statistical techniques in the fire risk analysis for the fire safety of airline passengers.

We will develop three progressively refined risk models: pilot, prototype, and production. For each of these we will first do the basic development which includes determining the alternatives, collecting the available information, and determining the decision maker's preferences. The second major step consists of developing the deterministic structures of the model. This is followed by the probabilistic evaluation which includes the use of probability distributions instead of unique values. Then the basic appraisal is done which includes sensitivity analysis, value of information analysis, value of control analysis, and a review of the decision maker's preferences. At this point the model is either complete or we start over and iterate the process until the decision maker is satisfied.

The selected approach utilizes influence diagrams rather than decision trees. Besides providing a clear and simpler representation of the problem, influence diagrams grow linearly with the size of the problem while decision trees grow exponentially. Some principal components of influence diagrams are: 1. Decision variables which are quantities over which the decision maker exercises direct control; 2 . Value parameters which represent aspects of the preferences of the decision maker; and 3. Chance variables which are quantities which represent properties of states of the world.

For the development of the pilot version of the risk model we are using a beta version of a commercial software program. A pilot model is an extremely simplified representation of the problem. Its main use is for determining the most important relationships. For this version the only decision is whether or not to add a water mist system to the airplane and the only preference variable is the number of deaths. The model determines the expected number of deaths with and without the water mist system. The model uses a subset of FAA's incapacitation model which addresses the effects of temperature, carbon monoxide, carbon dioxide, oxygen depletion, and hydrogen cyanide. 



\section{BUILDING AND FIRE RESEARCH LABORATORY \\ FIRE RESEARCH PROGRAM \\ OTHER AGENCY PROJECT - FY93}

\section{STUDY OF SMOKE AGGLOMERATES}

\section{Funding Agency:}

Professional Staff:

\section{National Aeronautics and Space Administration}

George Mulholland, Project Leader

Raymond Mountain, NIST Fellow

Nelson Bryner, Chemical Engineer

William Pitts, Research Chemist

Eric Steel, Supervisory Microscopist

Dave Bright, Analytical Chemist

\section{Project Objective:}

To provide NASA with measures of the validity and utility of fractal concepts in describing the growth and properties of large smoke agglomerates and design guidelines for a Large Agglomerate Optics Facility by January, 1995.

\section{Technical Accomplishments:}

The Large Agglomerate Optics Facility (LOAF) has been fabricated. It will be used to measure the radius of gyration and fractal dimension of smoke as it agglomerates in a smoke aging cell over about a one hour period. The effect of aging on the extinction, total scattering, and differential scattering crosssection will be measured with the LOAF.

The key components of the facility are a constant output smoke agglomerate generator, a smoke aging cell, rotary table and associated source and detector for differential scattering measurements, and light source and detectors for performing both light extinction and total scattering measurements. The salient features of the facility include the following:

- Tapered inlet and outlet in smoke aging cell to insure uniform filling

- Will allow first accurate total scattering measurements for large agglomerates (up to $3 \times 10^{3}$ primary spheres) by use of sensor with cosine response from 0 to $89^{\circ}$.

- Measurement of radius of gyration for agglomerates up to $1 \mu \mathrm{m}$ by small angle scattering down to $3^{\circ}$ with $\pm 0.4^{\circ}$ detector acceptance angle

- Computer controlled differential scattering measurement enabling measurement of scattering intensity at 12 angles in 60 seconds

\section{Publications:}

G.W. Mulholland, C.F. Bohren, and K.A. Fuller, submitted to Langmuir(1993), Light Scattering by Agglomerates: Coupled Electric and Magnetic Dipole Method. 



\section{BUILDING AND FIRE RESEARCH LABORATORY \\ FIRE RESEARCH PROGRAM \\ OTHER AGENCY PROJECT - 1993}

\section{SUPPORT OF THE NAVY FIRE MODELING PROGRAM}

\section{Funding Agency: Naval Research Laboratory \\ Professional Staff: $\quad$ Walter W. Jones, Project Leader \\ Paul A. Reneke}

\section{Project Objective:}

Develop specific algorithms to incorporate phenomena into the BFRL fire models which address problems unique to Navy ships.

\section{Technical Accomplishments:}

The zone model CFAST has been developed to predict fire growth and smoke spread in any compartmented structure. Several phenomena of particular interest to the US Navy have been incorporated. These include mechanical ventilation and vertical flow through hatches and other openings in decks.

An alogrithm for flame spread has been incorporated this year and will be tested against experimental data during the next fiscal year. In addition, CFAST was restructured this year to increase its speed for real time applications of damage assessment, and to allow more easily other Navy Commands to incorporate their own changes and additions.

\section{Reports and Publications:}

"Improvement in Predicting Smoke Movement in Compartmented Structures," Jones, W. W., and Fomey, G. P., Fire Safety Journal, in press.

"Modeling Smoke Movement through Compartmented Structures," Jones, W. W., Fire Sciences $I I$, 172 (1993).

"Comparison of Full Scale Fire Tests and a Computer Fire Model of Several Smoke Ejection Experiments," with Emil Braun, Darren L. Lowe, Patricia Tatem, Richard Carey and Jean Bailey, NISTIR 4961 (1992). 


\section{.}


A5. Fire Hazard Assessment 



\section{BUILDING AND FIRE RESEARCH LABORATORY \\ FIRE RESEARCH PROGRAM \\ NATIONAL INSTITUTE OF STANDARDS AND TECHNOLOGY \\ GRANTEE PROJECT - FY93}

\begin{tabular}{ll} 
Institution: & Clemson University \\
Grant No: & 60NANB2DI281 \\
Grant Title: & Computational Hèat Transfer for Zone Fire Modeling \\
\hline Principal Investigator: & Professor William F. Moss \\
& Department of Mathematical Sciences \\
& Clemson University \\
& Clemson, SC 29631 \\
& (803) 656-5225
\end{tabular}

Other Professional Personnel:

NIST Scientific Officer:
Mr. Jian Wang, Research Assistant

Dr. Glenn P. Fomey

Technical Abstract:

\section{Introduction}

Heat conduction through the ceilings, walls, and floors of the rooms in a zone fire model can be modeled by an initial-boundary value problem for the 1-D or 2-D heat equation. Using the method of lines (MOL), this problem can be reduced to a differential-algebraic equation (DAE) system. This DAE system, together with the ordinary differential equations for pressure, layer height, and upper and lower layer masses in a room, make up the full model which is a large DAE system. The bulk of the solution variables and the CPU time is attributable to the heat conduction submodel.

A domain decomposition method has been developed for splitting this large DAE system into a main system and a secondary one. The main system is solved for pressure, layer height, upper layer mass, lower layer mass, and the temperatures at ceiling, wall, and floor surfaces. The secondary system is used to model heat conduction. The main and secondary systems are coupled through heat flux boundary conditions at ceiling, wall, and floor surfaces (heat flux in equals heat flux out). Time discretization for the secondary system is done using the backward Euler method. The time stepsize used for the secondary system is the stepsize chosen by DASSL, the DAE solver used for the main DAE system. This method has proved to be both efficient and accurate.

This grant is the third in a series that have investigated various numerical aspects of NIST zone fire models. In the current grant the emphasis is on computational heat transfer. A number of experimental computer codes have been produced or are currently being produced for this grant. These codes are designated by names of the form CONRADx where $\mathrm{x}$ is a number. This summary is divided into sections by code name. The codes CONRAD1 and CONRAD2 were produced for the second grant. The codes beginning with CONRAD2.2 were produced for this grant. Our zone models incorporate heat transfer by radiation and 
conduction. Each room is divided into 4 heat conduction nodes, the ceiling, the upper wall, the lower wall, and the floor. The interface hetween the smoke and air layers divides the walls into upper and lower parts. The radiation submodel was constructed by Dr. Glenn Forney of NIST.

The code CONRAD I (see [ | |) implements a zone fire model hy solving a differential-algebraic equation (DAE) system for pressure, layer interface height, upper layer mass, lower layer mass, and the temperatures and temperature gradients at a set of hreakpoints through each heat conduction node. CONRADI is used as a henchmark code to test the accuracy of the other CONRAD codes. The code CONRAD2 and higher numbered CONRAD codes decompose the DAE system of CONRADI into a main system and a secondary one. The main system is solved for pressure, layer interlace height, upper layer mass, lower layer mass, and the temperatures at lieat conduction node interior and exterior surfaces. The secondary DAE system is used (1) model heat conduction through the heat conduction nodes. The main and secondary systems are coupled through heat flux houndary conditions (heat flux in equals heat flux out).

In CONRAD2 spatial discretization for the secondary system is done using the centered difference method of lines (MOL), while in CONRAD2.2 and higher numbered codes the cubic Hennite expansion MOL is used. These discretizations lead to tridiagonal Jacohians for CONRAD2 and pentadiagonal Jacobians for CONRAD2.2. Time discretization is done using hackward Euler. The time stepsize used for the secondary DAE system is the stepsize chosen hy DASSL, the DAE solver used for the main system.

\section{CONRAD2.2}

CONRAD2.2 uses the cuhic Hermite method of lines (MOL) to solve the heat conduction problem. The advantages of this approach are

1. higher order spatial accuracy.

2. huilt-in $C^{1}$ interpolant for temperature profiles,

3. casy to reinterpolate the temperature data on a new set of breakpoints,

4. temperature gradients are solution variables,

5. less sensitivity of numerical solution to hreakpoint placement.

The disadvantages of this approach are

1. greater coding complexity,

2. slightly longer CPU times.

\section{CONRAD2.3 and CONRAD2.35}

In all previous models, the node exterior surfaces transfered energy to ambient via convection and a temperature oo the fourth power radiation law. In CONRAD2.3 and CONRAD2.35 we experimented with a reduction in the number of solution variables in the main DAE system. The idea was to speed up the code. This reduction is accomplished hy moving the temperature solution variahles for node exterior surfaces from the main DAE system to the secondary DAE system. The nonlinear algehraic equation associated with these unknowns also moves to the secondary DAE system. This has the effect of making the secondary DAE system nonlinear.

In CONRAD2.3, we used a Taylor polynomial of degree one to linearize the radiation law. This essentially makes the radiation law look like a convection law with at temperature dependent heat transfer 
coefficient. The approach works well for 1,2, and 4 room test cases. We obtain CONRAD2.2 accuracy but with reduced CPU times.

The CONRAD2.3 approach has the disadvantage that the Jacobian matrix of the secondary DAE system now depends on node exterior surface temperature, time stepsize, and material, while for CONRAD2.2 the Jacobian only depends on time stepsize and material. In CONRAD2.2, once the time stepsize has been chosen by DASSL, the Jacohians for each material are factored. Then temperature profiles are updated on a node by node basis using forward and backward solves. In a simulation with 3 materials and 4 rooms, CONRAD2.2 would do 3 factorizations per time step and 16 forward and backward solves. On the other hand, it would appear that CONRAD2.3 would be forced to do 16 factorizations because the Jacobian is node dependent. There is a way around this difficulty as long as we are doing I-D heat conduction. We can do a nearly complete factorization on a material by material basis and then complete the factorization just before doing the forward and backward solves. The structural feature of the Jacobian on which this trick depends does not exist in the 2-D case so CONRAD2.3 does not generalize to the 2-D case.

We have found another way to handle the radiation law that does not have the above cited difficulty. In CONRAD2.35 we treat the radiation term as a nonhomogeneous term in the boundary condition equation and we evaluate this term using linear polynomial prediction; that is, to evaluate the radiation term at time $t+k$, we predict the node exterior surface temperature at time $t+k$ using two previously obtained values. CONRAD2.35 and CONRAD2.3 have nearly identical performance for 1,2 , and 4 room test cases. Linear polynomial prediction has the disadvantage of requiring more storage but the advantage of producing Jacobians that are not node dependent. We feel that this characteristic will be important for 2-D codes.

\section{CONRAD2.42}

A theoretical discussion of the method of decomposing the DAE system of CONRAD 1 into main and secondary systems is discussed in [2]. The goal of this decomposition is to reduce execution times. We have experimented with a more advanced approach for solving the secondary DAE system of CONRAD2.2, again for the purpose of reducing execution times.

In CONRAD2.2, solution of the discretized secondary DAE system involves solving a linear system in two stages. First, factorization is done for each node material used. Second, forward and hackward solves are done for each node in each room. The system is linear because the heat equation and houndary conditions are linear. The nonlinear heat flux houndary conditions are part of the main DAE system, not the secondary one. We can view this solution as the first iterate of Newton's method, and the matrix that is factored is the Jacohian. There is a case in which more than one iterate might be necessary. It is not necessary to factor the Jacobian at each time step as long as the time stepsize does not change too much. If the factorization is not updated, iteration is required. This approach generally goes by the name of the frozen Jacobian strategy. The matrices in CONRAD2.2 are so small that the cost of factoring is not dominant. However, with 2-D heat conduction, the matrices that must be factored will be much larger, so it is anticipated that avoiding factoring in favor of more solves will pay off in this case. CONRAD2.42 is a variant of CONRAD2.2 which implements the frozen Jacobian strategy. We use the same teclniques as in DASSL for deciding when to factor and when not to factor. We have set up a stopping criterion for the iteration based on our problem; that is we have not used the generic criterion in DASSL. Typically only one iteration is required, and we ohtain solutions with the high accuracy of CONRAD2.2 but with a significant decrease in CPU times (see [3]).

\section{CONRAD5}

In CONRAD5 we implemented a crude moving mesh strategy for breakpoints to see if improvements in accuracy or speed could be obtained. Currently, the peakpoint distribution for the heat conduction nodes is 
a compromise designed to produced reasonable accuracy at the first print output time and also at the end of the simulation. This hreakpoint distribution is extremely nonunilorm. In CONRAD5 we are experimenting with using two breakpoint distributions, one optimized for small heat penetration depths and one for large heat penetration depths. When a critical heat penetration depth is reach, CONRAD5 automatically changes breakpoint distribution. We are also experimenting with using fewer breakpoints with the moving mesh strategy than was used with the fixed mesh strategy. One of the strengths of the cubic Hermite MOL is that it has a huilt-in $C^{1}$ interpolant which makes it easy to reinterpolate the temperature and temperature gradient data on a new hreakpoint distribution. CONRAD5 precomputes for each material a switching time and updates the breakpoint distribution for each material at this time. This updating is done in the main DASSL loop and does not require a DASSL restart. Experiments to date have shown no improvement in accuracy hut modest improvements in speed.

\section{CONRAD3 and CONRAD4}

Previous CONRAD codes have used 1-D heat conduction models for the nodes. The 1-D model does not allow for vertical heat transfer in the walls and this is thought to be significant. We have developed a 2-D model and will compare it with our l-D model to test this significance. CONRAD3 is a 2-D hi-cubic Hermite MOL code for solving the standard initial-houndary value problem for the heat equation. This code has heen tested and IMSL Exponent Graphics routines have been used to visualize the 2-D heat surfaces. The number of unknowns in the linear system that must be solved (to advance the temperature one time step) is $1 n_{x} n_{y}$ where $n_{x}$ and $n_{y}$ denote the number of hreakpoints in the $x$ and $y$ directions. Using a block elimination strategy, the size of this system can he roughly cut in half. The resulting system is banded but with a fairly large handwidth. As an example, with $n_{1}=5$ and $n_{y}=4$, we have an $80 \times 80$ system that reduces to a is $\times$ ts system via hlock elimination. This smaller system is banded with a half handwidth of 20 and is solved hy Gauss climination with partial pivoting. Stability tests show that pivoting is necessary for this system. The usual banded factorization scheme is used.

CONRAD4 is currently heing written. This code will he modification of CONRAD2.2 in which the walls will be 2-D, while the ceilings and floors will he 1-D. The 2-D heat conduction will be provided by the CONRAD. 3 code.

\section{CONRAD6}

CONRAD6 will he our first test code for examination of heat transfer between rooms via conductive heat transfer. This code will examine a two room model with the rooms sharing a common wall. We will investigate and compare 1-D and 2-D models for heat conduction in the shared wall.

\section{References}

11] William F. Moss. Numerical analysis support for compartment fire modeling and incorporation of heat conduction into a zone fire model. Govenment Contract Report 605, National Institute of Standards and Technology, 1992.

12) William F. Moss and Glenn P. Forney. Implicitly coupling heat conduction into a zone fire model. Technical Report 4886, National Institute of Standards and Technology, 1992.

131 William F. Moss. Computational heat transfer for zone fire modeling. Govenment contract report, National Institute of Standards and Technology, 1993. 


\section{BUILDING AND FIRE RESEARCH LABORATORY \\ FIRE RESEARCH PROGRAM \\ PRIORITY PROJECT - FY 93}

\section{DEVELOPMENT OF THE FDMS DATABASE SYSTEM FOR FIRE RELATED DATA}

\section{$\underline{\text { Professional Personncl }}$}

Rebecca W. Portier, Project Leader

Dr. Vytenis Babrauskas, Firc Prevention Engineer

\section{$\underline{\text { Objective }}$}

Develop a centralized database of test values generated from a variety of sources within the fire community accessible through communications networks. Provide a platform-independent user interface to the database to support importing new data, editing existing data, querying and selecting specific test values, and interfacing to existing fire models.

\section{$\underline{\text { Scope }}$}

A unified method of accessing data is crucial to both experimental and modeling efforts in the development of the science of fire. FDMS, the Fire Data Management System, is a computer database for organizing and presenting fire data obtained from bench-scale and real-scalc tests as well as fire simulation programs. By storing available fire test values in a common format, this data is readily available to computer models, plotting programs, and report generators.

\section{Technical Accomplishments}

A beta version of the FDMS software currently exists which supports Cone Calorimeter and Furniture Calorimeter test results. The beta version FDMS provides for the selection and display of specific test results using several custom report formats. One of these custom reports is a statistical verification report which produces tabular output as specified by the ISO 5725 standard. The ISO5725 report generator was expanded this year to provide for the calculation of the repeatability and reproducibility values. A detailed evaluation of the FDMS beta version file formats was conducted and documented in order to make the current product compatible with other programs under development. This evaluation was then extended to determine any additional data required by existing fire models which was not supported by the beta version FDMS software. The results of the evaluation were detailed in a technical report which provides complete details for implementation of the second generation FDMS database. A new database engine and user interface library were selected which provide the platlorm independence desired for the FDMS database. Import routines were written to verify that all data existing in the beta version FDMS database can be successfully transferred to the new FDMS database engine. 
Reports and Publications

"A Programmer's Relerence Guide to FDMS File Formats," Porticr, R.W., NIST Internal Report $5162,1993$.

"Fire Data Management System, FDMS 2.0, Technical Documentation," Portier, R.W., NIST Internal Report, to be published.

\section{Related Grants}

"The Development of the Fire Data Management System," F. Mowrer, University of Maryland. 


\section{BUILDING AND FIRE RESEARCH LABORATORY \\ FIRE RESEARCH PROGRAM \\ OTHER AGENCY PROJECT - FY 93}

\section{EVALUATION OF FIRE SAFETY REQUIREMENTS FOR POTENTIAL APPLICATION TO U.S. PASSENGER GUIDED GROUND TRANSPORTATION SYSTEMS}

\section{Funding Agency}

U. S. Department of Transportation, Volpe National Transportation Systems Center and Federal Railroad Administration

\section{Professional Personnel}

Richard D. Peacock, Project Leader

Richard W. Bukowski, Group Leader, Fire Protection Applications

Walter W. Jones, Group Leader, Fire Modeling

Paul A. Reneke, Computer Scientist

\section{Objective}

To perform an independent review and detailed comparison to evaluate the compatibility of U.S. and European approaches to fire protection in guided transportation systems and provide the FRA with additional information to continue improvement of fire safety standards for guided transportation systems.

\section{Technical Accomplishments}

Recent advances in guided ground transportation, fire test methods, and hazard analysis necissitate reexamination of current requirements for fire safety. Several studies have suggested nearly random ability of current tests to predict actual fire behavior. A comparison of the approaches used in the United States, Germany, and France has been prepared. With the strengths and weaknesses of current methods for measuring the fire performance of materials used in rail transit systems reviewed, a direction is suggested in which most fire science-oriented organizations in the world are clearly headed - fire hazard and fire risk assessment methods supported by measurement methods based on heat release rate. This approach holds promise to simplify testing requirements for manufactures while providing better indicators of fire hazard of materials used in vehicle construction.

\section{$\underline{\text { Reports and Publications }}$}

"Fire Performance of Passenger Guided Ground Transportation, A Review of the Existing Methods and of New Concepts." Peacock, R. D., Bukowski, R. W, Jones, W. W., Reneke, P. A., and Babrauskas, V., NIST Technical Note, to be published.

"New Concepts for Fire Protection of Passenger Rail Transportation Vehicles." Bukowski, R. W., Jones, W. W., Peacock, R. D., and Reneke, P. A., to be presented at Fire and Materials Conference.

"New Concepts for Fire Protection of Passenger Rail Transportation Vehicles." Peacock, R. D. to be published. 



\section{BUILDING AND FIRE RESEARCH LABORATORY FIRE RESEARCH PROGRAM \\ NATIONAL INSTITUTE OF STANDARDS AND TECHNOLOGY GRANTEE PROJECT - FY93}

Institution:

Grant No:

Grant Title:

Brincipal Investigator:

NIST Scientific Officer:
National Fire Protection Association

6ONANB2D1286

\section{EXIT89}

Rita F. Fahy

Fire Analysis and Research Division

1 Batterymarch Park

Quincy, Massachusetts 02269-9101

Technical Abstract:

EXIT89 is an evacuation model designed to simulate the evacuation of a large population of individuals from a high-rise building or other complex space. It has the ability to track the location of individuals as they move through the building so that the output from this model can be used as input to a toxicity model that will accumulate occupant exposures to combustion products. EXIT89 uses occupant densities in building spaces to compute each occupant's walking speed. In this way, queueing effects are modeled. Ongoing development work on the model has been funded by this NIST grant.

EXIT89 was developed to meet the need for an evacuation model that could track large populations of individuals in high-rise buildings. The need for a model that can handle behavioral aspects of the evacuation of a high-rise building became obvious during some other project work being done at NFPA using Hazard I, a general fire hazard analysis model whose evacuation module has only behavioral features. Hazard I calculates toxic doses and other fire exposure by occupant, so it needs to track individuals along their routes out of the building. EXIT89 was specifically designed to track Indlviduals and address all key evacuation phenomena in high-rise buildings with large occupant populations.

\section{Qyerview of EXTT89}

EXIT89 requires as input a network description of the building, geometric data for each room and for openings between rooms, and smoke data if the effect of smoke blockages is to be considered. The user now has the option of having the model calculate shortest routes to a location of safety, or setting the path occupants will take from each location in the building. The model moves people along the calculated or specified routes until a location is blocked by smoke. Affected exit routes are recalculated and people movement continues until the next blockage occurs or until everyone who can escape has reached the outside. Evacuation can begin for all occupants at time 0 or can be delayed to reflect extemally calculated delays in alerting or responding. Smoke data can be used to predict when the activation of a smoke detector would occur and evacuation will begin then or after some user-defined delay beyond that time.

The model calculates walking speeds based on occupant densities. When escape routes are blocked by smoke, only the routes on the affected floor need to be recalculated. When the smoke blockage occurs in a stairwell, only the floors immediately above and below the blockage will be recalculated.

The model uses Predtechenskii and Milinskii's work that involved the calculation of average body sizes for Russian subjects in different types of dress. Subsequent work by Ezel Kendik using Austrian subjects found significant differences in the results. The Austrian data and available American data have been added to the model. 
From Predtechenskii and Milinskii's work, a value of $0.113 \mathrm{~m}^{2}$ (adults in mid-season street dress) is used. The Russian value used compares to the Austrian result for subjects between the ages of 10 and 15 years without coats. The value for Austrian subjects between ages 15 and 30 without coats was $0.1458 \mathrm{~m}^{2}$. The value for adults over age 30 without coats was $0.1740 \mathrm{~m}^{2}$. The lower value is used in the model. From a table of mean body dimensions representative of U.S. male and female workers between 18 and 45 years of age, mean values for shoulder breadth and chest depth were obtained. In order to add the additional bulk of clothing, both dimensions were increased by 0.02 meters. The resulting value was $0.0906 \mathrm{~m}^{2}$, far smaller than that calculated for Soviet or Austrian subjects.

The choice between these three sets of data is an input option set by the user. As part of the continuing work on the model, the differing results in EXIT89 will be examined.

\section{Other Ongoing Work}

Under the grant, the program was changed to give the user the option of either printing the full output listing or restricting the output to summary measures only. The summary measures added to the program are floor clearing times and stairway clearing times. The program prints out the time to complete evacuation, and the total number of occupants trapped or reaching safety. The model output has also been enhanced by adding a summary section showing the number of people who used each exit out of the building and at what time the last person passed through.

When people exit a building, even under emergency conditions, they will often take their most familiar route. The capability for occupants to travel along those paths has been added to EXIT89 in order for it to be able to model that behavior. As each node is described, the user specifies the adjacent node to which an occupant will move. If routes on a floor need to be recalculated due to smoke blockages, the specified routes are overridden by the calculated shortest routes.

Detailed results from building evacuations in the U.K. have been made available and are being used to compare the results generated by the model. One of the data sources included the effects of disabled occupants on occupant evacuation. Comparisons from the observations from these evacuations and from the model's output are being evaluated. The data on the impact of disabled occupants on the overall building evacuation will be used to add the presence of disabled adults to the model.

Other modifications planned include the use of CFAST output for smoke input, the addition of reverse flows in stairwells to simulate the effect of fire department operations in stairwells and the inclusion of additional human behavior data, such as delays in beginning evacuation and delays in the course of evacuating a building.

\section{Cenclusion}

The goal for the current phase of development of EXIT89 is to have a model ready for peer review and for use as an enhancement of the Hazard I package for high-rise buildings. It will incorporate available human behavior data to the extent possible. It will be tested using data from actual evacuations under either emergency or non-emergency conditions and it will include user options to allow a greater degree of flexibility and ease of use.

\section{Reports and Papers:}

"An Evacuation Model for High-Rise Buildings," Fahy, R.F., pp. 519-528 in Proceedings of Interflam '93, Interscience Communications, London (1993). 


\section{BUILDING AND FIRE RESEARCH LABORATORY \\ FIRE RESEARCH PROGRAM \\ PRIORITY PROJECT - FY 93}

\section{HAZARD DEVELOPMENT}

\section{Professional Personnel}

Richard D. Peacock, Project Leader

Walter W. Jones, Group Leader, Fire Modeling

Glenn P. Forney, Computer Scientist

Rebecca W. Portier, Mathematician

Paul A. Reneke, Computer Scientist

\section{$\underline{\text { Objective }}$}

To produce a fundamental capability to analyze the hazards associated with a specified fire scenario.

\section{$\underline{\text { Scope }}$}

Each year, billions of dollars are spent to protect occupants and equipment against fire and fire related damage and loss. Yet in spite of the increased spending many people continue to die annually and there is still a large dollar loss. To ease these problems, a systematic approach to understanding the effect of fires in buildings is necessary. The fundamental capability has been provided as a fully-supported software package for personal computers. While initially limited to residential-style occupancies, the software design is aimed at a broad range of applications from fire safety education to fire reconstruction.

\section{Technical Accomplishments}

BFRL developed the software HAZARD I, which predicts the hazard to a building and to occupants any where within the building. The fire hazard assessment methodology embodied in the HAZARD I software provides a vehicle which state-of-the-art fire science can be applied to improve fire safety. Continued enhancement of its capabilities and validity is a primary aspect to the mission of BFRL's fire program. Version 1.0 was released in summer of 1989. Version 1.1 was released in the fall of 1991 . This latter version includes new phenomenon and features to continue providing a state-of-the-art tool for hazard analysis for use by fire protection professionals. We have also improved the documentation by providing a step-by-step learning guide and integrating the example cases in the technical reference.

The research this year includes a most important missing pieces in most fire models: "prediction of the growth of the fire." Single-surface pyrolysis, and fire suppression algorithms are being incorporated in the fire model. We continued the unification of the user interface with a new-generation input editor and hazard shell. The internal structure of the core model of HAZARD, CFAST, has been addressed by redefining the internal data structures to be consistent with the streamlining of the solver routines completed last year. The benefits of this year's research are twofold: The pyrolysis and fire suppression algorithms will allow the user to study fire scenarios without costly full-scale testing to develop input data for the model. Improving the internal structure will allow easier inclusion of algorithms in the future and allow more researchers, both within NIST and elsewhere to contribute to the development of the model. 
The resulting model will provide a predictive tool for manufacturers, purchasers, architects, FPE's, code officials, and practitioners to evaluate safety performance, code equivalency, and code change proposal issues.

Pyrolysis model: Several single-surface pyrolysis models that predict real-scale fire growth from benchscale test data are being evaluated to find the one most appropriate for inclusion into the CFAST model. Beyond wall flame spread models developed in BFRL, we have also concentrated on simplifications to the existing furniture model by Dietenberger. This flame spread model described in this paper is a new algorithm which provides the capability to calculate a self-consistent fire based on bench scale fire data. The flame spread model simulates object fire growth and burnout of a slab in a room and produces acceptable predictions of the spread of fire, smoke and production of both toxic and non toxic gases. The purpose of the flame spread model is to allow a fire to grow realistically, possibly making a hole in the material surface. This is one mechanism for barrier penetration. The algorithm is based on empirical data, gathered from standard tests, including the Cone Calorimeter and the LIFT (lateral ignition flame spread test method). An objective of including the flame spread model is to predict the accelerative growth of a fire from ignition to a peak value and then the gradual termination normally seen in a fire. The threedimensional aspects of the flame spread model include: first, panels made of combustible materials with different thicknesses and at various orientations; second, flames of two basic types, pool fire and purely wall fire; third, radiation heat exchange between objects, flames, and gases. The pool fire has a flame spreading polygon on a horizontal panel and the wall fire is used either for inclined or vertical panels.

The dynamic features of the model include: (a) flame spreading in any (and all) direction(s) on a panel, (b) the varying mass and heat release rates in multiple flames because of the scaled burning history of surface elements on the panels, (c) the temperature changes of surface elements, walls, and gas layers, and (d) the growth of the upper gas layer with combustion products. The reliance of the model on effective scaling of the Cone Calorimeter data and of the flame spreading data, and its validation with the full scale fire tests is an important feature. Use of these test results allows us to avoid some theoretical difficulties associated with radiation blocking and charring. This also allows us to make a firm connection between bench scale tests and full scale predictions. This will be important for establishing the usefulness of bench scale testing as a substitute for full scale tests.

User interface: A new user interface to replace the existing CEDIT and HAZARD Shell has been developed. The interface, which will run on multiple computing platforms, allows the user to develop input for the model with a state-of-the art graphical interface. Significant features include:

Structure overview that allows a user to know at a glance the number of compartments, number of horizontal and vertical flow openings in each compartment, number of HVAC openings in each compartment, and "main" fire compartment and "other" objects compartments.

Horizontal and vertical flow selection screens allow a user to know at a glance all compartments with flow from current compartment, and the number of vents for each compartment pair, compartments that cannot be connected because of positioning, compartments that could be connected but are not currently.

HVAC system overview allows user to see graphically which compartments are connected by HVAC ducts and fans, and the topology of the connection path, direction of flow through fans, which nodes are "external" and which are "internal." 
Internal model improvements: The zone fire modeling equations in CFAST are expressed as a simultaneous system of algebraic and differential equations of the form

$$
\mathrm{F}\left(t, y(t), \frac{d y}{d t}\right)=0
$$

where $t$ represents time and $y(t), d y(t) / d t$ are vector valued functions with vector lengths $N$ where $N$ is the number of zone modeling equations. The components of $y$ for CFAST are compartment pressures $P$, mechanical ventilation pressures and temperatures $P_{M V}, T_{M V}$, upper layer volumes $V_{U}$, upper/lower layer temperatures $T_{U}, T_{L}$ and wall temperatures $T_{W}$. The vector $y$ then is given by $y=\left(\mathrm{P}, \mathrm{P}_{\mathrm{MV}}\right\}, \mathrm{T}_{\mathrm{MV}}, \mathrm{T}_{\mathrm{U}}, \mathrm{V}_{\mathrm{U}}$, $\left.T_{L}, T_{W}\right)^{N}$. The differential equation solver in CFAST (DASSL) solves equation (1) by first constructing backward difference formulas for $\mathrm{dy} / \mathrm{dt}$ and solving the resulting nonlinear finite difference equation using a variant of Newton's method. Newton-like methods require a derivative or in the multidimensional case a Jacobian of $\mathrm{F}$. If the matrix $A$ denotes the Jacobian of $\mathrm{F}$, then the construction of $A$ and the solution of linear systems of the form $A x=b$ are the dominant costs for solving the zone fire modeling equations in CFAST. In the improved model, the sparsity of $A$ is exploited to reduce the memory requirements. Semi-analytic formulas are derived for the columns of $A$ that correspond to partial derivatives with respect to wall temperatures to reduce computational costs. This approach has several advantages:

Numerical Speedup: Part of the Jacobian related to wall temperatures is computed more efficiently with a resulting speedup for some cases of 50 per cent. Normally, the routine RESID is called once for each solution variable to compute a finite difference approximation to the Jacobian. The speedup is possible because of the observation that Jacobian columns corresponding to partials with respect to wall temperatures can be computed by calling only a small fraction of the routines within RESID.

Memory Reduction: Part of the Jacobian related to wall temperature equations are stored more compactly. If $N R$ is the number of rooms, then DASSL can solve up to $N E Q=11 N R+6$ equations (assuming $4 N R$ gas layer equations, $3 N R+6 \mathrm{HVAC}$ equations and $4 N R$ wall temperature equations. The size of the Jacobian work array is then $N E Q^{2}$. The reduced Jacobian option decreases this number to $(N E Q-4 N R)^{2}$ since the Jacobian elements corresponding to the $4 N R$ wall temperature equations are stored compactly. The work array space requirements is then approximately $(7 / 11)^{2}=.4$ of the old.

\section{$\underline{\text { Reports and Publications }}$}

"Verification of a Model of Fire and Smoke Transport." Peacock, R. D., Jones, W. W., and Bukowski, R. W., Fire Safety Journal 21 89-129, 1993.

"Calculating Flame Spread on Horizontal and Vertical Surfaces." Ahmed, G. N., Dietenberger, M. A., and Jones, W. W., NIST Internal Report, to be published.

"CFAST, the Consolidated Model of Fire and Smoke Transport." Peacock, R. D., Jones, W. W., Forney, G. P., Reneke, P. A., and Portier, R. W., NIST Technical Note 1299, 1992.

"A User's Guide for CFAST Version 1.6." Portier, R. W., Reneke, P. A., Jones, W. W., and Peacock, R. D., NISTIR 4985, 1992. 
"Analysis of the Happyland Social Club Fire with HAZARD I," Bukowski, R. W., Fire and Arson Investigator, 42(3), 1992.

"Comparison of Full Scale Fire Tests and a Computer Fire Model of Several Smoke Ejection Experiments," Braun, E., Lowe, D. L., Jones, W. W., Tatem, P., Bailey, J., and Carey, R., NISTIR 4961 (1992).

"Analyzing and Exploiting Numerical Characteristics of Zone Fire Models." Forney, G. P. and Moss, W. F., NISTIR 4763, 1992.

"Modeling Smoke Movement through Compartmented Structures." Jones, W. W. and Forney, G. P., NISTIR 4872, 1992.

"Heat Release Rate: The Single Most Important Variable in Fire Hazard." Babrauskas, V. and Peacock, R. D., Fire Safety J., 18, 255-272, 1992.

"Computing Radiative Heat Transfer Occurring in a Zone Fire Model." Forney, G. P., NISTIR 4709, 1991.

"Fire-Plume-Generated Ceiling Jet Characteristics and Convective Heat Transfer to Ceiling and Wall Surfaces in a Two-Layer Zone-Type Fire Environment: Uniform Temperature Ceiling and Walls." Cooper, L. Y., NISTIR 4705, 1991.

\section{$\underline{\text { Related Grants }}$}

"Expansion of the Applicability of EXIT89." R. F. Fahy, National Fire Protection Association

"Development of a Graphical Interface for Post-Processing the Results of a CFAST Simulation." J. Barnett, Worcester Polytechnic Institute

"Computational Heat Transfer for Zone Fire Modeling," W. F. Moss, Clemson University.

"A Survival (Egress and Tenability) Model for Hazard Modeling." J. Barnett and B. Weissman, Worcester Polytechnic Institute

"Modifications to Furniture Fire Model for HAZARD System," M. A. Dietenberger, University of Dayton Research Institute.

"Mathematical Modeling of Human Egress from Fires in Residential Buildings," M. Kostreva, Clemson University. 


\section{BUILDING AND FIRE RESEARCH LABORATORY \\ FIRE RESEARCH PROGRAM \\ NATIONAL INSTITUTE OF STANDARDS AND TECHNOLOGY \\ GRANTEE PROJECT - FY92}

Institution: $\quad$ Clemson University

Grant No: $\quad$ 60NANB0D1023

Grant Title: $\quad$ Mathematical Modeling of Human Egress from Fires in Residential Buildings

Principal Investigator: $\quad$ Michael M. Kostreva, Professor

Department of Mathematical Sciences

Clemson University

Clemson, SC 29634-1907

Telephone: (803) 656-2616

Other Professional Personnel: Teodros Getachew, Doctoral Student

NIST Scientific Officer: $\quad$ Richard Peacock

Technical Abstract: In its first three years, this research project has produced some significant findings and discovered that there are some areas of research left to investigate. Mathematical modeling of egress of individual occupants from residential buildings remains the focus. The basic mathematical framework for all the fire egress models is a network superimposed on a geometric model of a residential building. Nodes in the network represent locations within and around the building, while links comprise potential egress routes. Each link carries several cost functions, possibly dependent on time, to be minimized by occupants in egress. Assignments of nodes, links and costs are made to closely reflect an actual scenario. Each occupant in the building is initially located at a unique node of the network, an origin node. The problem is to find, for each occupant, all nondominated paths (those minimizing all costs) leading from his/her origin node to a single destination node, representing safety outside the building.

In our research, we have derived several approaches which can solve the path planning problem in networks with multiple time varying objective functions. Applying dynamic programming to fire egress modeling allows for generalization of the network assumptions made in the current version of HAZARD I and development of a unified framework for handling a new more complex model based on a multiple objective dynamic network in which links and nodes may be removed, and in which link weights are multi- 
dimensional and changeable in time. Such assumptions provide the network model a perspective not previously considered in the literature. Although they increase the mathematical complexity of the problem, the network model becomes a more realistic representation of the highly variable environment. The network evacuation model is, in fact, strongly multiple objective in nature. There are various performance measures of a physical nature and of a behavioral nature inherent to the problem. Any meaningful model possesses dynamics due to an expanding and evolving fire and its changing parameters. An approach through time dependent multiple-objective dynamic programming, such as what we have developed, has the required capabilities for fire egress modelling and has great potential for application to fire safety planning and building design.

The results we have obtained so far are significant contributions to scientific knowledge and literature. Some results appear in (Kostreva and Wiecek 1993), in the Journal of Mathematical Analysis and Applications. This journal's high status in the applied mathematics community and the fact that it is well studied by most researchers in the area of dynamic programming, underline the impact of this contribution. Another paper, (Kostreva and Wiecek, 1992) presented in the Workshop on Negotiation and Multiple Criteria Decision Making sponsored by IFAC (International Federation on Automatic Control) and IFORS (International Federation of Operations Research Societies) held in Warsaw, Poland in June 1992. It contains a section in which Algorithm 2 is used to analyze the tragic fire at Hamlet, North Carolina in which twenty five people lost their lives. The situations in which a node is rendered impassable by fire or smoke may be modelled by the use of step functions. Such cases are shown to be approximately solvable by a simplified algorithm in (Kostreva and Wiecek 1992b). Finally, the question of how the set of nondominated paths might change as the egress starting time of the occupants changes is addressed in (Getachew and Kostreva, 1992). It is of interest to study this issue since there is an inevitable delay in egress starting time compared with the fire initiation time. It seems to have not been considered before.

Initial calculations demonstrate that the methods of dynamic multiple objective optimization can be successfully used to solve the following problems:

1)Finding the set of all best egress paths from all given origin nodes to a destination node, for single and multiple criteria optimization models.

2)Finding the optimal paths when a node is rendered impassable by fire or smoke.

3)Finding all the nondominated paths for a parmetric starting time of egress.

Benefits to the Building and Fire Research Laboratory of NIST include the following:

1)Time-dependency and multiple objective capabilities are handled in the same framework, while at the same time guaranteeing mathematically to obtain proven optimal paths for each occupant. Comparisons with existing heuristics, such as in HAZARD I are thereby possible.

2)Additional generalizations, such as the capability to handle dynamic changes in the network (e.g. occupants opening doors ) are also possible. 


\section{Reports and Papers:}

Kostreva, M. M., and Wiecek, M. M., Time Dependency in Multiple Objective Dynamic Programming, Journal of Mathematical Analysis and Applications 173, 289-307,1993.

Kostreva, M. M., and Wiecek, M. M., Multicriteria Decision Making in Fire Egress Analysis, Preprints of IFAC/IFORS Workshop on Support Systems for Decision and Negotiation Processes, Warsaw, Poland, June 1992, pp. 285-290. (a)

Kostreva, M. M., and Wiecek, M. M., Approximation in Time Dependent Multiple Objective Path Planning, Proceedings of IEEE International Conference on Systems, Man and Cybernetics, Chicago, 1992, pp. 861-866. (b)

Getachew, T.,and Kostreva, M. M.,, Transient Behavior in Multiple Criteria Path Planning Problems, Proceedings of IEEE International Conference on Systems, Man and Cybernetics, Chicago, 1992, pp. 867-873. 



\section{BUILDING AND FIRE RESEARCH LABORATORY \\ FIRE RESEARCH PROGRAM \\ STRS PROJECT - FY93}

\section{MERGER OF FPEtool AND HAZARD}

Professional Personnel

Richard W. Bukowski, Project Leader

Scot Deal

Charles Arnold

Project Objective

Utilize FPEtool as a front end to HAZARD I for making initial estimates with shared data inputs.

$\underline{\text { Scope }}$

The target is hazard predictors (FPEs, product manufacturers, regulators, product specifiers). Users of both products have asked for it as a tool with much broader utility. And it will be more efficient for us to support and further develop a single product.

\section{Technical Accomplishments}

In this effort, a new version of FPEtool was produced which incorporates new capabilities, including corridor tlows, flows into areas of refuge, and suppression. The documentation for the code was brought up to date, and the package was prepared for distribution through the HAZARD I distributors to relieve the need for staff to duplicate and distribute it.

As part of the preparation to release HAZARD I v1.2 next year, FPEtool is being incorporated into the user interface. Specifically, the FIREFORM routines are being integrated as a "pop-up" calculator in CEDIT to facilitate off line calculations needed to make decisions about inputs to CFAST. This should provide enhanced user capabilities while demonstrating the utility of both products. 



\section{A6. Large Fires}




\section{BUILDING AND FIRE RESEARCH LABORATORY \\ FIRE RESEARCH PROGRAM}

NATIONAL INSTITUTE OF STANDARDS AND TECHNOLOGY

GRANTEE PROJECT - FY93

Institution:

Grant No:

Grant Title:

Principal Investigator:

Other Personnel:

NIST Scientific Officer:
Massachusetts Institute of Technology

60NANBOD1036

Computer Simulation of the Environmental Impact of Large

Fires: Plume Rise and Dispersion

Professor Ahmed F. Ghoniem

Department of Mechanical Engineering

Massachusetts Institute of Technology

Cambridge, MA 02139

Xiaoming Zhang, Graduate Research Assistant

Dr. Howard Baum

\section{Technical Abstract:}

The rise, dispersion, physical and chemical transformations, and deposition of plumes generated from large fires are responsible for distributing hazardous material, including soot, unburnt hydrocarbon and nitric oxides, in the atmosphere and on the ground [1]. The objectives of this work is to develop an efficient and accurate computational tool for predicting plume trajectory, dispersion pattern, and ground deposition as a function of the fire conditions, wind, atmospheric conditions, and ground terrain, and to extend this tool so as to accommodate the complex physics controlling the fire dynamics. In the first phase of this work, we formulated a moving plane model to describe the dynamics of the plume in the cross sections normal to the wind direction. Using the assumption that the horizontal velocity component is that of the wind and that gravity is the dominant force in the cross wind direction, the formulation is reduced to that of an unsteady, two-dimensional, buoyancy driven flow. Numerical solutions are obtained using the Lagrangian transport element method, which is formulated as an extension of the vortex method to include the dynamic effects of density variation. Results, in terms of the plume trajectory and dispersion rates and patterns, are compared with experimental measurements.

During the past year, we focused on: (1) validating the model, especially the dispersion pattern, against laboratory and field observations; (2) investigating plume rise and dispersion in a linearly stratified atmosphere; (3) performing parametric studies on plume penetration through a low-level atmospheric inversion layer; (4) extending the computational capability to allow the model to incorporate complex phenomena, such as soot formation and dispersion, radiative heat transfer, and combustion, which occur closer to fuel burning zone. The latter was done in anticipation of having to extend the computation to the fire zone, i.e., couple the plume dynamics computation with a calculation of the fire evolutions. In the following, we present some results from the first three projects.

The evolution of the plume cross section, in terms of the density contours in the plume cross sections downwind the source, in a neutrally stratified atmosphere is compared with a water plume experiment in Fig. 1. The numerical [2] and laboratory results [3], almost identical, exhibit the generation and evolution of a kidney-shaped pattern which, as shown by our investigations, is associated with two buoyancy-generated large scale wind-wise vortices that govern the rise and dispersion of the plume and the entrainment into its cross section. Although in the experiment, the initial vertical momentum of the plume was finite, the eventual fate of the plume cross section, which is determined by the vorticity that has accumulated there due to the initial shear augmented by the buoyancy generated vorticity, is the same. Since the plume dynamics are fundamentally represented in the model, 
the simulation capture the underlying structure of the plume and properly accounts for its effect on the overall flow without introducing any adjustable parameters. Our detailed quantitative comparison between the predicted and measured plume trajectory show very good agreement and lend support to the $2 / 3$ power law often used for this purpose. However, the computed dispersion pattern, especially in the near field, do not corroborate the Gaussian model commonly used to represent the plume material distribution. This discrepancy is particularly important in the case of a fire since the plume dynamics in the near field are expected to dominate the entrainment field near the fire.

In the case of a linearly stratified stable atmosphere, the predicted plume trajectories are shown in Fig. 2 for different buoyancy ratios, defined as the ratio between the plume buoyancy and the background stratification [4]. In this case, vorticity is generated within the volume cross section as well as in the disturbed atmosphere due to the presence of a finite density gradient there. As expected, the stronger the stratification, the shorter the vertical rise of the plume. We have extended the conventional two-thirds power law for the trajectory to describe this case, and found that the added mass coefficient and the entrainment coefficient are 0.7 and 0.49 , respectively. The figure shows a good agreement between the results of the numerical simulation and the analytical model, can only be obtained in the region prior to the level-off height. The values of the coefficients in the model falls within the range suggest before. Clearly, the dynamics within the plume cross section are weakly effected by stratification while the overall trajectory is certainly changed substantially.

The trapping of buoyant plumes below low-level inversion is a strong function of plume buoyancy, the height, strength, and thickness of the inversion. The higher the inversion layer, the more difficult for the plume to penetrate through, thus, the larger the trapping fraction. The trapping fraction also increases as the inversion strength increases, or the inversion thickness decreases. Low level inversion is often observed in early to mid-morning and its effect on plume rise, while qualitatively resembling that of linear stratification, is found to be stronger. Smoke trapping in the case of a massive wild fire or urban oil spill fire could exasperate containment via vision impairment and suffocation. The asymptotic trapping ratio as a function of the dimensionless buoyancy flux, which incorporates the effects of both initial inversion height and strength, is shown in Fig. 3. The numerical results are indistinguishable from those obtained from laboratory experiments [5].

In the coming year, we plan to focus on the modeling of the burning fire zone, where fluid mechanics, radiative heat transfer, combustion physics and chemistry play important and interrelated roles. Results of this study should provide the initial conditions of the plume dispersion. In this regard, we plan to combine recently developed numerical schemes for reacting plumes [6] and radiative transfer [7] to study fire dynamics. This effort should result in a rational framework for accurate and comprehensive modeling of fire dynamics.

\section{References:}

1. Ghoniem, A.F., Zhang, X., Knio, O.M., Baum, H., and Rehm, R. J. Haz. Mat., 33, 275-293, 1993.

2. Zhang X. and Ghoniem A. F. "A Computational Model for the Rise and Dispersion of Windblown, Buoyancy-driven Plumes, Part 1, Neutrally Stratified Atmosphere," Atmos. Environ. (In press), 1993

3. Alton, B. W., Davidson, G. A. and Slawson, P. R. Atmos. Environ., 27A, 589-598, 1993.

4. Zhang X. and Ghoniem A. F. "A Computational Model for the Rise and Dispersion of Windblown, Buoyancy Driven Plumes, Part 2, Linearly Stratified Atmosphere," Atmos. Environ. (Submitted for publication ) 1993.

5. Zhang X. and Ghoniem A. F. "A Computational Model for the Rise and Dispersion of Windblown, Buoyancy Driven Plumes, Part 3, Atmosphere with Inversion Layer," Atmos. Environ. (In preparation), 1993.

6. Zhang, X. and Ghoniem, A.F., "Dispersion Patterns Resulting from Sudden Release of Heavy Gases," in preparation.

7. Ezckoye, O.A. and Baum, H.R., "The Thermal Element Model and its Integration into Large Scale Hydrodynamic Calculations," NIST Internal Report, in preparation. 

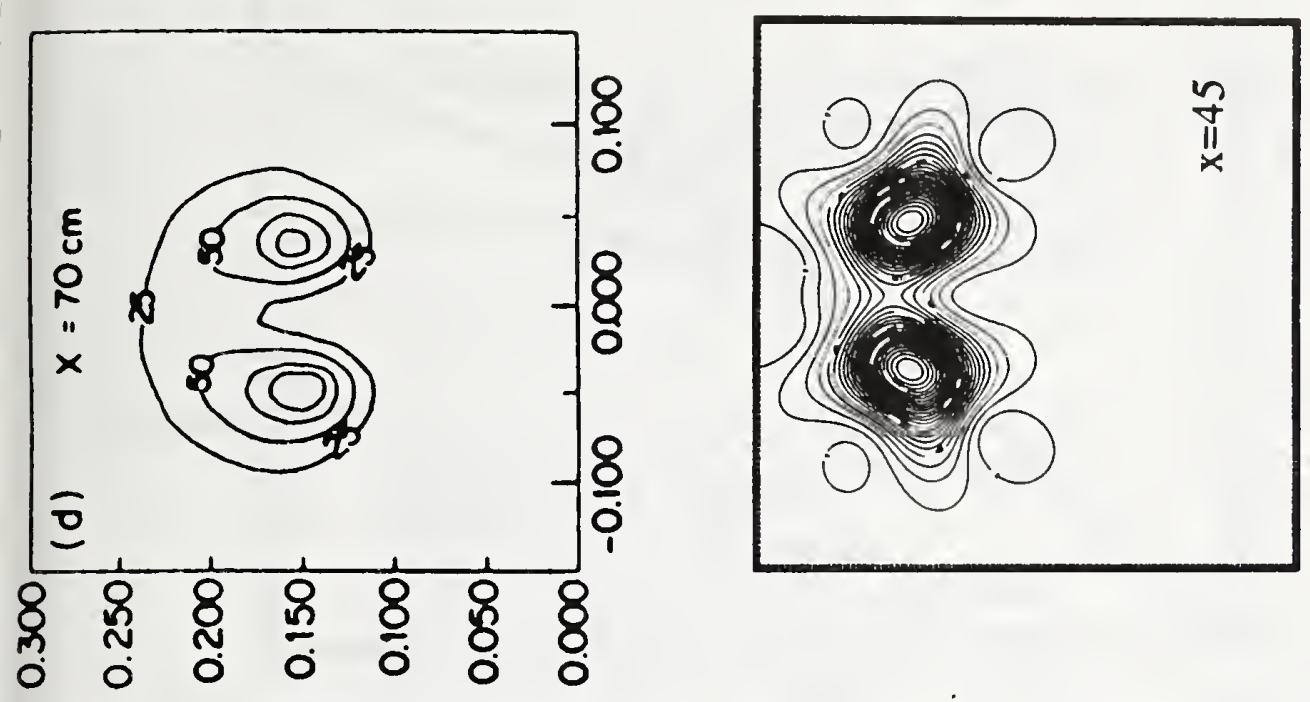

.
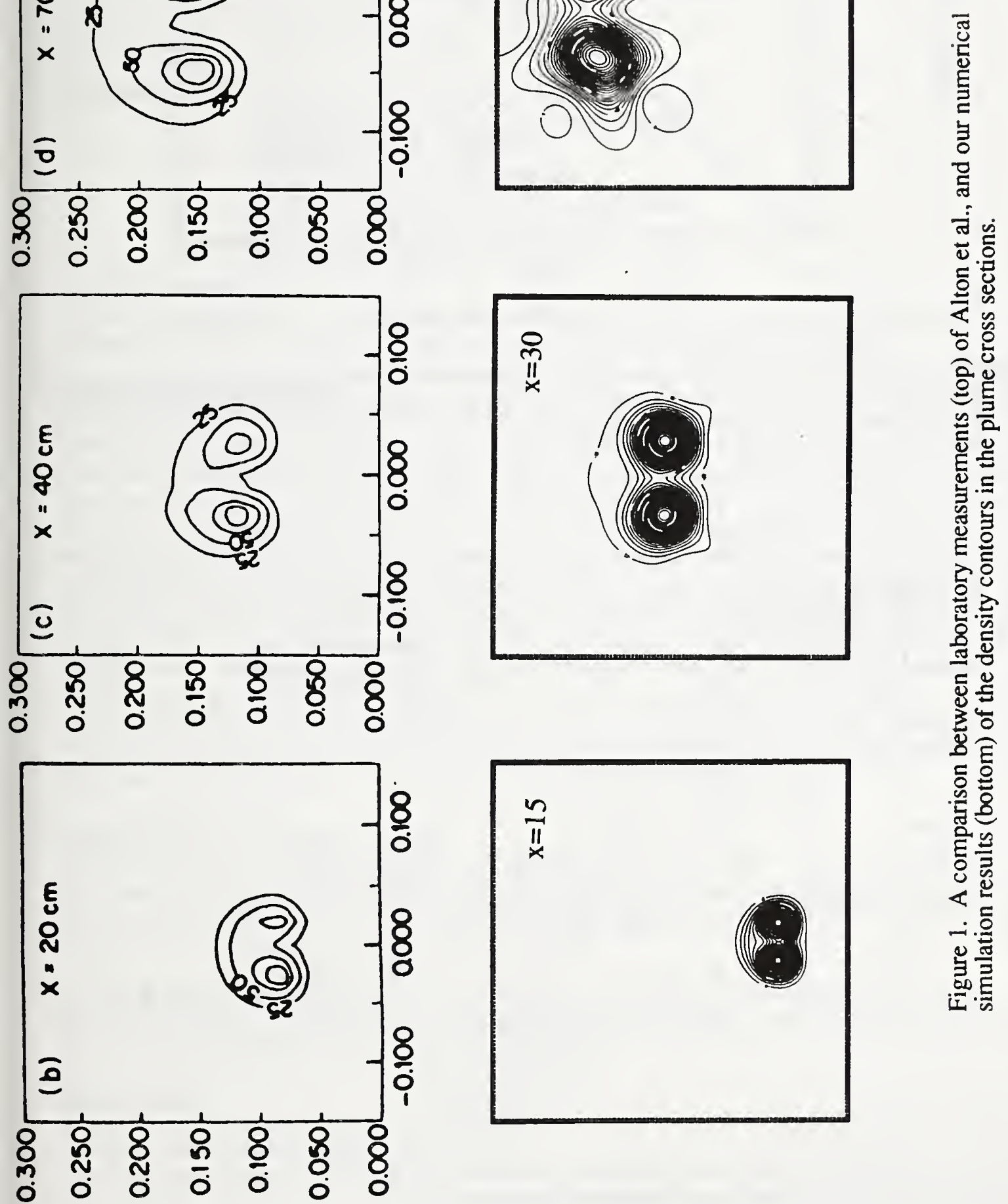

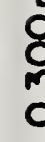

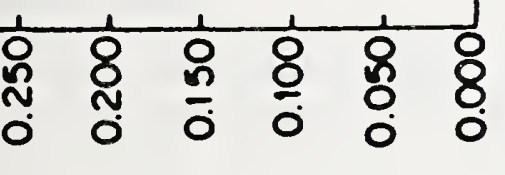

\section{(w) $\perp H O I 3 H$}




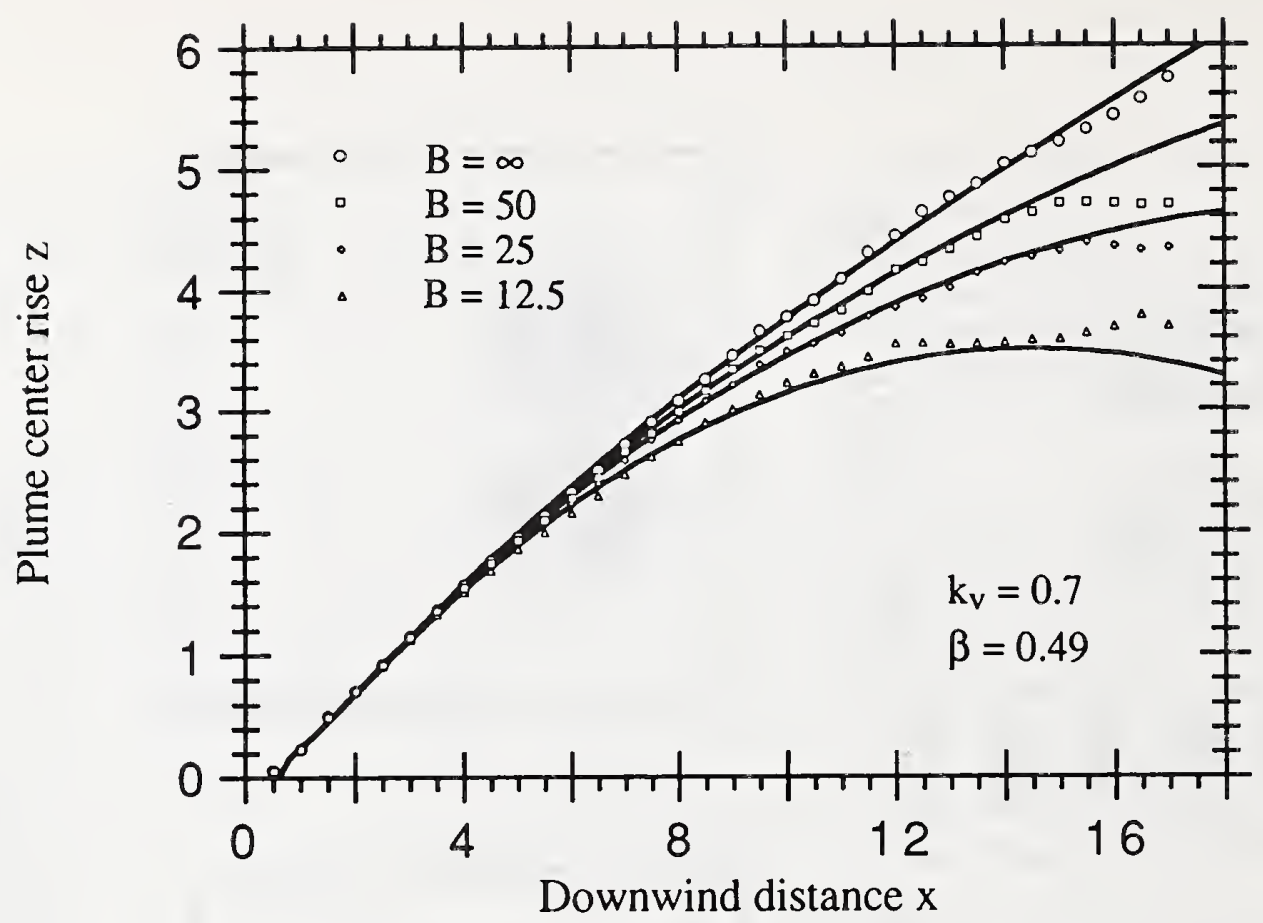

Figure 2. A comparison between the numerically predicted plume trajectory in a linearly stratified atmosphere, shown in open symbols, and the two-thirds power law model. Note that the latter cannot capture the level-off part of the trajectory.

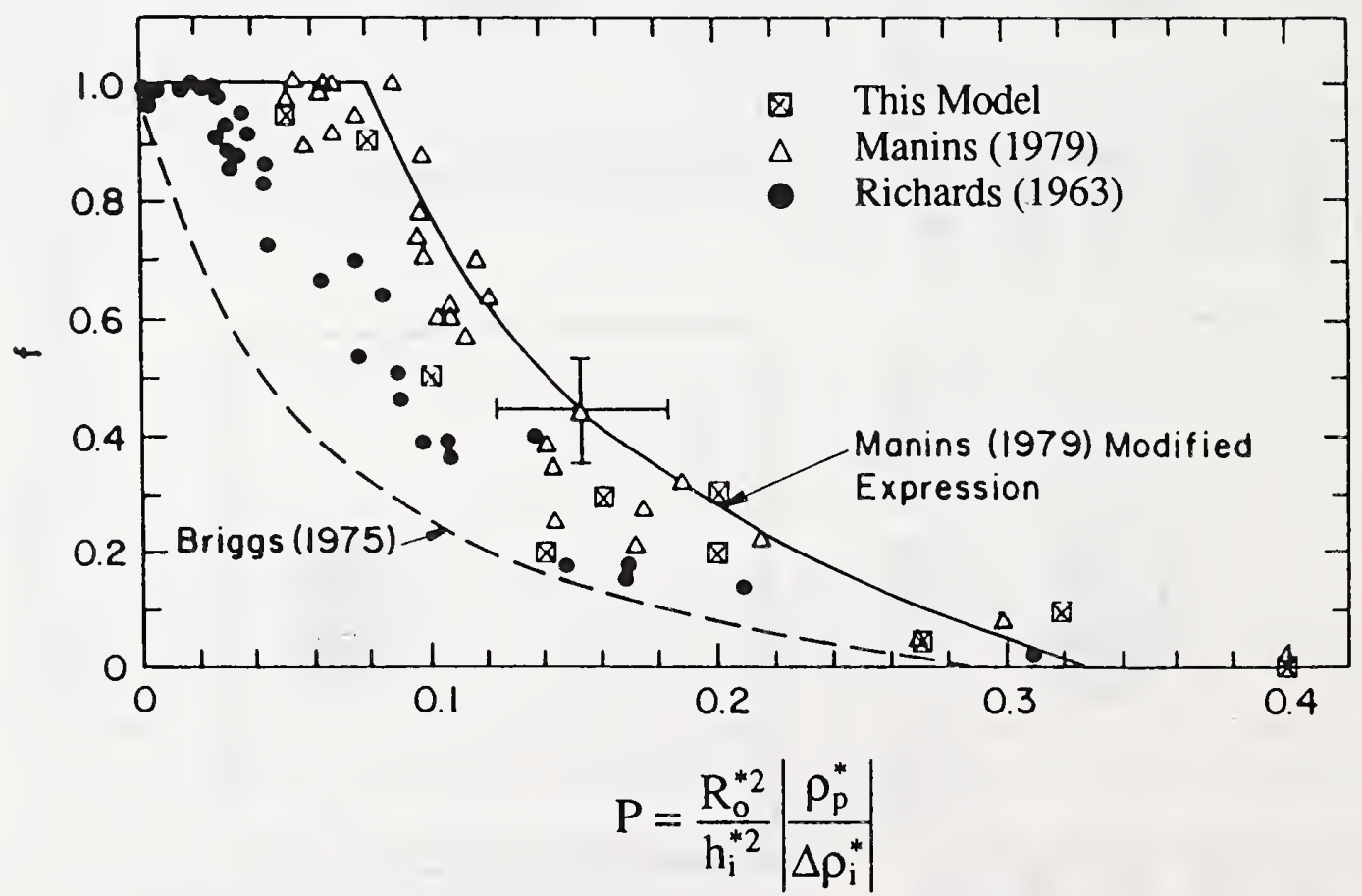

Figure 3. A comparison between the numerical predictions and the experimental measurements of the trapping fraction as a function of dimensionless buoyant flux. 


\section{BUILDING AND FIRE RESEARCH LABORATORY FIRE RESEARCH PROGRAM \\ OTHER AGENCY PROJECT - FY93}

\section{IN-SITU BURNING OF OIL SPILLS}

Funding Agency: Minerals Management Service, DoI

Professional Staff: David D. Evans, Project Leader

William D. Walton, Fire Protection Engineer

Howard R. Baum, NIST Fellow

Kevin McGrattan, Mathematician

James R. Lawson, General Physical Scientist

Daniel Madrzykowski, Mechanical Engineer

Kurt Keydel, Mechanical Engineer

Project Objective:

To develop and implement the instrumentation and data use methodology for quantifying the combustion of crude oil on water during field experiments of current oil spill burning technology.

Technical Accomplishment:

Six mesoscale $\left(231 \mathrm{~m}^{2}\right)$ louisiana crude oil pool fire experiments were conducted using the U.S. Coast Guard Fire and Safety Test Detachment facility in Mobile, Alabama. Results for burning rate and smoke yield were as expected from previous testing. The oil surface regression rate, a measure of burning rate, was found to be $0.062 \pm 0.003 \mathrm{~mm} / \mathrm{s}$. Smoke yield, the fraction of the fuel converted to particulate, was $11 \pm 1$ percent. Laboratory experiments in which $1.2 \mathrm{~m}$ diameter pans of the Louisiana crude oil were burned at the Fire Research Institute in Japan showed that for this crude oil the smoke yield was the same as for the larger mesoscale fires, but the surface regression rate was reduce to a value of $0.046 \mathrm{~mm} / \mathrm{s}$. In cooperative research between NIST and the Massachusetts Institute of Technology (MIT), a method has been developed to simulate smoke dispersion and settling from crude oil pool fires burning in a uniform wind. Calculation of the smoke plume trajectory and smoke particulate deposition were performed using a Large Eddy Simulation (LES) model for the smoke plume trajectory and smoke particulate deposition. The speed and accuracy of the calculations have been improved so that calculations of smoke plume trajectory and airborne particulate concentrations over a $30 \mathrm{~km}$ distance from the source can be performed in a few hours using an IBM RISC 6000 computer.

Publications:

"In-Situ Burning of Oil Spills: Mesoscale Experiments and Analysis," W.D. Walton, D.D. Evans, K.B. McGrattan, H.R. Baum, W.H. Twilley, D. Madrzykowski, A.D. Putorti, R..G. Rehm, H. Koseki, E.J. Tennyson, Proceedings of the Sixteenth Arctic and Marine Oil Spill Program (AMOP) Technical Seminar, June 7-9, 1993, Calgary, Alberta, pp 679-734, (1993).

"Smoke Plumes from In Situ Burning of Oil Spills," D.D. Evans, W.D. Walton, H.R. Baum, R.G. Rehm, E.J. Tennyson, Proceedings of the Eighth Symposium on Coastal and Ocean Management, July 19-23, 1993, New Orleans, LA, pp 3409-3417, (1993).

Related Grants:

Numerical Modeling of Plume Dispersal and Smoke Deposition from Large Scale Fires, Ahmed F. Ghoniem, Massachusetts Institute of Technology. 



\section{BUILDING AND FIRE RESEARCH LABORATORY \\ FIRE RESEARCH PROGRAM \\ NATIONAL INSTITUTE OF STANDARDS AND TECHNOLOGY \\ GRANTEE PROJECT - FY93}

Institution:

Grant No.:

Grant Title:

Principal Investigator:

Other Professional Personnel:

NIST Scientific Officer:
The University of Califomia at Berkeley

60NANBID 1168

Large Fire Analyses

Professor Patrick J. Pagni

Mechanical Enginecring Department

5131 Etcheverry Hall

University of Califomia

Berkelcy, CA 94720

Dr. Charles M. Fleischmann

Javier J. Trelles (Ph.D. Candidate)

Alvin Lee

Dr. Howard R. Baum

Technical Abstract:

Introduction. Two categories of large fires are being studied under this grant: the urban/wildland interface and backdrafts in large occupied structures. A devastating example of the former occurred near the U.C. Berkeley campus on 20 October 1991 and is the focus of our attention in this abstract. In addition we are numerically modeling transient fire plumes to provide a foundation for urban/wildland interface fire growth models. The second category, backdrafts, is primarily experimental. Unusually detailed data have been obtained from a fully-instrumented half-scalc apparatus. This work is motivated by high loss of life hotel fires where backdrafts are thought to have played an important role.

Urban/Wildland Interface. During October 1991 two fires occurred in the same canyon in the hills southeast of the University of Califomia at Berkeley campus. The 19 October fire bumed $2 \times 10^{4} \mathrm{~m}^{2}$ and was controlled with relative ease. The 20 October fire burned $6 \times 10^{6} \mathrm{~m}^{2}$, killed 25 people, and damaged 2334 structures. Why was the 20 October fire so terribly different from the 19 October fire? Post-fire investigations revealed that the 20 October fire propagated $\sim 2 \mathrm{~km}$ downwind in 15 min., growing from $5.5 \times 10^{4} \mathrm{~m}^{2}$ to $1.5 \times 10^{6} \mathrm{~m}^{2}$ between 1115 and 1130 PDT as shown in Fig. 1. Once that accelerated fire growth occurred, the heroic performance of the local fire service was overwhelmed. The final firc outline, indicated by the 1800 contour, is also partially shown on Fig. 1 . The purpose of our analysis was to explain the catastrophically swift fire spread between 1115 and 1130 .

The direction of the hot, dry, fast (>10 m/s) wind during this rapid spread, $\mathrm{N} 35^{\circ} \mathrm{E}$, is right to left on the Fig. 1 diagonal arrow. The USGS survey topography along this line is shown to scale in Fig. 2. The horizontal location of the 19 October fire is the origin in Fig. 2. Atmospheric temperature profiles from the Oakland Airport suggest a strong inversion layer between 300 to $600 \mathrm{~m}$ at the time of rapid firc spread as shown in Fig. 2. The hot, flaming debris channeled downwind by the inversion layer found a rich fucl source in a $35 \mathrm{~m}$ high stand of Eucalyptus globulus at $600-700 \mathrm{~m}$ from the origin in Figs. 1 and 2. Local wind gusts and some NE fire-induced winds augmented the Fig. 2 velocities by as much as a factor of two. Further downwind spread of the 1115 to 1130 blow-out was impeded by some SW fire-induced winds which opposed the NE ambient winds. These detailed flow 
effects are currently being studied using the Baum-McCaffrcy multiple plume source large fire model.

The scenario that emerges for 20 October 1991 is a fire occurring after a very dry, hot, strong wind has desiccated vegetal and structural fuel. This fucl is initially dry from a long drought, an unusual freeze and a rainless extended summer. The altitude of the fire places it within a strong inversion layer so that vegetal brands are rapidly channcled downwind directly into a heavy fuel load urban/wildland interface. That interface is in tum clevated above the surrounding urban plain so that vegetal and structural brands have extended trajectories which aid the fire's growth to conflagration. A consequence of this scenario is that the 20 October conflagration was generated by topographic and metcorologic conditions which cannot be mitigated. It then becomes necessary to require strong fire prevention measures such as residential sprinklers, fire-resistant construction, defensible space vegetation control and local weather augmentation of the national fire danger rating system.

Backdrafts. A half-scalc apparatus was used to obtain data from 52 backdraft experiments including 40 with early, 5 with middle, and 3 with late ignition. Backdraft was defined as a rapid deflagration following the introduction of oxygen into a compartment filled with accumulated excess pyrolyzates. Experimental paramcters measured including species concentrations, $\left(\mathrm{HC}, \mathrm{CO}, \mathrm{CO}_{2}, \mathrm{O}_{2}\right)$, layer temperatures, layer height, vent flow, compartment pressure, leakage rate, and fuel flow rate. A gas burner supplied a range (70-180 kW) of methane fires in a $1.2 \mathrm{~m}$ high, $1.2 \mathrm{~m}$ wide, $2.4 \mathrm{~m}$ long compartment with two different opening geometries: a centered horizontal slot $0.4 \mathrm{~m}$ high by $1.1 \mathrm{~m}$ wide and a centered window 0.4 high by $0.4 \mathrm{~m}$ wide. Significant unburned fuel $(18 \%$ to $35 \%$ by volume) accumulates in the compartment after the oxygen concentration drops below $\approx 10 \%$ as shown in Fig. 3. Once the hatch is opened, a gravity current of cold oxygen rich air enters through the new opening and propagates across the compartment. This gravity current carries a flammable mixed layer to an existing spark located near the bumer on the opposite wall (early ignition). Upon ignition, a rapid dellagration moves through the compartment culminating in a large exterior fire ball. Compartment pressure $>70$ Pa were recorded in these experiments. Middle ignitions were obtained by delaying the spark onset by 4 to $12 \mathrm{~s}$ to allow the reflected gravity current to generate a larger mixed region. Late ignitions, with 60 to $600 \mathrm{~s}$ delays, occurred in unburnt fuel trapped by the soffit. These backdraft scenarios are known to cause occupant and firefighter injuries. Additional salt water model experiments of backdraft gravity currents have been compared with NIST computations by McGratten.

\section{Reports and Papers:}

1. Pagni, P. J., "Causes of the 20 October 1991 Oakland Hills Conflagration," Fire Safety Journal, 1993.

2. Joshi, A. A., and Pagni, P. J., "Fire Induced Thermal Fields in Window Glass: I - Theory," Fire Safety Journal, 1993.

3. Joshi, A. A., and Pagni, P. J., "Fire Induced Thermal Fields in Window Glass: II - Experiments," Fire Safety Journal, 1993.

4. Flcischmann, C. M., Pagni, P. J., and Williamson, R. B., "Exploratory Backdraft Experiments," Fire Technology, 1993.

5. Fleischmann, C. M., and McGratten, K., "Modeling Compartment Gravity Currents," submitted to Fire Safety Journal. 


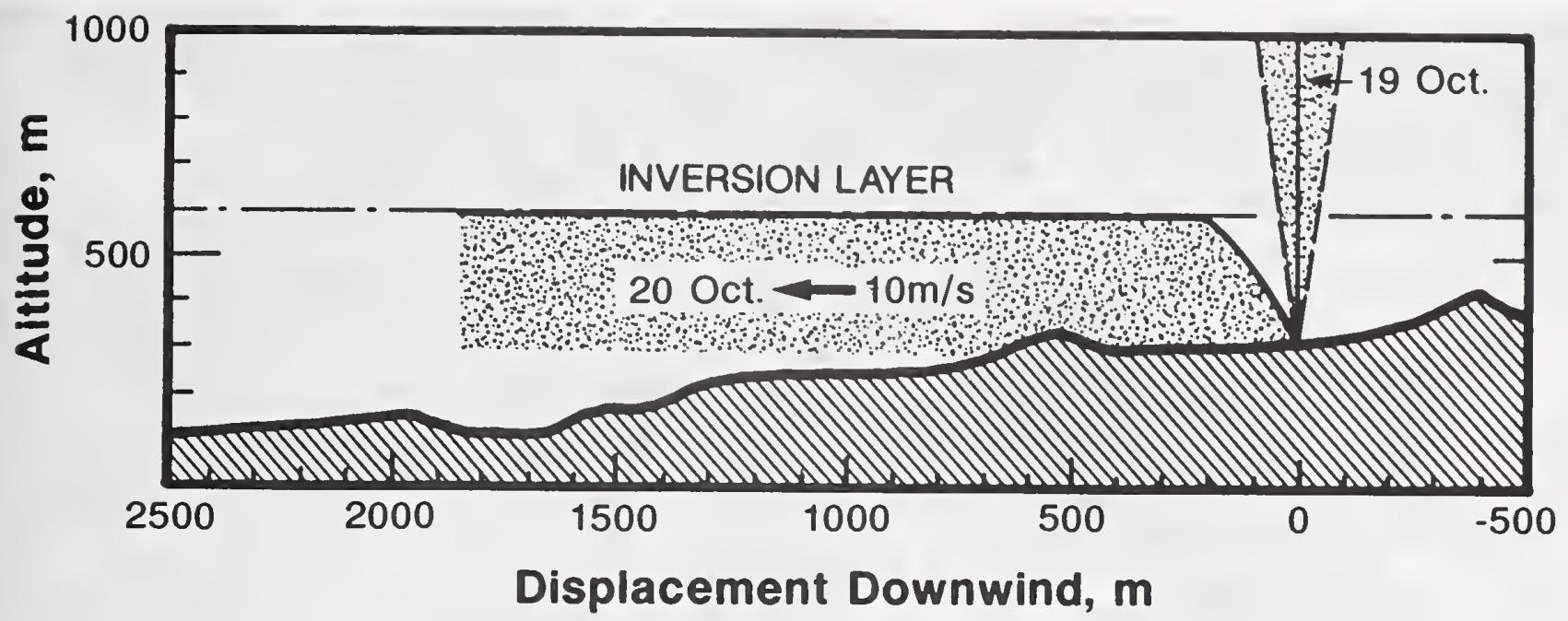

Fig. 2. This is an elevation looking NW perpendicular to the wind trajectory in Fig. 1a. The lower solid line is the hill topography. The upper dashed line is the top of the 20 October inversion layer. The speckled areas indicate the fire plumes on the 19th and 20th of October. Heavy vegetal and structural fuel load existed prior to the fire from 0 to $1200 \mathrm{~m}$ downwind of the fire origin.

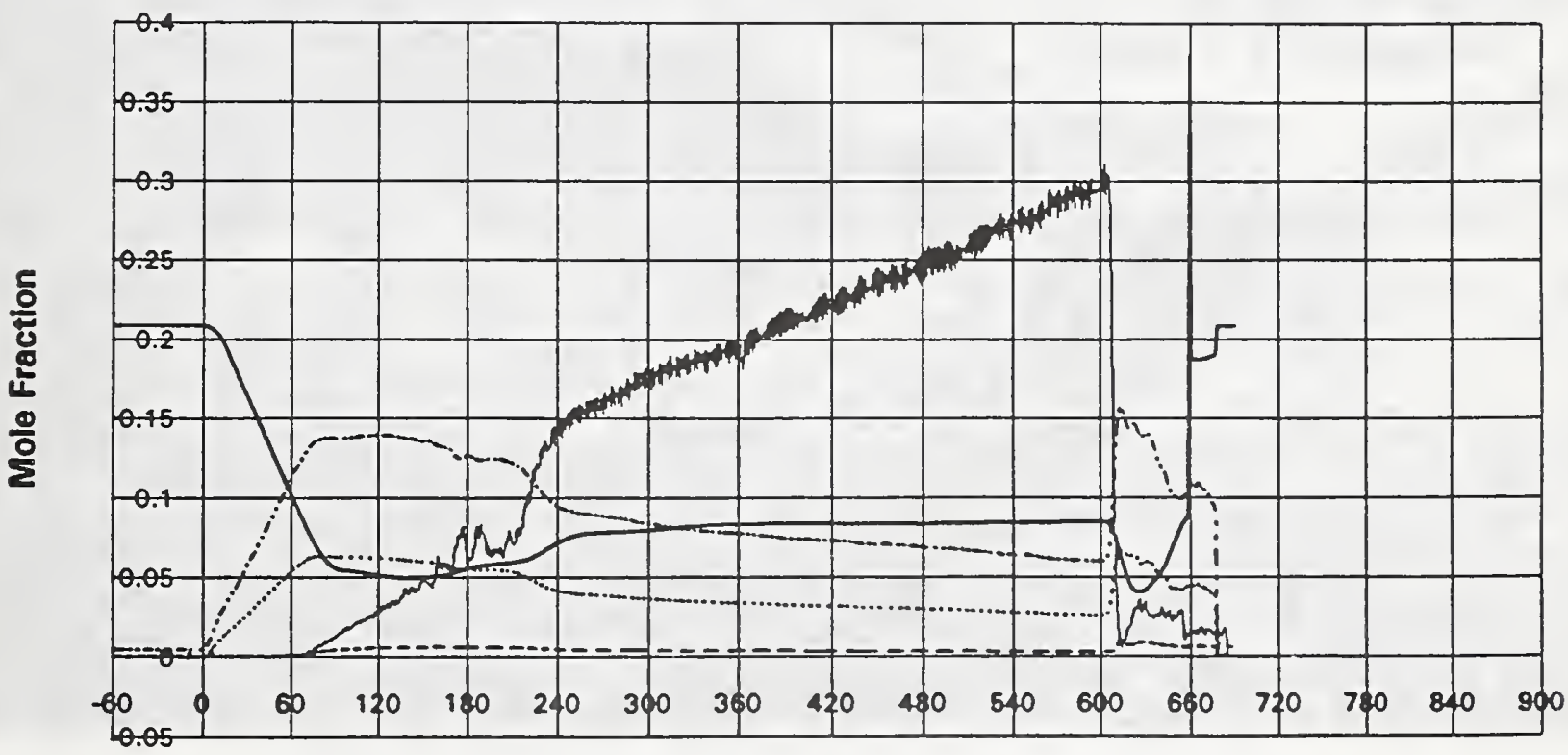

Time (sec)

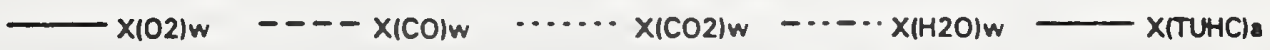

Figure 3, Typical measured upper layer gas species $\left(\mathrm{O}_{2}, \mathrm{CO}, \mathrm{CO}_{2}, \mathrm{H}_{2} \mathrm{O}\right.$, and $\left.\mathrm{HC}\right)$ histories prior to the rich early ignition backdraft at $604 \mathrm{~s}$. 


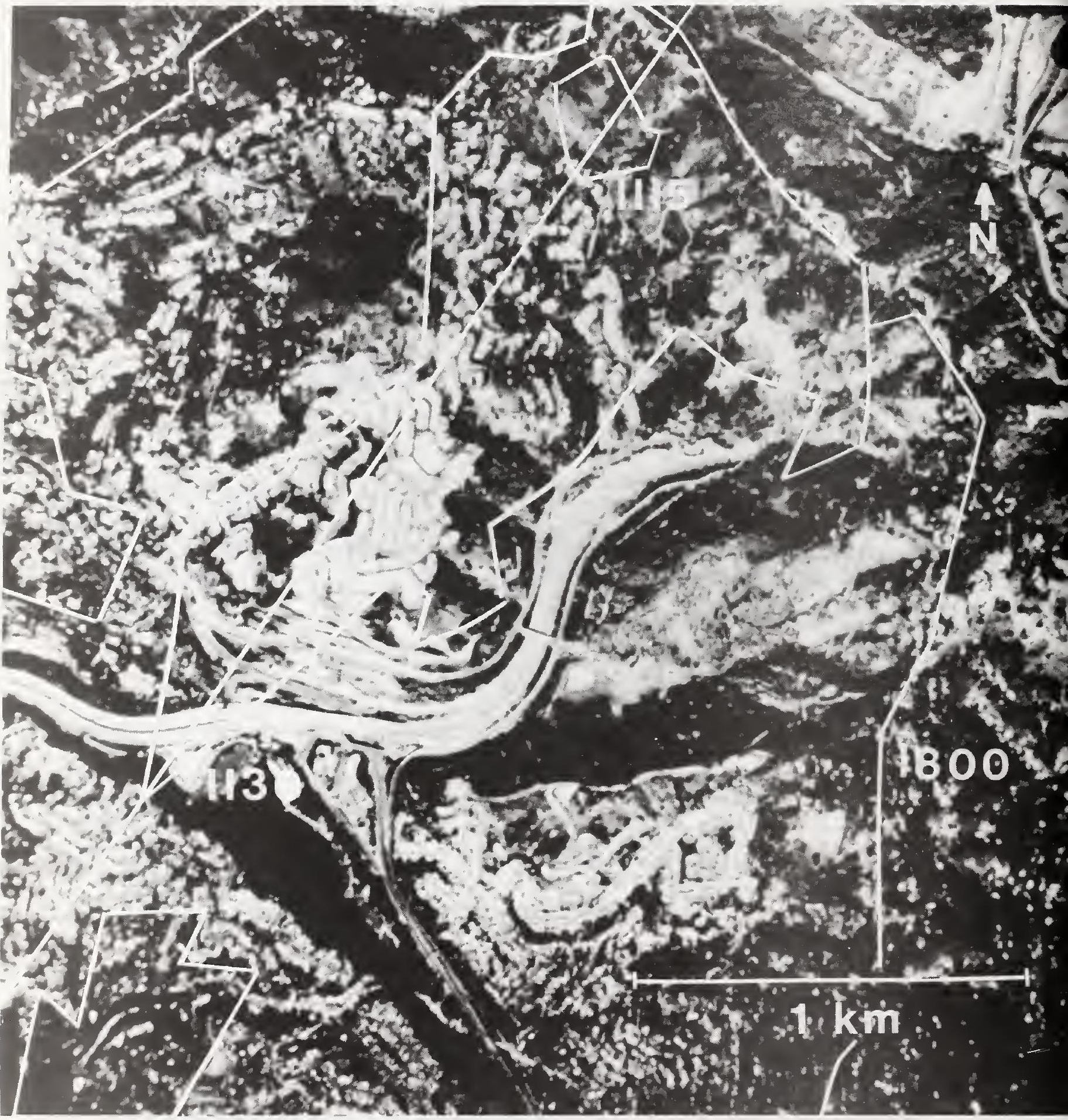

Fig. 1. This infrared NASA photo shows most of the burned area enclosed within the 1800 PDT contour. Highways 24 and 13 intersect near the center of the photo at $37^{\circ} 50^{\prime} 55^{\prime \prime} \mathrm{N}$ and $122^{\circ} 13^{\prime} 35^{\prime \prime} \mathrm{W}$. The wind vector at 1100 PDT on 20 October 1991 is indicated by the diagonal arrow. The outer boundaries of ignited areas at 1115 and 1130 PDT are enclosed by the labeled contours. 


\section{BUILDING AND FIRE RESEARCH LABORATORY \\ FIRE RESEARCH PROGRAM \\ PRIORITY PROJECT - FY93}

LARGE SCALE TEST FACILITY

\section{Professional Personnel}

Emil Braun, Physicist

\section{Project Objective}

To perform large scale fire tests and provide data to support other fire research projects. To apply, refine, and develop methods and equipment that contribute to the successful conduct of large scale fire tests. To develop plans for the expansion and modernization of the facility.

\section{$\underline{\text { Scope }}$}

Improve the utilization of the current facility, upgrade existing hardware, develop calibration techniques for primary fire test equipment, and introduce new measurement techniques to measure critical fire parameters. Development of a laboratory for the calibration and repair of measurement tools such as heat flux meters, pressure transducers, gas analyzers, etc. Provide a testbed for the evaluation of new measurement equipment, such as the Open Path FTIR, and new developments in computer fire modeling, such as model verification tests for HAZARD, wind aided plume flow, etc. Investigate and measure new fire phenomena in a large scale environment.

\section{Technical Accomplishments}

Activities in FY 1993 consisted of:

- the redesign of the exhaust system of the furniture calorimeter and the initiation of an investigation into the alteration of the hood shape as it may affect the upper range of the calorimeter;

- the removal of the old floor/wall furnace to accommodate large scale plume experiments planned for FY 1994;

- the introduction of new data acquisition equipment;

- the development of a master plan for the expansion of the large scale fire test facility. The expanded facility, figures 1 and 2, will result in an expanded testing range for model verification and the investigation of large scale fire phenomena. The expanded facility is projected to consist of a high bay test facility approximately $22 \mathrm{~m}$ high and $60 \mathrm{~m}$ by $50 \mathrm{~m}$ construction area. The facility will include a new shops area as well as offices and small scale test laboratories. Currently planned for the new facility are a new fire wind tunnel and a multi-story corridor/stair tower facility.

\section{$\underline{\text { Publications }}$}

Cooper, L.Y., Guidelines for the Design of a furniture calorimeter hood and exhaust, NISTIR, in review. 


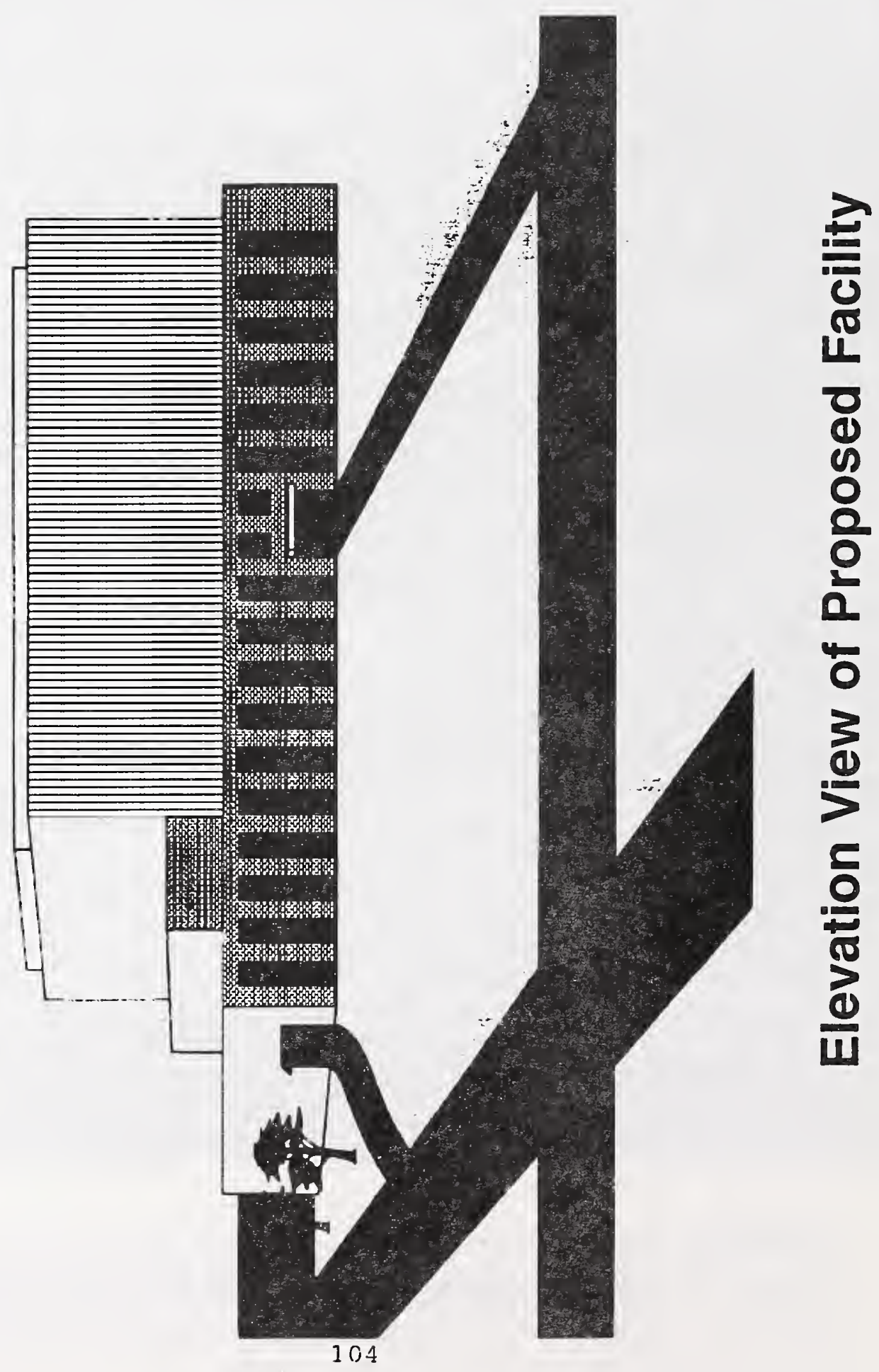




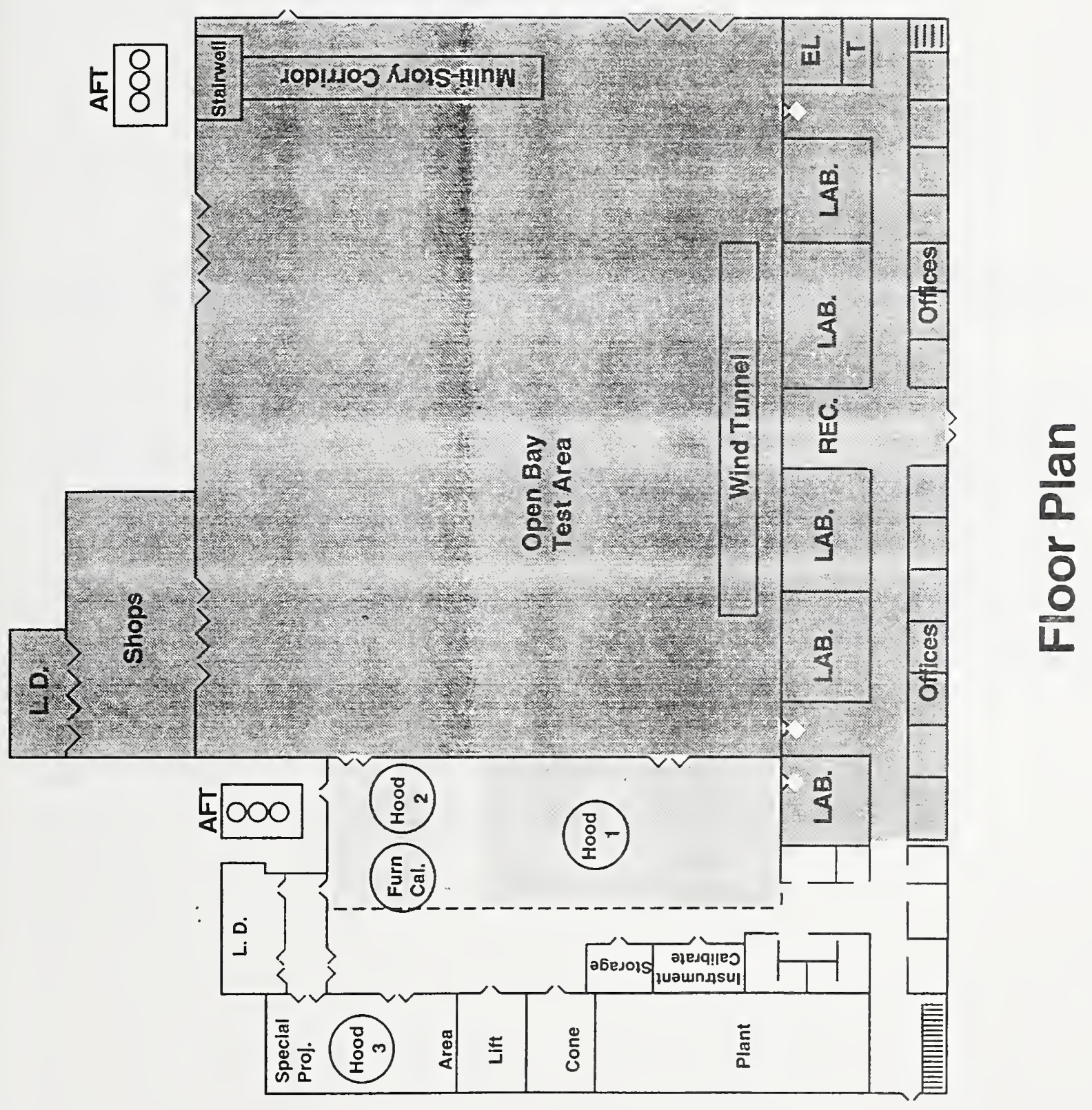





\section{BUILIIN(; ANI) FIRE; RESEARCII LABORATORY \\ FIRE RESEARCII PROGRAM \\ O'TIILR AGENCY PRO.JECT - FY93}

OFFICE BUIL.DING FIRE RESEARCII I'ROGRAM

Funding Agency: $\quad$ U.S. General Services Administration

Professional Staff: $\quad$ Danicl Madrzykowski, Project Leader

Robert Vettori, Fire Protection Engineer

\section{Project Objective:}

Quantify the impact of large fires on buildings and their occupants, and investigate the use of current technology/resources for mitigating the hazards.

\section{Technical Accomplishments:}

Specific tasks currently being addressed by this program are 1) to analyze smoke flows down a corridor with and without sprinkler intervention and 2) to investigate the extent that materials or geometry effect the fire performance of systems furniture.

If the fire can not be suppressed in the room of origin, the impact of the smoke flow in the corridor (means of egress) with and without sprinkler intervention needs to be quantified. The pre-flashover condition series of fire tests in the U.S. Coast Guard's full scale corridor fire test facility have been completed. Smoke flows in the $37.5 \mathrm{~m}$ long corridor have been measured for fires with heat release rates ranging from 450 to $1200 \mathrm{~kW}$. The post-flashover series of fire tests will be completed by 10/93. Results from these tests will be compared with predictions from the existing corridor model in FPETOOL and the Harwell FLOW 3D field model.

Due to the wide spread use of systems furniture in open office plan space, the potential fire hazard of these furnishings in "as used" situations needs to be quantified. A combination of laboratory scale and full scale tests will be used to quantify the fire development in open office plan scenarios and address means of mitigating the potential fire hazard. Results of the tests will be compared with predictive methods for determining peak heat release rates and flame spread rates. The testing will begin in FY 94.

\section{Reports and Publications:}

New Project

\section{Related Grants:}

None 



\section{BUILDING AND FIRE RESEARCH LABORATORY \\ FIRE RESEARCH PROGRAM \\ OTHER AGENCY PROJECT - FY93}

\section{SMOKE PLUME TRAJECTORY FROM IN SITU BURNING OF CRUDE OIL IN ALASKA}

Funding Agency: Alaska Department of Environmental Conservation (ADEC)

Professional Staff: Kevin McGrattan (project leader)

Anthony Putorti

William Twilley

Dave Evans

Howard Baum

Ronald Rehm (CAML)

$\underline{\text { Project Objective }}$

Provide information about the expected trajectory of smoke plumes from the use of in situ burning as a response method for oil spills in Alaska.

Technical Accomplishments

Measurements of the burning rate, smoke yield and particulate size distribution from the burning of two varieties of Alaskan crude oil (Cook Inlet and North Slope) were made. The tests consisted of burning layers of oil in a 1.2 meter diameter pan in the large scale fire testing facility at NIST. The laboratory measurements were extrapolated to the expected size of fires at operational scale based on previous reported results from laboratory and mesoscale experiments. This information was then used as input for the Large Eddy Simulation model of smoke transport, which solves the conservation equations of mass, momentum and energy, predicting the downwind trajectory and concentration of particulate matter and other combustion products.

\section{Publications}

Walton, W.D., et al. "In Situ Burning of Oil Spills: Mesoscale Experiments and Analysis", Proceedings of the Sixteenth Arctic and Marine Oil Spill Program Technical Seminar, June 7-9, 1993, Calgary, Alberta, pp. 679-734.

NISTIR, to be completed. 



\section{BUILDING AND FIRE RESEARCH LABORATORY \\ FIRE RESEARCH PROGRAM \\ NATIONAL INSTITUTE OF STANDARDS AND TECHNOLOGY \\ Grantee Project FY93}

Institution:

Grant No:

Grant Title:

Principal Investigator:

Qther Personnel:

NIST Scientific Officer:

\author{
Purdue University
}

60NANB2D1291

A Study of Entrainment and Flow Patterns in Pool Fires Using Particle Imaging Velocimetry

\author{
Professor J. P. Gore \\ School of Mechanical Engineering \\ Purdue University \\ West Lafayette, IN 47907
}

Mr. X. C. Zhou, Doctoral Student

Dr. Y. Sivathanu, Research Associate

Drs. Takashi Kashiwagi and Anthony Hamins

\section{Technical Abstract:}

Introduction: Entrainment of ambient air by a fire determines the flame size, shape and the composition of the fire products that are transported to the upper layer and to surrounding passages. The availability of air also determines the smoke and $\mathrm{CO}$ production, thermal radiation and fuel depletion. The existing experimental data involving entrainment have been obtained with three different techniques and are not in agreement with each other. The existing entrainment correlations are based on data obtained using gas fueled fires and have generally not been compared to data from liquid fueled fires. The present research is aimed at the application of laser Doppler Velocimetry (LDV) and Particle Imaging Velocimetry (PIV) to entrainment measurements. Measurements using a conventional technique (involving sampling of exhaust products captured in a hood) are also completed simultaneously to compare the results. The resulting data are expected to delineate the effects of fuel type, fire size, combustion efficiency and radiative heat loss fractions on the entrainment rates and lead to an improved understanding of the flow and flame structure.

Entrainment is defined as the mass flow rate of air that is set in motion including the portions that are engulfed by the flame and mixed, heated and possibly chemically reacted. The total entrainment as defined above is important in determining the properties of the upper layer or of the total flow leaving a fire. The portion that participates in combustion is important in determining the flame length and size as well as degree of ventilation. Defining, delineating and measuring these portions is important for practical applications. However, the concept has limitations in that a well-defined separation between the portions can be obtained only with the definition of the complete flow field.

Operating Conditions: A $7.1 \mathrm{~cm}$ toluene pool fire studied previously in this laboratory was used for the first set of entrainment measurements. The burner involved a constant $2 \mathrm{~mm}$ height of the liquid fuel below the rim maintained by supplying liquid fuel at a rate of 83 $\mathrm{mg} / \mathrm{s}$ and adjusting the jacket cooling water flow to control the burning rate. Recognizing the sensitivity of the entrainment flows to ambient disturbances, floor size and height of liquid below the pool edge, these variables were controlled as much as possible. The 
exhaust damper and fan motor control were set to obtain a fixed lower layer height of 73 $\mathrm{cm}$. The upper layer constituted approximately $100 \mathrm{~cm}$ of the space above the pool under this condition. The fire was enclosed in a $100 \times 100 \times 300 \mathrm{~cm}$ Plexiglas enclosure with 150 $\mathrm{cm}$ gap at the base to admit room air seeded with smoke from six incense sticks per $100 \mathrm{~cm}$ mounted at the bottom. The background velocity caused by the incense sticks was measured to be negligible compared to the entrainment velocity.

LDV Measurements: The instrument consisted of a TSI dual beam forward scattered arrangement with a frequency shifter and a burst processor. Approximately $200 \mathrm{~mW}$ power from a $4 \mathrm{~W}$ Ar-ion laser was used to obtain the optimum Doppler bursts with the smoke seed. The data rates were between 100 to $1000 \mathrm{~Hz}$. Velocities in the radial direction (flowing inwards towards the fire center) were measured at $11.5 \mathrm{~cm}$ from the axis. This location is always in the ambient air. Therefore, if the axial velocity at this location is small, the ambient density multiplied by the radial velocity is equal to the entrainment mass flux.

Measurements using Species Sampling: A hood of $45 \mathrm{~cm}$ diameter and $45 \mathrm{~cm}$ depth was placed at $34 \mathrm{~cm}$ from the pool surface to utilize the conventional entrainment measurement method. It was observed that the burning rate increased by approximately $20 \%$ due to the placement of the hood. In order to obtain comparable data, the flow rate of cooling water was increased to maintain the burning rate. LDV measurements in the presence of the hood showed substantial reduction compared to the value without the hood. These observations suggest the intrusive nature of the measurement technique. A quartz microprobe was used to sample the species in the hood. The carbon dioxide concentrations were obtained using a gas chromatograph and soot and CO concentrations were estimated from the generation factors given by Faeth and coworkers in order to estimate the entrainment.

Results and Discussion: Figure 1 shows a verification of the present entrainment measurement techniques using measurements of velocity around an air jet. The entrained mass flow rate is plotted as a function of normalized distance from the injector exit. Beyond 10 diameters from the injector exit the measurements are in very good agreement with the Ricou and Spalding correlation.

Figure 2 shows measurements of mean and RMS entrainment velocity for the toluene pool fire. The data show that the radial velocity is highest near the $51 \mathrm{~cm}$ floor mounted flush with the pool edge. The mean velocity decreases with height. At all heights, a large fluctuating velocity component is observed. Figure 3 shows the probability density function of entrainment velocity at three heights above the pool. Large RMS and both positive and negative radial velocities are observed indicating the complex flow field near the fire.

Figure 4 shows the mass flux of air entrained into the flow induced by the fire based on the radial velocity measurements at $11.5 \mathrm{~cm}$ compared to data from the literature and the correlation of Delichatsios. An estimated combustion efficiency of $85 \%$ and a radiative loss fraction of $30 \%$ were used in plotting the present data. As noted by Delichatsios, the correlation has not been tested for a range of these parameters. It should also be emphasized that the measurement of entrained mass flow rate may depend on the radius selected for the velocity data. According to the basic definition of entrainment, these measurements must be carried out at a point where axial velocity component is negligible. Such a location is expected to be far away from the fire axis, hence a relatively large radius was selected. Present measurements based on the method of Zukoski are 20\% lower than the LDV data at $Z / D=4.8$. If the $51 \mathrm{~cm}$ floor is remover the entrained mass flow is reduced by a factor of two. 

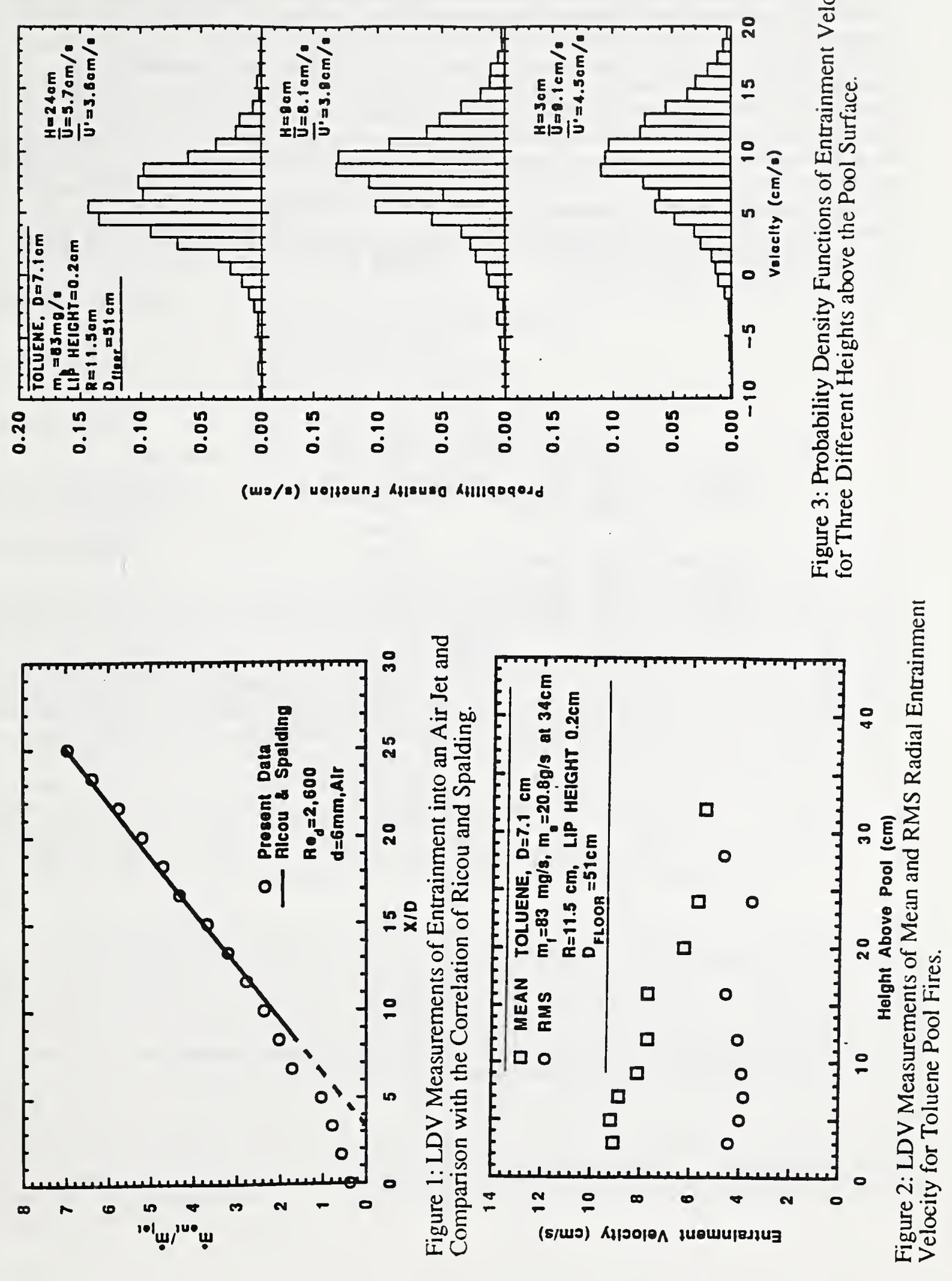
At lower heights, existing data show much lower entrainment mass flow than the present measurement. The selection of a large radius for the present radial velocity data (consistent with the definition of entrainment) may be one of the reasons for this discrepancy. Interference caused by the hood to the entrainment process is being examined as a possible cause of the differences between the present data and those of Cetegen and coworkers and Beyler. The early measurements of Thomas were at a much closer relative location to a very large pool fire. The data of Weckman were obtained from axial velocity measurements and are expected to be clipped at radii away from the fire edge. However, it must be recognized that the present pool is much smaller than those studied by the previous investigators and an entirely different measurement technique is being utilized. The present approach is to delineate the reasons for the differences in the data as well as map the entire flow field around the fire to separate between air set in motion by the fire and the air that is entrained by the fire. PIV has been procured and tested in this laboratory to accomplish the flow field mapping simultaneously.

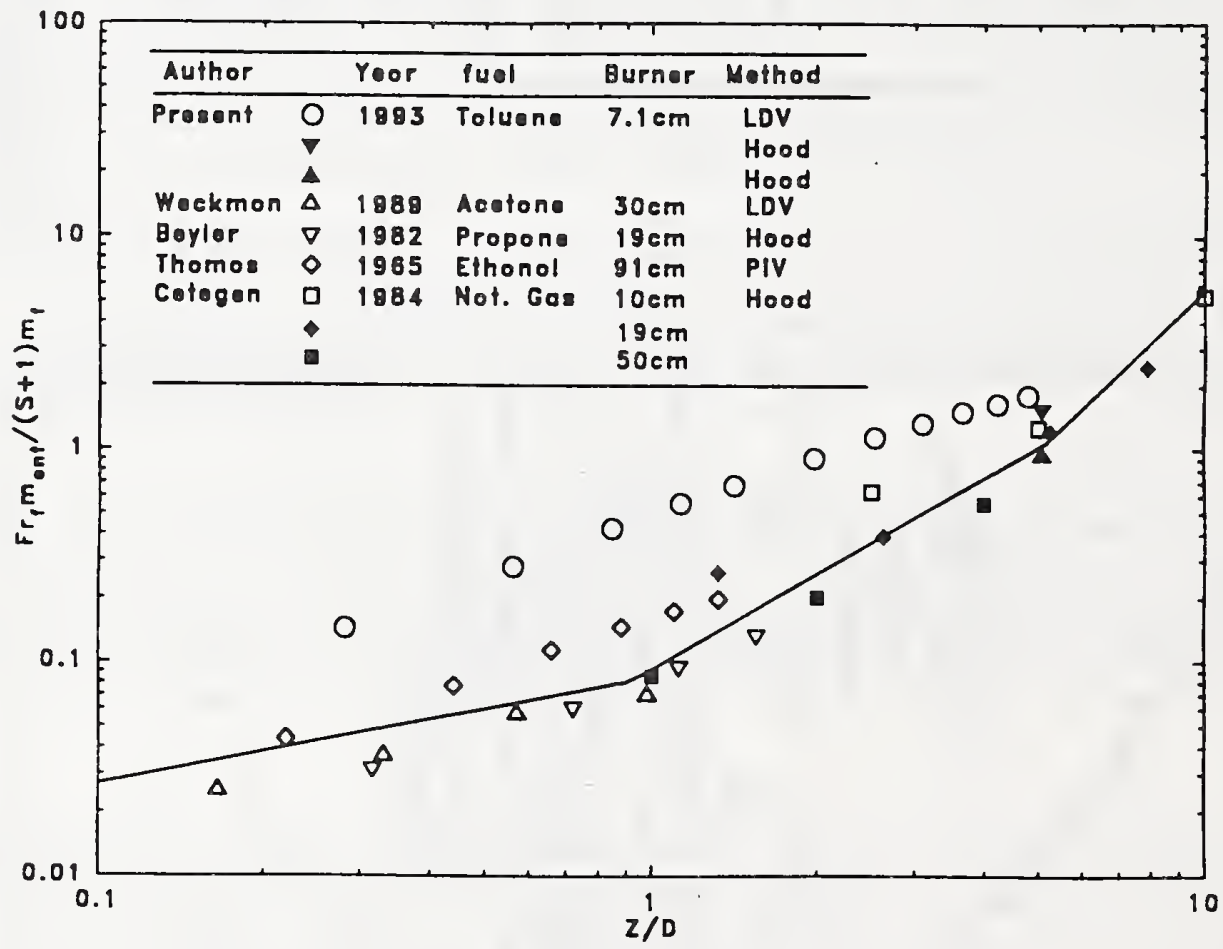

Figure 4: Entrainment Mass Flow Rate and Preliminary Comparison with Existing Data and Correlations. 


\section{BUILDING AND FIRE RESEARCH LABORATORY}

FIRE RESEARCH PROGRAM

\section{NATIONAL INSTITUTE OF STANDARDS AND TECHNOLOGY \\ Grantee Project FY93}

Institution:

Grant No:

Grant Title:

Principal Investigator:

Qther Personnel

NIST Scientific Officer:
Purdue University

60NANB1D1172

A Study of Simulated Oil Well Blowout Fires and Flares

Professor J. P. Gore

School of Mechanical Engineering

Purdue University

West Lafayette, IN 47907

Mr. P. Dutta, Doctoral Student

Dr. Y. Sivathanu, Research Associate

Dr. David D. Evans

\section{Technical Abstract:}

Introduction: High liquid loading ( 85 to $95 \%$ liquid by mass) spray fires may occur following accidental ruptures of flammable liquid storage tanks and pipe lines as well as oil well blowouts. The resulting industrial fires can be costly in terms of downtime, lost production, hazard to personnel, and litigation. The mechanisms of stabilization of such fires as well as their global properties remain poorly understood and correlated. One of the reasons for this difficulty was that controlled laboratory experiments with high liquid loading stable flames could not be established. An effervescent atomizer burner has been developed in this project to overcome this difficulty. The atomizer relies on the process of expansion of small dissolved gaseous bubbles upon depressurization of a two phase stream resulting in fine atomization. The resulting spray can be evaporated and burnt using a pilot flame in an axi-symmetric jet configuration at laboratory scales. In the present work, lengths, radiative heat flux, temperature and transmittance properties of the high liquid loading jet flames were studied. Comparison of the flame length data with existing correlations show important two phase flow effects that need further consideration.

(1) Operating Conditions: Table 1 shows the operating conditions for the flames studied during the present investigation. The mass flow rate of the atomizing methane was varied between 5 and $20 \%$ of the mass flow rate of the crude oil. The hydrogen flow used for flame stabilization did not affect the atomization quality significantly. The heat release rates for the flames varied between 9 and $21 \mathrm{~kW}$ based on nominal heating values for the three fuels. The Reynolds number characteristic of the jet can be based on the external orifice or the atomizing port. The two different selections lead to an order of magnitude difference in the exit Froude numbers. The appropriate Froude number in terms of buoyancy Vs momentum domination is currently unknown. The atomization quality produced by the present burner was measured in terms of Sauter Mean Diameters (SMD) using a Malvern instrument. Figure 1 shows the probability in terms of percent particles in a band as a function of diameter for three liquid loadings with a fixed methane to liquid ratio of 5\%. The SMD appears to increase initially with liquid loading but is almost constant at 46 microns for the two larger flames. 
(2) Radiative Heat Loss Fractions: The radiative heat flux from the fires to a surrounding cylindrical enclosure was measured using non-dimensional groups that are consistent with the single point method established previously in this grant. Figure 2 shows the data from the eight crude oil + methane flames with fixed hydrogen flow rate. The data are observed to collapse on one curve within the measurement accuracy. Thus the single point heat flux measurement technique of Sivathanu and Gore is seen to be applicable to the two phase fires. The total radiative heat loss fractions summarized in Table 1 are in the range 10 to 20\%. These are relatively low suggesting that the flames may be highly forced. However, direct velocity measurements are necessary to understand this further.

Figure 3 shows the flame height normalized by the external orifice diameter plotted as a function of heat release rate for the first seven flames in Table 1. As seen in Fig. 3, the flames are taller for lower methane loading. For a methane loading of 5\%, the flame height increases with heat release rates. This is probably because of the increased evaporation length needed due to larger drops as well as higher liquid loading. The height of buoyant jet flames also increases with increasing heat release rates due to the reduction in relative rate of entrainment due to reduced influence of buoyancy. Depending up on whether the present flames are in the forced or the buoyant regime, the appropriate mechanisms would contribute to the flame height variation. Measurements of velocities and evaporation lengths are planned to understand this further.

Figure 3 shows that for a fixed heat release rate of $14 \mathrm{~kW}$, the flame height normalized by the external orifice diameter decreases with increasing methane to crude oil mass flow rate ratio. This is in agreement with smaller drops created by larger atomizing gas flow rate leading to shorter evaporation length. It also suggests that the flame length variation with heat release rates is at least partly due to two-phase flow effects unique to spray flames.

Flame heights based on the correlation of Hustad and Sonju are also plotted in Fig. 3. As can be seen from the figure, a systematic variation of 20 to $40 \%$ exists for the different conditions. The Froude number has not been modified by the two phase correction suggested by Hustad and Sonju. If used, it would show even higher differences between the correlation and the measurements. The differences in the trend of the data and the correlation suggest that two-phase effects are not accounted for by the present correlation.

Measurements of emission temperature and transmittance of soot particles at $632 \mathrm{~nm}$ were measured for the three $14 \mathrm{~kW}$ flame as function of axial distance for diametric paths to understand the radiative heat flux behavior. Figure 4 shows these data. For the highest methane loading the peak temperature is approximately $2200 \mathrm{~K}$ near the injector exit and reduces to $2150 \mathrm{~K}$ at approximately $x / d=70$ before decreasing beyond the flame tip. The small decrease in the temperature is due to the relatively small heat loss. The high peak temperatures represent almost complete combustion of the fuel. With increasing liquid loading the peak temperatures decrease only slightly near the burner exit. For the lowest methane loading the temperatures decrease by approximately $300 \mathrm{~K}$ with axial distance primarily due to radiative heat loss. Naturally, soot oxidation reactions are slowed down due to this decrease in temperature. Thus the highest liquid loading flame shows emission due to soot until $\mathrm{x} / \mathrm{d}=120$. The reduction in temperature nullifies some of the expected increase in radiant output with higher liquid loading.

The increase in flame emissivity characterized by the decrease in transmittance of the diametric path is also shown in Fig.4. The transmittance of the highest liquid loading flame decreases to approximately 0.6 while that for the intermediate and low liquid loading cases is much higher. The overall decrease in transmittance causes the total radiant energy for the high liquid loading flame to increase from $10.2 \%$ to $21.4 \%$ in spite of the reduction in temperature. The high 

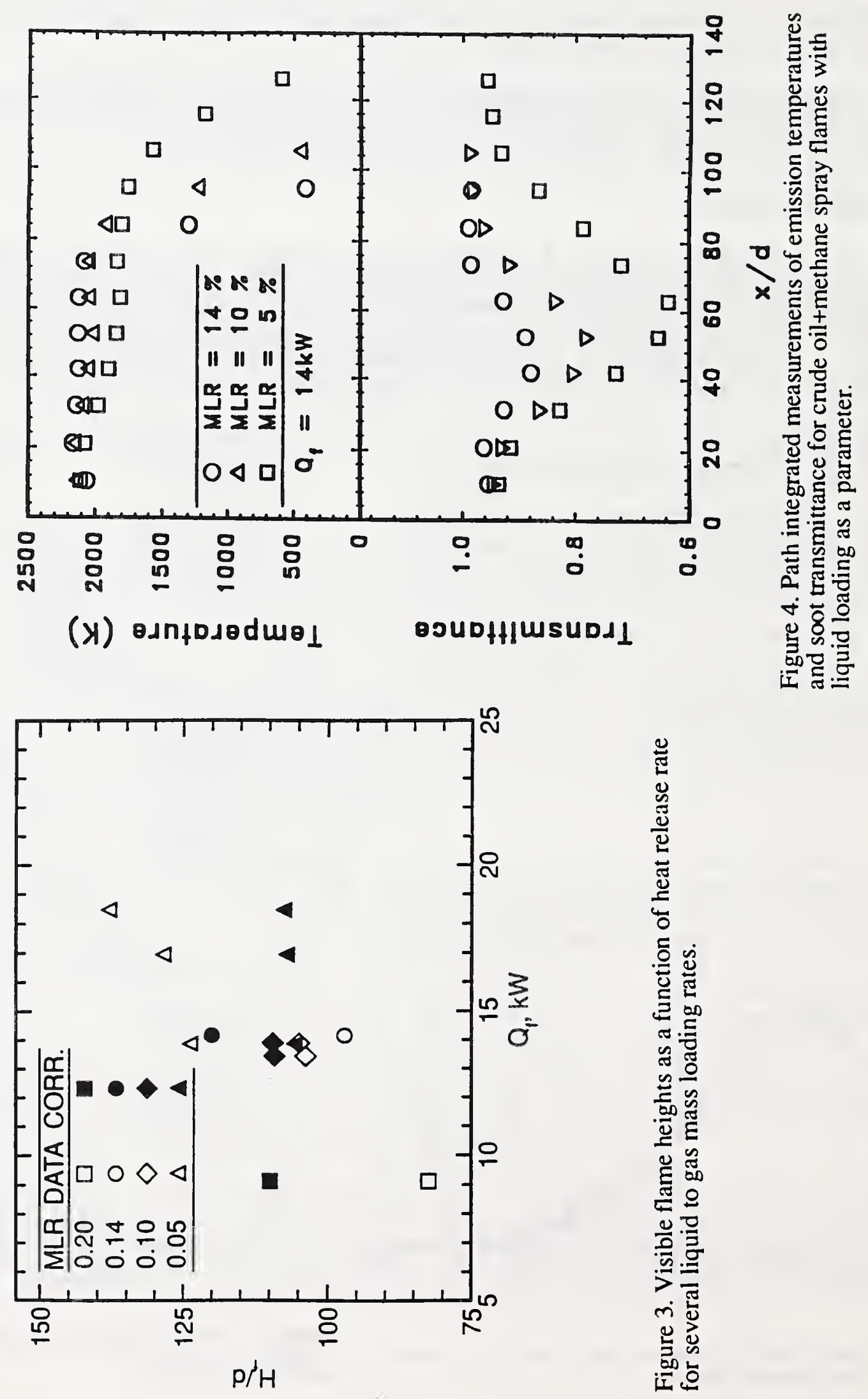


\title{
BUILDING AND FIRE RESEARCH LABORATORY \\ FIRE RESEARCH PROGRAM \\ PRIORITY PROJECT - FY93
}

\section{WIND BLOWN LARGE FIRES}

\author{
Professional Staff: $\quad$ David D. Evans, Project Leader \\ William Walton, Fire Protection Engineer \\ Howard Baum, NIST Fellow \\ Kevin McGrattan, Mathematician \\ Daniel Madrzykowski, Fire Protection Engineer
}

\section{Project Objective:}

Develop measurement and analytical methods needed to characterize large fires capable of threatening the environment or integrity of urban building complexes, industrial and commercial facilities, and transportation systems by 1997 .

\section{Scope:}

This project is directed at measurement and prediction of large wind blown fires that occur as the result of industrial accidents and natural disasters. Research effort is directed at the development of nonintrusive means to assess major burning characteristics of large fires including geometry, motion, heat release rate, and emissions. The fate of wind blown combustion products in the near fire region that may extend downwind $100 \mathrm{~km}$ are included in this study of fire effects.

\section{Technical Accomplishment:}

A new area for research at BFRL dealing with open fires in the environment was proposed as a $\$ 1.5$ million NIST FY 1995 initiative. This initiative addressed the technical problems of assessing large fire situtions from industrial accidents or natural fire diasters and predicting the major effects including the impact of the smoke plume downwind of the fire. The proposal focused on developing measurement methods capable of quantifing fire conditions and the actions of fire fighter over broad areas and the development of high resolution short range forcasting methods for the smoke plume trajectory. This program would enable the development of a high quality information system for response decisions that would provide for efficient use of limited resouces during large fire emergencies. The initiative was withdrawn to promote a research program clearly focused on building fires.

The dynamics of wind blown smoke plumes was studied both experimentally and through computational fluid dynamic based modeling. Existing corridor fire tests facilities are being modified to construct a modest $12 \mathrm{~m}$ long wind tunnel to assess wind blown smoke plume trajectories in a series of tests to be conducted in September, 1993. A Fourier Transform Infrared Spectrometer (FTIR) will be used in conjuction with traditional point measurements of $\mathrm{CO}_{2}$ using non-dispersive IR instruments to assess the concentrations of $\mathrm{CO}_{2}$ in a wind blown smoke plume. In these experiments the use of FTIR in both the transmission and emission mode will be explored. The experiments have been planned in part using a CFD model of the wind blown smoke plume. Measurements from the experiments will in turn be used to verify parts of the model. 
The numerical model is a modified version of the Large Eddy Simulation (LES) plume trajectory model which consists of solving the conservation equations of mass, momentum and energy which govern the convective transport of smoke and particulate matter from a large outdoor fire. The modifications for the tunnel geometry include a no-flux rather than open boundary condition at the walls and a constant background temperature and density profile rather than a stratified atmosphere. Shown in figure 1 is a typical simulation of the modified model. A fire in the lower left produces smoke and hot gases which are hlown by a steady wind through the tunnel. The spatial resolution of these calculations is on the order of ten millimeters, and the Reynolds number assumed in the calculation is on the order of $10^{4}$. It is believed that this resolution is sufficient to simulate the large scale mixing and transport, and therefore no empirical turbulence model is included. Calculated results for the plume trajectory can be used to assess concentration of combustion products in the ambient flow. These results can be compared directly to experiments on a time averaged hasis.

\section{Publications:}

"Engineering Analysis of the Kuwait Oil Fires," D. Madrzykowski, D.D. Evans, G.A. Haynes, Large Fires: Causes and Consequences, SFPE Engineering Seminars, November 16-18, 1992, Dallas, Texas, SFPE, Boston, MA., pp.40-47, (1992)

\section{Related Grants:}

Numerical Modeling of Plume Dispersal and Smoke Deposition from Large Scale Fires, Ahmed F. Ghoniem, Massachusetts Institute of Technology.

An Investigation of Oil and Gas Well Fires and Flares, J. P. Gore, Purdue University.

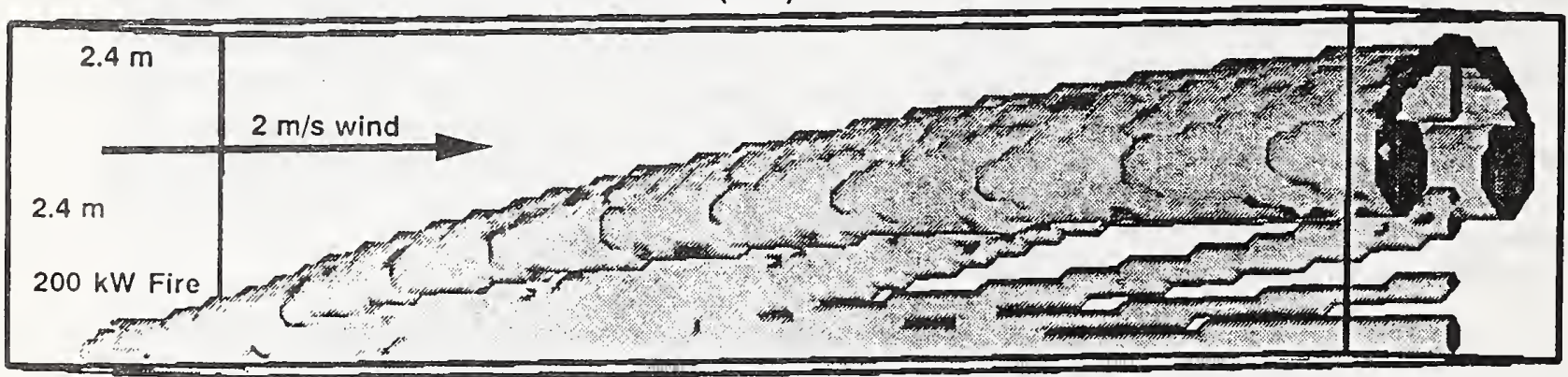

Figure I Calculated wind blown smoke plume in the NIST tunnel geometry 
B. Fire Safety of Products and Materials

\section{B1. Materials Combustion}





\section{BUILDING AND FIRE RESEARCH LABORATORY \\ FIRE RESEARCH PROGRAM \\ PRIORITY PROJECT - FY93}

BURNING RATE OF MATERIALS

\section{Professional Personnel}

Takashi Kashiwagi, Group Leader

Anthony Hamins, Mechanical Engineer

Kenneth Steckler. Physicist

Mun Choi, Post-Doctoral Associate

\section{Principal Objectives}

To develop the capability to predict the hurning rates of thermoplastic and char-forming polymers based on improved understanding of the physics and chemistry of gasification and the energy feedhack from a pool flame to the fuel surface by September, 1995.

\section{$\underline{\text { Scope }}$}

In order to accurately model the burning rates of polymers, both gasification rates and heat feedback rates from a flame to the fuel surface must he understood. Polymer gasification consists of three parts: thermal clegradation chemistry, heat transfer and mass transfer processes in the polymer. Through a detailed study of each major component in the gasification process, a global model consisting of simplified sub-models will be developed. Flame heat transfer processes including heat feedback to the fuel surface are studied in a pool fire configuration. Pure liquid fuels are used to simulate the burning of polymer degradation products.

\section{Technical Accomplishments}

\section{Polymer Gasification Rate Model}

Condensed phase processes were moleled using one-dimensional transient numerical computations which assume that the solid is opaque, has finite thickness, temperature-dependent thermal properties, and that the heat of vaporization, and the vaporization temperature can be specitied and are constant. The condensed-phase molels -- one for the preheating period, the other for the gasification period -- are heat conduction equations without and with a moving houndary, respectively. The governing equations are the same as those used in previous work $[1,2]$ except their range has been changed from semi-infinite to finite and the unexposed-surface boundary is now adiabatic.

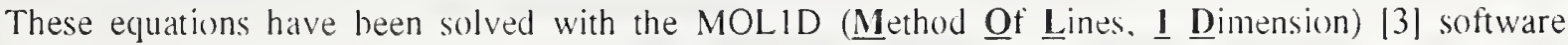
package. MOLID is a PDE solver which provides minimal and cumbersome access to intermediate results. Recently, we hegan working with MATHEMATICA [4], a very extensive mathematics software package, which includes a simultaneous ODE solver. Working with $\mathrm{H}$. Baum, we solved several PDE preheating and gasitication problems hy expressing the spatial derivatives at $\mathrm{N}$ grid nodes as finite differences and solved the resulting $N$ simultaneous ODEs (in which time was the independent variable) using MATHEMATICA. Intermediate results are readily available with this latter approach. 
Simultaneous local optical pyrometry and laser absorption were used to measure the temperature and soot volume frations ( $f_{\text {vil }}$, hated on absorption and $f_{\text {we }}$ based on emission) in rich premixed hydrocarbon flames which provided a homogeneous environment for the experiments. A significant discrepancy between $f_{v i t}$ and $f_{v i}$ was determined as shown in Fig. 1. Measurements showed that scattering by soot particles and absorption by large molecules did not significantly contribute to the discrepancy, but that source wavelength and the values used for the indices of refraction were important. An independent measurement of soot volume fractions was obtained by iso-kinetic sampling. This work was undertaken (1) validate the technique for use in heat transfer studies of pool tires and to improve the gas phase model.

\section{Verification of Current Burning-Rate Model}

The combustion of a horizontal slab of polymethylmethacrylate (PMMA), exposed to an external radiant source, was modeled in terms of two coupled submodels which simulate gas and condensed phase processes. A simple analytic stealy-state global model /1], which was developed during an earlier phase of this project, was used to describe the gas phase processes while the condensed phase processes were modeled using the one-dimensional transient numerical computations described in (sec. 1.) In this case, the equations were solved with MOLID.

These particular condensed-phase models are limited in that they permit either a fixed surface boundary with a rising surface temperature (preheating) or a moving surfice with a constant surface temperature (gasification/hurning). These models do not allow simultaneous gasification and surface-temperature rise.

ligure 2 shows the experimental surfice-temperature history of a $0.30 \mathrm{~m}$ diameter. $12.7 \mathrm{~mm}$ thick, horizontal slah of P.MMA ats it was heated beneath radiant heating panels in the presence of a small ignitor. Note the rapid increase in temperature from the piloted-ignition temperature (about $565 \mathrm{~K}$ ) to the vaporization temperature $(673 \mathrm{~K})$ in the brief period following piloted ignition. Clearly a) the ignition temperature and vaporization temperature are not equal and b) simultaneous gasification and rapid temperalure change occurred during the transition between these two temperatures. Although the transition could not be modeled accurately by either of the condensed-phase options cited above. an approximate solution was obtained by continuing the preheating calculation (without gasification) using a higher ahsorbed heat flux that includes an approximate contribution from the flame that appears after piloted ignition. For the case at hand, the absorbed external flux of $21.4 \mathrm{~kW} / \mathrm{m}^{2}$ (the product of the incident external tlux and the surface absorptivity) was increased by $15.5 \mathrm{~kW} / \mathrm{m}^{2}$ to accoune for the presence of a tlame fueled at the rate of $0.01 \mathrm{~kg} / \mathrm{s}-\mathrm{m}^{2}$. This gasification rate was judged to be the average mass-loss rate observed during the experiment during the transition period. Given this gatsification rate. the gass-phase model predicted that the resulting flame would add $15.5 \mathrm{~kW} / \mathrm{m}^{2}$ to the allsorbed flux.

When the cialculated surfice temperature reached the vaporization temperature, the condensed-phase simulation was switched to the moving-surface constant-surface-temperature model, which then interacted with the analytic gas-phase sub-model to simulate the burning process.

Figures 2 and 3 present the experimental and calculated surface temperatures and gasification rates, respectively. The theoretical curve in Fig. 3 shows the onset of gasification/burning at 176.5 seconds. The solution was unstable during the first few seconds but stabilized quickly thereafter. The rapid increase of the theoretical curve after about 600 seconds is the result of a decrease of conduction from 
the surface as the slab hecomes thinner. This sharp increase is not mitigated in the calculation hy the back-face heat losses (o a calcium silicate board that occurred in the experiment. The calculation terminated at 790 seconds when surface regression reduced the total number of computational nodes below 5 , the minimum required for solution by MOLID.

\section{References}

1. Hamins, A., Yang, J.C., and Kashiwagi, T., 1993, A Simple Global Model Predicting the Burning Rate of Liquid Pool Fires, submitted to Fire Safety Journal.

2. Steckler K.D. Kashiwagi, T., Baum, H.R., and Kanemaru, K.. Analytical Model for Transient Gasification of Noncharing Thermoplastic Materials. Fire Safety Science - Proceedlings of the Third International Symposium. 1991, pp. 895-904.

3. Hyman, J.M. . The NYU Report - The Method of Lines Solution of Partial Differential Equations, October, 1976, Los Alamos Scientifï Laboratory, Los Alamos, NM. (computer colle Revision No. 1, October 1978).

4. Woltram, S., MATHEMATICA: A System tor Doing Mathematics by Computer, Second Edition, Addison-Wesley, 1991.

\section{Recent Publications}

"An Experimental Investigation of the Pulsation Frequency of Flames," Hamins, A., Yang, J.C., and Kashiwagi. T., The Twenty-Fourth Symposium (International) on Combustion. 1992, pp). 1695-1702.

"Radiative Heat Feedback in a Toluene Pool Fire," Klassen, M., Gore, J.P., Sivathanu, Y.R., Hamins, A., and Kashiwagi, T. The Twenty-Fourth Symposium (International) on Combustion, 1992, pp. 17131719.

"Heat Feedhack to the Fuel Surtace in Pool Fires", Hamins, A., Klassen, M., Gore, J.P., Fischer, S.J. and Kashiwagi, T., submitted to Combust. Science \& Technology (1993).

"Simultaneous Optical Measurement of Soot Volume Fraction and Temperature". Choi, M. Y.. Hamins, A., and Kashiwagi, T., submitted to Combust. and Flame (1993).

\section{Related Giants:}

"The Behavior of Charring Materials in Simulated Fire Environments", Eric Suuberg. Brown University.

"A Study of Entrainment and Flow Patterns in P(o) Fires using Particle Imaging Velocimetry", J.P. Gore, Purdue University. 


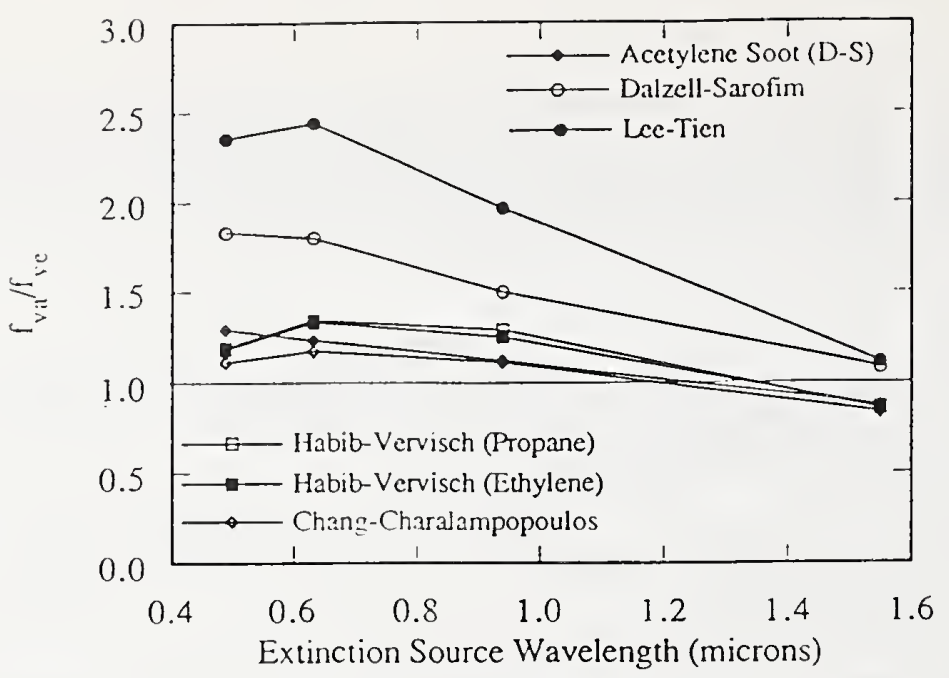

Figure $1 . f_{v a} / f_{v e}$ ratio in a homogeneous environment (premixed ethylene/air flame) as a function of source wavelength using various sets of ahsorption coefficients.

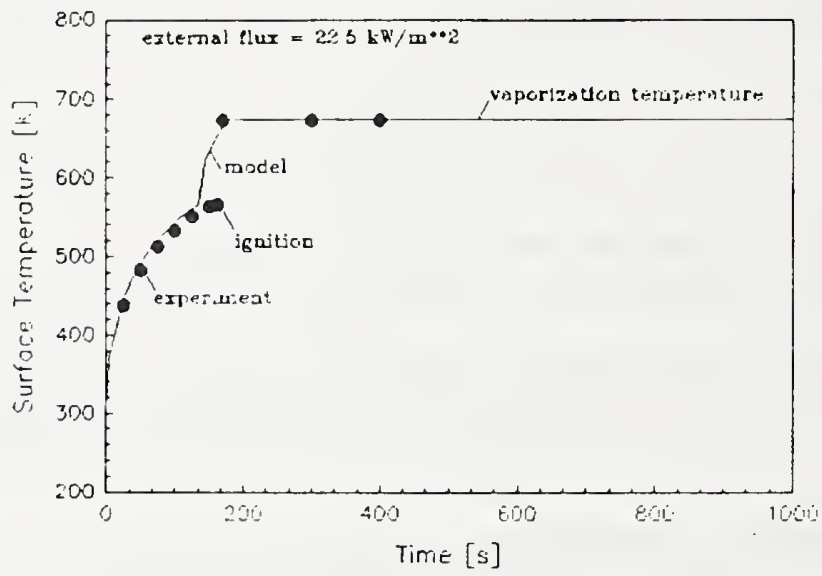

Figure 2. Surface temperature of PMMA while prehedting and burning under $22.5 \mathrm{~kW} / \mathrm{m}^{2}$ incident external heat tlux.

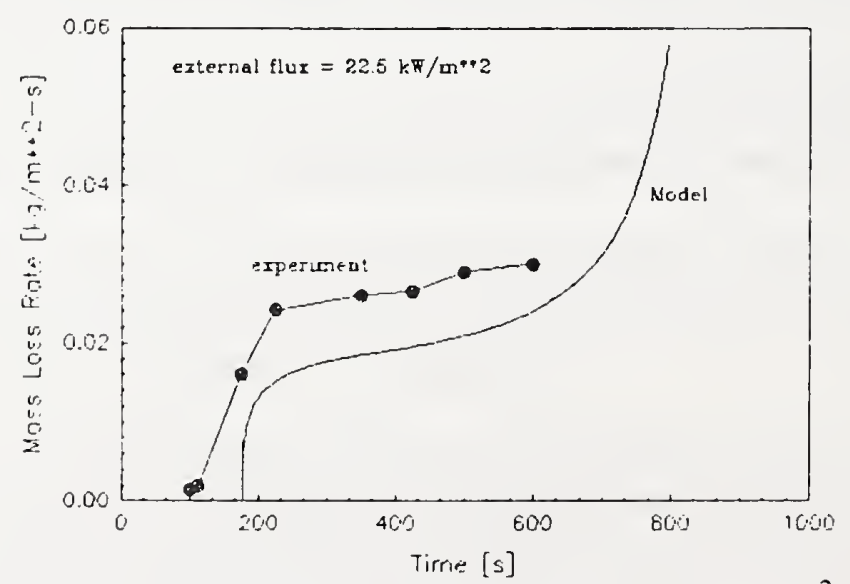

Figure 3. Burning rate of PMMA under $22.5 \mathrm{~kW} / \mathrm{m}^{2}$ incident external radiative heat tlux. 


\section{BUILDING AND FIRE RESEARCH LABORATORY \\ FIRE RESEARCH PROGRAM \\ NIST DIRECTOR'S FUND - FY93}

\section{CHAR STRUCTURE AND FLAMMABILITY}

Professional Staff: $\quad$ Takashi. Kashiwagi, Group Leader

Thomas J. Ohlemiller, General Engineer

\section{Project Objective:}

To determine the optimal way in which to suppress polymer flammability through the control of char structure. This requires a detailed examination of the links between original polymer structure, cbar characteristics and realistic flammability properties for a series of polymer systems by September, 1993.

Technical Approach and Accomplishments:

To provide partially charred samples for analyses, the polymer samples are exposed to well-defined temperatures or radiant fluxes comparable to those in fire environments. These samples are heated, degraded, and partially charred in a nitrogen atmosphere. Completely charred samples to slightly charred samples are formed by varying exposed temperature or external radiant flux, yiclding a series of snapshots of the thermal behavior of the polymer in fire-like conditions. Measurements are being made on each char sample of $\mathrm{C} / \mathrm{H}$ ratio by elemental analysis, aliphatic and aromatic carbon content by solid phase NMR and functional group content by FTIR. Measurement of the number of cross-linking sites is attempted by a solvent swelling technique. Heat transfer characteristics of the char residue and measurement of pore size distribution in the char sample are planned. Flammability properties of the char residue are measured by bench-scale techniques. They will provide critical information regarding at what stage of the char formation and char structure flammability of the polymers is significantly reduced.

The construction of a new large heated flow tube is nearly completed. About $10 \mathrm{~g}$ of powdered sample will be fed in to the tube and will be degraded to form char at various selected temperatures in a nitrogen atmosphere. Evolved gaseous products will be continuously fed into FTIR to measure change in products distribution. 



\section{BUILDING AND FIRE RESEARCH LABORATORY \\ FIRE RESEARCH PROGRAM \\ OTHER AGENCY PROJECT - FY93}

\section{CIGARETTE IGNITION METROLOGY}

Funding Agency:

Professional Staff:

\section{U.S. Consumer Product Safety Commission}

Richard Gann (Project Leader), Emil Braun, Keith Eberhardt (882), Richard Harris, Randall Lawson, Henri Mitler, Thomas Ohlemiller, Kay Villa (ATMI), George Walton (863)

Project Objective: Fulfill NIST responsibilities under P.L. 101-352, the Fire-Safe Cigarette Act of 1990, by August 10, 1993: develop a standard test method to determine cigarette ignition propensity; compile performance data for current cigarettes using the method; and conduct laboratory studies on and computer modeling of ignition physics to develop a predictive capability.

Technical Accomplishments: The development of two test methods is complete, including successful interlaboratory evaluations of both. The Mock-Up Ignition Test Method uses substrates physically similar to upholstered furniture and mattresses: a layer of fabric over padding. The measure of cigarette performance is ignition or non-ignition of the substrate. The Cigarette Extinction Test Method replaces the fabric/padding assembly with multiple layers of common filter paper. The measure of performance is full-length burning or self-extinguishment of the cigarette. Routine measurement of the relative ignition propensity of cigarettes is feasible using either of the two methods. Improved cigarette performance under both methods has been linked with reduced realworld ignition behavior; and it is reasonable to assume that this, in turn, implies a significant realworld benefit. Both methods have been subjected to interlaboratory study. The resulting reproducibilities were comparable to each other and comparable to those in other fire test meihods currently being used to regulate materials which may be involved in unwanted fires. Using the two methods, some current commercial cigarettes are shown to have reduced ignition propensities relative to the current best-selling cigarettes. A final report is in press. Complementary models of a furniture-like substrate reacting to a burning cigarette and a cigarette burning on such a substrate, along with a protocol for their use, have been completed. A final report is in review.

Publications: $\quad$ Ohlemiller, Thomas J., Villa, Kay M., Braun, Emil, Eberhardt, Keith R., Harris, Jr., Richard H., Lawson, J. Randall, and Gann, Richard G., "Test Methods for Quantifying the Propensity of Cigarettes to Ignite Soft Furnishings," NIST Special Publication 851, National Institute of Standards and Technology, in press, 1993.

Mitler, Henri E. and Walton, George N., "Modeling the Ignition of Soft Furnishings by a Cigarette," NIST Special Publication 852, National Institute of Standards and Technology, Gaithersburg, MD, in press, 1993. 



\section{BUILDING AND FIRE RESEARCH L.ABORATORY \\ FIRE RESEARCH PROGRAM \\ NATIONAL INSTITUTE OF STANDARDS AND TECHNOLOGY \\ GRANTEE PROJECT - FY93}

Grant Title: Fire Growth Models for Materials

Grant Number: 60NANB2D 266

Institution: Department of Fire Protection Engineering, University of Maryland, College Park, MD

Principal Investigator: J. G. Quintiere, Prot. Other Personnel: B. Rhodes, Graduate student

NIST Scientific Officer: T. Ohlemiller

Technical Abstract:

The principal objective of this project is to develop engineering models to predict the fire growth of materials. Specitically we are currently investigating the dynamics of burning rate under the heat transfer conditions of the Cone Calorimeter. Data from the Cone Calorimeter are used in several models to predict the fire growth on wall and ceiling materials in a room corner test scenario. We have developed one such model (Quintiere,1993) that attempts to generalize energy release rate data from the Cone Calorimeter in terms of the heat flux imposed on the material. This includes the external and the flame heat transfer. In that model, the hurning rate is considered to be quasi-steady. It depends on the transient external heat flux and on a specified flame heat flux. Specifications of flame heat flux in the room-corner test scenario can be developed from the summary presented by Quintiere and Cleary (1992). However, in general, more data are needed on flame heat flux in order to generalize this approach. The present study is designed to provide more insight into the dynamics of transient burning and the role of flame heat flux in the Cone Calorimeter. The premise is that if these aspects can be better quantitatively understond, then the data from the Cone Calorimeter and other such devices could be more effectively used in predictive models for fïre growth.

Before explaining our approach to studying the dynamics of burning under the Cone Calorimeter heat transter conditions, we will give some background related to this work. The framework for the burning rate model we are considering has been outlined by Quintiere (1992). It considers an integral approach to the burning rate of a finite solid. Flame radiative heat flux is specified, but can be a function of the mass loss rate. The gas phase aspects are considered steady, whereas the solid phase is one-dimensional and unsteady. This model has be addressed for semiinfinite thermoplastic materials hy Iqbal (1993). The model includes preheating to ignition before pyrolysis based on the use of ignition temperature. Also, only surface vaporization is considered at a constant vaporization temperature. An integral solution yields a solution for the preheating period in terms of a single nonlinear algebraic equation for the net surface heat flux. An extension of the integral solution to the vaporization period yields the following equations for solution.

$$
\begin{aligned}
& \frac{\mathrm{d} \delta}{\mathrm{dt}}=\frac{6 \alpha}{\delta}-\frac{3 \mathrm{~m}^{\prime \prime}}{\rho} \\
& \dot{m}^{\prime \prime}=\frac{\frac{h_{c}}{c_{g}}\left(\frac{\xi}{e \xi-1}\right)\left[Y_{o x, o d}\left(1-\chi_{r}\right) \frac{\Delta H}{r}-c_{g}\left(T_{v}-T_{v}\right)\right]-\frac{2 k}{\delta}\left(T_{v}-T_{0}\right)+\left(1-r_{s}\right) \dot{q}_{f, r}^{\prime \prime}-\varepsilon \sigma T_{v}^{4}}{\Delta H_{v}}
\end{aligned}
$$

where

$\mathrm{m}^{\prime \prime}$ is the mass loss rate per unit area.

$\delta$ is thermal penetration depth.

$t$ is time.

$\alpha$ is the thermal diftusivity of the solid. 
$k$ is the thermal conductivity of the solid.

$\rho$ is the density of the solid.

$T_{\text {, }}$ is the vaporization temperature of the solid.

$r_{s}$ is the reflectivity of the sorlid surface.

$\varepsilon$ is the emissivity of the solid surface.

$\Delta H_{1}$ is the heat of vaporization of the solid.

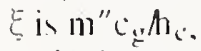

$h_{c}$ is the convective heat transfer coefficient relavent to the flame system,

$Y_{6 x_{0} \infty}$ is the ambient mass fraction of oxygen,

$T_{6}$ is the ambient and initial temperatures.

$\Delta \mathrm{H}$ is the effective heat of combustion,

$r$ is the effective stoichiometric oxygen to fuel mass ratio,

$\chi_{r}$ is the frilction of energy radiated hy the flame,

$c_{z}$ is the gas phase specitic heat.

$y_{1,1}$ is the flame radiative heat flux, and

$q_{c}$. is the external radiative heat flux.

The initial condition is given at the time $\mathrm{t}_{1}$ of ignition. In terms of the integral model used,

$$
\delta=\sqrt{6 \alpha \mathrm{t}_{1}} .
$$

It is interesting to note that the initial condition is not a function of the heat flux.

The above model has heen tested for the non-flaming transient mass loss case against exact and other approximate solutions in the literature with satisfactory results. Its relatively simple form makes it attrative for applications. This gives it some possibility of being useful in the generalization of the hurning rate for real materials. However it needs to be demonstrated that it can give satisfactory results for experimental data in the flaming and non-flaming cases. Moreover, practical means for evaluating the property data required by the model need to be developed. Some of these properties are already evaluated in the context of tire tests for real materials.

One application of the above model is to infer information about the flame heat flux under transient hurning conditions. This can he done if the model is reasonably accurate for transient pyrolysis. We teel this is the case for a substance like PMMA. In a study of PMMA pool fires by Modak and Croce (1977), they analyzed their data in this fashion to infer the flame radiative heat tlux. They assumed a constant tlame convective heat flux, hut surprisingly ignored the surface reradiation. The latter introduces a significant error in the tlame radiative heat flux inferred. Igbaal (1993) used the above model to perform similar calculations. The results are presented in Figures 1 and 2. Their experimental mass loss rate results are presented in Figure 1 for square pools ranging in size from $0.023 \mathrm{~m}^{2} \mathrm{to} 1.5 \mathrm{~m}^{2}$, or $15 \mathrm{~cm}$ to $1.22 \mathrm{~m}$ on a side. These sizes are expected to produce laminar to turhulent hurning conditions as the size increases. The above model attempts to account for these convective effects by using a standard natural convection heat transfer correlation to compute $h_{i}$. These computations suggest that the three smallest pools are laminar, and the rest are turhulent. The experimental results were interpreted to yield an initial constant mass loss rate of 4 $\mathrm{g} / \mathrm{m}^{2}-\mathrm{s}$ for all cases. It is interesting to note that the inferred results from the model yield initial results for tlame convective heat thuxes of approximately 7 to $9 \mathrm{~kW} / \mathrm{m}^{2}$, and radiative heat fluxes of approximately 15 to $20 \mathrm{~kW} / \mathrm{m}^{2}$. As huming increases, the convective heat flux decreases to as low as $3 \mathrm{~kW} / \mathrm{m}^{2}$, and the radiative heat flux increases to as high as $40 \mathrm{~kW} / \mathrm{m}^{2}$ for the largest pool at steady burning. It is not clear whether the dynamic results for the flame radiative heat flux is completely accurate in Figure 2, so it is not appropriate to explain all of the variations in the curves. However, it is expected that the flame radiative heat flux will increase as the buming rate increases for the larger persls. This is generally the case in Figure 2. Accurate methods to predict the flame radiation in such fires are not available despite much work. Yet the significant role of flame radiation in burning rate is readily apparent. A knowledge of this heat flux is crucial to any attempts at developing methods to predict the hurning rate of real materials. 
It is surprising that so little is known about the flame heat fluxes under realistic fire conditions. The effects of scale, orientation, and enclosure have not heen studied in a systematic way. Lacking fundamental approaches that can be practically implemented, it is suggested that experimental correlations might have greater immediate practicality. However. data are lacking to even explore such an approach. This bring us to the current experimental study under heat transfer conditions in the Cone Calorimeter. Since this device is in such wide spread use, it was decided to) explore the flame heat flux under its range of external radiative conditions. Our strategy is to attempt to make direct measurements and to use the inferred technique described above. The experimental results have recently commenced, and we shall describe the experimental approach.

The experimental apparatus consists of a Cone heating element and load cell identical to the standard Cone Calorimeter. The heating element is manually maintained at a constant temperature hy a variable transformer during a test. PMMA is hurned on an insulated platform as in the standard Cone test. No edge frame is employed, however, thin cardhoard is honded to the sides of the PMMA to prevent edge effects during huming. This tends to) provide a fixed face area as the sample regresses. A $3.2 \mathrm{~mm}$ (1/8 inch) water cooled heat flux meter is inserted in a slightly over-sized hole at the center of the PMMA sample to measure the surface heat flux. As the sample regresses the heat flux meter remains fixed, so that the surface heat flux is not measured any longer as significant regression occurs. The heat flux sensor is a thermopile type with a high emissivity surtace. It is designed to measure the incident total heat flux. Water at approximately $50 \mathrm{C}$ maintains the sensor at a fixed temperature, and prevents condensibles from contaminating it during a test. The sensor is continually calibrated hefore and after a test, and up to now no significant degradation effects have occurred. The following measurements are being taken, hut not necessarily all simultaneously in the same test run:
1. mass loss,
2. surface heat flux,
3. surface temperature, and
4. hack surface temperature.

Data for hlack PMMA are currently being taken over a range of external radiative heat fluxes of up to $70 \mathrm{~kW} / \mathrm{m}^{2}$. Also a simulated burning sample is employed consisting of a glass head hurner supplying methane. The burner has a metal sleeve to accommodate the heat flux sensor in order to measure the flame heat flux under simulated steady burning conditions in the Cone assembly. Experiments are expected to be concluded and the data analyzed over the next few months. The model described above will be further tested and utilized to compute the flame heat flux from the measured burning rate. Thus the two methods for determining the flame heat flux can be compared.

\section{Acknowledgeinents:}

We wish to thank Drs. T. Kashiwagi and T. Ohlemiller for their assistance in providing logistic and technical support for the laboratory experiments. Also we are grateful for the valuahle assistance of Mr. E. Braun for providing the guidance in establishing the data acquisition system, and to Mr. R. Shields for assisting in the experimental assembly.

\section{References:}

Cleary, T. and Quintiere, J. G., 1992, ASME Winter Annual Meeting. Anahiem, CA.

Iqhaal. N., 1993, "Burning Rate Model for Thermoplastic Materials", Master of Science Thesis, Department of Fire Protection Engineering, Univ. of Maryland, College Park. MD.

Modak, A. and Croce. P.. 1977. Plastic Pool Fires". Combustion and Flame, Vol. 30, pp. $251-265$.

Quintiere, J. G.. 1992, "A Semi-Quantitative Model for the Burning Rate of Solid Materials". NISTIR 4840. National Inst. of Standards and Technology, Gaithershurg. MD.

Quintiere. J. G., 1993. "A Simulation Model for Fire Growth on Materials Subject to a RoomCorner Test", Fire Safety Journal, Vol. 18. 


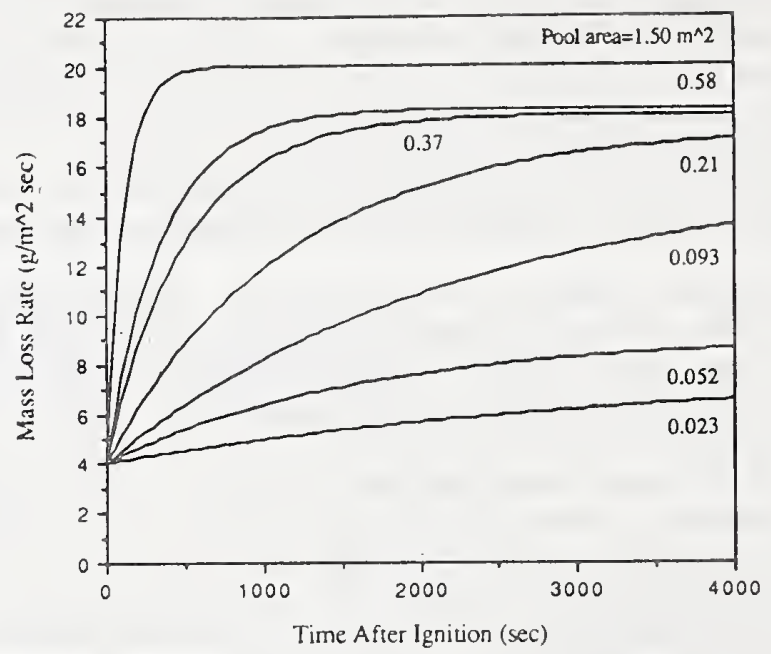

Figure 1. Experimental huming rate results for seven square PMMA pool fires hy Modak and Croo (1977).

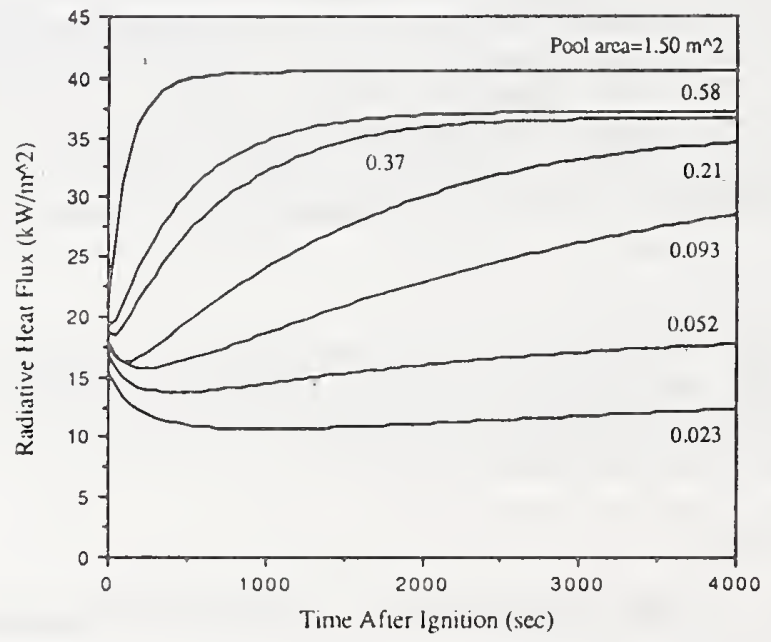

Figure 2. Computed tlame radiative heat tlux for PMMA pool fires (liqhaal, 1992). 


\section{BUILDING AND FIRE RESEARCH LABORATORY \\ FIRE RESEARCH PROGRAM \\ OTHER AGENCY PROJECT-FY93}

FIRE RESISTANT AIRCRAFT MATERIALS

\section{Funding Agency}

Federal Aviation Administration

\section{Professional Statf}

Marc R. Nyden, Research Chemist

James E. Brown, Research Chemist

Barry Bauer, Research Chemist (MSEL)

Charles Dick, Research Physicist (Physics)

\section{Project Objective}

To develop a technical basis (by September 1994) for increasing the fire resistance of existing aircraft materials and for the design of a new generation of ultra-fire resistant polymer grafts and composites for use in the interiors of commercial aircraft.

\section{Technical Accomplishments}

Synthetic polymers comprise a significant fraction of the fire load borne by commercial aircraft. The flammahility and combustion toxicity of these materials impact the passenger survivability of in-flight and post-crash fires. In recent years the FAA has issued improved fire test standards for aircraft seat cushions, panels, cargo liners and evacuation slides. Flammability measurements on the honeycomb composite panels used in the sidewalls, ceilings and stowage bins of commercial aircraft indicates that this material burns in two distinct stages. Only the initial stage is associated with a significant release of heat. A dramatic reduction in the peak rate-of-heat-release $(\sim 100 \%)$ was observed when the honeycomb panels were heated overnight in an oven at $250{ }^{\circ} \mathrm{C}$. Analyses of the FTIR spectra of the evolved gases indicates that this reduction in flammability is probably due to decreased levels of $\mathrm{CH}_{4}$ produced in the thermal decomposition of the heat treated resin. Thermal gravimetric analyses of the resin indicates that gases are not produced at temperatures below $450^{\circ} \mathrm{C}$, which when taken in conjunction with the FTIR-EGA results, suggests that the heat treatments actually induce a chemical change in the resin.

\section{Publications}

"Computer Aided Molecular Design of Fire Resistant Aircraft Materials," International Conference for the Promotion of Advanced Fire Resistant Aircraft Interior Materials, Federal Aviation Administration, Atlantic City, NJ, 1993. 



\section{BUILDING AND FIRE RESEARCH LABORATORY \\ FIRE RESEARCH PROGRAM \\ OTHER AGENCY PROJECT - FY93}

\section{FLAME RETARDANT STUDY}

Funding Agency: $\quad$ Gencral Electric Co.

Professional Staff: $\quad$ Takashi Kashiwagi, Project Leader

Thomas G. Cleary

\section{Project Objective:}

To understand the effects of polymer structure and certain flame retardant treatments on flammability properties of engineering thermoplastics and advanced structural composites.

\section{Technical Accomplishment:}

Various flammability properties, ignition, flame spread rate, heat release rate, $\mathrm{CO}$ and soot yields, and smoke extinction, are measured for various GE's polycarbonates, polyimides and polyphenyleneoxides with and without flame retardant treatments. The effects of external radiant flux on the flammability properties of these sample were determined using Cone Calorimeter and LIFT devices. Since all of these samples intumesce during burning, two sample mounting configurations are used. One of them is with a metal frame and a course grid to retain the sample surface at the original location. The other is without any frame or a grid and the sample intumesces without any restriction. The former tends to gencrate lower heat release rate and the latter higher heat release rate. Since the sample size used in the Cone Calorimeter is relatively small ( about $10 \mathrm{~cm} \times 10 \mathrm{~cm}$ ), the amount of intumescent might be affected by the size. In order to study this effect samples with the size of $61 \mathrm{~cm} \mathrm{x} 61 \mathrm{~cm}$ was tested to measure the amount of intumescent and also heat release rate. It was observed that heat release rate of the polycarbonate-siloxanc copolymer samples was much lower (about one third) than that for the pure polycarbonate sample; also extinction area calculated from the measured He-Ne laser beam transmission through the exhaust duct for the polycarbonate-siloxane copolymer sample was significantly lower (about one order) than that for the latter sample. These trends are consistent with those measured in the Cone Calorimeter. Therefore, the size of the sample does not significantly affect the flame retardant performance of the polycarbonate-siloxane copolymer sample. The significant differences between the small sample and the large sample are in the total mass loss as a fraction of original weight from the sample and also in the total heat release per unit surface area. The large sample lost more weight and produced more total heat than the small sample.

Gasification rate, temperature distribution in the sample, and evolved gaseous products of selected combinations of polymer samples will be measured using the new radiative gasification device. The gasification experiment will be conducted in nitrogen atmosphere to make certain that there are no gas phase reactions. The sample will be exposed to external fiux up to $75 \mathrm{KW} / \mathrm{m}^{2}$. Samples with and without the treatments will be studied to determine the effects of the treatments on the gasification process and hopefully to understand the mechanism of the flame retardant treatment.

\section{Reports and Publication:}

"Effects of Sample Mounting on Flammability Propertics of Intumescent Polymers", Kashiwagi, T. and Cleary, T.G., Fire Safety J., 20, 203-225 (1993). 

Funding Agency: U.S. Navy, David Taylor Research Center

Professional Staff: James E. Brown, Research Chemist Thomas J. Ohlemiller, Research Engineer Thomas G. Cleary, Chemical Engineer

\section{Project Objective:}

To develop for the U. S. Navy by September, 1993 an assessment of the correct external heat flux levels to be used in bench-scale flammability data intended to predict the full-scale behavior of composite materials.

\section{Technical Accomplishments:}

Medium-Scale Upward Flame Spread on Composite Materials

Most materials of interest to the Navy are sufficiently fire resistant as to require some external heat flux before they will yield upward flame spread in a flat wall configuration. For this reason, and to meet other program goals, we have built an medium-scale radiant panel facility which can be used under the hood of our furniture calorimeter. This facility allows uniform irradiation on samples $38 \mathrm{~cm}$ wide by $122 \mathrm{~cm}$ tall. The spread of flames and the resulting heat release process can be measured simultaneously. This facility has been applied to a pair of resin/woven glass composites. Flame spread behavior was measured as a function of external flux and of igniter size. The heat flux into the surface is being measured at several points during the flame spread process. The flux will also be measured on these same materials in cone calorimeter scale experiments. One goal is to determine the appropriate external flux conditions for small-scale measurements intended to be input into flame spread models. A second goal is to test the ability of existing spread models to predict the observed full-scale behavior.

\section{Publication:}

Ohlemiller, T., Cleary, T., Brown, J. and Shields, J., "Assessing the Flammability of Composite Materials", J. Fire Sciences, 4 , July/August, 1993 , p. 308 

BUILDING AND FIRE RESEARCH LABORATORY

FIRE RESEARCH PROGRAM

OTHER AGENCY PROJECT - FY93

\section{RADIATIVE IGNITION AND SUBSEQUENT FLAME SPREADING IN MICROGRAVITY ENVIRONMENT}

Funding Agency: $\quad$ NASA Microgravity Science Program

Professional Staff: $\quad$ Takashi Kashiwagi, Co-Project Leader

Howard R. Baum, Co-Project Leader

Kevin B. MacGrattan

Project Objective:

Develop a theoretical model to be able to predict ignition and subsequent flame spreading over a thin cellulosic material in a microgravity environment using the material characteristics determined in normal gravity by September, 1994.

Technical Accomplishment:

Two-dimensional, two-dimensional axisymmetric, and three-dimensional time-dependent ignition and subsequent flame spread with slow forced flows from 0 to $10 \mathrm{~cm} / \mathrm{s}$ in microgravity has been developed. Its gas phase model is based on irrotational flow mainly controlled by the slow forced flow, gas expansion and mass addition from a degrading condensed fuel with one-step oxidative reaction with energy and chemical species equations. Its condensed phase model is based on the thermally thin cellulosic sheet with three global degradation reactions, pyrolysis reaction and oxidative degradation of the sheet to generate char and gaseous products, and oxidative char degradation. Preliminary results show that ignition parameters, the size of irradiated area, its duration and flux, have significant effects on transition to flame spread. The effects of flow velocity, oxygen concentration, the size and its duration of external radiant flux, with and without a pilot, and many other parameters (gas phase reaction kinetics,..) on transition from ignition and flame spread will be studied. It appears that transition from spontaneous ignition to flame spread tends to be difficult without the slow flows. Determination of kinetic constants of the three degradation reactions was completed using TGA analysis with multiple heating rates and oxygen concentrations and by continuous evolved gas analysis of $\mathrm{CO}, \mathrm{CO}_{2}, \mathrm{H}_{2} \mathrm{O}$ and $\mathrm{O}_{2}$. A series of experiments corresponding to the above calculation will be planned in the glovebox of the USML-2 shuttle mission which is scheduled to fly in September 1995. The effects of external wind velocity and the size of irradiated area on ignition, the transition to flame spread and flame spread process will be determined for comparison with the predicted results.

\section{Reports and Publication:}

"Heat and Mass Transport From Thermally Degrading Thin Cellulosic Materials in a Microgravity Environment", Kushida, G., Baum, H.R., Kashiwagi, T. and Di Blasi, C., J. Heat Transfer, 114, 494-502 (1992).

"Global Kinetic Constants for Thermal Oxidative Degradation of a Cellulosic Paper", Kashiwagi, T. and Nambu, H., Combustion and Flame, 88,345-368 (1992).

"Heat Transfer from Radiatively Heated Thick Material in a Low Reynolds Number Microgravity Environment", Yamashita, H., Baum, H.R., Kushida, G., Nakabe, K. and Kashiwagi, T., J. Heat Transfer, 115, 418-425 (1993). 



\section{BUILDING AND FIRE RESEARCH LABORATORY \\ FIRE RESEARCH PROGRAM \\ PRIORITY PROJECT-FY93}

POLYMER FLAMMABILITY MODELING

\section{Professional Personnel}

Marc R. Nyden, Research Chemist

James E. Brown, Research Chemist

\section{Project Objective}

To develop a technical basis for the design of a new generation of fire retardants and fire resistant materials.

$\underline{\text { Scope }}$

The demand for better, cheaper and safer products has lead to a rapid proliferation of high performance and specialty polymers. This development has created a pressing need for new and more versatile approaches to increasing fire resistance. There is a strong correlation between char yield and fire resistance. This follows because char is always formed at the expense of combustible gases and because it protects the underlying polymer from the heat generated in combustion reactions. The presence of a surface char layer also acts as a physical barrier which obstructs the flow of gases produced in the degradation of the interior and thereby depresses the concentration of fuel in the gas phasc.

In principle, the tendency of a polymer to char can be increased by chemical additivcs and/or by altering its molecular structure. We have demonstrated that factors which promote char formation are revealcd in molecular dynamic simulations of degrading polymers. In particular, we observed that cross-linked model polymers charred more readily than their linear counterparts. This prediction has been confirmed by Cone Calorimeter measurements made on $\gamma$ and electron bcam - irradiatcd polyethylene (PE), as wcll as, on chemically cross-linked poly(methyl methacrylate). We are now investigating the efficacy of chemical additives which, though inert at ambient temperatures, will promote cross-linking at the onset of the thermal degradation of the bulk polymer.

\section{Technical Accomplishments}

We have demonstrated that molecular dynamics modeling is useful in providing concepts for the development and design of fire resistant materials. In particular, we have established that the flammability of certain polymers can be reduced by the addition of cross-linking agents and/or by exposing them to ionizing radiation.

\section{Publications}

"An Investigation of the Thermal Stability and Char Forming Tendency of Cross-linked Poly(methyl methacrylate)," S.M. Lomakin, James E. Brown, Robin S. Breese and Marc R. Nyden, Polymer Degradation and Stability, in press.

"A New Generation of Fire Resistant Polymers: Part I Computer-Aided Molecular Design," Marc R. Nyden and James E. Brown, Procecdings of the $12^{\text {th }}$ Joint Panel Mceting, UJNR Panel on Fire Rcsearch and Safety, Tskuba, Japan, 1992. 


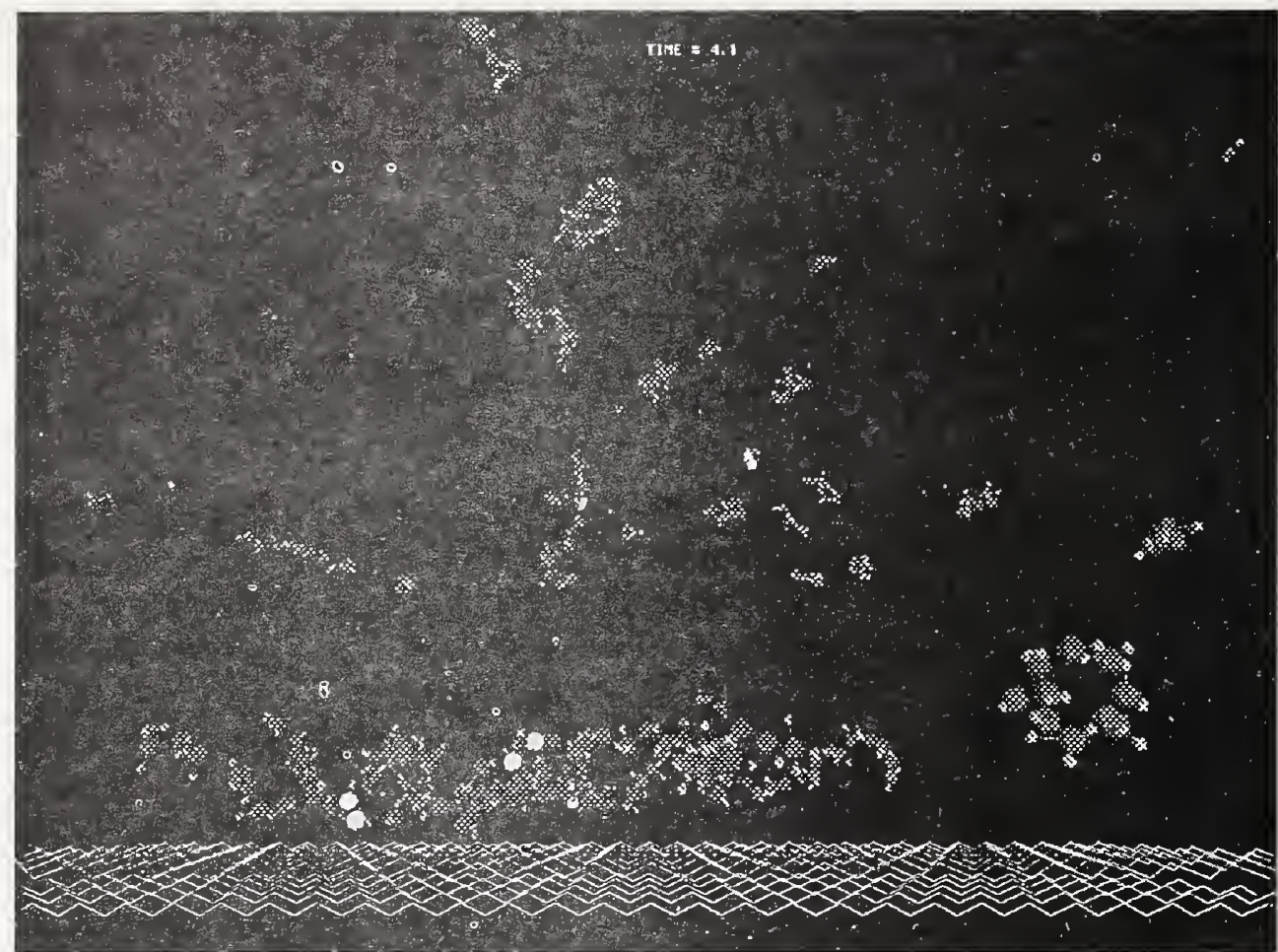

Figure 1. The thermal degradation of linear polyethylene interacting with a surface (white zig-zag lines). Carbon atoms involved in cross-links are highlighted in white.

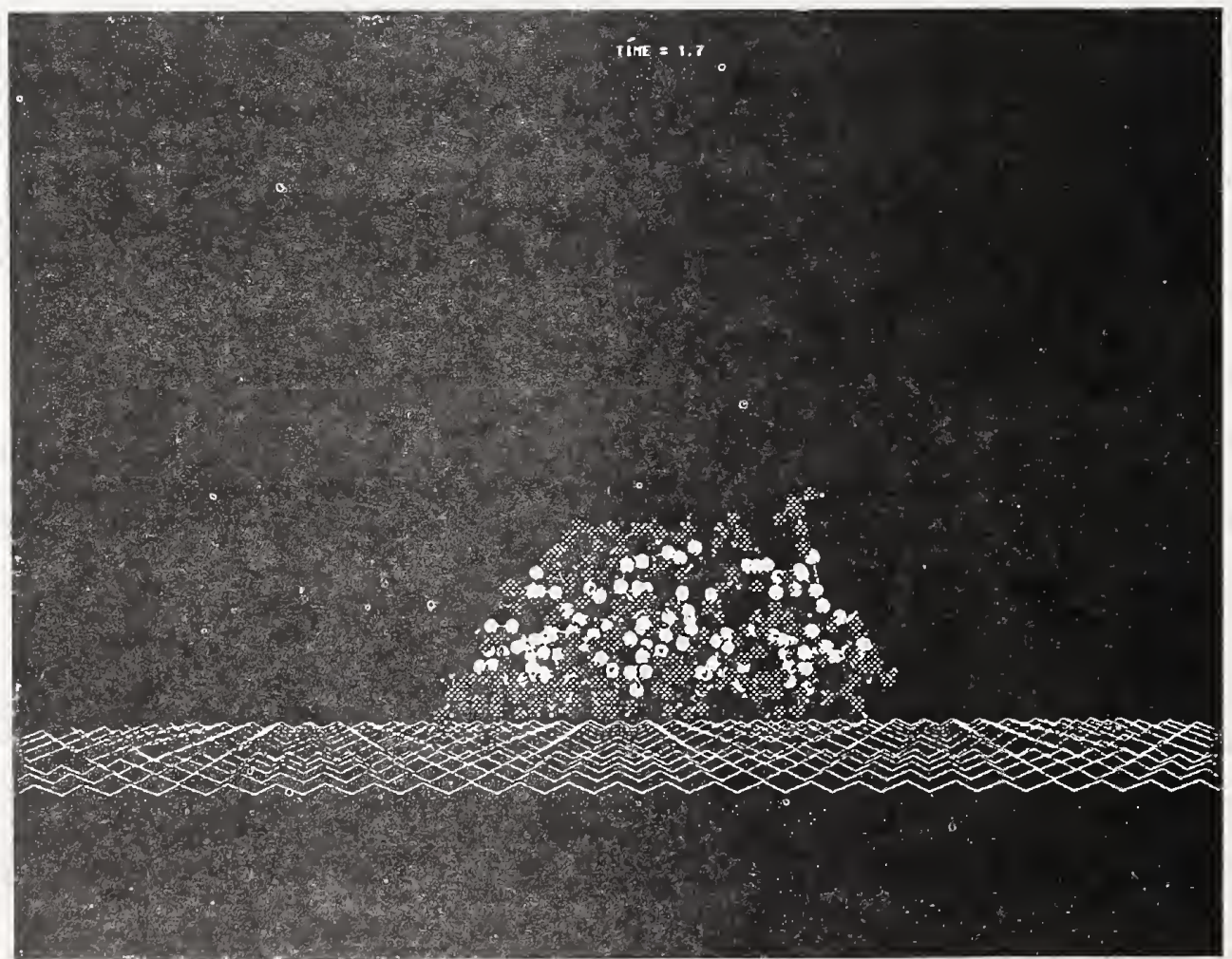

Figure 2. The thermal degradation of cross-linked polyethylene. 


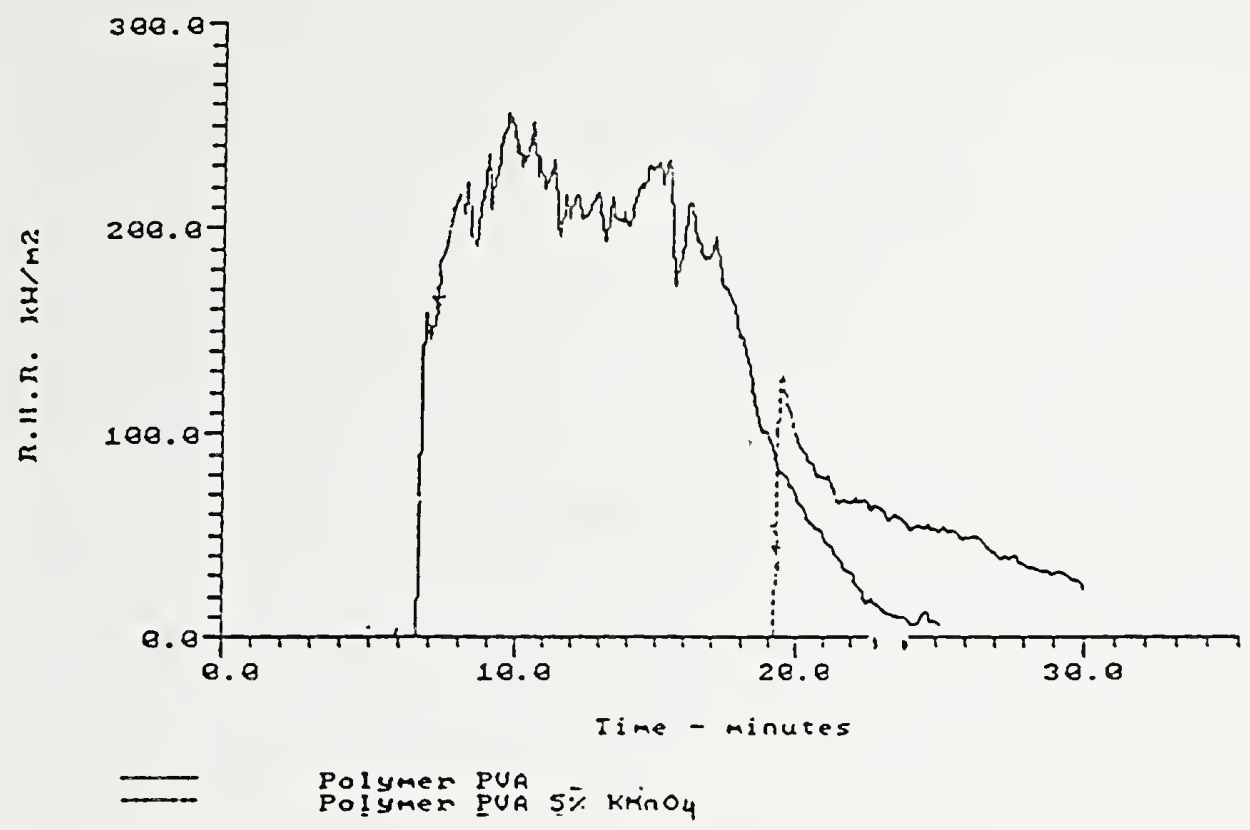
Figure 3 . The presence of only $5 \% \mathrm{KmO}_{4}$ in poly (vinyl alchol) increases the time to ignition by more than
a factor of two and reduces the peak rate of heat release by almost $50 \%$.

145 

B2. Furniture Flammability 


\section{BUILDING AND FIRE RESEARCH LABORATORY \\ FIRE RESEARCH PROGRAM \\ PRIORITY PROJECT - FY 93}

FURNITURE FLAMMABILITY

\section{Professional Personnel}

Andrew Fowell, Division Chief

Thomas Ohlemiller, Research Engineer

John Shields, Physical Scientist

\section{Project Objective}

Develop by 1996 a method by which manufacturers can predict the peak rate of heat release of residential furniture.

\section{$\underline{\text { Technical Approach }}$}

The overall approach focuses on enabling the broader use of fire barrier technology in lessening furniture flammability. Fire barriers are non-combustible layers placed between fabric and polyurethane foam to minimize the contribution of the latter to any fire. They are a key element in furniture which passes the requirements of California Bulletin 133 (no more than $80 \mathrm{~kW}$ peak heat release rate in response to a 18 $\mathrm{kW}$ ignition source). There are two possible failure domains for a furniture item subjected to this test, during burner application or subsequent to it. In the former domain the barrier is intact, typically, but the fabric itself, coupled with the area of involvement, yields an excessive heat release rate. In the latter domain, which typically occurs long after burner termination, the barrier may fail in areas where flaming persists for an extended time. The work in the current year seeks to assess whether the former failure mode is predictable by (or at least correlatable with) the behavior of the material combinations as tested in the Cone Calorimeter and LIFT tests. As a part of this we are performing heat flux measurements on burning chairs to assist in determining the most meaningful external flux domain in which to make small scale measurements. We also seek to determine, at least qualitatively, the mechanism behind the later domain failures of barrier materials; visible and infrared images of the test items are used for this purpose.

\section{$\underline{\text { Technical Accomplishments }}$}

A test series is underway using a variety of cushion materials in what is essentially the CB 133 mock-up frame for upholstered furniture testing. Six fabrics, three commercial barrier materials and two types of polyurethane foam are being examined using the Ch 133 test protocol. Typically a set of four cushions (seat, seat back and two arms) is subjected to the CB 133 gas burner; the resulting heat release is measured in the NIST Furniture Calorimeter. A pair of silicone oil "cooled" heat flux gages is placed on the fabric surface near one corner juncture of three cushion surfaces. The gages are run at two different temperatures; a thermocouple sewn into the fabric near the gages measures the local fuel surface temperature. Test specimen behavior is recorded with visible and infrared video cameras, as well as still photo cameras. The test series is incomplete at this point but one new observation has emerged from the results thus far. A late peak in heat release (which may or may not exceed the $80 \mathrm{~kW}$ limit) can occur even if the barrier remains intact. Fires can become established on the lower surfaces of the cushions and sustain themselves by a continuing downward flow of polyurethane melt produced by heat transferred 
through the intact harrier to higher portions of the cushion. All of the factors which determine how large such a lire hecomes are not yet clear.

\section{$\underline{\text { Publication }}$}

"The Influence of Ignition Source on the Flaming Fire Hazard of Upholstered Furniture", Cleary, T., Ohlemiller, T. and Villa, K., submitted to Fire Safety Journal 
B3. Wall and Ceiling Fires 


\title{
BUILDING AND FIRE RESEARCH LABORATORY \\ FIRE RESEARCH PROGRAM \\ PRIORITY PROJECT - FY93
}

\section{CEILING FIRES}

\section{Professional Personnel}

\author{
H.E. Mitler, Project Leader \\ K.D. Steckler, Physicist \\ P. Reneke, Programmer
}

\section{Project Objective}

To develop an understanding of the effects of the presence of a ceiling on the evolution of a wall, corner, or other room fire, followed by the spread of the fire across the ceiling. This should be at a level sufficient to produce a preliminary (engineering-level) algorithm by September 1993, a much superior one by September 1994, and which can be incorporated into HAZARD.N by September 1995.

\section{$\underline{\text { Scope }}$}

This project addresses the problem of fire growth on walls and ceilings in enclosures, and particularly on their mutual interactions. The effects of the ceiling on room fires is one of the most notable lacunae in our ability to predict the development of room fires. The wall-fire project (as well as other studies) have yielded reasonably successful models which predict wall fires. Most of these studies, however, neglect the effect of the ceiling; this is the case, in particular, for SPREAD, the BFRL model which is being prepared for insertion into HAZARD. That is, most extant models assume (in effect) that the wall is infinitely high. In fact, the presence of a ceiling has several important effects. Studying and modeling these phenomena is a natural -- indeed, a necessary -- sequel to the Wall Fire project. There are a number of other areas where having such a model will be important.

\section{Technical Approach}

The work is being done in three phases. In the first year, a literature survey of fires impinging on ceilings, including axisymmetric fires, wall fires, and corner fires, will be carried out. Flame extensions, fluxes and their position dependence, entrainment rates, effect on combustion rates, and ignition of flammable ceilings will all be looked at. As a result of the survey, determine what areas need to be studied further. Establish how much time, other resources, are needed. Suggest work for grantees to carry out, see what experimental work we can carry out at BFRL. Develop more detailed work plan, especially for years two and three. Finally, tie together theoretical understanding of flows and combustion under ceilings with empirical observations and put together a preliminary algorithm.

In the second year, a preliminary plan for writing a stand-alone ceiling fire computer program will be formulated; this will include the interaction with the wall-fire computer program SPREAD and plans for its insertion into CFAST. Numerical investigation of the fluid flows, using FLOW3D, might supplement experiments to yield a quantitative understanding of this behavior, the obvious first condition for constructing a predictive algorithm. Scaling laws can be examined and/or established, and parameters varied in ways that might be prohibitively time-consuming and expensive -- or, indeed, impossible -- by experiment. Plan and carry out new experiments. Based on the new data, devise a much better algorithm, and write an NISTIR on the work. In the third year, calculate effects of ceiling ignition when ceiling is 
flammable, program the algorithm, merge it with SPREAD, and harmonize it with CFAST. Finally, validate the new program, write documentation, and help Hazard Analysis group to insert program into CFAST.

\section{Technical Accomplishments}

The last difficulties in SPREAD, the wall-fire spread computer model, were fixed; the resulting SPREAD. 8 was given to P. Reneke for study and possible incorporation into CFAST. Documentation for SPREAD has been completed, and will soon go to WERB review.

A literature survey on studies of fires on ceilings, was carried out. Milestone \#1, to produce a Definitive Project Plan, based on analysis and literature survey, was completed, in the form of a (17-page) memo. Discussions were held with FMRC regarding possible cooperative work on the project. Several other people ware contacted re cooperative work, with some success; particularly, with Prof. Williamson at the University of California (Berkeley).

A report comparing experimental and/or theoretical results for fire growth with and without ceiling is about $80 \%$ completed, and will appear as a NISTIR.

The analysis of a ceiling's effects on wall fires has been started, and two approaches for a first-order algorithm for the growth rate of a wall flame in the presence of a ceiling are being investigated (numerical and analytic). Moreover, relevant wall/ceiling fire experiments at UCB have begun, and we will have the resulting data soon, enabling us to accelerate completion of this phase. Some of the UCB data will be used to establish the coefficients and parameter values needed for the algorithm; if there are enough data, some validation will also be carried out.

\section{$\underline{\text { Reports and Publications }}$}

H.E. Mitler and K.D. Steckler: Memo outlining detailed three-year project plan, March 1993.

\section{$\underline{\text { Related Grants }}$}

"Prediction of Fire Dynamics," R. Alpert and J. deRis, Factory Mutual Research Corp. "Upward Flame Spread on a Vertical Wall," A. Kulkarni, Pennsylvania State University.

"A Study of Fire-Induced Flow Along the Vertical Corner Wall," K. Saito, University of Kentucky. 


\title{
BUILDING AND FIRE RESEARCII LABORATORY \\ FIRE RESEARCII PROGRAM \\ NATIONAL INSTITUTE OF STANDARDS AND TECIINOLOGY \\ GRANTEE PROJECT - FY93
}

Institution:

Grant Number:

Grant Title:

Principal Investigator:

Other Personnel:

NIST Scientific Officer:
University of Kentucky

60NANB2D1295

Fire Spread along the Vertical Corner Wall, Part I

Kozo Saito, Professor of Mechanical Engincering

Cheng Qian, Doctoral Student Hiroki Ishida, Visiting Scholar Ted Oizumi. Visiting Scholar

Dr. Henry Mitler

\begin{abstract}
Based on the previous experimental results on non-spreading corner fire studies at the Combustion and Fire Research Laboratory of the University of Kentucky, flame spread behavior and spread rate of pyrolysis front along the vertical corner walls were investigated in detail using an automated infrared imaging system (AIIS). A unique feature of AIIS is: for flames whose emissivity is less than 0.1, the flame interference effects (soot, $\mathrm{CO}_{2}$ and $\mathrm{H}_{2} 0$ ) can be eliminated using a $10.6 \mu \mathrm{m}$ band-pass filter, so that a time series of temperature map on a relatively large material surface area can be obtained from a remote location. Our experiments also showed that emissivity of pyrolysis front for most of building materials is nearly one [1]; therefore, it is possible to accurately measure the spread rate of pyrolysis front in any direction from the obtained time series of infrared images [1]. To demonstrate this, the infrared images were obtained at six different time periods after ignition of bottom of the corner wall, the location of the 329 ${ }^{0} \mathrm{C}$ isotherm at corresponding times are shown in Fig. 1, and the maximum spread rate in upward direction, deduced from the figure 1 results, is shown in Fig. 2. If an attempt was made to duplicate the similar result by multi-point thermocouple measurement, the work will be extremely elaborate. In addition, the thermocouple temperature measurement technique may be unreliable due to the uncertainty of pyrolysis temperature of the wall surface. It is obvious that visual observation techniques which were employed previously by several rescarchers can produce ambiguous results in the determination of the two-dimensional transient pyrolysis front location [1].
\end{abstract}

\section{RECENT RESULTS}

Our upward flame spread study in the grant 60NANB2D1295 period includes: (1) the effect of ceiling on the spread rate, and that on temperature and heat flux distributions over the corner walls; (2) mechanism of $\mathrm{M}$-shape pyrolysis front formation along the vertical corner wall which was observed during the flame spread with ceiling and without ceiling; and (3) applicability of a simple one-dimensional thermal prediction model to the 
prediction of the maximum upward spread rate along the vertical corner wall. The study (1) will aid us to quantitatively understand how the ceiling affects heat transfer rate to the vertical corner wall. The study (2) will help us developing a model to predict upward spread rate along the vertical corner wall, since the maximum spread rate is achieved at the peak of the M-shape pyrolysis front. The study (3) will provide the data for assessing the need for developing complex two-dimensional prediction model. In this abstract, we only present outlines of the results from studies (1) and (2), although the other part of study (1) and study (3) include some new findings.

Ceiling Effects on Temperature and IIeat Flux Distributions on the Vertical Corner Wall Our one-half scale room corner model ( $1.6 \mathrm{~m}$ high $\times 1 \mathrm{~m}$ wide $\times 1 \mathrm{~m}$ long) was used for this measurement. Two vertical corner walls, ceiling and floor were made of Marinite board of $1.5 \mathrm{~cm}$ thickness (see Fig. 1). A propane gas burner $(15 \mathrm{~cm}$ long $\mathrm{x} 15 \mathrm{~cm}$ wide $\mathrm{x}$ $5 \mathrm{~cm}$ high) was placed on the floor near the corner. Both the heat flux and temperature distributions were measured after a steady state temperature distribution was achieved at the corner wall. The heat flux was measured with three water-cooled heat flux meters. Two of them were fixed on the corner wall; while one flux meter was traversed from point to point. Representative temperature and heat flux distributions with and without ceiling are shown in Figs. 3. An interesting aspect of these results is that: both the heat flux and temperature clistributions with the ceiling are lower than those without the ceiling. The reason was thought that the ceiling may play as a resistance, therefore, the buoyancy induced flow is not able to fully develop resulting in a poor convective heat transfer to the wall.

\section{Mcchanism of M-Shape Pyrolysis Front Formation}

The maximum flame spread rate along the vertical corner wall was achieved a few inches away from the corner; and the flame did not spread along the corner until the pyrolysis front reach the ceiling forming $M$-shape pyrolysis front (see Fig. 1)[2]. Four possible mechanisms were thought to explain the formation of the M-shape pyrolysis front: M1 Ignition source effect; M2 - Solid phase conduction heat loss; M3 - Fire-induced flow cooling; and M4 - Flame displacement effect. Each mechanism was experimentally investigated. To test Ml, PMMA corner walls with $30 \mathrm{~cm}$ wide $\times 1 \mathrm{~m}$ long $\mathrm{x} 1.2 \mathrm{~cm}$ thick were used; in one case bottom of the corner walls was uniformly ignited by a line gas burner and in another case only the bottom vertex was ignited by a propane torch. Both cases resulted in M-shape pyrolysis formation proving the role of M1 is minor. M2 was tested building two different PMMA corner walls: in one case the two PMMA boards were glued together in order to enhance the conductive heat loss at the vertical corner, while in another case the two PMMA boards were fixed on a large Marinite wall in order to mininize the conductive heat loss at the vertical corner. Both cases, however, resulted in the formation of $\mathrm{M}$-shape pyrolysis front proving the role of M2 is minor. M3 was tested placing a small disc on the corner half way between the ceiling and floor with the aim to prevent the fire induced air to cool the corner. M-shape pyrolysis front formation appeared regardless of existence of the disc proving the role of M3 is minor. Finally M4 was tested by changing the corner angle, since flame displacement distance defined as the distance between the corner and the flame surface can be changed by changing the corner angle without clianging the flame temperature. As a result, for the PMMA corner walls with 13.5 degree angle, the flame displacement distance was decreased by approximately half of that for the 90 degrec corner angle; while with decreasing the corner angle (i.e, increasing the flame (lisplacement distance), M-shape formation was enhanced on the PMMA corner walls. 


\section{ACKNOWLEDGEMENTS}

KS wishes to acknowledge Henry Mitler for his guidance in this research program. John deRis who offered corner heat loss mechanism for $\mathrm{M}$-shape formation, and Forman Williams who offered fire induced air flow cooling mechanism. Matching grants from Vice Chancellor's Office for Research and Graduate Studies and the Center for Robotics and Manufacturing Systems, both at the University of Kentucky are acknowledged.

\section{REFERENCES}

(1) Arakawa, A., Saito, K., and Gruver, W.A., Combust. Flame, 92:222 (1993).

2] Qian. C., Ishida, H., and Saito, K., Presented at the Central States and Easterm States Section Combustion Institute Joint Meeting, New Orleans, AL, March 15-17, 1993.

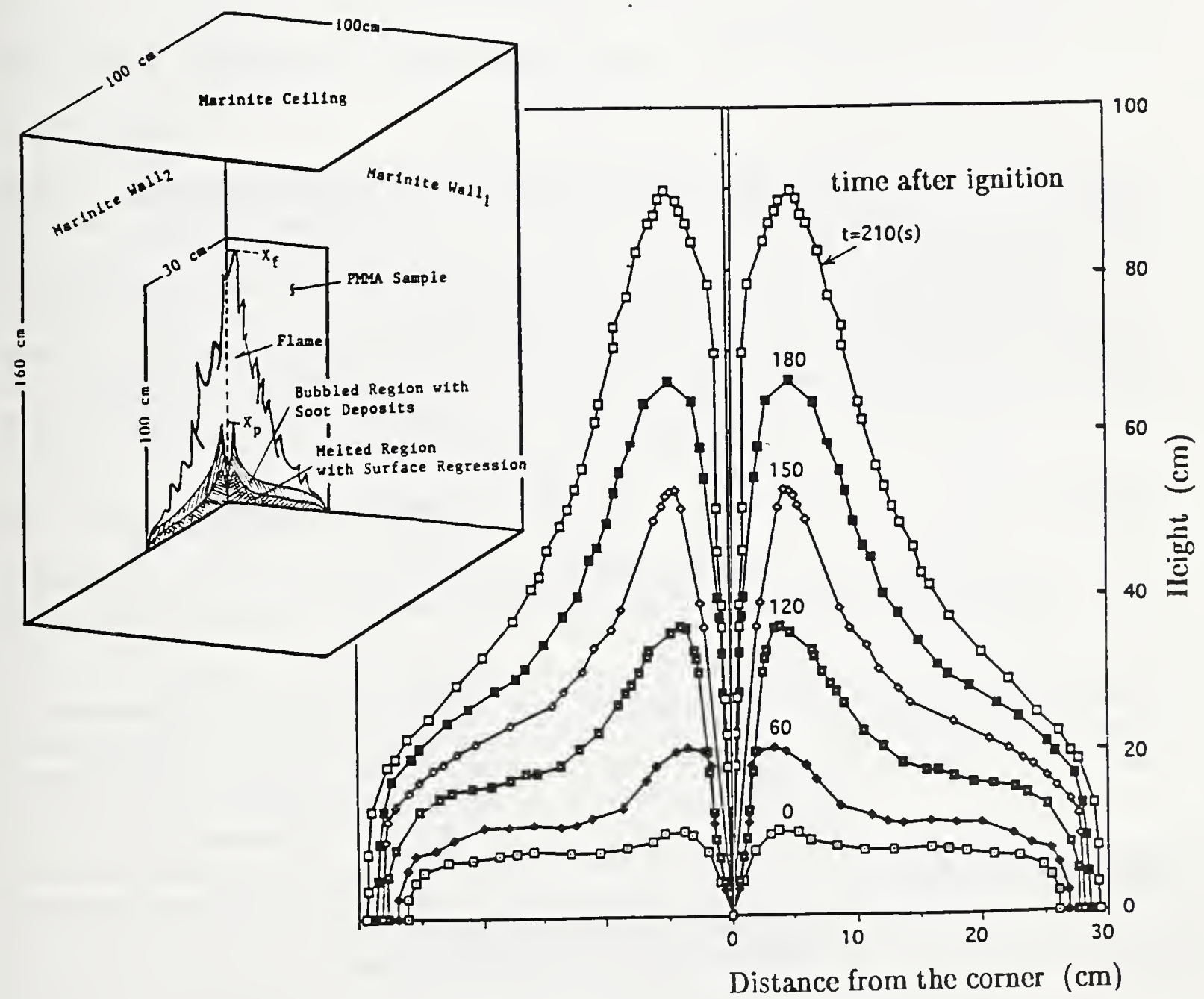

Fig. 1 Experimental apparatus and a $329^{\circ} \mathrm{C}$ isotherm pyrolysis front location measured at six different time periods after ignition by an automated infrared imaging system. 


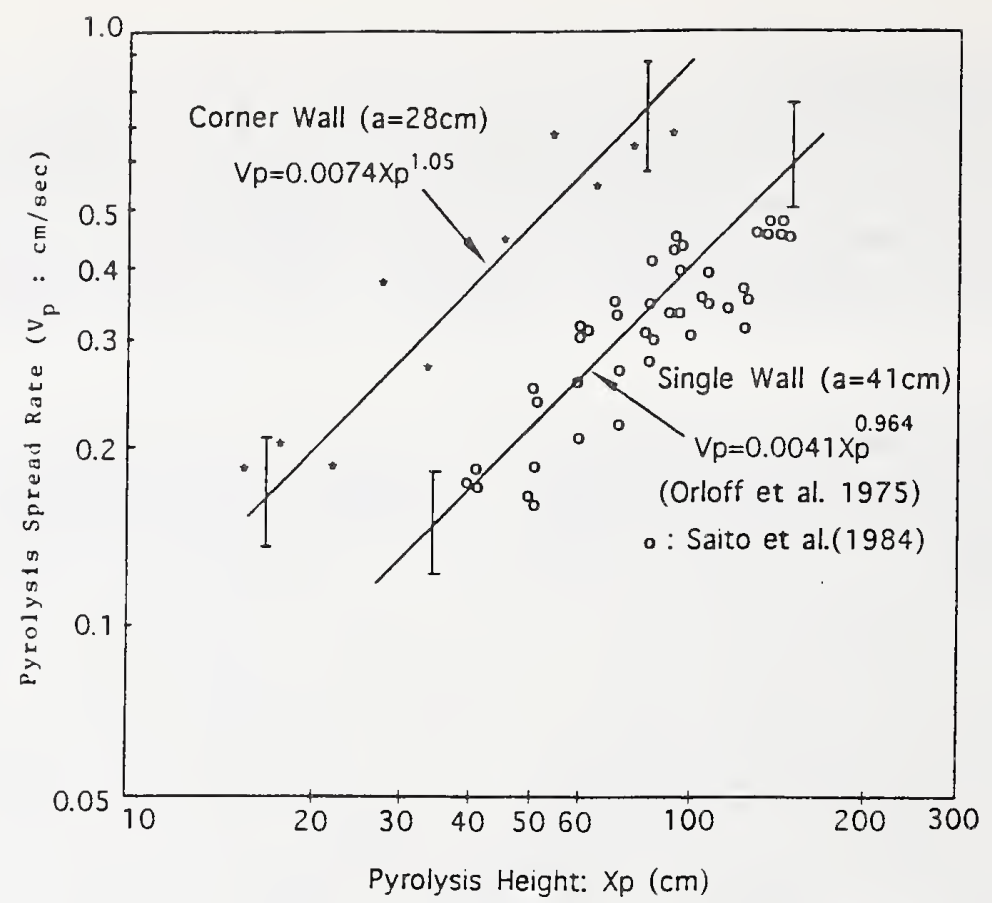

Fig. 2 The maximum upward pyrolysis spread rate as a function of pyrolysis height.
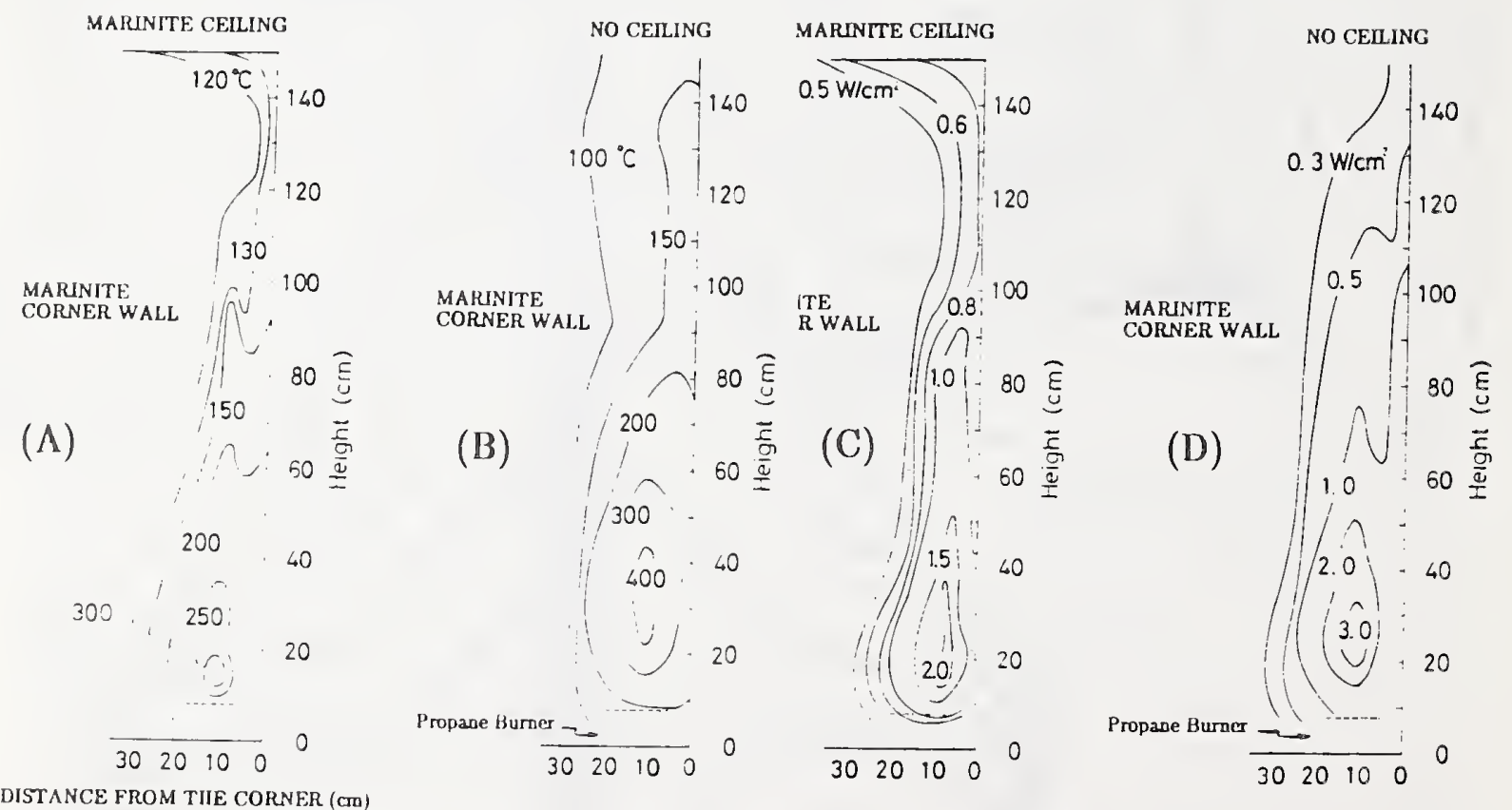

BURNER HEAT RELEASE RATE: $18 \mathrm{~kW}$ BURNER STAND-OFF DISTANCE: $5 \mathrm{~cm}$

Fig. 3 Temperature and heat flux distributions on a fire-heated Marinite vertical corner wall ( $A$ and $C$ : with a Marinite ceiling; $B$ and $D$ : with no ceiling). 


\section{BUILDING AND FIRE RESEARCH LABORATORY \\ FIRE RESEARCH PROGRAM \\ NATIONAL INSTITUTE OF STANDARDS AND TECHNOLOGY \\ GRANTEE PROJECT - FY93}

Institution:

Grant No:

Grant Title:

Principal Investigators:

Qther Professional Personnel:
Factory Mutual Rescarch Corporation

60NANB 1 D 1177

Prediction of Fire Dynamics

Ronald L. Alpert and John de Ris

H.W. Emmons

G.H. Markstein

L. Orloff

Dr. Henri Mitler

Technical Abstract:

This report summarizes accomplishments of a Factory Mutual Research Corporation (FMRC) project on the Prediction of Fire Dynamics for the NIST grant period indicated. Work performed under a subcontract by Professor H.W. Emmons on Ceiling-Jet Dynamics and on Development of Strategies for Perfom ance Fire Codes is described under Task 1. The accomplishments of three tasks performed at FMRC are then presented in summaries of Tasks 2 - 4. All of this work is aimed at the development of submodels or algorithms that can be used in NIST/BFRL comprehensive computer fire models. These tasks have also led to the development of practical smoke-point measurement techniques for solid combustible materials to provide input data for the global model of flame radiation previously developed. A paper documenting the smoke-point measurement methodology has been provided to NIST.

\section{Task 1: Prediction of Fire in Buildings (H.W. Emmons)}

The objective of this task is to advance the knowledge of the science of fire physics, chemistry, psychology, and physiology, so as to make rational quantitative design for fire safety possible.

The primary objective of this task has been for some years to predict the transient development of the movement of hot gases along a ceiling. There are for current use various empirical formulas based upon limited experimental results and approximations. There are also 2- and 3-D theories requiring hours on a supercomputer. These are probably very accurate although no careful comparison has yet been made. However, such calculations are not yet practical for routine enginecring use.

The simple 1-D ceiling jet theory - long used in hydraulics - was expected to serve as the best engineering approximation (with perhaps some empirical flow coefficients to correct for the effects of velocity profile and turbulence). This appears to be correct for cases of no density change, i.c., no gas heat transfer. No case with heat transfer can be thus solved since no steady state solutions exist which satisfy the required end boundary conditions. Partial progress has been made in the following three directions:

1. A solution for transient heat transfer to a finite heat capacity ceiling and the am bient below together with heat transfer from the ceiling to ambient is available with constant heat transfer coefficients. This 
theory briefly reponed some time ago predicts that the ceiling jet will cool until its buoyancy can no longer hold it at the cciling but will cause it to break up with part retuming below into the fire and the remainder producing the fire expansion flow throughout the building.

2. The simplest case without heat transfer or entrainment has been computed for the case of steady flow from a source which transiently develops an extending cciling jet in a corridor. Figure 1 is such a solution without friction. If friction is included (friction factor - .01), the solution develops as in Figure 2. While the ceiling jet is advancing along the ceiling, the frictionless flow behind the front is slightly above Froude Number 1 ( $F r=1.003$ ) while with friction it moves slightly below $\mathrm{Fr}=1(\mathrm{Fr}=.9)$.

3. On several occasions, the effect of the y momentum on the $x$ momentum equation has been discussed. If the $y$ momentum equation is used without the viscous tems, the resulting $x$ differential equation is a Kurtsweg-DeVres equation all but one of whose solutions either drop to minus infinite depth or are oscillatory. The one finite smooth intemediate solution increases in length with an increase in precision of the initial data - to reach infinity requires infinite precision. However, if the $y$ momentum equation viscous tems are included, the resultant $\mathrm{x}$ momentum equation contains, in addition to the K-DV third order tem, viscous second and fourth order tems. Hopefully, these will be large enough to remove most if not all of the oscillations and make it possibie $\mathrm{o}_{\mathrm{s}}$ satisfy the essential boundary conditions when heat transfer is present.

\section{Task 2: Models for Turbulent Flame Chemistry and Radiation (J. de Ris)}

The objective of this task is to develop models for predicting: 1) wall fire radiation which controls wall fire buming rates, and 2) the combined soot and $\mathrm{CO}$ oxidation which controls the release of incomplete (toxic) products of combustion (soot, $\mathrm{CO}$, etc.) and radiation from buoyant turbulent diffusion flames.

Perhaps the two most urgent and challenging problems of fire research are the prediction of fire heat relcase rates and the release of toxic (or otherwise damaging) products of incomplete combustion. The heat release rates of hazardous-scale fires are generally govemed by the radiant heat feedback to the pyrolyzing surface from the flames. Over the past several years we have established that the radiant fraction of the heat release rate is govemed by the fuel smoke-point which provides a convenient measure of flame sootiness. Radiant fractions have now been measured and correlated for a wide range of hydrocarbon fuels, fuel mixtures, fuel dilutions with nitrogen and am bient oxygen concentrations. The correlations of turbulent radiant fractions against the laminar flame smoke points are considerably improved when the comparisons are made at fixed adiabatic stoichiometric flame temperatures and oxidant to fucl stoichiometric ratios.

We have already completed the development of our Global Flame Radiation Model which shows how the radiant fraction from buoyant turbulent diffusion flames can be predicted from the fucl's lam inar smokepoint value. The model considers the separate roles of soot and gascous radiation, as well as the effects of: 1) turbulent mixing fluctuations, 2) incompleteness of combustion, and 3) radiant heat loss, on the effective flame radiation temperature in good agrement with experiment. The soot absorption coefficient for the buoyant turbulent diffusion flames is shown to be proportional to the fluid flow time (for fuel decomposition) and almost inversely proportional to the fuel/oxidant smoke point. The predicted radiant fractions are in excellent agreement with experiment for different oxidants and fuel dilutions covering a wide range of flame sootiness. The model provides better agrement with experiment than our previous empincal correlations, because it can include more physical/chemical effects. The smoke points for realistic fucls can be obtained by heating them in a quartz vial, by translating them under a $\mathrm{CO}_{2}$ or Nd:Yagg laser, or by an apparalus to be developed by Advanced Fuel Research for the U.S. Amy. 
The Global Flame Radiation Model achieves its simple algebraic form by treating the flame as a whole. It does not explicitly consider the flame chemistry. It is applicable only to well-ventilated fires having a prescribed incompleteness of combustion. Instead, we need a more detailed integral model which explicitly considers the chemical mechanisms of soot and $\mathrm{CO}$ formation/oxidation as well as the flame radiation at each elevation. This model should be capable of predicting the combustion and release of soot and $\mathrm{CO}$ from a fire plume entering a vitiated upper ceiling layer. Initially, the model will demand more complicated mathematics (O.D.E.s) for it to provide definite understanding and useful insight. However to be practical, the physical assumptions and mathematics must be kept as simple as possible.

Considerable experimental data exists to guide the model development. Time-averaged species composition $\left(\mathrm{O}_{2}, \mathrm{CO}_{2}, \mathrm{CO}, \mathrm{H}_{2} \mathrm{O}, \mathrm{TH} / \mathrm{C}\right)$ measurements throughout the lower part of buoyant turbulent diffusion flames are generally well correlated by the local time-mean equivalence ratio, $\Phi$. This is true for both well-ventilated and under-ventilated fires. It is particularly interesting to note that the deviations of $\mathrm{CO}$ concentrations in these flame correlations for different fuels generally rank with the fuel smokepoint values. Sootier fuels produce higher local CO concentrations and greater eventual CO overall release rates. Taken together these empirical studies suggest that the local turbulent flame chemistry is principally govemed by the local equivalence ratio and the fuel smoke point.

\section{Task 3: Turbulent Flame Heat Transfer to Surfaces (J. de Ris)}

The overall objective of this task is to provide experimental data for the development of submodels (i.e., formulae or correlations) of wall flame heat transfer components for inclusion in upward spread and fire growth models.

Recently, our experimental results have shown that: 1) much of the radiation emitted by the soot in flames is reabsorbed by the flames; and 2) the flames often have a cold sooty layer near the fuel surface which tends to biock some of the radiant heat transfer. An 11th burser panel has been designed, built and is now being tested to specifically overcome the above problems. This panel (see Figure 3 ) consists of a porous-metal bumer instrumented with four ray radiometers and an additional channel using an infraredemitting diode source and a silicon detector for narrow-band emission-absorption measurement. Two radiometers are oriented nom al to the bumer surface and two at an angle of $60^{\circ}$ to the nom al direction, with one of each pair located in front of the bumer panel and the other one in the rear. The radiometers in the rear are looking at the flame through nitrogen-purged apertures in the porous metal. The emissionabsorption device also is oriented nomal to the bumer surface, using another aperture in the metal. As an additional feature, a device for automatically changing two altemative interference filters $(\lambda=900 \mu \mathrm{m}$ and $1000 \mu \mathrm{m}$ ) has been incorporated in the emission-absorption channel, which will permit temperature determinations by two-color pyrometry. It is also planned to add a therm ocouple rack perpendicular to the bumer surface for measurements of flame thickness. Check-out tests of this new apparatus are now in progress.

Our previous experiments dealt primarily with the verical distributions of radiant emission and heat transfer within the gas supply (or simulated pyrolysis) zone. The main results of these experiments are contained in a paper presented at the 24 th Intemational Combustion Symposium. Among the conclusions, it was found that 1) the outward-directed radiance $N_{0}$ emitted nomal to the bumer surface increased roughly linearly with height $Z$ for fixed fuel mass flux; 2) linear relationships between reciprocal radiance $1 / N_{\text {o }}$ and reciprocal fuel mass flux $1 / \dot{\mathrm{m}}$ were obtained at fixed heights; these relationships held over the entire range of mass/flux for methane and ethane, while, for ethylene and propylene, abrupt transitions separating two regimes occurred at critical mass fluxes; ordinate intereepts $\mathrm{N}_{\infty}$ and reciprocal slopes $1 / \mathrm{s}$ are functions of height $z$ that increase with fuel sooting tendency for fixed $7 ; 3$ ) heat fluxes to the porous metal bumer decrease with increasing fuel mass flux, particularly near the flame base. In general, the heat 
fluxes increase with fuel sooting tendency. In the overfire region, fluxes as high as $57 \mathrm{~kW} / \mathrm{m}^{2}$ were obtained with the most sooty fuel, propylene.

An immediatc objective of our ongoing grant is to provide empirical correlations of our existing wall heattransfer data for preliminary use in fire growth models. For this purpose we have developed non-linear optimization software which finds the best parameter fits in empirical correlation formulas for the total pyrolysis zone heal transfer (and outward radiation) in terms of: 1) fuel mass transfer, 2) pyrolysis height, and 3) fuel/oxidant smoke point. Trial polynomial function fits were obtained for 106 experimental runs to establish the functionality of the optimization software. Presently we are formulating various physically motivated trial functions for use by the optimization software. Results from this work will be discussed in a Fire Growth Workshop being set up. While such purely empirical correlations should be very helpful for developing firc growth models, they will not provide the insight required for predicting the effects of: geometry, vitiation and non-isothemal radiative blockage, needed for practical applications.

\section{Task 4: Soot and CO Oxidation in Buoyant Turbulent Diffusion Flames (L. Orloff)}

The objective of this task is to provide experimental data for the devclopment of models describing soot and $\mathrm{CO}$ production and oxidation in buoyant turbulent diffusion flames. The experimental investigation will include 1) measurements of the effects of $\mathrm{H}_{2} \mathrm{O}, \mathrm{CO}_{2}$ and $\mathrm{N}_{2}$ fuel ciiluents on incompleteness of combustion; 2) optical (non-invasive) mapping of soot radiation temperatures and soot concentrations in these flames; 3) gas temperature distributions in flames using a themocouple rake, and 4) gas compositions in flames to reveal the controlling chemical mechanisms.

In a previous task completed in this program, we developed a Global Flame Radiation Model, which shows how the radiant fraction from turbulent diffusion flames can be predicted from the fuel's laminar smoke-point value. The model can be generalized to extend its range of application to important fire problems including wall fires, large-scale fires, various ambient atmospheres, restricted ventilation, chemical inhibitors, etc. These applications require knowledge of the completeness of combustion, $\chi_{A}$, associated with the fucl and ambient oxidant. Duc to the lack of experimental data and a theoretical model for soot and $\mathrm{CO}$ oxidation in generalized $\mathrm{O}_{2} / \mathrm{N}_{2}$ atmospheres, applications of the global model are restricted to configurations for which $\chi_{\mathrm{A}}$ is known, typically those with air atmospheres.

General turbulent combustion occurring in hazardous-scale fires is simulated by buoyant turbulent fuel-jet flames inside an cnclosure capable of handling a wide range of gascous fucls and ambient oxygen concentrations. The bumer design features a streamlined profile that reduces co-flow effects. Air plus added nitrogen or oxygen is supplied to the enclosure at twenty to thiny times the stoichiometric requirement of the flimes.

High-resolution $\mathrm{O}_{2}$ and $\mathrm{CO}_{2}$ analyzers have been installed to provide continuous independent measurements of $\chi_{\wedge}$ based on carbon balance and oxygen depletion in the combustion product stream. These respective methods provide a cross-check of the $\chi_{\mathrm{A}}$ measurement. We have also installed a heated fucl or fucl diluent delivery system to investigate the effect of chemical structure on soot fom ation and oxidation. One such fucl diluent (which occurs during real vertical surface fires) is water, which is vaporized and mixed with gascous fuels supplied to the bumer. Altematively, liquid fucls such as methanol can be vaporized to study fires with non-luminous radiation. Initial measurements have shown that the apparatus delivers a constant flow of water vapor mixed with fucl gas to the bumer resulting in a decrease in measured $\chi_{\mathrm{A}}$ for $\mathrm{C}_{3} \mathrm{H}_{6}$ fires. Radiant fraction, $\chi_{\mathrm{k}}$, measurements and the observance of blue flames indicate that the flane soot can be entirely suppressed by the addition of an equal mass flow of water vapor into the fuel stream, as shown in Figure 4, for four of the five hydrocarbons. 


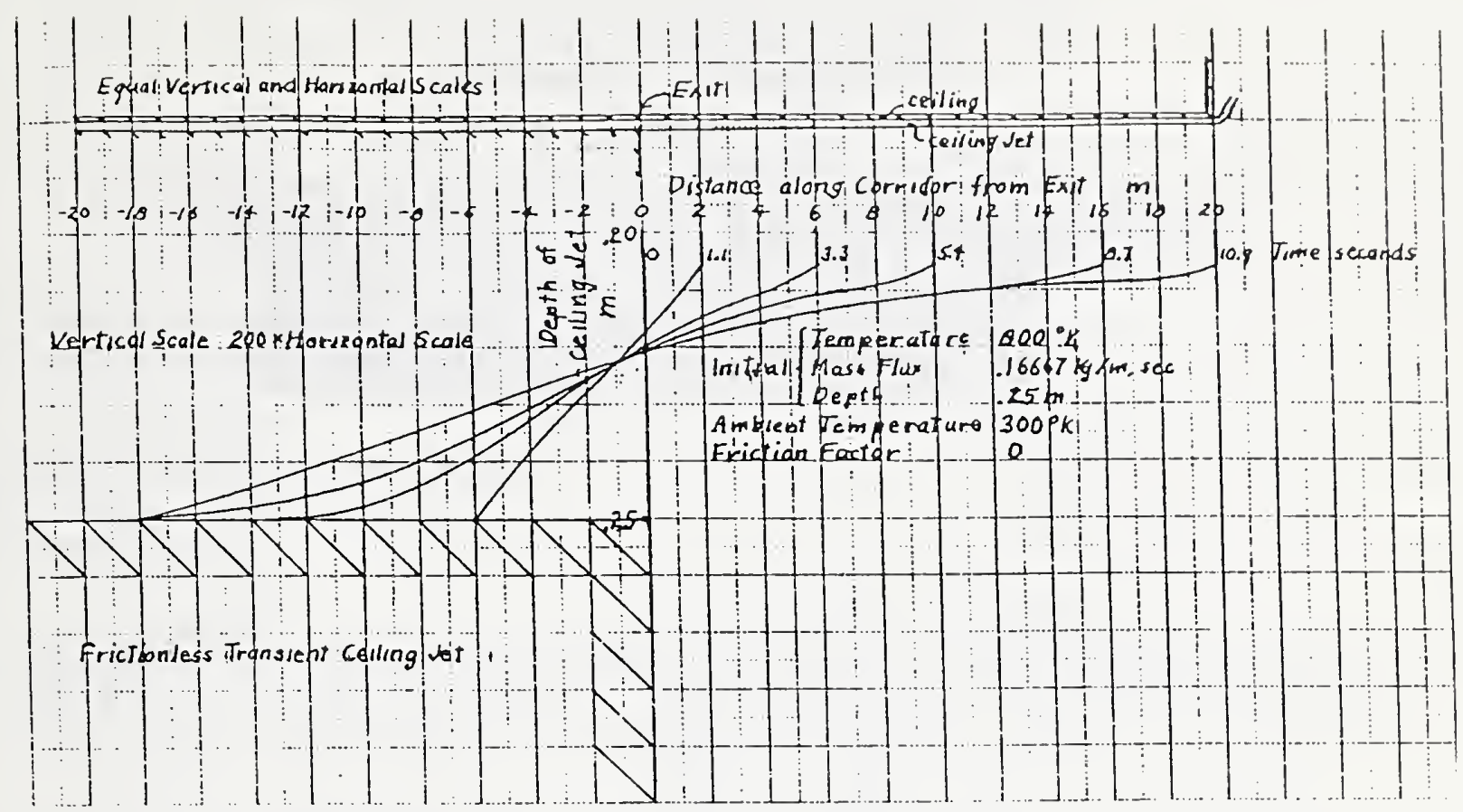

Fig. 1

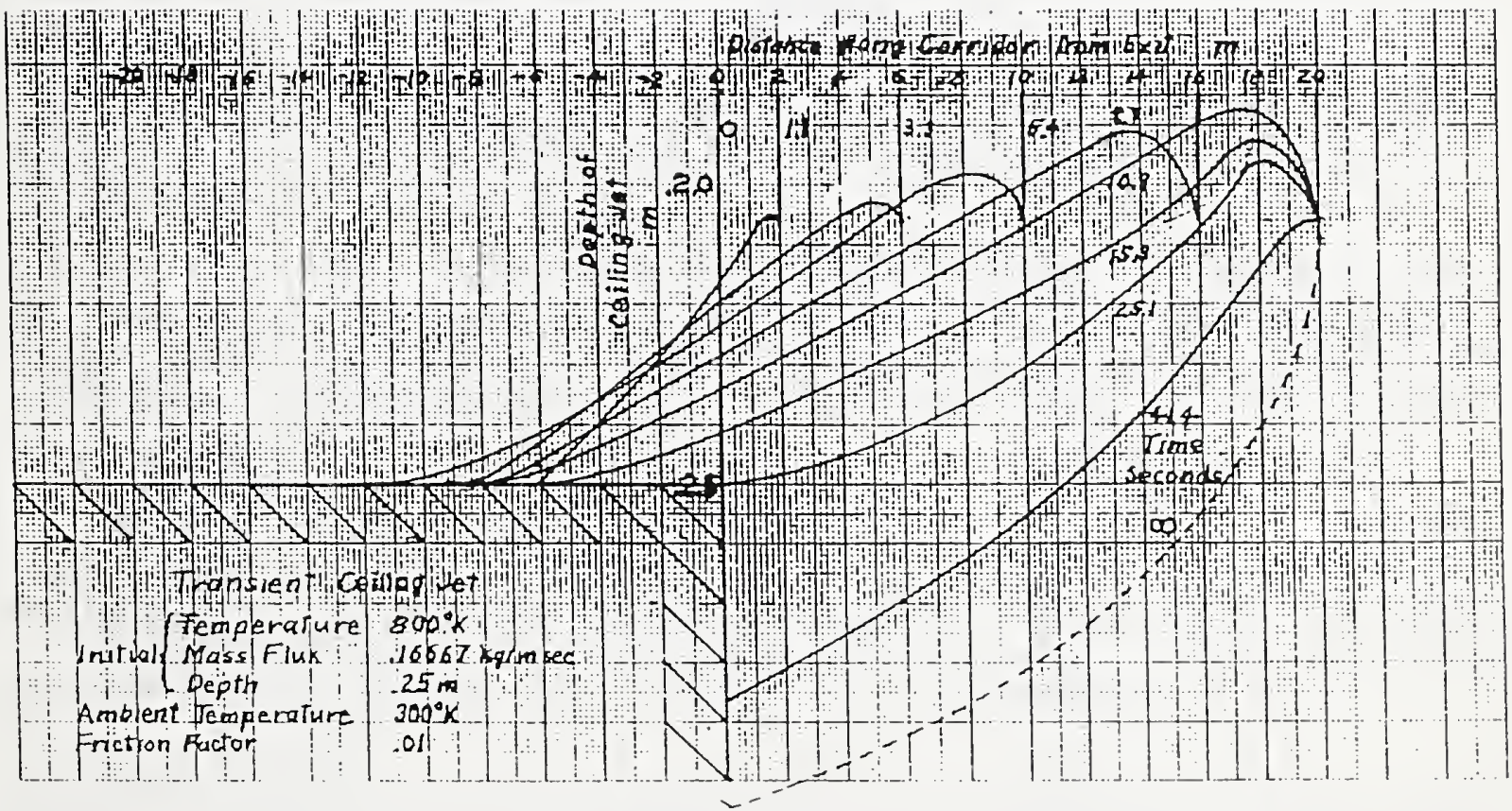

Fig. 2 


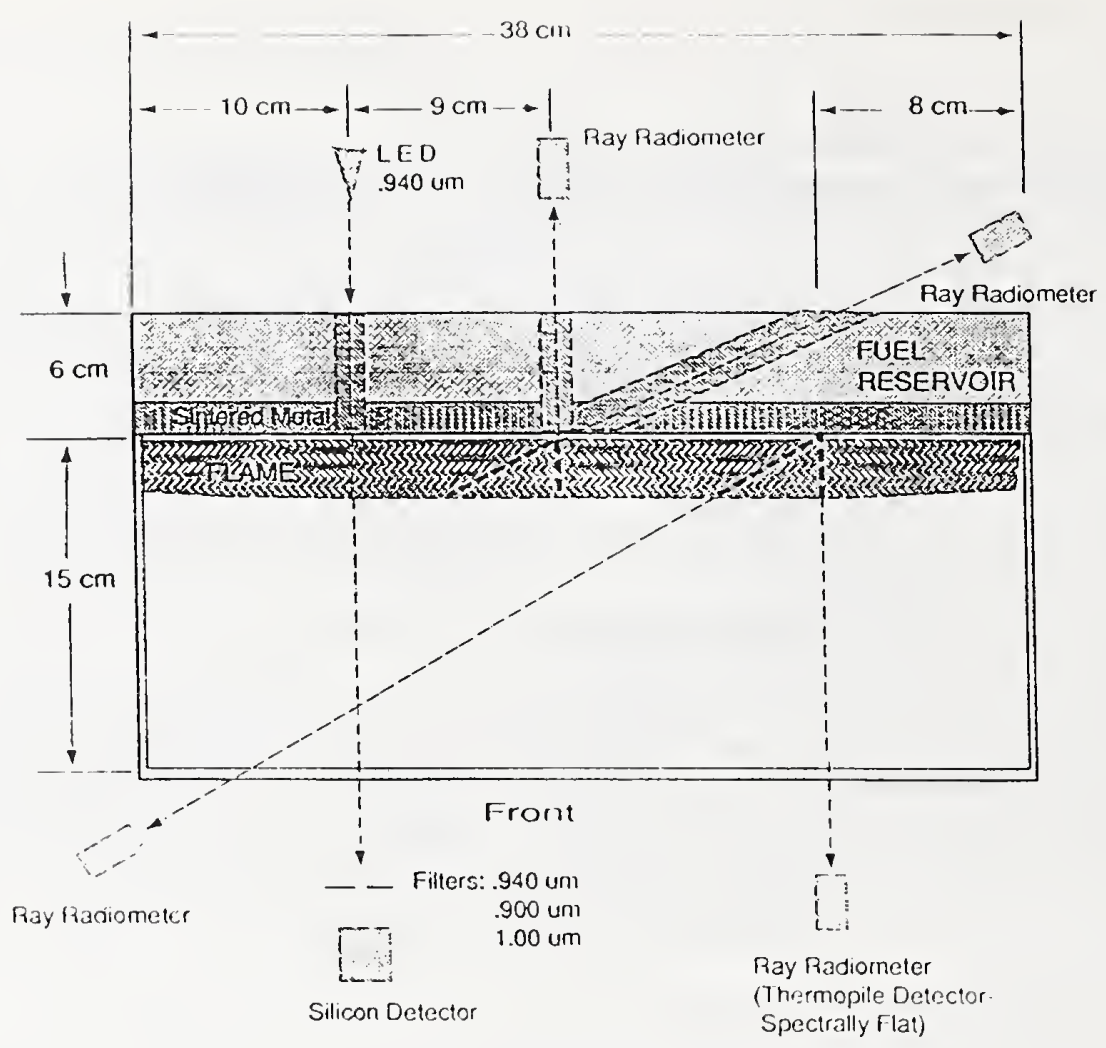

Fig. 3

TOP VIEW OF THE 11th PANEL

$12 \mathrm{~kW} 0.26 \mathrm{~g} / \mathrm{s}$ fuel $2 / 22-23 / 93$

Effect of $\mathrm{H}_{2} \mathrm{O}$ Diluent in Fuel

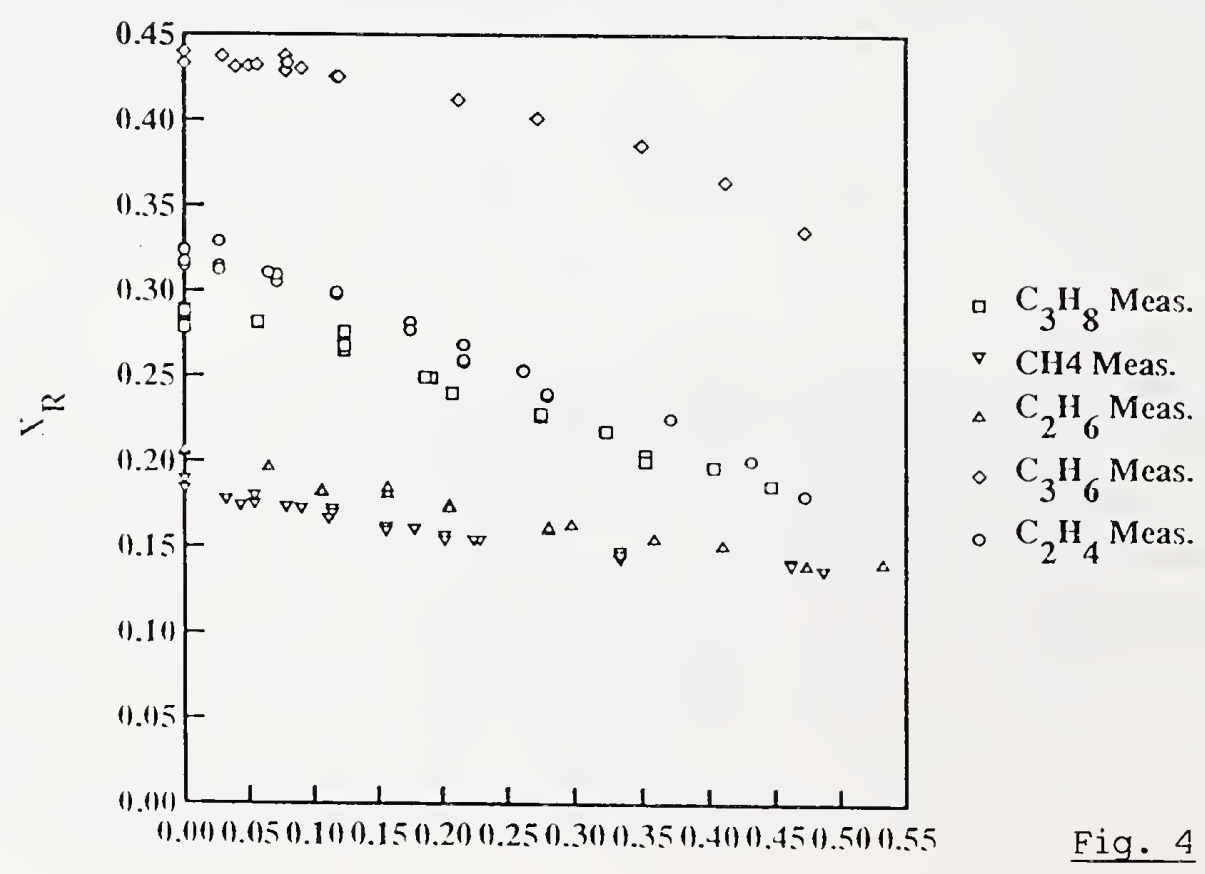

$\mathrm{HI}_{2}$ () Hiluent Mass Jatcion in l'uel 


\section{BUILDING AND FIRE RESEARCII LABORATORY \\ FIRE RESEARCH PROGRAM \\ OTHER AGENCY PROJECT - FY93}

\section{STUDY OF HEAT AND SMOKE MOVEMENT \\ AND THEIR INFLUENCE ON DETECTOR AND SPRINKLER RESPONSE IN ENCLOSED SPACES WITH COMPLEX CEILING GEOMETRIES}

Funding Agency

National Fire Protection Research Foundation

Professional Staff

Richard W. Bukowski, Project Leader

Glen Forney

William Davis

\section{Project Objective}

To examine the effect of complex ceiling geometry and obstructions on the distribution of heat and smoke in order to optimize requirements for automatic fire detector location found in NFPA 72E and for automatic sprinklers as covered by NFPA $13,13 \mathrm{D}$, and $13 \mathrm{R}$.

\section{Technical Accomplishments}

At present, recommendations for the placement of automatic fire detectors found in the NFPA Standard on Detection Devices (72E) are based either on engineering judgement or on experiments done by Heskestad and Delichatsios on flat, unobstructed ceilings. In the implementation of these data, tables and curves were developed from calculations with a zone model which are also only applicable for flat, unobstructed ceilings. Since $72 \mathrm{E}$ includes recommendations for placement of fire detectors in spaces with sloping or peaked ceilings, or with open beams and joists, some validation of these recommendations is necessary. Further, detector siting problems associated with stratification and high air movement from HVAC systems are mentioned in the standards, but only limited installation guidance is provided which are based only on judgement.

In the first year of this planned four year effort, the use of CFD models was validated by reproducing the results of full-scale experiments conducted a decade ago by Heskestad and Delicatsios. Parametric studies were then conducted on a set of independent variables including fire size, ceiling height, beam depth and spacing, and room volume, and constant response surfaces were plotted for the principal types of fire sensors.

The ability of the approach to address small fires and stratification was explored with success. Sensor response characteristics were demonstrated for fires of 100 Watt release rates in a typical sized room with and without a vertical temperature gradient which exceeded the plume temperature -- resulting in a stratified tlow. While there are no experimental data against which to verify these calculations, the physical processes evident in the simulation appear valid and reasonable.

\section{Reports and Publications}

NISTIR 4994, Forney, G.P., Davis, W.D., and Klote, J.H., Simulating the Effect of Beamed Ceilings on Smoke Flow, Part. 1, Comparison of Numerical and Experimental Results. 


\section{BUILDING AND FIRE RESEARCH LABORATORY \\ FIRE RESEARCH PROGRAM \\ NATIONAL INSTITUTE OF STANDARDS AND TECHNOLOGY \\ GRANTEE PROJECT-FY93}

Institution:

Grant No:

Grant Title:

Principal Investigator:

Other Professional Personnel:

NIST Scientific Officer:

Technical Abstract:

Introduction: The overall objective of the present project is to understand the upward flame spread phenomenon under simulated surrounding fire conditions. This is achieved by conducting experiments on upward flame spread under external radiation, developing a mathematical model, measuring relevant material properties needed, and checking validity of the model by comparing predictions with data. Emphasis is placed on studying and predicting the behavior of practical wall materials used in building interiors and textiles. Presented below is a concise description of progress made in the past year; details on these tasks can be found in other reports and papers.

Technical Accomplishments:

(i) Upward Flame Spread - Model and Experiments: In the current phase of the project, flame spread tests were conducted on several new materials and a numerical model of the upward flame spread process was developed. The physical situation being modeled is shown in Figure 1. A slab of material is subjected to a known, transient heat flux on its face, it is ignited at the bottom, and the flames are allowed to spread upward. External radiation affects upward flame spread in two ways. Ahead of the pyrolysis front, the radiant heat flux adds to the heat feedback from the flame and causes the yet-unburned surface of the sample to heat up to the pyrolysis temperature quicker. Behind the pyrolysis front, where the surface area that is already burning, the external radiation increases the mass loss rate of the sample which in turn causes larger flames and enhanced heat feedback to the surface. Both of these effects of external radiation accelerate the upward flame spread. The general model equations were described in the last annual report. The effect of external radiation is included in two terms, the forward wall heat flux, $\dot{\mathrm{q}}_{\mathrm{w}}^{\prime \prime}$, and the local mass loss rate, $\dot{\mathrm{m}}$ ". The heat feedback is modeled as,

$$
\dot{\mathrm{q}}_{\mathrm{w}}^{\prime \prime}(\mathrm{x}, \mathrm{t})=\dot{\mathrm{q}}_{\mathrm{wo}}^{\prime \prime} \exp \left[\mathrm{C}_{\mathrm{o}}\left(\frac{\mathrm{x}-\mathrm{x}_{\mathrm{p}}}{\mathrm{x}_{\mathrm{f}}-\mathrm{x}_{\mathrm{p}}}\right)\right]+\dot{\mathrm{q}}_{\mathrm{cr}}-\dot{\mathrm{q}}_{\mathrm{rcrad}}
$$

where $\dot{\mathrm{q}}_{w_{0}}$ is the maximum forward heat flux measured for a specific material, $\mathrm{C}_{\mathrm{o}}$ is a constant applicable for all materials, equal to $-1.37, \dot{\mathrm{q}}_{\mathrm{er}}^{\prime \prime}$ is external radiation and $\dot{\mathrm{q}}_{\mathrm{rerad}}$ is reradiation of the 
wall to the surroundings. The justification for using the above form of the equation and constants is available from our work on experimental measurements. The second important parameter, $\dot{\mathrm{m}}$ ", is determined from small scale experiments and takes into account the effect of external radiation in addition to the material characteristics such as thickness and charring. Some preliminary results of the numerical model have been obtained for 3.2 thick mm hardboard and are shown in Figure 2. Flame height and pyrolysis front histories at two levels of external radiation are compared in the figure. The convergence of the flame and pyrolysis height for the unradiated case is indicative of extinguishment of the upward flame spread prior to reaching the top of the sample. The experimental measurement for hardboard also confirmed this result. For the case with an average external flux of $2.2 \mathrm{~kW} / \mathrm{m}^{2}$ applied, the flame and pyrolysis front spread is faster and the sample sustained flame spread to the top.

Measured flame spread under external radiation for four materials (particle board, cotton textile, poplar, and plywood) is presented in figures 3 through 6 . The figures show that below some critical level of external flux, flame spread is not sustained to the top of the sample. Also, with higher levels of external flux the flame spread is more rapid. Further work on comparison of predicted data with experimental results and predictions for other materials is in progress.

(ii) Reflectance Measurements: The objective of this part of the project is to determine the spectral variation of the radiation properties of nonburning as well as burning materials. The spectral reflectance properties are measured using a Fourier Transform Infrared spectrometer (FTIR) and a modified version of heated cavity reflectometer. A schematic of the apparatus is shown in Figure 5. The reflectometer consists of a cavity formed by twelve flat plate heating elements that are heated to approximately $650 \mathrm{deg}$. C. The material sample is mounted on a water-cooled sample holder. The sample holder is rotated to provide a variation in the polar angle. Provision is made for igniting the sample and purging the cavity of exhaust gases. The FTIR acquires and processes the thermal radiation energy reflected by the sample. Relative directional spectral reflectance is obtained by subtracting the background emission from the reflected signal and the blackbody emission signal, and then taking the ratio of the two.

Results of measurements for various materials are shown in figure 6. Measurements for commercial finish aluminum were made to check validity of experimental data. The results for black PMMA reveal an increase in reflectance with increase in the polar angle while that for clear PMMA does not. Commercial cotton paper exhibits diffuse behavior. Properties of samples while they are burning will be measured in the next phase of this project. The reflectance property data can be useful, for example, in the analysis of a combustible wall or floor subjected to strong radiation. For certain materials, a significant fraction of the radiation may be simply reflected off the surface, not contributing to the ignition, combustion or flame spread process. Also, the properties may change significantly once the wall or floor starts burning. Analytical models may yield misleading results unless these properties are adequately taken into account.

\section{Selected Reports and Papers:}

Kulkarni, A. K., E. G. Brehob, S. S. Manohar, and R. Nair, Turbulent Upward Flame Spread on a Vertical Wall Under External Radiation, Annual Report to NIST, May 1993.

Brehob, E. G. and Kulkarni, A. K., Experimental Measurements of Upward Flame Spread with External Radiation, to be presented at the First ISHMT/ASME (US-India) Joint Heat and Mass Transfer Conference, January 1994.

Brehob, E. G. and A. K. Kulkarni, Time-dependent Mass Loss Rate Behavior of Wall Materials Under External Radiation, Fire and Materials, (to be published).

Kulkarni, A. K., F. Murphy, and S. S. Manohar, Interaction of Buoyant Plumes with

Two-Layer Stably Stratified Media, Experimental Thermal and Fluid Science (to be published).

Manohar, S. S., A. K. Kulkarni, and S. T. Thynell, In-Depth Absorption of Externally Incident Radiation in Nongray Media, Journal Heat Transfer (to be published). 


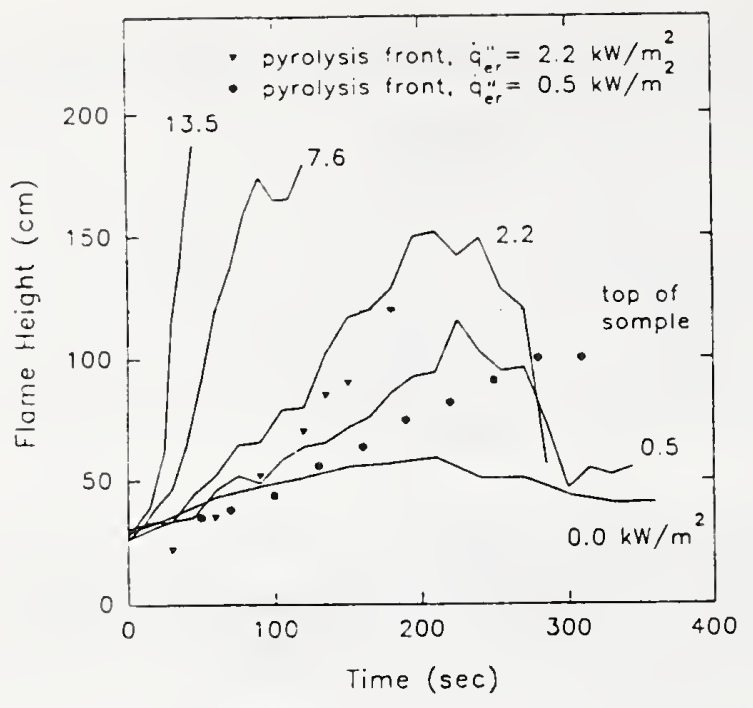

Figure 5. Flame Height for Poplar at Various Levels of Ext. Radiation

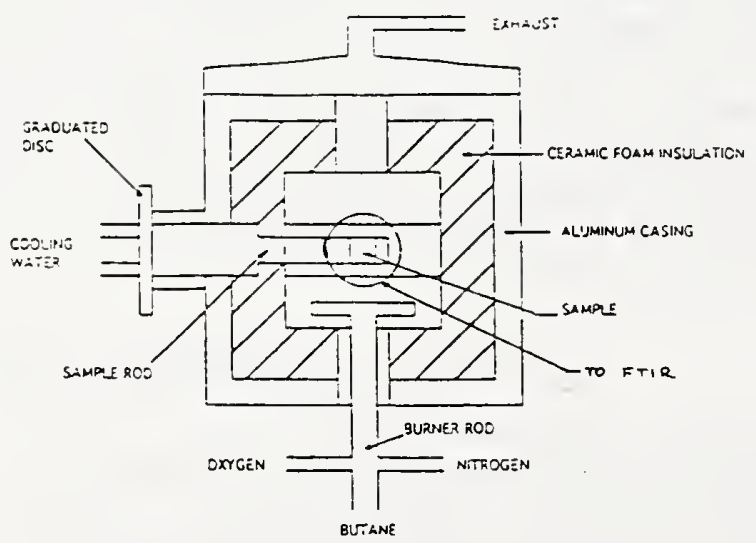

Figure 7. Schematic of Heated Cavity Reflectometer Apparatus

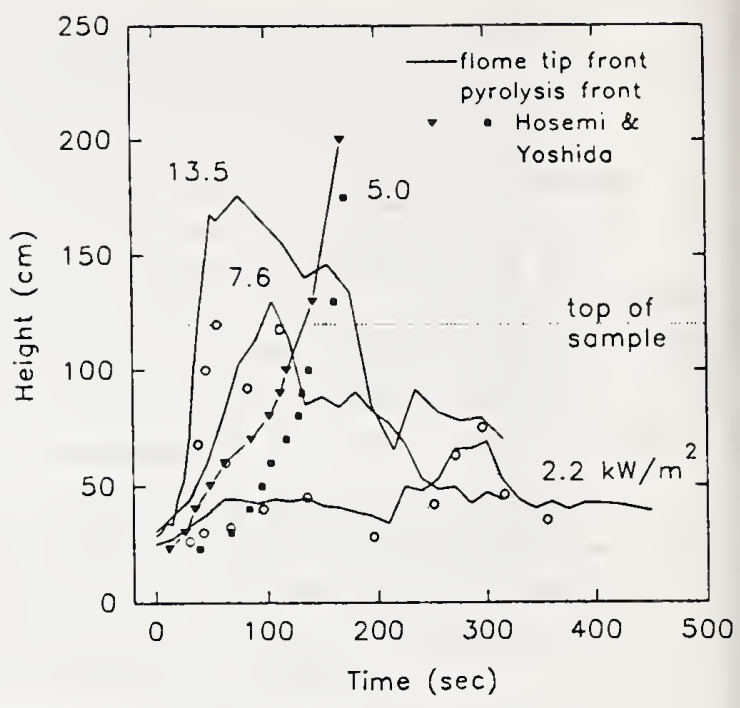

Figure 6. Flame Height for Plywood at Various Levels of Ext. Radiation

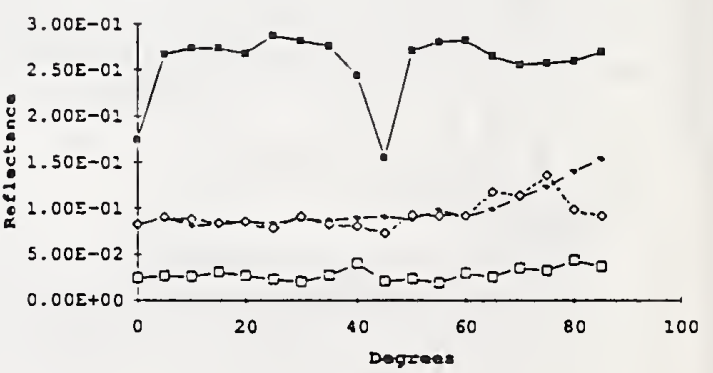

Figure 8. Relative Directional Reflectance for Various Materials 
C. Advanced Fire Sensing and Suppression

C1. Fire Detection 



\section{BUILDING AND FIRE RESEARCH LABORATORY \\ FIRE RESEARCH PROGRAM \\ PRIORITY PROJECT - FY93}

\section{ADVANCED FIRE DETECTION SYSTEMS}

\section{Professional Personnel}

William Grosshandler, Project Leader

Richard Smith, Physical Scientist

Marc Nyden, Research Chemist

Margaret Jackson, Co-op Student

\section{Project Objectives}

To demonstrate novel techniques for early sensing of both traditional and heretofore unidentified products of and precursors to a fire (by 9/94), and to establish a methodology for evaluating the performance of advanced fire detection systems (by 9/96).

\section{Technical Approach}

A properly designed detection system must be able to identify in a matter of seconds a fire event which may occur only once in one hundred years, and the identification must lead to an action which is appropriate to the space being protected. This disparity in time scale and the variability in geometry, content and occupancy of the space impose great demands on the system. False alarms, maintenance problems, incomplete or inaccurate information, and inappropriate suppression responses are problems which can plague current fire detection systems, especially when cost is an overriding constraint. The phase out of halons and the increased capital investment in modern industrial processes make early sensing and suppression even more imperative.

The general approach in this research is to increase the amount of unambiguous information from the fire and protected environment, and to process the information in an intelligent manner consistent with the decisions which have to be made. Advances in the sensing of temperature, species concentrations, particulate matter, and acoustic and electromagnetic radiation have been surveyed to determine their applicability to fire detection. Of the many possible stimuli generated early in a fire, we have focused our investigations on ultra-sonic acoustic emission (AE) and infrared radiation.

\section{Technical Accomplishments}

The portable open-path Fourier transform infrared (OP-FTIR) spectrometer is a recent innovation which offers distinct advantages over conventional fire detection techniques. In situ measurements of the atmosphere of interest can be made directly and in real time, circumventing problems of extractive sampling. The limits of detection decrease in direct proportion to the path length over which the spectrum is collected, with the result that extended path lengths using multiple passes can produce high 
sensitivity. The ability to operate the spectrometer in the passive and active modes can be exploited to measure both the infrared radiation emitted from a fire and the IR absorption in cooler atmospheres surrounding the fire. This could be used to locate a variety of combustion gases anywhere along its line of sight within seconds of their production, and could scan a large warehouse or outdoor storage facility in less than a minute. Research is being conducted to collect and analyze spectral features of these data and to interpret, unambiguously, those characteristic of an early fire event. The limits on sensitivity and spatial resolution are being determined so that the technique can be applied to early warning fire detection. IR spectra from 4 to $12 \mu \mathrm{m}$ have been measured with $1 \mathrm{~cm}^{-1}$ resolution in a few seconds using a recently purchased Midac OP-FTIR. Some measurements have been obtained in burning and nonburning pools of crude oil. These are described in more detail in the summary of another project, Detection and Monitoring of Fires with Open-path FTIR Spectroscopy. The narrow-band radiation model, RADCAL, has been used to produce the spectra one might expect from the early stage of pyrolyzing material.

In an experimental study conducted last year, the viability of using the acoustic signal emitted by a variety of structural materials exposed to nonuniform heating as an early indicator of a fire was demonstrated. The number of $\mathrm{AE}$ events in a minute and the cumulative energy released during the heating cycle were shown to provide a good measure of the overheated state of some structural materials. This year, a full scale room $(2.4 \mathrm{~m} \times 2.4 \mathrm{~m} \times 2.4 \mathrm{~m})$ was constructed of standard lumber and gypsum board and instrumented with $\mathrm{AE}$ transducers in a wall and in the ceiling. The structure was exposed to a $500 \mathrm{~W}$ electrical heat source within the wall and an open gas flame varying in intensity from 12 to $100 \mathrm{~kW}$. In the electrical heating experiment, the AE transducer located on the same wooden beam as the heat source responded to numerous emissions from the heated solid within a minute of the power being applied. Only one of the ceiling mounted transducers responded to the heating, which occurred about 10 minutes into the test. A conventional ceiling-mounted smoke detector did not respond at all. The amount of acoustic activity registered in the open gas burner experiments was significantly less, but two of the three AE devices did respond within about ten minutes. Again, there was no indication of a fire from the smoke detector during the 38 minutes that the flame was lit. The conclusion is that $\mathrm{AE}$ devices can detect a fire whether it is totally obstructed behind a wall or cleanly flaming in the room, two conditions under which conventional smoke detectors do not perform well. A caveat is that the performance of the AE device is dependent upon the fire or heat source being within about two meters of the fire. Whether or not this distance could be extended or the spurious signals from non-fire events could be eliminated would require additional research.

A workshop on advanced fire detection systems was held with BFRL and industrial participation. Several critical research issues were identified, with new approaches to early, reliable fire detection being one. Built-in intelligence with multi-variable signal analysis was thought to be a fruitful area for continued study. A methodology to accomplish this is being developed in this project.

\section{$\underline{\text { Reports and Publications }}$}

Grosshandler, W., "RADCAL: A Narrow-band Model for Radiation Calculations in a Combustion Environment," NIST Technical Note 1402, April, 1993.

Grosshandler, W., and Jackson, M., "Acoustic Emission of Structural Materials Exposed to an Open Flame," Fire Safety Journal, in press, 1993 (also available as NISTIR 4984, December, 1992). 


\section{$\underline{\text { Related Grants }}$}

Plumb, O.A. and Richards, R.F., "Development of an Economical Video-based Fire Detection and Location System," Washington State University.

Milke, J.A. and McAvoy, T.J., "Smart Fire Detection Using Neural Networks," University of Maryland.

Langley, L.W., "Evaluate Heat Flux Microsensor for Automatic Fire Detection," Vatell Corporation (SBIR). 



\section{BUILDING AND FIRE RESEARCH LABORATORY \\ FIRE RESEARCH PROGRAM \\ PRIORITY PROJECT - FY93}

\section{BALANCED DESIGN}

Professional Personnel

Richard W. Bukowski, Project Leader

John Gross, Structural Engineer

Scot Deal, Fire Protection Engineer

\section{Project Objective}

To quantify the performance and reliability of detection systems, suppression systems, and compartmentation including the field assessment of performance; to determine the conditions under which reduction or elimination of one or more of these results in unacceptable risk of loss, and to conduct a comparative analysis of compartmentation using fire resistive and noncombustible construction.

\section{$\underline{\text { Scope }}$}

The time available for the study is insufficient to develop the needed predictive methods to address these issues solely by modeling. Thus, there needs to be a short term approach and a long term approach. For this study, it will be necessary to rely on field data for estimates of both performance and reliability; supplemented by predictive methods wherever possible.

If the full funding can be obtained it would be possible to incorporate all of the available data and utilize existing predictive capabilities to thoroughly quantify the performance and reliability of the three target technologies. In recent years the standards (i.e., NFPA 72E and 13) have incorporated procedures for performance prediction and, in the case of detectors, for design of systems on the basis of detecting critical rates of heat release. Once these levels of performance are quantified, risk assessment techniques can be used to relate reliability modified performance levels to the risks to life and property (task one).

Risk methods will also be utilized to quantify the conditions (along with uncertainties based on sensitivity analyses) for a range of trade-off options. Again, these analyses will quantify these impacts on the basis of life safety and property protection (task two). Finally, these risk methods will be used to quantify the impact of field conditions including the propensity of FR and NC constructions to compromise and field modification on performance and reliability and thus on the risks to life safety and property protection (task three).

\section{Technical Accomplishments}

During FY93 the project planning was carried out for both the technical approach and identification of resources -- both financial and informational. A workshop was held through which the state of knowledge on field performance and reliability of the key systems was explored and the potential benefits to various industries were identified in order to build a coalition. A workshop report was prepared and committees for technical and tinancial planning were established. A general consensus was reached as to timing and direction and a program start date of October 1, 1993 was agreed. 



\section{Professional Personnel}

William Grosshandler, Project Leader

Marc Nyden, Research Chemist

Emil Braun, Physicist

\section{Project Objectives}

To determine by September, 1993, if the open-path Fourier transform infrared (OP-FTIR) spectrometer shows promise for monitoring the products formed during the overheating of materials or smoldering prior to ignition, and for measuring the concentration of noxious combustion products created in a flaming fire and during active suppression.

\section{Technical Approach}

FTIR spectroscopy is a well-established and powerful means for measuring molecular species which have infrared activity. Traditionally, gases are extracted and placed in a sample cell through which an infrared beam is passed. Recently, a new version of the FTIR spectrometer has become available which circumvents the need to physically remove the gas sample from the volume of interest. Line-of-sight measurements along paths extending over a kilometer have been demonstrated. The research challenge for BFRL is to learn how to adapt the FTIR to open path monitoring of the products formed during the overheating of materials or smoldering prior to ignition, and to measuring the concentration of toxic species created in a flaming fire and during active suppression. Sensitivity, time response and interpretation of complex spectra in a background of particulate radiation need to be established before the OP-FTIR can be integrated into an early warning fire detection system or used to assist the fire suppression process.

Application of the instrument to four different situations has been planned: controlled, large environmental oil spill fires; laboratory pool fires; pyrolyzing solids; and the release of a suppressing agent into a closed room. The features of spectra obtained under different scan rates, number of scans, and spectral resolution will be examined in these different systems to ascertain limitations to resolution of minor constituents. The Midac OP-FTIR purchased for this study operates in both the passive and active mode, and both modes will be explored.

Difficulties in interpretation of the signal from the OP-FTIR are a result of overlapping spectra multiple species, strong temperature and concentration gradients along a line of sight, fluctuations in concentrations during the sampling period, and obscuration by smoke. Our understanding of radiative heat transfer in nonisothermal environments with and without soot will be applied to the FTIR spectrum to develop narrow-band models of the important chemical species. The goal is a numerical model which will yield estimates of concentrations and their uncertainty, as well as some estimate of the temperature profile and soot concentration. Supplemental temperature measurements and multiple views of the fire may be necessary to achieve the accuracy desired. 


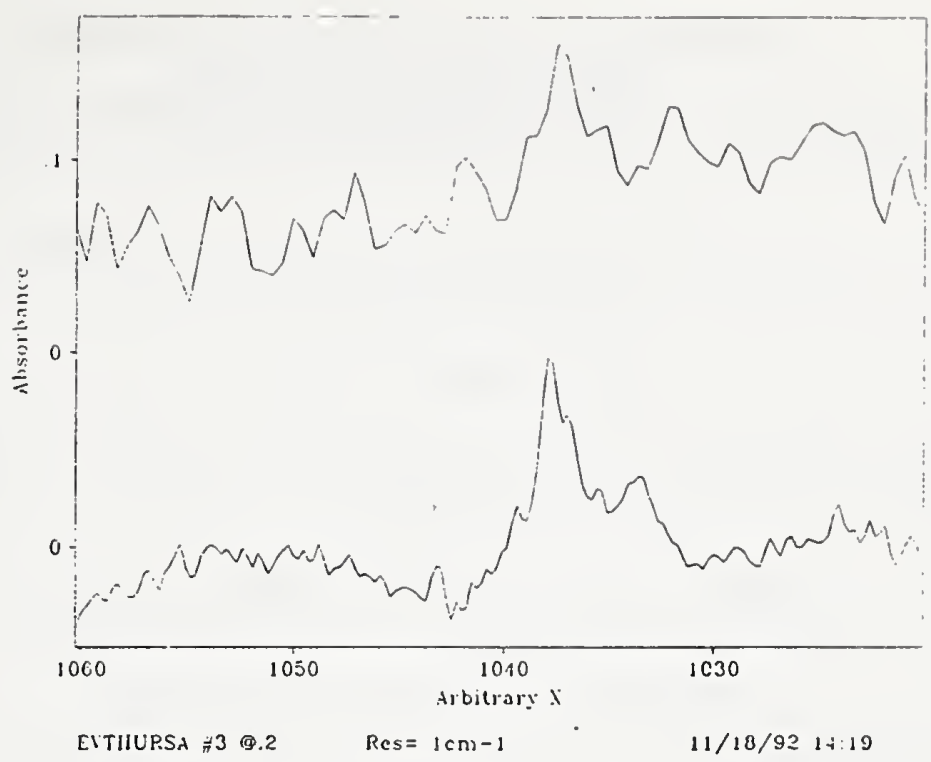

Figure 2. A spectrum measured during evaporation (top) is compared to library spectrum of benzene (bottom). The presence of benzene is indicated by peak at $1037 \mathrm{~cm}^{-1}$.

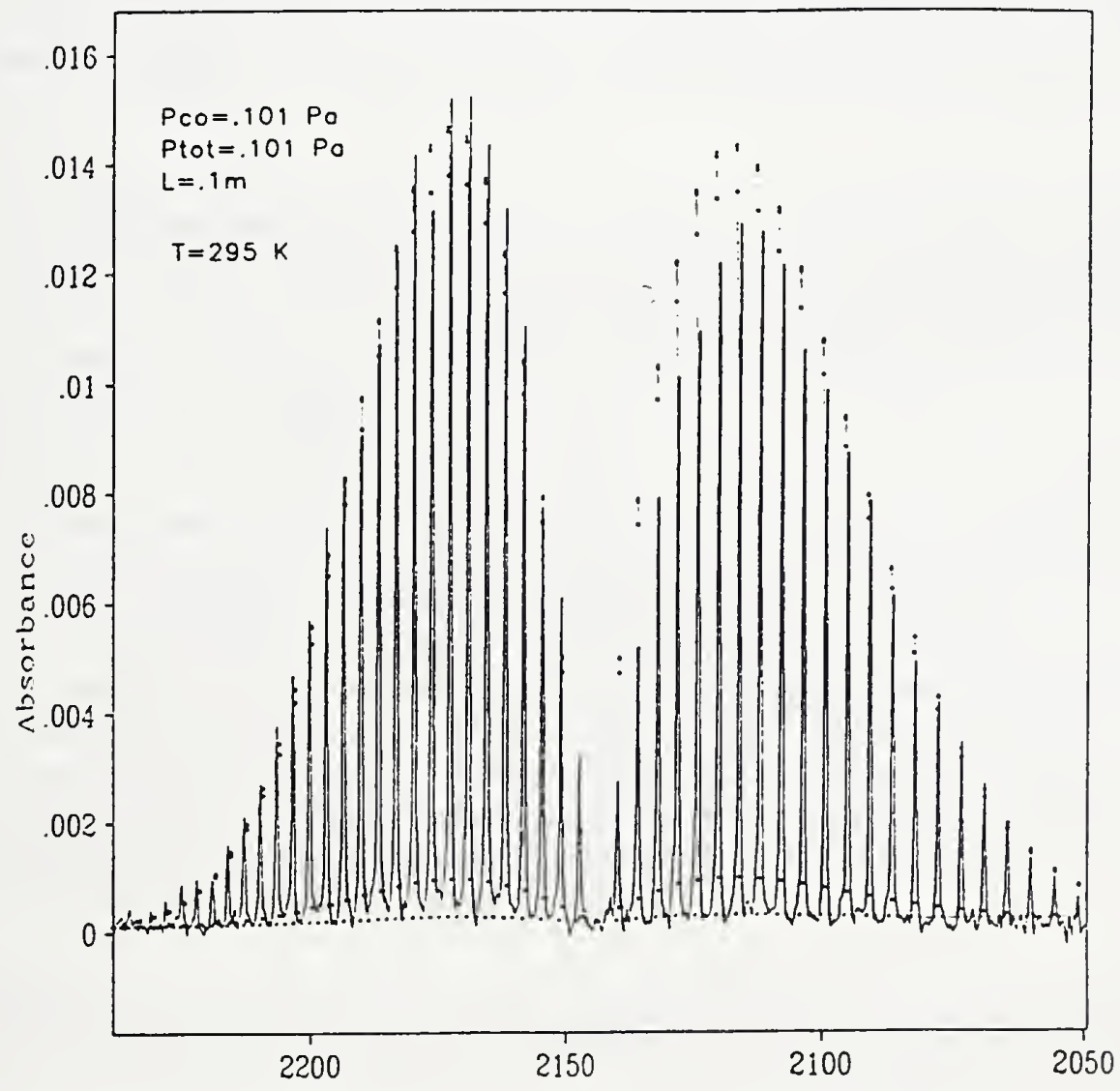

Figure 3. Result of line-by-line calculation (dotted line) compared to reference spectrum. 



\title{
BUILDING AND FIRE RESEARCH LABORATORY \\ FIRE RESEARCH PROGRAM \\ NATIONAL INSTITUTE OF STANDARDS AND TECHNOLOGY \\ GRANTEE PROJECT - FY93
}

\author{
Department of Mechanical and Materials Engineering \\ Washington State University
}

Award No. 60NANB2D1290

\section{DEVELOPMENT OF AN ECONOMICAL VIDEO BASED FIRE DETECTION AND LOCATION SYSTEM}

Principle Investigators: O.A.Plumb and R.F. Richards

NIST Scientific Officer: W. L. Grosshandler

A video fire detection system employing themochromic sensors to monitor the temperature field near the ceiling of an industrial workspace is described. The system detects and then locates fires using information about changes in the temperature field acquired by a video camera and analyzed by a personal computer. The operation of the proposed fire detection system is simulated using the compartment fire zone model LAVENT. Modifications to LAVENT, made to facilitate the analysis, are discussed. The modifications include accounting for radiative transfer between compartment surfaces and between compartment surfaces and hot emitting-absorbing combustion gases. An analysis of a prototype video fire detection system and comparison of the response times of an optimized system with a standard fusible-link sprinkler system are presented.

\section{Proposed video fire detection system}

The proposed fire detection system consists of an array of temperature-sensitive, color-changing, sensor sheets suspended from the ceiling or posted on the vertical walls of the workspace to be protected from fire threat. The sensor sheets are fabricated of microencapsulated themochromic liquid crystals (TLC) bonded to plastic backings. TLC's respond to changes in temperature by displaying a range of colors in a precise and repeatable manner. The temperature range over which the TLC color play occurs can be specified at the time of manufacture.

An inexpensive black and white video camera is used to monitor the TLC sensor sheets. Although the TLC sensor sheets are able to display a range of colors indicating a range of temperatures the proposed system makes use only of the onset of color (black to red) at the lower end of the TLC color band and the cessation of color (blue to black) at the upper end of the TLC color band.

A personal computer digitizes the image from the video camera and then determines which, if any, sensor sheets have changed color, their location in the monitored space, and the time at which the sensor sheets changed color. In this way the video system can continuously monitor the temperature field near the ceiling of the protected work space. Detecting and locating a fire depends on solving an inverse problem: calculating the location and magnitude of a heat source within a domain, given the temperature history at specified locations on the boundaries of the domain. Solving the inverse problem requires the specification and solution of the forward problem.

\section{System Simulation}

The solution to the forward problem for a compartment fire is given by the compartment fire 
zone model LAVENT. LAVENT, developed by L.Y. Cooper ${ }^{1}$ to predict in-service behavior of fusible links, computes convective heat fluxes and resultant temperatures at the ceiling of a compartment undergoing a fire. In order to accurately simulate the response of the TLC sensor sheets used in the proposed video fire detection and location system modifications were made to the LAVENT code. The modified code includes: (1) radiative heat transfer between isothemal surface elements covering the inner surface of the compartment, and (2) radiative heat transfer between compartment surfaces and the zone of isothermal, homogeneous combustion gases which accumulates at the ceiling of the compartment.

The calculation of radiative heat transfer rates involves dividing the inner surface of the compartment into 17 isothermal, rectangular area elements. Upper sidewall elements coincide with the upper hot gas zone and lower sidewall elements with the lower zone of cool ambient air. Shape factors between each of the isothemal area elements are determined by linear interpolation on tabulated values of selected shape factors and subsequent shape factor algebra.

The effect of the accumulation of absorbing-emitting combustion gases near the compartment ceiling is accounted for using a mean beam length formulation. Geometric mean beam lengths are found in the same way that shape factors are found: linear interpolation on tabulated values for selected geometric mean beam lengths and subsequent shape factor algebra. The tables of geometric mean beam lengths for parallel and perpendicular plate geometries in which the entire intervening volume is filled with absorbing-emitting gas are computed using closed form expressions.

For geometric mean beam lengths where both absorbing-emitting gas zones and diathermanous gas zones are traversed (for example between an upper sidewall element surrounded by hot gas and a lower sidewall element surrounded by ambient unbumed air) no closed form equation is available in the engineering literature. Numerical integration was performed to produce the geometric mean beam lengths for the geometries of interest.

Upon inspection the new geometrical mean beam lengths were found to be well characterized with the closed fomm solutions mentioned above and an " $f$ " factor. The f factor is defined to be the ratio of the geometric mean beam length for the partially absorbing gas filled compartment to the geometric mean beam length for the entirely absorbing gas filled compartment. The factor $f$ can be correlated, to good approximation, as a function only of the ratio of the absorbing gas layer thickness to the total compartment height. As a consequence engineering calculations for partially gas filled compartments can be made conveniently using the new f function. At present geometric mean beam lengths are used in the radiation code as a first order approximation to the true mean beam lengths.

Effective absorptivities for the hot, soot-laden combustion gases produced by the fire are calculated using the "ABSORB" subroutine developed by Modak. The code accounts for band radiation from carbon dioxide and water vapor as well as continuous radiation from soot for homogeneous, isothemal gas volumes.

Transfer factors between compartment surface elements and between surface elements and the enclosed absorbing-emitting gas are calculated using the plating algorithm of Edwards. The routine involves a recursive algorithm in which transfer factors are found by changing the emissivity of each surface in tum from unity to its actual value (hence "plating").

\section{Optimization of the Proposed Video Fire Detection System}

The modified version of LAVENT was used to optimize a prototype video fire detection system, and then to compare the response time of the optimized system with a standard fusible-link sprinkler system. In the present analysis the time to detection for the video system, $t_{d}$, is taken to be the time

1 Cooper, L.Y., "Estimating the Environment and the Response of Sprinkler Links in Compartment Fires with Draft Curtains and Fusible Link-Actuated Ceiling Vents - Theory," Fire Safety Joumal 16, 137-163 (1990). 
from the start of the fire to the first sensor sheet color change. The optimization and evaluation of the video fire detection system was carried out for two workspace environments: a large warehouse $(76 \times 61$ $x 9 \mathrm{~m})$ and a medium size commercial or office space $(10 \times 10 \times 3 \mathrm{~m})$. Two kinds of fire threats were simulated in each of the workspaces: fires with constant themal output and fires with growth rates that are quadratic in time.

The performance of the proposed video fire detection system was analyzed by running the modified LAVENT code to determine heat fluxes and resultant temperatures across the ceiling of the monitored space over time. Figure 1 shows the temperature rise on the ceiling of the large warehouse versus $\mathrm{r} / \mathrm{H}$ for three constant output fires $(\mathrm{Q}=200,600,1000 \mathrm{~kW})$ after 300 seconds. The variable $\mathrm{r}$ is the horizontal distance to the fire while $\mathrm{H}$ is the height of the enclosure $(\mathrm{H}=9 \mathrm{~m}$ in the warehouse). The temperature profiles represent very nearly steady-state conditions in the warehouse.

Figure 1 clearly shows that to detect small fires $(Q=200 \mathrm{~kW})$ any temperature sensors mounted at or near the enclosure ceiling must be able to respond to small increases in temperature above ambient. However, if sensors can reliably respond to small temperature increases above ambient sensors can be spaced fairly far apart. In the case of a $200 \mathrm{~kW}$ fire, sensors responding at a detection temperature above ambient of $\left(T_{d}-T_{a m b}\right)=10 \mathrm{C}$, could be at a distance of $r / H=0.3$ from the fire and still detect the fire. This value of $r / H$ corresponds to a distance between sensors of $d_{s}=6 m\left(d_{s}=2(r / H) H\right)$.

Figure 2 shows the time to detection, $t_{d}$, versus $r / H$ for the three constant output fire scenarios considered in Fig. 1. For comparison purposes, the time to detection of a quadratically growing fire $(\mathrm{Q}(\mathrm{t})$ $\left.=1055(\mathrm{t} / 130 \mathrm{~s})^{2}\right)$ is also shown. Each curve has been calculated assuming a sensor sheet detection temperature of $T_{d}=311 \mathrm{C}(100 \mathrm{~F})$ and an ambient temperature of $T_{\text {amb }}=300 \mathrm{~K}(80 \mathrm{~F})$.

For the larger constant output fires $(\mathrm{Q}=600 \mathrm{~kW}, 1000 \mathrm{~kW})$ the time to detection is seen to rise slowly with $\mathrm{r} / \mathrm{H}$ for values of $\mathrm{r} / \mathrm{H}<0.5$ and then more rapidly for $\mathrm{r} / \mathrm{H}>0.5$. The time to detection for the quadratically growing fire, rises even more slowly with $\mathrm{r} / \mathrm{H}$. Only for the smallest constant output fire $(\mathrm{Q}=200 \mathrm{~kW})$ does time to detection increase rapidly for all values of $\mathrm{r} / \mathrm{H}$. Except for small fires, the use of widely spaced sensors does not necessarily result in significantly longer detection times.

Sensor spacing may be formally optimized by introducing a Figure of Merit. Figure 3 shows the Figure of Merit, $t_{d} n_{s}$, plotted against $r / H$ for the fire scenarios of Fig. 2. The presence of the time to detection , $t_{d}$, in the Figure of Merit is self-explanatory. The number of sensor per unit area, $n_{s}$, is included as a multiplicative factor with the time to detection, $t_{d}$, because the cost and complexity of the fire detection system is expected to scale with the number of sensors that must be installed and monitored. Defined in this way, the Figure of Merit gives an indication of how increasing the number of sensors, $n_{s}$, (or decreasing sensor spacing, $d_{s}$ ) affects the time to detection, $t_{d}$, for the system. Where the curve in Fig. 3 is flat, cutting sensor spacing in half will also cut time to detection in half. Where the curve has a negative slope, decreasing sensor spacing will bring diminishing retums in reduced time to detection. An optimized system would have sensor sheets spaced with an $\mathrm{r} / \mathrm{H}$ at or just to the left of the minimum of the Figure of Merit curve.

Figure 3 shows that sensor spacing is optimized for all four fire scenarios simulated in the large warehouse over the same range of $\mathrm{r} / \mathrm{H}: 0.1<\mathrm{r} / \mathrm{H}<0.3$ (sensor spacing of $1.8 \mathrm{~m}<\mathrm{d}_{\mathrm{s}}<5.5 \mathrm{~m}$ ). An optimized system requires relatively few sensors: the $9 \mathrm{~m}$ warehouse could be protected with sensors distributed on a square grid of 2 to 5 meters.

To demonstrate the performance of the video fire detection system the time to detection for an optimized system was compared to the response time of a standard fusible-link sprinkler system. The optimized video system was taken to have sensor sheets spaced 3 meters apart with a detection temperature $T_{d}=311 \mathrm{~K}(100 \mathrm{~F})$. The fusible-link sprinkler system was specified to conform to NFPA codes with fusible links, spaced 3 meters apart, having a Response-Time-Index (RTI) of $220(\mathrm{~m} \mathrm{~s})^{1 / 2}(400$ $\left.(\mathrm{ft} \mathrm{s})^{1 / 2}\right)$ and a fuse temperature of $347 \mathrm{~K}(165 \mathrm{~F})$. Ambient temperature was taken to be $300 \mathrm{~K}(80 \mathrm{~F})$ for both systems.

Table 1 gives a summary of the times to detection for the proposed video system and the response times of the standard sprinkler system for four fire threat simulations. In every case the video 
fire detection system responds significantly faster than the standard sprinkler system. Most noteworthy is the case of the $600 \mathrm{~kW}$ constant output fire in the large warehouse. In that case the video system responds in 40 seconds while the fusible link sprinklers are never activated.

\section{Inverse Problem}

Present work is focussed on solving the inverse problem so that the proposed video system is capable not only of detecting an incipient fire but of locating the fire and gauging its size and rate of growth.

\section{Reports and Papers}

Munk, B.N., Richards, R.F. and Plumb, O.A.,"Heat Transfer in Compartment Fires," ASME Northwest Regional Graduate Student Research Conference, Corvallis, OR, April,1993.

Munk, B.N., Richards, R.F. and Plumb, O.A., "Evaluation of a Video Fire Detection System," NIST Annual Conference on Fire Research, Gaithersburg, MD, October, 1993.

\section{Figures and Tables}

TABLE 1 Time to detection of fires for proposed video syste $m$ and a standard sprinkler system

\begin{tabular}{cccc} 
Fire Output $(\mathrm{kW})$ & Environment & $\begin{array}{c}\text { Video System Time to } \\
\text { Detection (seconds) }\end{array}$ & $\begin{array}{c}\text { Sprinkler System } \\
\text { Response Time (seconds) }\end{array}$ \\
\hline $6(0)$ & Warehoust & 40 & Not activated \\
$1055(\mathrm{~V} / 30)^{2}$ & Warehouse & 100 & 250 \\
200 & Mid Size Workspace & 20 & 190 \\
$98(\mathrm{~V} / 30)^{2}$ & Mid Size Workspace & 100 & 290
\end{tabular}

Figure 1

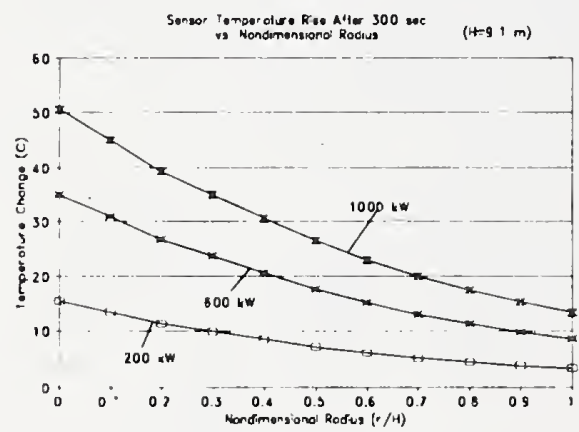

Figure 2

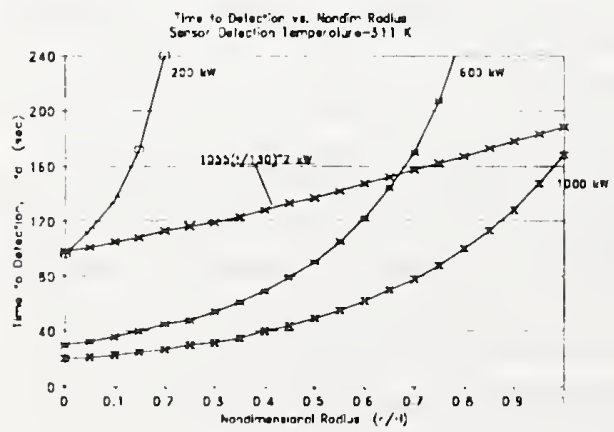

Figure 3

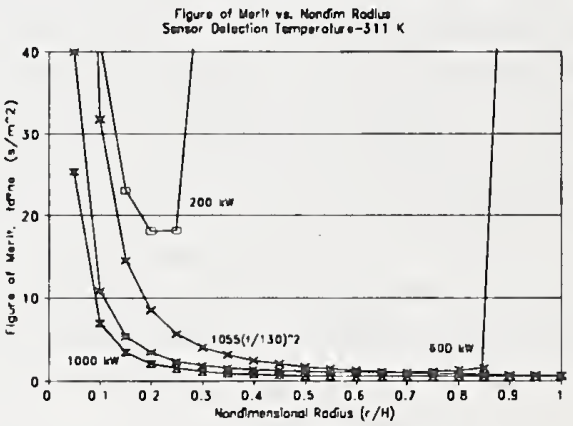




\title{
BUILDING AND FIRE RESEARCH LABORATORY \\ FIRE RESEARCH PROGRAM \\ NATIONAL INSTITUTE OF STANDARDS AND TECHNOLOGY \\ GRANTEE PROJECT FY93
}

\author{
DEPARTMENT OF FIRE PROTECTION ENGINEERING AND \\ DEPARTMENT OF CHEMICAL ENGINEERING \\ UNIVERSITY OF MARYLAND AT COLLEGE PARK
}

\author{
60NANB2D 1300 \\ SMART FIRE DETECTION USING NEURAL NETWORKS
Principal Investigators: James A. Milke and Thomas J. McAvoy
Research Assistants: Samuel J. Denny and Dongling Pan \\ NIST Scientific Officer: William L. Grosshandler
}

\begin{abstract}
This research was motivated by progress made by Okayama. As a result of Okayama's small-scale experiments, the combination of the gas sensors and a neural network was able to discriminate between odors from fire and non-fire sources. The purpose of the research is again to integrate neural networks with sensors to develop a smart fire detector. The desired capabilities of this detector include very short response times, detection of fires associated with a wide variety of scenarios and discrimination between fire and non-fire or environmental sources. Complete development of such a detector involves a multi-year effort. During this one year study, effort concentrated on assessing sensor response characteristics relative to smoldering fires and nonfire or environmental sources associated with residences. In addition, initial neural networks were developed to demonstrate their utility in improving the discrimination ability of very sensitive fire sensors.
\end{abstract}

At the University of Maryland, the initial research effort was conducted by two teams: one in the Department of Fire Protection Engineering under the direction of J. Milke and another in the Department of Chemical Engineering under the direction of T. McAvoy. The fire protection engineering team concentrated on designing and building a small-scale experimental apparatus and initiating experiments to identify signatures from fire and non-fire sources. The chemical engineering team investigated the applicability of various neural networks for fire detection. The accomplishments of each team are described below.

\section{Fire Protection Engineering Team}

An operational, small-scale experimental apparatus was developed to characterize the signatures from fire and non-fire sources. The apparatus and experimental procedure are conceptually similar to those by Okayama. Okayama's experimental program was modified to provide a greater range of measurements to describe the signature.

The experimental apparatus illustrated in Figure 1 includes a means for generating smoke or odors, measurement equipment and sensors. The apparatus is adapted from the "smoke-box" specified in UL 217. The principal modification consists of the straight configuration rather than the U-shaped configuration in UL 217. The overall length of the apparatus is approximately $150 \mathrm{~cm}$ and the cross-sectional area is $0.09 \mathrm{~m}^{2}$. Instruments provide measurements of light obscuration, temperature, presence of oxidizable gas and gas species concentrations $\left(\mathrm{CO}, \mathrm{CO}_{2}\right.$ and $\left.\mathrm{O}_{2}\right)$.

Sources of the smoke or odor are placed under a hood at the inlet end of the apparatus. Smoke and odors can be produced from a wide range of conditions: flaming and smoldering combustion of samples, heating 
to increase the volatility of samples and samples maintained at ambient conditions where the odor is introduced into the box via an atomizer.

To date, 42 experiments have been conducted using a varicty of fuels and environmental sources which are encountered in the home. Examples of fuels include kerosene, paint thinner, household vegetable oil, paper, styrofoam, burnt toast and hair spray. The tests consist of introducing vapors or combustion products into the test apparat us using a blower to induce movement of the vapors past the sensors. As an example, the set of data obtained from the experiment with flaming isopropyl alcohol is provided in Figure 2.

\section{Chemical Engineering Team}

During the first year several major objectives were achieved. In addition to existing software developed at Maryland, new programs have been developed and codes have been obtained from other researchers. Simulations of the Freeman olfactory models, based on real olfactory neural systems, have been developed and run on a SPARK workstation. A computer code from Purdue on an ellipsoidal, radial basis neural network has been obtained and made operational. The ellipsoidal network has a number of excellent features in terms of detecting faults. Mathematically, the fire detection problem is a special case of fault detection. Third, data containing measurements on good and bad screws has been obtained from Freeman at Berkeley. This data has been analyzed using the ellipsoidal network to compare its results with those published by Freeman who used several neural networks including his own olfactory models. While the ellipsoidal network did well, a network based on the offactory system did the best. The results of using various neural network approaches on the screw data are given in Table 1. The results for the first five cases are taken from Yao, et al.

The results in Table 1 were calculated from two different methods of preprocessing the raw data: binarization via a geometrical approach and via a statistical approach. The most important classification problem is determining which parts are unacceptable. For this problem, the more complicated Freeman olfactory model performed the best, though only a small data set was involved, including 10 good and 10 bad screws.

As mentioned above, fire detection is a special case of fault detection. Thus, a good method for fault detection is potentially a good method for fire detection. Initial simulation studies on detecting faults in chemical plants and will continue this work in the second year. A test problem from the literature has been coded for this work. It can also be mentioned that coupling sensors and neural networks has potential in other problem areas as well. Most important of these areas is detection of emissions from chemical plants.

Summary

As a result of the initial effort in smart fire detection using neural networks, an early fire detection system based on odor detection appears feasible. An excellent computational foundation has been laid to begin the analysis of the data from the fire experiments. However, many questions still remain prior to the application of this technology as a means of early fire detection. Additional research is required to identify optimum types of sensors which should be coupled together to provide prompt detection and discriminate between fire and environmental sources of odors.

Acknowledgements:

The technical guidance provided by William Grosshandler on sensor technology is appreciated. In addition, technical information on the operating mechanisms of gas sensors, with emphasis on metal oxide sensors, provided by Steve Semancik, Process Measurements Division, NIST, has been very beneficial. 
TABLE 1

\begin{tabular}{||l|c|c|}
\hline & \multicolumn{2}{|c|}{ Classification Rates } \\
Classification Approach & Unacceptable Parts & Acceptable Parts \\
\hline \hline Direct classification by distance (G)* & $56 \%$ & $56 \%$ \\
Direct classification by distance (S)** & $60 \%$ & $70 \%$ \\
\hline Olfactory KII model (G) & $70 \%$ & $70 \%$ \\
Olfactory KII model (S) & $60 \%$ & $70 \%$ \\
\hline Olfactory KIIl model (G) & $70 \%$ & $100 \%$ \\
Olfactory KIII model (S) & $70 \%$ & $60 \%$ \\
\hline Hopfield model (G) & $60 \%$ & $70 \%$ \\
Hopfield model (S) & $60 \%$ & $70 \%$ \\
\hline Backpropagation network (G) & $60 \%$ & $75 \%$ \\
Backpropagation network (S) & $60 \%$ & $75 \%$ \\
\hline Ellipsoidal network*** & $62.5 \%$ & $80 \%$ \\
Ellipsoidal network(G) & $70 \%$ & $80 \%$ \\
Ellipsoidal network(S) & $72.5 \%$ & $80 \%$ \\
\hline
\end{tabular}

* G: Binarization via Geometrical Approach

** S: Binarization via Statistical Approach

*** No Binarization

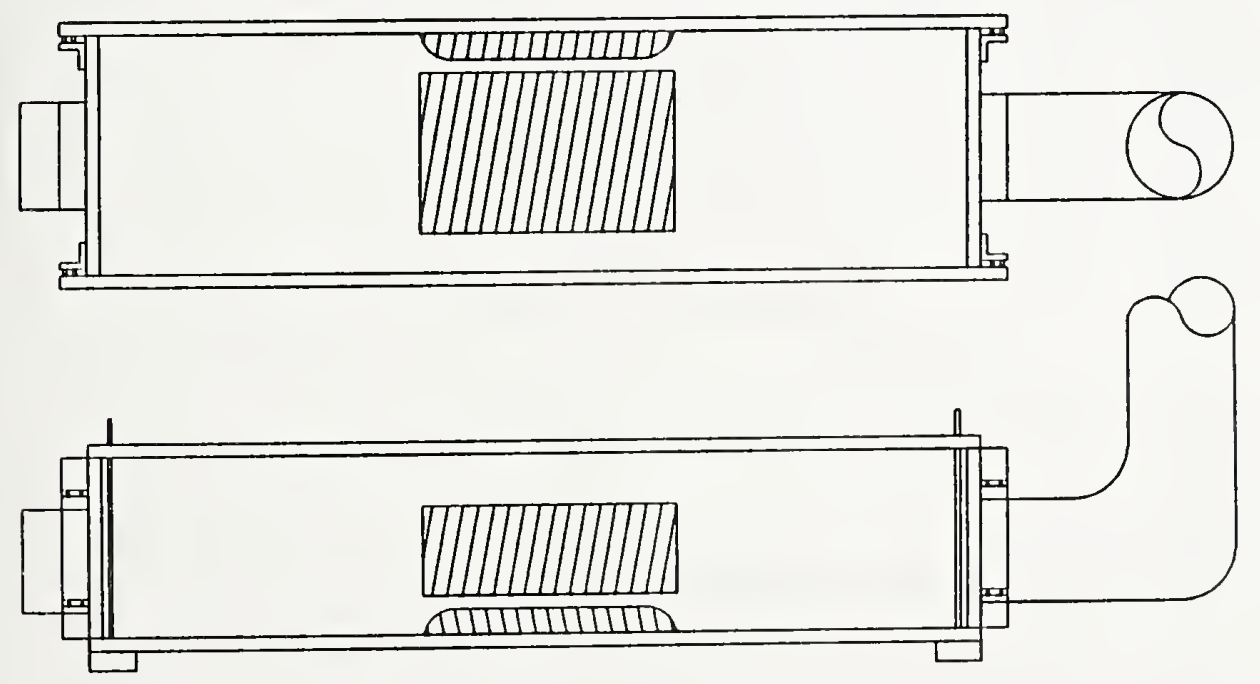

\section{IIIIIIII Sensor placement regions}

Figure 1. Schematic Diagram of Experimental Apparatus 

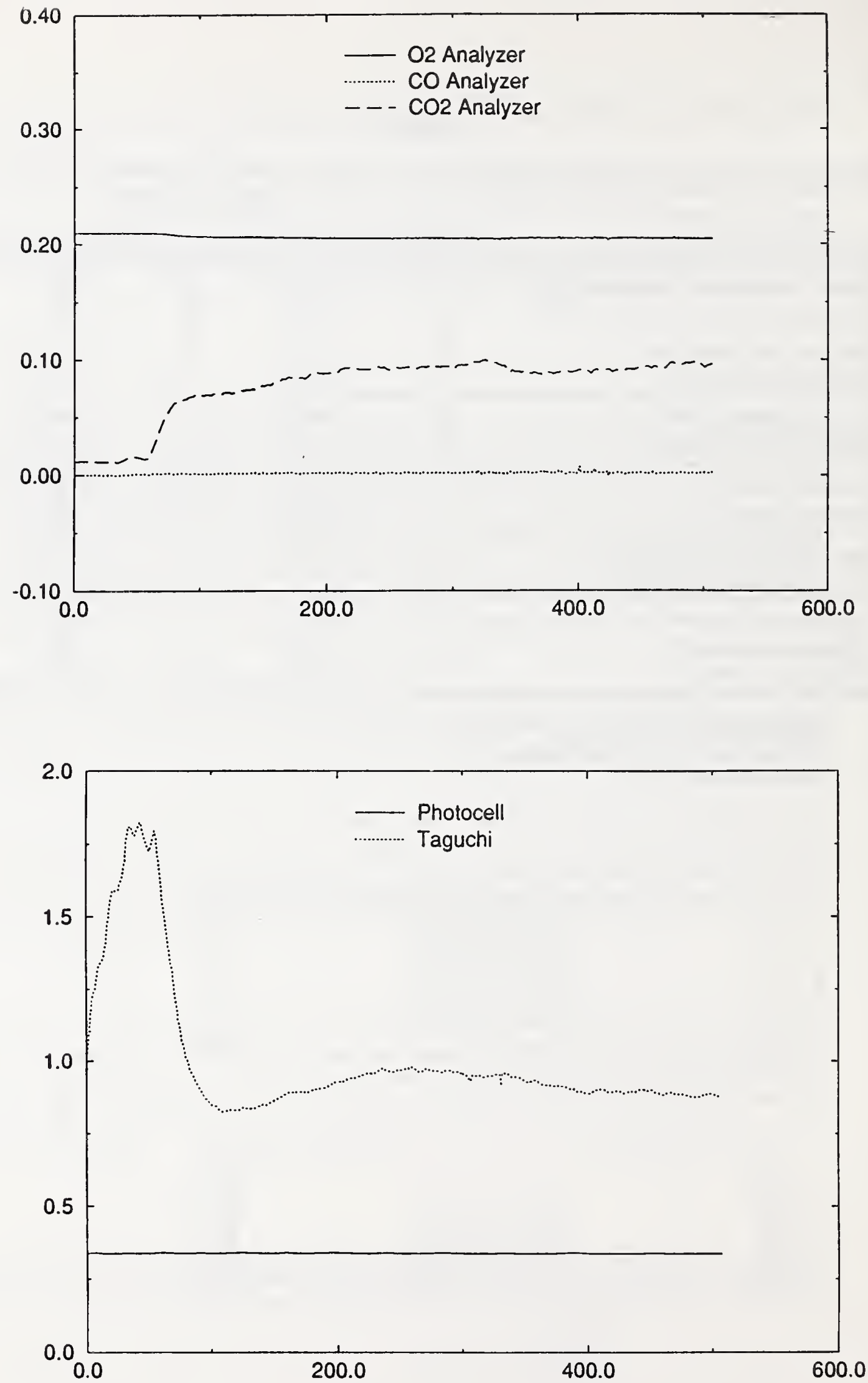

Figurc 2. Ditat from Flaming Isopropyl Alcohol (ignited (a $60 \mathrm{~s}$ ) 
C2. Fire Suppression 



\section{BUILDING AND FIRE RESEARCH LABORATORY \\ FIRE RESEARCH PROGRAM \\ OTHER AGENCY PROJECT - FY93}

\section{AGENT SCREENING FOR HALON 1301 AVIATION REPLACEMENT}

Funding Agency: U.S. Air Force, Wright Laboratory

Professional Staff: William Grosshandler (Project Leader), Richard Gann, Anthony Hamins, Marc Nyden, William Pitts, John Yang, Michael Zachariah

Project Objective: To establish a comprehensive experimental program to screen eleven specified agents, sodium bicarbonate powder, and other promising chemicals as a means to identify (by 9/30/93) the best three candidates for a subsequent full-scale aircraft fire extinguishment evaluation program.

Technical Approach: A series of carefully designed experiments is being conducted to examine the thermodynamic properties of alternative fire fighting agents, their behavior during two-phase flow and interaction with flame chemistry, and the effect of the nature of the fire and the timing of release on the agents' effectiveness. Theoretical models are being used to interpret the results, to increase understanding of the suppression process, and to predict behavior over an expanded range of operating conditions.

Technical Accomplishments: The pressure of the eleven agents, pure and mixed with nitrogen and $\mathrm{CF}_{3} \mathrm{H}$, has been determined for a $1 / 3$ liquid-filled condition at a temperature of 210,295 and $422 \mathrm{~K}$. The rate at which the material leaves a $500 \mathrm{ml}$ vessel pressurized to $4 \mathrm{MPa}$ with a $17 \mathrm{~mm}$ opening has been measured in about half of the compounds. The thrust of the liquid jet and the droplet behavior is being measured using high speed photography, piezo-electric transducers and laser extinction. The concentrations of all eleven agents necessary to extinguish flames in three distinct burner arrangements (cup burner, opposed-flow diffusion burner, and turbulent jet spray burner) have been measured. The decrease in pressure ratio and flame speed is being used to assess the performance of the eleven agents in a detonation tube burning ethene/air mixtures. Experiments with sodium bicarbonate powder are being conducted in the cup burner, OFDF and jet burner facilities. In addition to the experimental program, considerable effort has gone into modeling various phenomena associated with the suppression process. A chemical kinetic mechanism for the interaction of fluorinated agents with a flame has been developed; molecular bond computations are being used to help identify other promising chemicals not on the original list of eleven; and fluid mechanical models of the discharge process are assisting in the interpretation of the cold-flow experiments.

\section{Reports and Publications:}

Pitts, W.M. et ai., "Dynamics of the Release of Alternate Halon Replacement Agents from Pressurized Bottles," Halon Alternatives Tech. Working Conference, Univ. of New Mexico, Albuquerque, May 1993.

Yang, J.C., et al., "Solubilities of Nitrogen and Freon-23 in Alternative Halon Replacement Agents, " Halon Alternatives Technical Working Conference, University of New Mexico, Albuquerque, May 1993.

Grosshandler, W.L., et al., "Assessment of Halon Alternatives for Suppression of Turbulent Spray Flames," Halon Alternatives Technical Working Conference, University of New Mexico, Albuquerque, May 1993.

Cooper, L.C., "Discharge of Fire Suppression Agents from a Pressurized Vessel: A Mathematical Model and its Application to Experimental Design," NISTIR 5181, May 1993. 


\section{BUILDING AND FIRE RESEARCH LABORATORY \\ FIRE RESEARCH PROGRAM \\ OTHER AGENCY PROJECT - FY93}

\section{AGENT/SYSTEM COMPATIBILITY FOR HALON 1301 AVIATION REPLACEMENT}

\section{Funding Agency: $\quad$ U.S. Air Force, Wright Laboratory}

Professional Staff: $\quad$ Richard Gann (Project Leader), Emil Braun, Thomas Cleary, George

Mulholland, Richard Harris, Gregory Linteris, Richard Peacock; Gregory McKenna (MSEL), Richard Ricker (MSEL), Mark Stoudt (MSEL), William Waldron (MSEL)

Project Objective: $\quad$ Provide data for the appraisal of twelve USAF-specified candidate halon 1301 replacements for compatibility with flight systems, people, and the environment; recommend (in conjunction with the "Agent Screening" project) 3 candidates for further examination; perform longer-term testing to increase confidence in the preliminary results.

Technical Accomplishments: There have been two additions to the list of chemicals to be assessed and one deletion. All chemicals have been screened for non-volatile residues. One-month tests for compatibility with metals (for potential storage cylinders), gasket materials and lubricants are underway. These are being followed by testing of mechanical properties. One-month tests for storage under elevated pressure and temperature are nearly complete. Determinations are underway to assess possible uneven distribution of the chemicals following an accidental discharge in a compartment. An evaluation of potential environmental regulations that could restrict the use of the chemicals is underway.

Publications: None 



\section{BUILDING AND FIRE RESEARCH LABORATORY \\ FIRE RESEARCH PROGRAM \\ NATIONAL INSTITUTE OF STANDARDS AND TECHNOLOGY \\ GRANTEE PROJECT - FY 93}

Institution:

Grant Number:

Title:

Principal Investigators:

Other Professional Personnel:

NIST Scientific Officer:
The University of Michigan

60NANB2D 1293

BASIC RESEARCH ON FiRE SUPPRESSION

Dr. Arvind 'Atreya

Department of Mechanical Engineering and Applied Mechanics The University of Michigan; Ann Arbor, MI 48109-2125

Todd Crompton (M. S. candidate) \& Jacil Suh (Ph.D candidate)

Dr. William Grosshandler

\section{TECHNICAL ABSTRACT:}

\section{INTRODUCTION:}

Literature on fire suppression severely lacks quantitative results on the amount of agent required and the application rate needed to suppress fires and prevent their re-ignition. As a result, little comparison between various agents is possible. Also, qualitatively the suppression actions of various agents are known (such as cooling of the condensed-phase, isolation of fuel and oxidizer, etc.) but the quantitative details of the mechanisms responsible for the agent's action are not well known. Even for water, there is little quantitative understanding regarding the extinguishment mechanisms. Thus, it has not been possible to determine how much water is actually required and what should be the application strategy. The amount of water used is often about two orders of magnitude larger than that nceded in controlled laboratory experiments. The current knowledge of suppression mechanisms of halons is also insufficient to provide a clear understanding of the important chemical mechanisms. Most importantly, there does not exist a scientific basis for comparing the suppression effectiveness of physical and chemical suppression agents. This prevents development of new, perhaps more efficient, suppression agents and application strategies.

Thus, as a first step, we are devcloping an experimental and theoretical framework that will: (i) provide a quantitative understanding of the mechanisms (chemical and/or physical) responsible for extinguishment, (ii) enable determination of the suppression rate, time to extinguishment and agent application strategies, (iii) enable evaluation of suppression effectiveness which is needed for rational comparison of various suppression agents. The present work addresses this research problem through well-controlled small-scale laminar stagnation-point flow and counterflow diffusion flame experiments and modeling. This work focuses on water to help establish a standard for comparison with other suppression agents.

\section{SUPPRESSION EXPERIMENTS:}

Water, the most widely used suppression agent, is thought to be chemically inert in a fire and is believed to have a physical effect. However, there is little information on the magnitude of these effects during fire suppression. Physical coolir r. of porous and non-porous solids by water droplets was 
investigated extensively carlier by Dr. diMarzo ${ }^{(1)}$ and the present author ${ }^{(2)}$. Both these are quantitative studics, but were conducted on hot solids in the absence of a diffusion flame. Current results are obtained in the presence of a diffusion flame. (At the time of these earlier studies, physical cooling by water droplets and reactant dilution were belicved to be the only fire suppression mechanisms of water). Initially experiments were done with water as the extinguishing agent applied to a burning PMMA sample in the stagnation-point flow configuration. These experiments revealed some unexpected and very interesting phenomena. Two simultaneous cffects were found as a result of water application: (i) chemical enhancement of burning rate (which is important only when the flames become sooty; Note: most fires are sooty), and (ii) physical cooling of the solid via water evaporation and the resulting dilution of combustible vapor. The chemical enhancement effect is new and has not been previously reported. This is probably because water is usually applied in large quantities and in this domain the physical cooling effect dominates. To scparate the chemical and physical effects of water application, PMMA was replaced by a porous ceramic gas burner. Thus, physical cooling effect was eliminated leaving only dilution and chemical enhancement effects.

Results of the gas experiments conducted in both stagnation-point flow and counterflow diffusion flame configurations are described below. Methane was chosen as the fuel and methane flow rate, oxidizer flow rate and extcrnal radiation were held constant. Experiments were conducted for different $\mathrm{O}_{2}$ concentrations (to change the soot volume fraction) and for different constant water application rates. The overall transient species composition measurements in the exhaust gases of the stagnation-point flow apparatus were used to calculate the effect of water droplets on the overall heat release rate. Clearly, an increase in the $\mathrm{CO}_{2}$ production rate and $\mathrm{O}_{2}$ depletion rate corresponds to an increase in the burning rate and vice versa. Representative results for three different oxygen concentrations are presented here: (i) $12 \% \mathrm{O}_{2}$ which produced a bluc flame, (ii) $15 \% \mathrm{O}_{2}$ which produced a sooty yellow flame, and (iii) $30 \%$ $\mathrm{O}_{2}$ which produced a high temperature bright and sooty flame.

\section{Blue $\underline{C H}_{4}$ flame $\left(12 \% \underline{O}_{2}\right)$}

As a result of fuel dilution due to water evaporation: $\mathrm{CO}_{2} \& \mathrm{CO}$ production rates and $\mathrm{O}_{2}$ depletion rates were decreased. Less hydrocarbons were burned and hydrocarbon percentage increased until extinguishment was obtained. Chemical enhancement was not observed in any of our experiments with non-sooty (bluc) flames. $\mathrm{CO}_{2}$ production rates for a blue methane flame are presented in Fig. 1 for various water application rates (applied during 300 to $1200 \mathrm{sec}$ ). Absence of chemical enhancement of the burning rate may be becausc of low flame temperatures. It is also possible that water reacts more easily with intermediate products of soot formation. Flame structure measurements in the counterflow diffusion flame apparatus are being performed to resolve these questions.

\section{Sooty $\mathrm{CH}_{1}$ flame $\left(15 \% \mathrm{O}_{2}\right)$}

As the water application rate was increased, first the $\mathrm{O}_{2}$ depletion rate and $\mathrm{CO} \& \mathrm{CO}_{2}$ production rates were observed to increase. This implies an increase in the heat release rate (i.e. more efficient combustion). With further increase in the water application rate, $\mathrm{CO}$ production rate continued to increase even after the $\mathrm{CO}_{2}$ production rate stopped increasing. Thus, there was not enough $\mathrm{O}_{2}$ available to oxidize $\mathrm{CO}$ to $\mathrm{CO}_{2}$. Eventually, with further increase in the water application rate, dilution effects become dominant and the flame was extinguished. Also, unburned hydrocarbon concentration increased throughout -first due to reduction in soot formation and later due to dilution effects. $\mathrm{O}_{2}$ depletion measurcments for various water application rates are shown in Fig.2. It is interesting to note that $\mathrm{CO}$ production rate increased for all cases of the yellow flame, whereas it decreased for all cases of the blue flame. 
Bright sooty flame $130 \% \mathrm{O}_{2} \mathrm{~L}$

Further increase in the oxygen concentration makes the flame more sooty and bright yellow. Also, for the same flow rates of fuel and oxidizer, the flame moves closer to the porous ceramic surface. Since the flame temperature is significantly increased, water addition is expected to be more effective. Results of such an experiment are shown in Fig. 3 for $13.3 \mathrm{mg} / \mathrm{sec}$ water application rate. Note that both $\mathrm{CO}$ and unburned hydrocarbons are oxidized to $\mathrm{CO}_{2}$. This clearly shows chemical enhancement of the buming rate due to water application. Similar experiments conducted with $40 \%$ dilute solution of $\mathrm{HBr}$ show a reduction in the burning rate.

These results are consistent with the experiments conducted in sooty (fuel-rich) methane counterflow diffusion flames ${ }^{(3)}$. Here detailed flame structure measurements were made. It was found that by reducing the $\mathrm{O}_{2}$ concentration while maintaining the flame temperature by preheating the reactants (thus reducing the $\mathrm{H}_{2} \mathrm{O}$ concentration in the reaction zone) led to an early soot inception and increased soot volume fraction. However, direct addition of only $3.6 \% \mathrm{H}_{2} \mathrm{O}$ (while holding all other conditions constant) resulted in delayed soot nucleation and a significant reduction in the soot volume fraction. These observations can be consistently explained by the mechanism of $\mathrm{OH}$ interference with soot inception. An increase in the $\mathrm{H}_{2} \mathrm{O}$ concentration (brought about either by an increase in the $\mathrm{O}_{2}$ concentration or by direct addition) results in an increase in the $\mathrm{OH}$ concentration provided the flame temperature is high enough. This reduces the $\mathrm{PAH}$ and $\mathrm{C}_{2} \mathrm{H}_{2}$ concentrations (the corresponding reduction in total hydrocarbons and CO was observed in the stagnation-point flow diffusion flame) and delays soot inception. This substantially decreases the ultimate soot loading and increases the combustion efficiency and hence the burning rate.

A model based upon the SANDIA CHEMKIN ${ }^{(4)}$ code is being used to help understand the changes in the flame structure caused by water addition. Comparison of the model results with experiments and possible suppression mechanisms are also presented.

\section{REFERENCES}

[1] Abu-Zaid, M., and Atreya, A., "Transient Cooling of Hot Porous and Non-Porous Ceramic Solids by Droplet Evaporation," Presented in the Poster Session of the 22nd. Symposium (International) on Combustion and accepted for publication in the ASME J. Heat Transfer, being revised, 1992.

[2] diMarzo, M.; Liao, Y.; Tartarini, P.; Evans, D. D.; Baum, H. R.; "Dropwise Evaporative Cooling of a Low Thermal Conductivity Solid," IAFSS, 3rd International Symposium, 1991.

[3] Zhang, C., Atreya, A. and Lee, K., "Sooting Structure of Methane Counterflow Diffusion Flames with Preheated Reactants and Dilution by Products of Combustion," Twenty-Fourth Symposium (International) on Combustion, The Combustion Institute, 1992, in press.

[4] Kee, R. J., Rupley, F. M., and Miller, J. A., "A Fortran Chemical Kinetics Pakage for the Analysis of Gas-Phase Chemical Kinetics," SANDIA REPORT, Sand89-8009B.UC-706, Sandia National Laboratories, 1991. 
Blue methane flame: $12 \% \mathrm{O}_{2}$

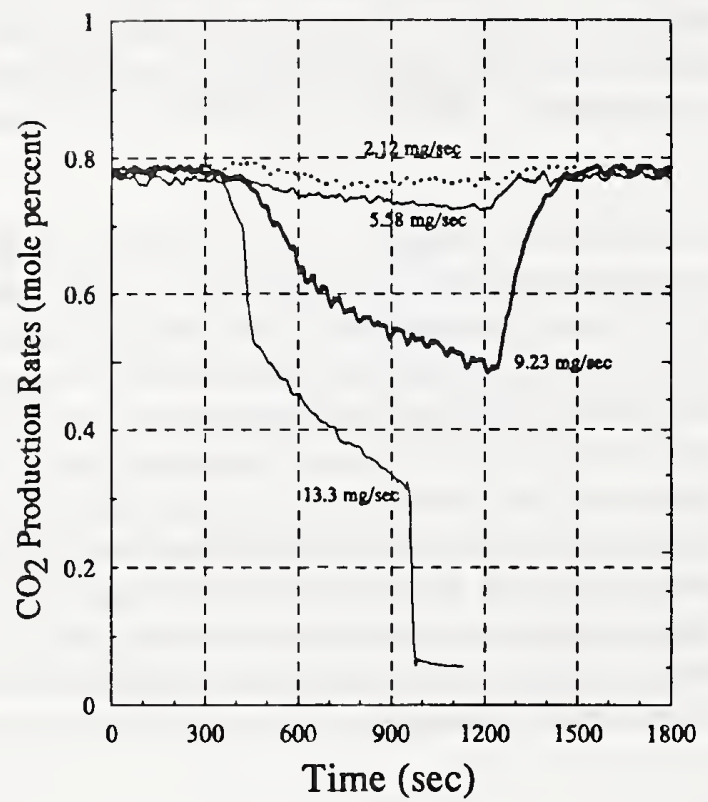

Methane: $15 \% \mathrm{O}_{2} ; 2.12-13.3 \mathrm{mg} / \mathrm{s} \mathrm{H}_{2} \mathrm{O}$

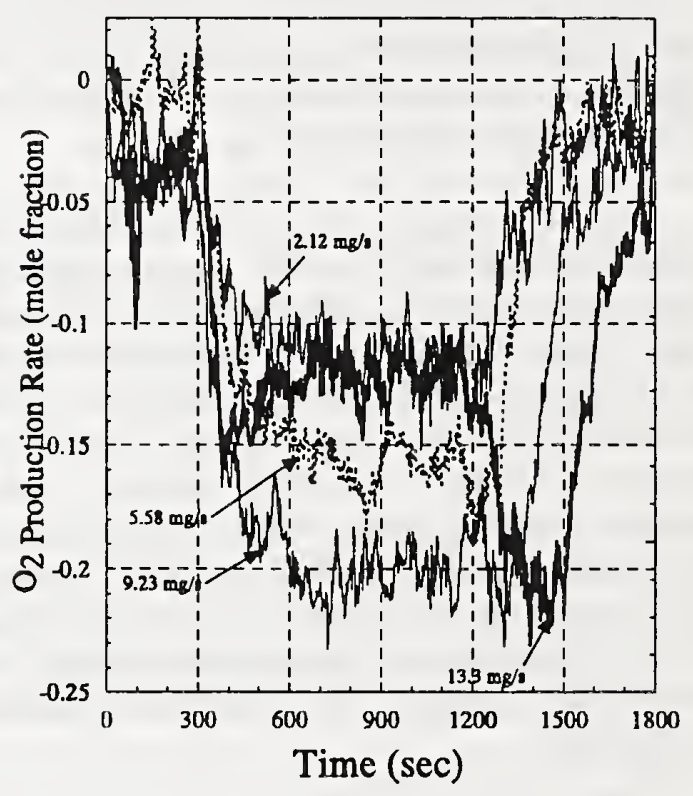

Fig. 1: $\mathrm{CO}_{2}$ production rates for various water application rates Fig. 2: $\mathrm{O}_{2}$ depletion rates for various water application rates

Methane: $30 \% \mathrm{O}_{2} ; 13.3 \mathrm{mg} / \mathrm{s} \mathrm{H}_{2} \mathrm{O}$

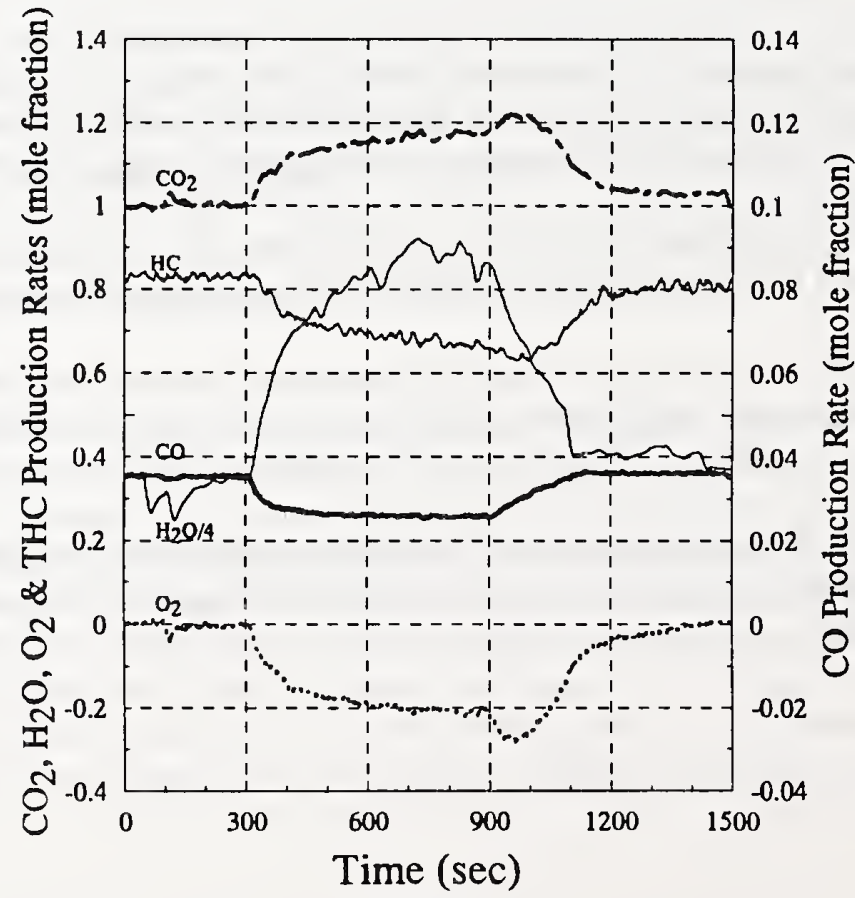

Figure 3 


\section{BUILDING AND FIRE RESEARCH LABORATORY \\ FIRE RESEARCH PROGRAM \\ PRIORITY PROJECT - FY93}

\section{DYNAMICS OF FIRE SUPPRESSION}

Professional Personnel

Gregory T. Linteris, Project Leader

Kathy Notarianni

\section{Project Objective}

To develop a long-range plan of exploratory research by June, 1993 to obtain a sufficiently fundamental understanding of the mechanisms of flame extinction by existing gaseous and water mist fire suppressants to enable the development of the next generation of suppression agents and technologies.

\section{$\underline{\text { Scope }}$}

Despite their widespread use, and notwithstanding the abundant experimental information on the quantities of inhibitors necessary to inhibit and extinguish flames, surprisingly little is known about the fundamental mechanisms by which some widely used suppressants work. Consequently, efforts to optimize the delivery and effectiveness of existing suppressants are limited. It is believed that improving the fundamental understanding of extinction and suppression will facilitate the development of more effective delivery systems as well as new agents and provide a basis for comparison of alternative suppressants.

Fire suppressants and their application methods should be effective, fast-acting, economical, have low toxicity, permit a habitable environment during suppression, leave no residue, and cause no damage to the protected space. Existing suppressants, however, are non-ideal: water can cause excessive damage, metal-based suppressants leave a residue, and the currently favored halogenated hydrocarbons may leave a corrosive residue after passing through a flame. Also, because of their suspected destruction of stratospheric ozone, the most effective halons are being phased out. There exists a continuing need for better suppressants and suppression methods.

In general, flame extinction occurs when the time necessary for chemical reaction is longer than the characteristic flow time of the system under investigation. Suppression requires flame extinction as well as prevention of re-ignition. Extinction can be achieved by increasing the reaction time, decreasing the flow time, or both. Because of the exponential dependence of reaction rate on temperature, lowering the peak flame temperature has a large affect on the reaction rate. A reduction in peak temperature can be achieved by: increasing the heat loss, reducing the heat feedback to the flame, or by lowering the effective heat release per unit mass of the reactants (often referred to as the "thermal " or "heat capacity" effect). The heat release can be reduced by addition of inert species, acting either through sensible or latent heats, or with endothermic reactions of the inhibitor. The reaction rate can also be reduced solely through kinetic effects. In these cases, the inhibitor disrupts the normal kinetics of the flame so that even at the same temperature the reaction rate is slower. For example, the inhibitor may decrease the production rate of the chain-carrying radicals in the flame (hy promoting reactions which compete with the chain-branching steps), or may increase the destruction rates of radicals (through gas-phase or surface 
catalytic reactions which recombine radicals in the reaction zone). Often both the heat release and kinetic mechanism are affected and it must be determined which is more important.

\section{Technical Approach}

Although great advances have been made in combustion science in the past eighty years, existing suppressants are based on scientific knowledge of a century ago; modern methods of combustion science have not been applied, per se, to the study of fire suppression. In fact, the modes of action of the more effective suppressants are still not fully understood. It is believed that a detailed examination of the behavior of existing fire suppressants will provide a basis for development of advanced suppressants. Fires involve an intimate coupling of chemistry with fluid dynamics and transport. The approach in this project is to study the chemical and physical mechanisms of existing suppressants through detailed flame structure measurements in a laboratory scale burner to establish the relationship between the characteristic times of the chemistry and fluid dynamics. In order to understand the simultaneous thermodynamic, fluid mechanic and chemical kinetic behavior of the inhibitors, the experimental results will be interpreted through limited numerical calculations of the flame structure using existing well developed codes. These experimental and modelling results should lead to a unified method of describing, and an improved fundamental understanding of the mechanisms of flame inhibition, extinction, and stabilization relevant to the advanced suppression of fires.

\section{Technical Accomplishments}

A new suppression laboratory has been designed and specified and will be completed by physical plant services by the end of the fiscal year. Equilibrium calculations have been performed on hydrocarbon -air flames with numerous halogenated hydrocarbon inhibitors to estimate the magnitude of the thermal dilution effect of these suppressants. Preliminary numerical calculations have been made on inhibited premixed flames using the mechanism being developed by CSTL which contains fiuorine chemistry. Measurements have been performed on the acid gas formation in inhibited flames when inhibitor is added to the air and fuel stream for a variety of flame types. These measurements allow an assessment of the degree of chemical interruption of the normal flame chemistry by the halogen. From these data a global model of acid gas formation has been developed which accounts for the effects of fuel and inhibitor structure, flame type, and inhibitor and oxygen diffusion rates. A turbulent diffusion flame has been constructed and tested, and the concentrations of several inhibitors added to the air stream necessary to cause extinction have been determined. These measurements, together with the strain rate in the flame to be measured with the laser Doppler velocimeter (which should be delivered before the end of the fiscal year), will be used to compare the extinction conditions with those predicted using the recently reported results of other researchers on different flames. A premixed burner suitable for flame speed measurements has been constructed and tested, and burning rate measurements have been obtained in a $\mathrm{CF}_{3} \mathrm{H}$-inhibited methane-air flame. A workshop was held in New Orleans on Halogen inhibition of hydrocarbon flames and attracted researchers in the combustion community who are doing related work. A workshop on water mist was held at NIST with participants from industry, both end users and system suppliers, research organizations, and approval and insurance laboratories. 
$\underline{\text { Publications }}$

Linteris, G.T., "Flame Speed Measurements in a Premixed Methane-Air Flame inhibited with $\mathrm{CF}_{3} \mathrm{H}_{\text {, }}$ to be submitted to the Eastern States Section Meeting of the Combustion Institute, Princeton, NJ, October 1993.

Notarianni, K., and Jason, N. (Eds.), "Water Mist Fire Suppression Workshop Proceedings," NISTIR 5207, March 1-2, 1993.

\section{Related Grants}

"Experimental Studies of Diffusion Flame Extinction Using Halon Substitutes," K. Seshadri, University of California, San Diego.

"Basic Research on Fire Suppression," A. Atreya, University of Michigan. 



\section{BUILDING AND FIRE RESEARCH LABORATORY \\ FIRE RESEARCH PROGRAM \\ OTHER AGENCY PROJECT - FY93}

\section{AN EVALUATION OF METAL VS. PLASTIC PIPING FOR USE IN FIRE SPRINKLER SYSTEMS}

Funding Agencies: $\quad$ United States Fire Administration

Professional Staff: Kathy A. Notarianni, Project Leader Margaret Jackson, Mechanical Engineer

Project Objective: $\quad$ To provide a report which compares and evaluates performance of metal vs. plastic piping for use in fire sprinkler systems by October, 1993.

Technical Accomplishments: An extensive review of the fire and other relevant literature was conducted in order to compare and evaluate plastic pipe in terms of the key performance variables:
Corrosive conditions
Material degradation during a fire
Maintaince
Economics
Occupancy classifications limitations
System modification limitations
Material limitations with types of systems
System design (hydraulic calculations)
Hanger and bracing considerations
High water pressure
UL listing and FM approval of material

Several databases were searched including but not limited to:

$\begin{array}{ll}\text { Aerospace Database; } & 1962 \text { to } 1993 \\ \text { Chemical Abstracts; } & 1970 \text { to the present } \\ \text { Defense Technical Information Center; } & 1950 \text { to the present } \\ \text { Engineering Index; } & 1970 \text { to } 1993 \\ \text { FIREDOC; } & 1974 \text { to the present } \\ \text { National Technical Information Service; } & 1963 \text { to } 1993 \\ \text { RAPRA Abstracts; } & 1972 \text { to } 1993\end{array}$

The search was conducted in an $\mathrm{X}+\mathrm{Y}$ manner to locate references containing an $\mathrm{X}$ variable such as plastic pipes, sprinkler pipes, polybutylene pipes or CPVC pipes AND a Y variable such as corrosion, corrosivity, maintenance, economics, system design, etc...

Meetings were held with manufacturers, system designers, and end users. In the ongoing phase of the project, information gathered is being summarized in terms of the key performance variables, and areas where little or no information exists are will be identified.

Publications: none 



\section{BUILDING AND FIRE RESEARCH LABORATORY \\ FIRE RESEARCH PROGRAM \\ NATIONAL INSTITUTE OF STANDARDS AND TECHNOLOGY \\ GRANTEE PROJECT - FY 93}

Institution; University of California, San Diego.

Grantno; \#60NANB2D1285.

Grant Title; Experimental Studies on the Extinction of Diffusion Flames Using Halon Substitutes.

Principal Investigator; Kalyanasundaram Seshadri, Department of Applied Mechanics and Engineering Sciences, University of California, San Diego, La Jolla, CA 92093-0310.

\section{Other Personnel; D. Trees, Staff Research Associate.}

NIST Scientific Officer; Dr. Anthony Hamins.

Technical Abstract; The principal objective of the proposed research is to investigate the relative influence of various agents, which are considered as substitutes for Halon 1301, in extinguishing diffusion flames burning liquid hydrocarbon fuels, specifically heptane and JP-8. The experimental configuration chosen for the study, is the diffusion flame stabilized in the mixing layer produced by directing an oxidizing gas stream downward on to the burning surface of the liquid fuel. This configuration is referred to in the literature as the counterflow configuration and is a convenient geometry for detailed fundamental studies of the structure and mechanisms of extinction of diffusion flames. The oxidizing gas used in the experiments was a mixture of air and the inhibiting agent. The agents tested were $\mathrm{C}_{3} \mathrm{HF}_{7}$ (HFC-227), $\mathrm{CHF}_{2} \mathrm{Cl}$ (HCFC-22), $\mathrm{CF}_{3} \mathrm{CH}_{2} \mathrm{CF}_{3}$ (HFC-236), $\mathrm{CH}_{2} \mathrm{FCF}_{3}$ (HFC134a), $\mathrm{C}_{2} \mathrm{~F}_{6}(\mathrm{FC}-116), \mathrm{CHFClCF}_{3}$ (HCFC-124), $\mathrm{CHF}_{2} \mathrm{CF}_{3}$ (HFC-125), $\mathrm{C}_{3} \mathrm{~F}_{8}$ (FC-218), $\mathrm{C}_{4} \mathrm{~F}_{10}$ (FC-31-10), and cyclo- $\mathrm{C}_{4} \mathrm{~F}_{8}$ (FC-318). Since, these agents are considered as possible substitutes for Halon $1301\left(\mathrm{CF}_{3} \mathrm{Br}\right)$, the effectiveness of these agents in extinguishing diffusion flames were compared with that of $\mathrm{CF}_{3} \mathrm{Br}$.

The design of the counterflow burner is similar to that employed in previous experimental studies [1]. A schematic illustration of the counterflow burner is shown in Fig. 1. This burner consists of a fuel cup which has a diameter of $45 \mathrm{~mm}$ and a depth of $18 \mathrm{~mm}$, and a gas duct through which gaseous oxidizer containing the gaseous inhibitor to be tested is introduced. The fuel cup is cooled by water at the bottom in order to prevent the fuel from boiling, but is not cooled at the rim as that would establish a radial temperature gradient within the liquid fuel. A narrow annulus surrounds the wall of the cup near the rim to catch any overflow of the fuel and prevent it from entering the exhaust duct. A fine pointer projecting up through the liquid pool is used as an aid in adjusting the height of the fuel surface. Satisfactory repeatability has been obtained by setting the pool at the level at which the pointer just forms a discernible dimple on the fuel surface. Since, the flame sheet is very sensitive to surface movements, the fuel height in the cup is accurately controlled by a device similar to that used previously in 'cup burner' studies [1,2]. The gas handling system is designed such that it is possible to introduce measured amounts of air, oxygen, nitrogen and the gaseous inhibitor from the top duct. The gas duct has an inner diameter of $50.1 \mathrm{~mm}$. A number of fine wire screens ( $200 \mathrm{mesh} / \mathrm{inch})$ are placed in the duct to reduce turbulence and ensure a flat velocity profile at the exit of the duct. The distance between the ducts is adjustable and the duct can be swivelled to allow access to the fuel cup. The flowrates of air, nitrogen and the inhibitor are measured accurately by use of variable area flowmeters. Pressure gauges are arranged in parallel with the flowmeters to 
insure that the flowrate of the gas stream is not affected by fluctuations in the output pressure from compressed gas cylinders or from variations in stagnation pressure caused by adjusting the flowrates of the gases. The flowmeters are rated at an accuracy of $3 \%$. Mild suction is used to pull the combustion product gases into a heat exchanger surrounding the fuel-overflow rim. The suction minimizes the influence of the ambient air currents on the flame, and prevents afterburning in the heat exchanger. It was possible to stabilize a steady flame indefinitely in this apparatus.

Critical conditions of extinction of the flame, in terms of the composition of the oxidizing stream as a function its volumetric flow-rate at extinction, were measured over a wide parametric range. The injection velocity of the oxidizing stream was presumed to be equal to the ratio of the volumetric flow rate of the oxidizing gas mixture to the crosssectional area of the duct. The strain rate, which is a measure of the characteristic flow time tf was calculated from the injection velocity of the oxidizing gas stream and the characteristic length of the system which is taken to be the distance between the exit of the gas duct and the surface of the liquid pool. In Figs. 2 and 3 the strain rate is plotted as a function of the mass fraction of the inhibiting agent at extinction for diffusion flames burning heptane and JP-8 respectively. For comparison Figs. 2 and 3 also shows the amount of $\mathrm{N}_{2}$ which must be added to the air stream to extinguish the flame in absence of the inhibitor. At a given value of the strain rate the mass fraction of $\mathrm{CF}_{3} \mathrm{Br}$ required to extinguish the flame is lower than the mass fractions of all other agents and $\mathrm{N}_{2}$. Therefore, when compared to all the agents tested here, $\mathrm{CF}_{3} \mathrm{Br}$ is most effective in extinguishing the flame. The results shown in Figs. 2 and 3 are a rough measure of the effectiveness of various agents in extinguishing these flames. With the exception of FC-116 for extinction of heptane diffusion flames, the relative rankings of the various agents measured in the counterflow configuration at the low rates of strain were similar to those measured in the cup burner studies [3]. In Fig. 4 the mass fraction of the inhibiting agent at extinction for diffusion flames burning heptane is shown for the case where the oxidizing stream was preheated to a temperature of $150^{\circ} \mathrm{C}$. Interpretation of these measurements are in progress.

\section{References}

1). Hamins, A., The Structure and Extinction of Diffusion Flames, Ph.D. Thesis, University of California, San Diego, 1985.

2). Bajpai, S. N., " An investigation of the extinction of diffusion flames by Halons", Ser. No. 22391.2, Factory Mutual research Corporation, Norwood, Massachusetts, November 1973.

3) Hamins, A, private communication

Acknowledgements; Ms. J. Wong assisted in interpretation of the experimental data. 


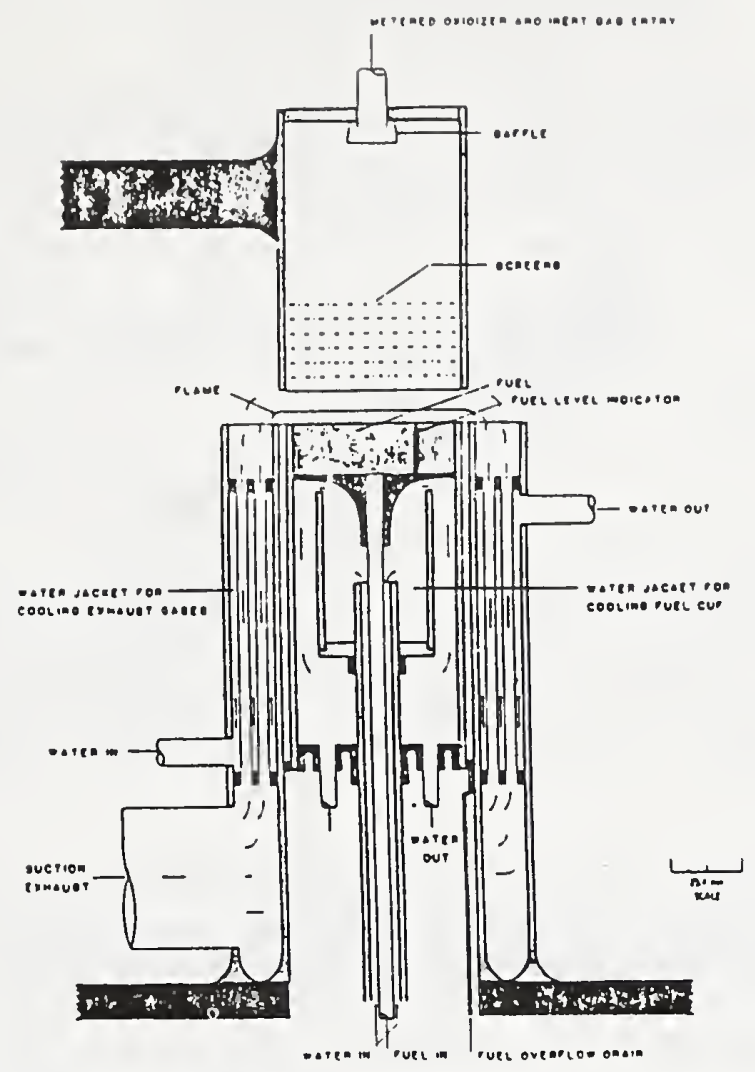

Figure 1. Schematic illustration of the counterflow bumer.

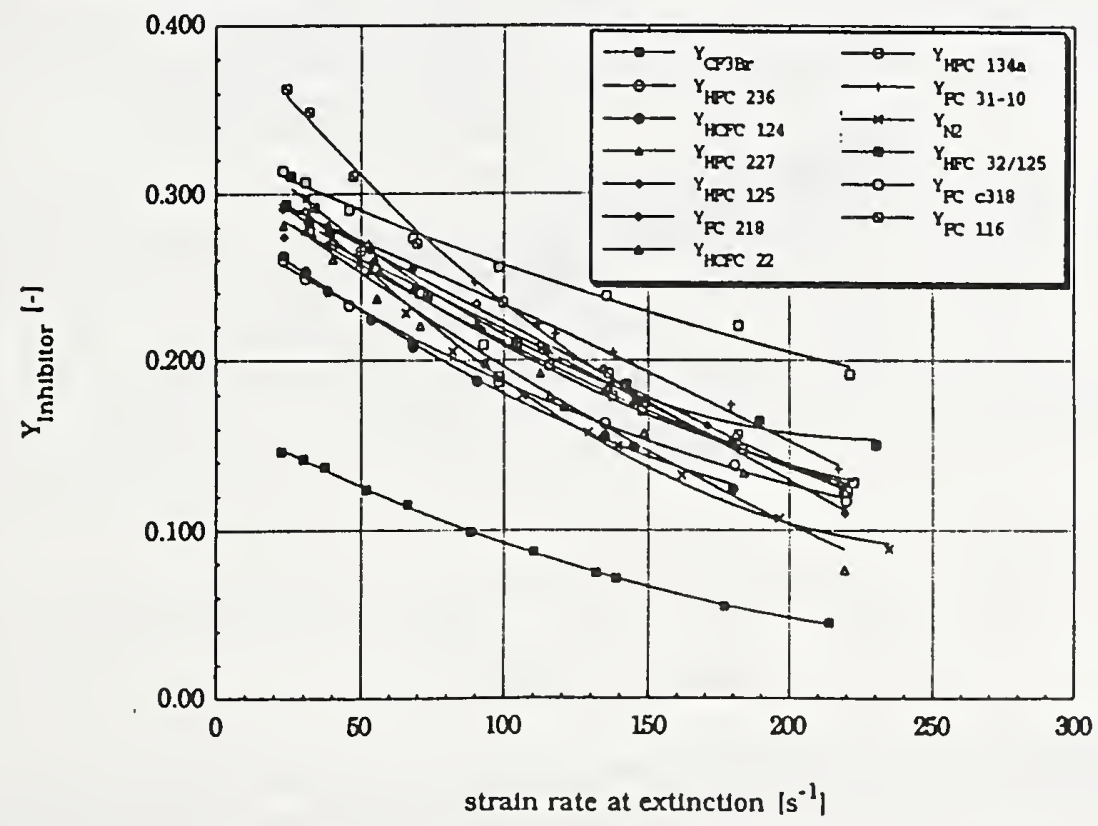

Figure 2. The strain rate as a function of the mass fraction of the inhibiting agent in the oxidizer gas stream at extinction of diffusion flames burning heptane. 


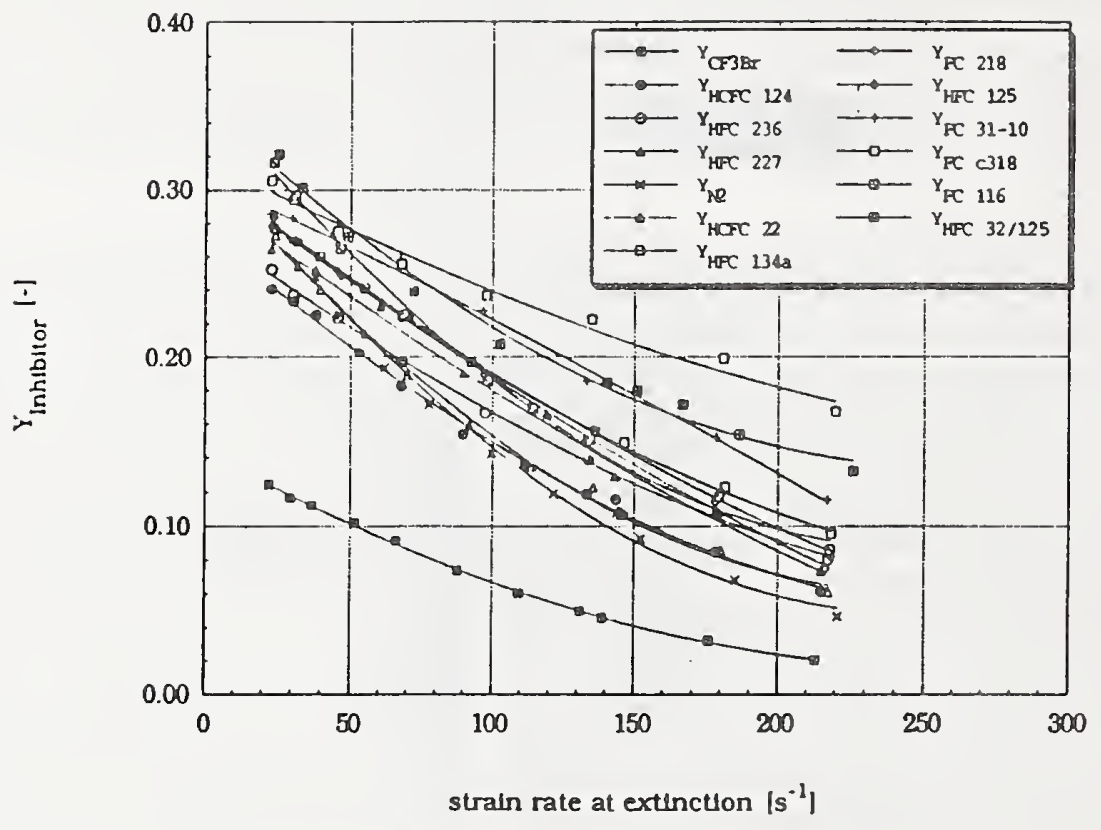

Figure 3. The strain rate as a function of the mass fraction of the inhibiting agent in the oxidizer gas stream at extinction of diffusion flames burning JP-8.

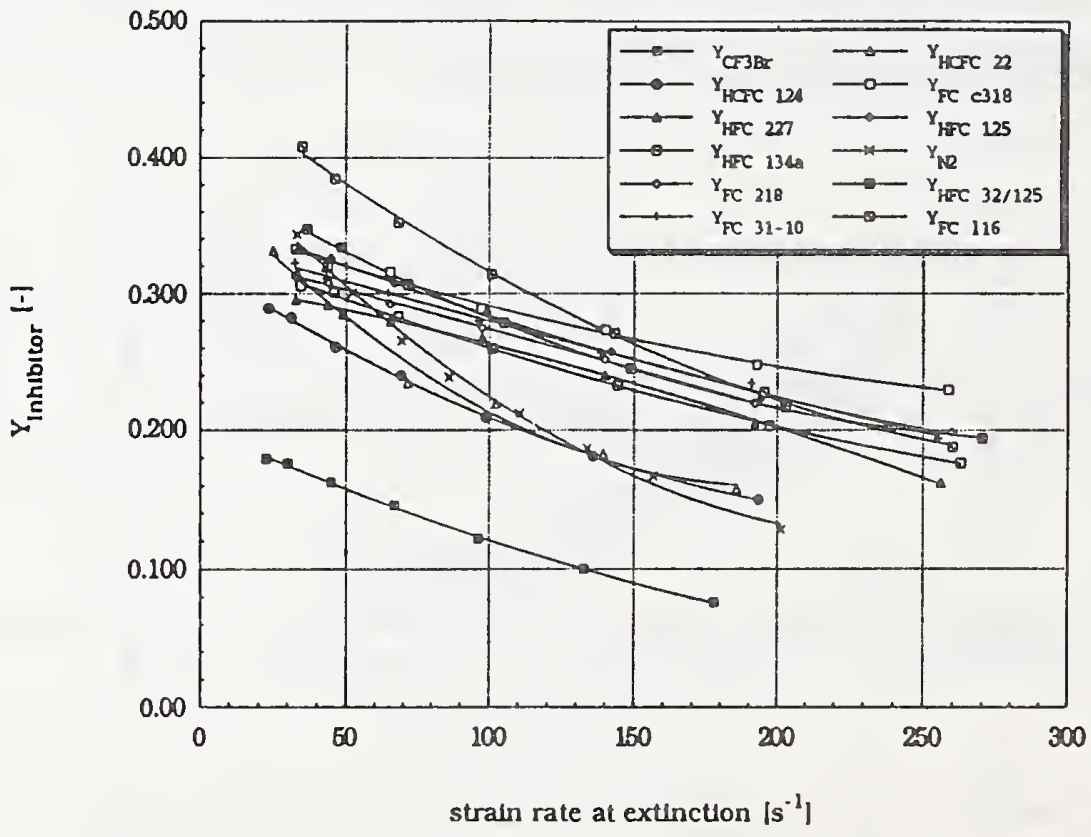

Figure 4. The strain rate as a function of the mass fraction of the inhibiting agent in the oxidizer gas stream at extinction of diffusion flames burning heptane. The oxidizer stream. is preheated to a temperature of $150^{\circ} \mathrm{C}$. 


\section{BUILDING AND FIRE RESEARCH LABORATORY \\ FIRE RESEARCH PROGRAM \\ OTHER AGENCY PROJECT - FY93}

\section{THE NEED FOR A SPRINKLER STANDARD \\ FOR BOARD AND CARE FACILITIES}

Funding Agency

US Fire Administration

Professional Staff

Scot Deal, Project Leader

Richard W. Bukowski

\section{Project Objective}

To produce a technical report which analyzes the need for a fire protection standard for board and care facilities. The function of the standard is to provide a reasonable degree of protection for life and property from fire through standardized installation requirements for sprinkler systems based upon sound engineering principles and test data.

$\underline{\text { Scope }}$

The current Life Safety Code contains requirements for sprinkler protection of new and substantially renovated $\mathrm{B} \& \mathrm{C}$ facilities according to NFPA $13 \mathrm{D}$. For existing facilities, a strong compartmentation option is provided. In all cases, smoke detection is required in limited areas. Some questions exist as to the potential impact of fires beginning in spaces not required to be sprinklered under $13 \mathrm{D}$. especially in light of the limited capacity of many $B \& C$ home residents to react properly and quickly.

\section{Technical Accomplishments}

The project involved an analysis of the potential impacts of sprinklers in Board and Care facilities where such are not currently required by the Life Safety Code. This includes facilities housing "prompt" residents in small and medium sized properties.

The analysis demonstrates the benefits of sprinklers relative to resident and staff safety for several common fire scenarios similar to documented fire incidents. The intent is to provide compelling information which will lead to the decision to voluntarily install sprinklers where not mandated by the code. The report is not necessarily intended to convince the code to change its minimum requirements as this is not held to be practical; particularly for small facilities with limited resources. However, the additional tlexihility in admitting residents or where the capabilities of residents changes with their physical condition is hoped to be persuasive. 



\title{
BUILDING AND FIRE RESEARCH LABORATORY \\ FIRE RESEARCH PROGRAM \\ OTHER AGENCY PROJECT - FY93
}

\section{PREDICTING THE RESPONSE OF SPRINKLERS AND DETECTORS IN LARGE SPACES}

\author{
Funding Agencies: General Services Administration \\ National Aeronautics and Space Administration
}

Professional Staff: $\quad$ Kathy A. Notarianni, Project Leader

William D. Davis, Physicist

Project Objective: $\quad$ To provide NASA with data on smoke movement and layer development in high bay areas by September, 1993.

Technical Accomplishments: Fire gas and disk temperatures were measured above the fire and along the ceiling in locations corresponding to the expected location of sprinklers or detectors during fire tests conducted in an aircraft hanger with a ceiling height of $30.4 \mathrm{~m}$. The results of the experiments were then compared to the predictions from the zone fire models FPETOOL, DETACT-QS, and LAVENT inside and outside of the plume region.

Inside the plume region, both the FPETOOL and DETACT-QS computer programs underpredict the ceiling jet temperatures, thereby providing a conservative estimate of the time to activation of a sprinkler or detector. LAVENT predicts a greater temperature gradient in the vertical direction in the ceiling jet than was measured. The predictions of LAVENT for the positions nearer to the ceiling are closer to the measured values, and thus more accurate than the DETACT-QS or FPETOOL predictions. For the positions further from the ceiling, the predictions of DETACT-QS and FPETOOL are closer to the measured values. Outside of the plume region, the comparison of the measured and predicted ceiling jet temperatures is more accurate than inside the plume region.

In the second phase of this project, a computational fluid dynamic model, HARWELL FLOW3D, was used to model the hanger. Reasonable agreement was found between the computational fluid dynamic calculations and the experimental data.

\section{Publications:}

Notarianni, K.A., Predicting the Response of Sprinklers and Detectors in Large Spaces, Proceedings, SFPE Engineering Seminars, Large Fires: Causes and Consequences, Dallas, TX., November, 1992.

Notarianni, K.A., and Davis, W.D. , "Use of Computer Models to Predict the Response of Sprinklers and Detectors in Large Spaces", Proceedings, Symposium on Computer Applications in Fire Protection Engineering, Worcester Polytechnic Institute, Worcester, MA, June, 1992.

Notarianni, K.A. and Davis, W.D.,"Predicting the Response of Sprinklers and Detectors in Large Spaces," National Institute of Standards and Technology, NISTIR XXXX (to be published) 



\section{BUILDING AND FIRE RESEARCH LABORATORY \\ FIRE RESEARCH PROGRAM \\ NATIONAL INSTITUTE OF STANDARDS AND TECHNOLOGY \\ GRANTEE PROJECT - FY93}

Institution:

Grant No:

Grant Title:

Principal Investigator:

\section{Other Personnel:}

NIST Scientific Officer:
University of Maryland

70NANB1H1173,2

Transient Cooling of a Hot Surface by Droplets Evaporation

Dr. Marino di Marzo

Mechanical Engineering Department

University of Maryland

College Park, MD 20742

S. Tinker, Graduate Student

G. White, Graduate Student

Dr. David D. Evans

Technical Abstract:

Introduction. The modelling of the heat and mass transfer phenomena associated with the evaporation of a water droplet deposited on a glass-like material (Macor) surface is discussed for the case of heat input from above the surface by radiant heating panels. Previous validated computations, for the case of heat input by conduction from below the solid, have shown that a one-dimensional model for the transient conduction in the liquid provides a reasonable representation of the phenomena in a thin water layer (diMarzo et al., 1993). With reference to the shape factor $\beta$ (see diMarzo et al., 1992) the droplet configuration for the radiant heat input case exhibits a larger value of $\beta$ than for a similar conduction heat input case thus reinforcing the one-dimensional hypothesis. Three aspects of the modelling effort are outlined here: a) the effect of direct radiation from above on the droplet evaporation; b) the three sub-models used for the liquid layer during the various phases of the transient; and c) the evolution of the droplet shape during the transient.

Direct Radiation. The geometry of the radiant heat source has been described in Fig. 1 where the three electric radiant panels located above the surface are identified in terms of their respective fractional surface area coverage at various polar angles $\phi$. Note the cumulative effect of the two truncated conical panels on either side of the surface and the third, lower-aspect-ratio panel located around the whole surface around its perimeter. The following assumptions are made: a) the radiant panels behaves as black bodies; b) the radiation scattering within the water droplet is negligible; c) the liquid-vapor interface is horizontal and flat; and d) the radiation reaching the liquicl-solid interface is completely absorbed by the solid. The volumetric heat generation in the liquid layer is given as: 


$$
H=-\frac{\partial F}{\partial z}=2 \int_{0}^{\infty} E_{\lambda, b} \kappa_{\lambda} \int_{0}^{\pi / 2} \frac{1}{\mu} f_{\phi} \cos \phi \sin \phi\left(1-\rho_{\phi}\right) e^{-\frac{\kappa_{\lambda} z}{\mu}} d \phi d \lambda
$$

The absorption coefficient $\kappa_{\text {i }}$ is a very strong function of the wave length $\lambda$, the direction cosine $\mu$ is given by the Snell's law, the fractional surface area coverage $f_{\phi}$ is obtained from Fig. 1 and the reflectivity $\rho_{\phi}$ is less than 0.1 for $\phi$ less than $65^{\circ}$ and it is given by the electromagnetic theory. Figure 2 depicts the value of the radiative heat flux $\mathrm{F}$ as a function of the liquid layer depth. For the typical experimental conditions (Dawson and diMarzo, 1993), the panels temperature is less than $1000 \mathrm{~K}$. Therefore, the direct radiation contribution is limited to a liquid-vapor interfacial boundary condition since the contribution of the radiant heat input in the layer thickness is negligible. For higher temperatures of the radiant surfaces, typical of fire environments, one would have to consider the contribution in the depth of the water layer. Figure 3 suggests that this contribution can be simulated with a constant, uniformly distributed, heat source throughout the layer. This distributed term relates to the residual amount of volumetric heat generation which is noticeable in Fig. 3 for liquid layer depths in excess of 0.2 millimeters at high temperature.

Liquid Laver Sub-Models. The modeling of the transient heat conduction in the liquid region is one dimensional and it is constituted of three sub-models: a) initial contact close form solution; b) full transient diffusion equation; and b) quasi-steady state conduction equation. In the early portion of the transient the liquid layer behaves as a semi-infinite solicl while the heat wave propagates through its depth. The solution of this problem is the classical solution for two semi-infinite solids (initially at different temperatures) brought in sudden contact. Note that this solution is valid for a very short time (fraction of a second) especially where the liquid layer is thin (i.e. at the droplet edge). The relevance of this submodel is to provide a starting condition for the computations. When the heat wave through the liquid reaches the liquid-vapor interface, the full transient diffusion equation sub-model is used. This model is a typical diffusion equation model which yields a tri-diagonal matrix solution with the one-dimensional heat flux approximation used here. When the liquid heat capacity term becomes small (i.e: the transient solution and the quasi-steady state solution provide results within less than 3 percent), the quasi-steady state conduction equation submodel takes over. This third sub-model provides a very fast solution for the liquid layer and it is used (on average) for more than half of the evaporation time. The quasi-steady state conduction equation with the constant heat source term discussed in the previous paragraph is yields, at the liquid-solid surface, the heat flux given by:

$$
\begin{aligned}
q^{\prime \prime} & =\frac{k}{k+A \delta}\left(\frac{A H \delta^{2}}{2 k}+H \delta-A T_{s}-B\right) \\
\text { where } A T_{i}+B & =0.62\left(\frac{h \Lambda}{c_{p, a} L e^{2 / 3}}\right) \frac{x_{i, T_{i}}-x_{\infty}}{1-x_{i, T_{i}}}+h\left(T_{i}-T_{\infty}\right)-F_{i}
\end{aligned}
$$

Droplet Shape. The droplet shape is rather complex because, initially, the liquid layer 
exhibits a low-aspect-ratio disk-like shape which then regresses to a spherical cap with shrinking base. The model generating the transient droplet shape assumes that, at the receding angle, the droplet has reached a spherical cap configuration. This is reasonable because, in order for the surface tension to shrink the wetted surface, the liquid-vapor surface configuration must maximize the bounded volume. This receding angle configuration identifies the aspect ratio of the droplet which will be preserved for all the remaining portion of the transient. Considering the apex of the droplet at the receding angle, one can construct an initial droplet shape with identical apex. This configuration yields the maximum contact angle $\theta_{\text {max }}$. Chandra and Avedisian ${ }^{a}$ showed that, for an evaporating droplet, this angle is less than or equal to $90^{\circ}$. Should the computed $\theta_{\max }$ exceed $90^{\circ}$, then the initial configuration will exhibit an apex higher than the apex at the receding condition (if one maintains the contact angle at $90^{\circ}$ ). The minimum value of the contact angle $\theta_{\min }$ can be found by imposing a spherical cap configuration at deposition. This configuration is possible only if the value of $\theta_{\min }$ is greater than or equal to the receding angle. A sensitivity study of the effect of $\theta_{0}$ shows that its impact is not significant. It is reasonable to argue that its upper bound is more physically justifiable (if one assumes that the recoiling phenomenon observed by Chandra and Avedisian ${ }^{a}$ is limited). Figure 4 illustrates the transient droplet configuration for the case of $\theta_{\max }$ exceeding $90^{\circ}$. In this case, a locus of the intercepts of the tangents to the liquid-vapor interface at the apex and at the liquid-vapor-solid contact point is traced. The equation describing this locus univocally determines the transient droplet shape. Note that for the case of $\theta_{\max }$ less than or equal to $90^{\circ}$, this locus reduces to a horizontal line tangent the droplet apex.

Extensive validation of this model is currently being conducted and it is providing significant insight into the evaporative cooling process. The results of this model constitute the basis for the code simulating the cooling effect of a water spray (Tartarini et al. 1992) which is being developed and validated against the data of Dawson and diMarzo, 1993.

\section{Reports and Papers:}

1. M. di Marzo, C.H. Kidder, P. Tartarini, "Infrared thermography of Dropwise Evaporative Cooling of a Semiinfinite Solid Subjected to Radiant Heat Input" Experimental Heat Transfer, Vol. 5, pp. 101-114 (1992)

2. M. di Marzo, P. Tartarini, Y. Liao, D. Evans, H. Baum, "Evaporative Cooling Due to a Gently deposited Droplet" International Journal of Heat and Mass Transfer, in press (1993)

3. P. Tartarini, Y. Liao, M. di Marzo, "Numerical Simulation of Multi-Droplet Evaporative Cooling" Proceedings of the X UIT National Heat Transfer Conference, Genova, Italy, pp. 123-132 (1992) also appeared in Heat and Technology, Vol. 11, No. 1-2, pp. 98-106 (1993)

4. H. Dawson, M. di Marzo, "Multi-Droplet Evaporative Cooling: Experimental Results" Proceedings of the 29th ASME/AIChE/ANS National Heat Transfer Conference, Atlanta, GA, (1993)

a S. Chandra, C.T. Avedisian, "On the Collision of a Droplet With a Solid Surface" Proceedings of the Royal Society of London, A, Vol. 432, pp. 13-41 (1991) 
FIGURE 1 -

Fractional radiant source coverage as a function of the polar angle

FIGURE 2 -

Normalized radiative heat flux versus liquid depth
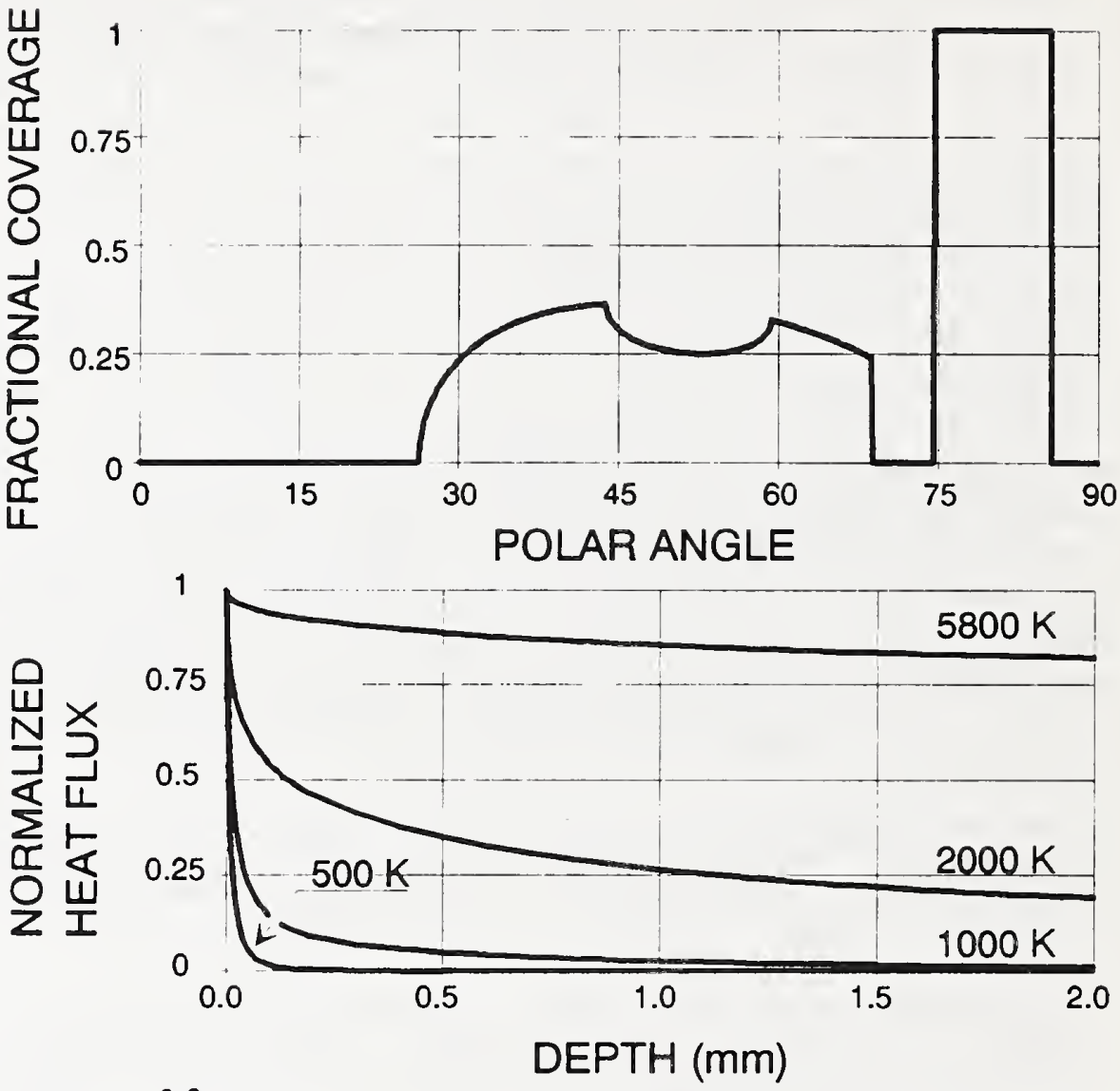

FIGURE 3 -

Normalized

volumetric heat generation due to the radiant heat flux versus liquid depth

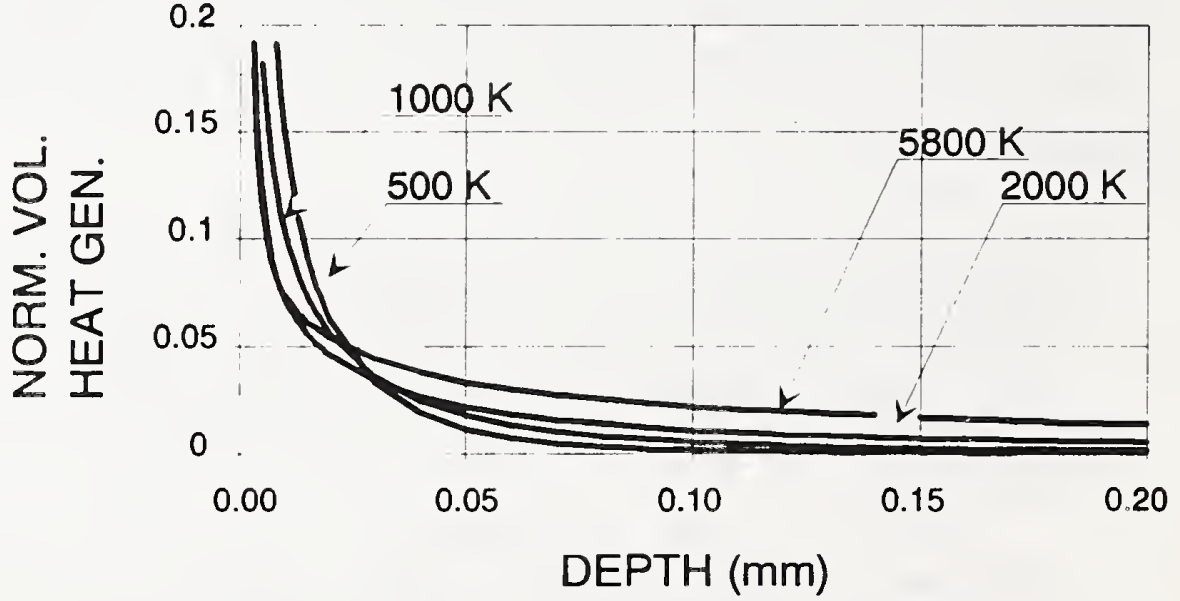

FIGURE 4 -

Normalized droplet shape during the evaporative transient

$y / R$ 0.2

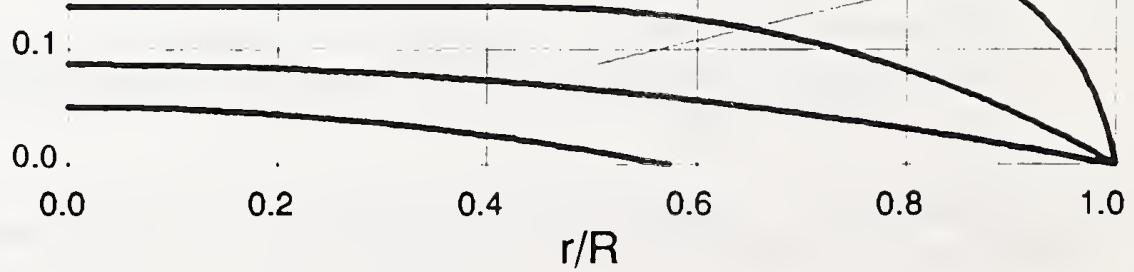


Part 2.0 Alphabetical Listing of BFRL Fire Research Grantees and Their Grants 

California Institute of Technology

Experimental Study of Heat Transfer and the Environment in a

Room Fire

Clemson University

Computational Heat Transfer for Zone File Modeling

Mathematical Modeling of Human Egress from Fires in Residential

Buildings

Factory Mutual Research Corporation

Prediction of Fire Dynamics.

George Washington University

Experimental and Modeling Studies of Soot and Carbon Monoxide in an

Ethylene/Air Diffusion Flame

Kansas State University

Light Scattering Studies of Fractal Soot Aggregates .

Massachusetts Institute of Technology

Computer Simulation of the Environmental Impact of Large Fires:

Plume Rise and Dispersion

National Fire Protection Association

EXIT89

Pennsylvania State University

Fundamental Mechanisms for $\mathrm{CO}$ and Soot Formation in

Diffusion Flames

Upward Flame Spread on a Vertical Wall Under External Radiation

Purdue University

Study of Entrainment and Flow Patterns in Pool Fires Using Particle

Imaging Velocimetry . $\quad . \quad$. . .

Study of Simulated Oil Well Blowout Fires and Flares . . .

Rutgers, the State University of New Jersey

Movement of Smoke and Hot Gases in Open Shafts _ . $\quad$ • $\quad 59$

University of California, Berkeley

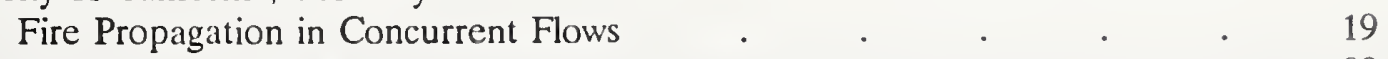

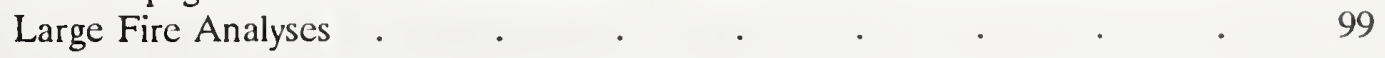


University of California, San Diego

Experimental Studies on the Extinction of Diffusion Flames Using

Halon Substitutes

University of Kentucky

Fire Spread Along the Vertical Corner Wall, Part I $\quad$. $\quad . \quad$. $\quad 155$

University of Maryland, College Park

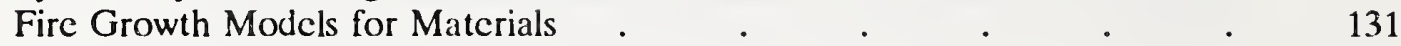

Smart Fire Detection Using Neural Networks $\quad$. $\quad$ • $\quad$. $\quad$. 187

Transient Cooling of a Hot Surface by Droplets Evaporation $\quad$. $\quad 215$

University of Michigan

Basic Rescarch on Fire Suppression

Soot, Carbon Monoxide and Radiant Emissions of Luminous Turbulent

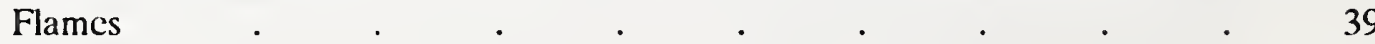

Virginia Polytechnic Institute \& State University

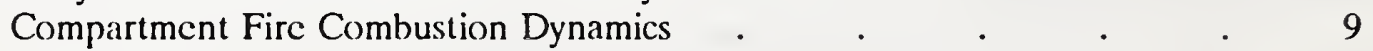

Washington State University

Development of an Economical Video Based Fire Detection and Location

System 


\section{MANUSCRIPT REVIEW AND APPROVAL}

INSTRUCTIONS: ATTACH ORIGINAL OF THIS FORM TO ONE (1) COPY OF MANUSCRIPT AND SEND TO THE SECRETARY, APPROPRIATE EOITORIAL REVIEW BOARD. TITLE AND SUBTITLE (CITE IN FUUL)

Summaries of BFRL Fire Research In-House Projects and Grants, 1993

\begin{tabular}{|c|c|c|}
\hline CONTRACT OR GRANT NUMBER & TYPE OF REPORT AND/OR PERIOD COVERED \\
\hline AUTHOR(S) (LAST NAME, FIRST INITIAL SECONO INITIAL) & $\begin{array}{c}\text { PERFORMING ORGANIZATION (CHECK X) ONE BOX) } \\
\text { JaSON, NoIa H. }\end{array}$ & $\begin{array}{c}\text { NIST/OATHERSBURO } \\
\text { NIST/EOULDER } \\
\text { JILA/BOULDER }\end{array}$ \\
\hline
\end{tabular}

LABORATORY AND DIVISION MAMES (FIRST NIST AUTHOR ONLY)

Building and Fire Research Laboratory, Fire Safety Engineering Division SPONSORING ORGANIZATION NAME AND COMPLETE ADDRESS (STREET, CITY, STATE, ZIP)

PROPOSED FOR NIST PUBLCATION

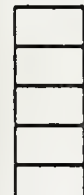

JOURMAL OF RESEARCH (NIST JAES)

J. PHYS. \& CHEM. REF. DATA (JPCRO)

HANOBOOK (NIST HB)

SPECLAL PUBUCATION (NIST SP)

TECHNICAL NOTE (NIST TN)

PROPOSED FOR NON-NIST PUBLICATION (CITE FULIV)

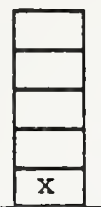

MONOORAPH (NIST MN) NATL STD. REF. DATA SERIES (NIST NSRDS) FEDERAL INF. PROCESS. STDS. (MIST FIPS) LST OF PUBUCATIONS (NIST LP) NIST INTERAGENCY/INTERNAL REPORT (NISTIR)
(ERB USE ONLY)

\begin{tabular}{|l|l|}
\hline ERB CONTROL NUMBER & DIVISION \\
\hline $\begin{array}{c}\text { PUBUCATION REPOAT NUMBEA } \\
\text { NISTIR 5263 }\end{array}$ & CATEOOAY CONE \\
$\begin{array}{c}\text { PUBLCATION DATE } \\
\text { SEP TEMber 1993 }\end{array}$ & $\begin{array}{c}\text { NUMBER PAIMTED FAGES } \\
184\end{array}$ \\
\hline
\end{tabular}

\begin{tabular}{l|l|l|l|l}
\hline U.S. & FOREION & PUBUSHING MEDIUM
\end{tabular}

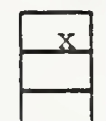

PAPER

DISKETTE (SPECIFY)

OTHER (SPECIF)

SUPPLEMENTARY NOTES

ABSTRACT (A 2000-CHAAACTER OR LESS FACTUAL SUMMARY OF MOST SIGNIFICANT INFORMATION. IF DOCUMENT INCLUDES A SIGNIFICANT BIBLOGRAPHY OR LTERATURE SURVEY, CITE IT HERE. SPELL OUT ACRONYMS ON FIRST REFERENCE.) (CONTINUE ON SEPARATE PAGE, IF NECESSARY.)

This report describes the fire research projects performed in the Building and Fire Research Laboratory (BFRL) Fire Research Program and under its grants program from October 1, 1992 through September 30, 1993.

KEY WOQDS (MAXIMUM OF 9: 28 CHARACTERS AND SPACES FACH: SEPARATE WITH SEMICOLONS; ALPHABETIC ORDER; CADITALZE ONLY PROPER NAMES) Charring; combustion; fire models; fire research; flame spread; blowout $E$ ires; hazards; ignition; polymers; soot; smoke; sprinklers

AVAILABIUTY

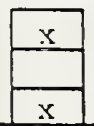

UNLIMITED ORDER FROM SUPERINTENDENT OF DOCUMENTS. U.S. OPO. WASHINOTON, DC 20402 ORDER FROM NTIS. SPRINGFIELD. VA 22161
NOTE TO AUTHOR(S): IF YOU OO NOT WISH THIS MANUSCRIPT ANNOUNCEO BEFORE PUBLCATION. PLEASE CHECK HERE. 


8

8

3

㝵

공. 